Universidade de São Paulo

INSTITUTO DE FÍSICA

\title{
Sistemas de nanopartículas magnéticas: estudos experimentais e simulações Monte Carlo
}

\author{
Fabiana Rodrigues Arantes
}

Orientador: Prof. Dr. Daniel Reinaldo Cornejo

Tese de doutorado apresentada ao Instituto de Física para a obtenção do título de Doutor em Ciências.

\section{Banca Examinadora:}

Prof. Dr. Daniel Reinaldo Cornejo (IFUSP)

Prof. Dr. Giancarlo Espósito de Souza Brito (IFUSP)

Prof. Dr. Marcos de Abreu Avila (UFABC)

Prof. Dr. Gabriel Teixeira Landi (UFABC)

Prof $^{a}$. Dr ${ }^{\mathrm{a}}$. Elis Helena de Campos Pinto Sinnecker (UFRJ)

São Paulo

2014 


\section{FICHA CATALOGRÁFICA}

Preparada pelo Serviço de Biblioteca e Informação do Instituto de Física da Universidade de São Paulo

\section{Arantes, Fabiana Rodrigues}

Sistemas de nanopartículas magnéticas: estudos experimentais e simulações Monte Carlo. São Paulo, 2014.

Tese (Doutorado) - Universidade de São Paulo. Instituto de Física. Depto. Física de Materiais e Mecânica.

Orientador: Prof. Dr. Daniel Reinaldo Cornejo

Área de Concentração: Física

Unitermos: 1. Nanopartículas; 2. Efeito magnetoviscoso; 3. Superparamagnetismo; 4. Ferrofluidos. 
There is a theory which states that if ever anyone discovers exactly what the Universe is for and why it is here, it will instantly disappear and be replaced by something even more bizarre and inexplicable. There is another theory which states that this has already happened. — The Hitchhiker's Guide to the Galaxy, Douglas Adams

Dedico esta tese aos meus pais, meu irmão e ao Renato. 

Nesta tese apresentamos um estudo do comportamento magnético de sistemas de nanopartículas por meio de medidas experimentais e simulações Monte Carlo. Estudamos o papel das interações entre partículas experimentalmente a baixas temperaturas em amostras de ferrofluidos comerciais por meio de curvas ZFC-FC, $\Delta m$ e diagramas FORC. Observamos nas curvas ZFC-FC o fenômeno de superresfriamento e transições de fase do estado sólido para o líquido em ferrofluidos. Para amostras de cristais líquidos dopados com nanopartículas magnéticas, observamos a transição entre as fases isotrópica e nemática. Detectamos em amostras de ferrofluidos e em soluções micelares dopadas com nanopartículas um aumento da viscosidade na presença de um campo magnético aplicado, o chamado efeito magnetoviscoso, que surge devido às interações entre partículas. Nas simulações Monte Carlo, vimos que a temperatura crítica $\left(T_{C}\right)$ diminui com o tamanho das partículas, e que esse comportamento pode ser descrito por uma lei de escala. As simulações também mostraram que uma camada morta na superfície das nanopartículas provoca uma pequena diminuição na temperatura crítica, o que não ocorre quando adicionamos uma camada dura, que pode aumentar significativamente $T_{C}$. Para simulações de um sistema de nanopartículas interagentes, demos especial atenção a interpretar de que forma as interações magnetizantes e desmagnetizantes se manifestam em diagramas FORC para um conjunto de nanopartículas com distribuição de tamanhos. Observamos que uma interação desmagnetizante está associada a um deslocamento do pico do diagrama FORC para campos locais de interação $H_{b}$ positivos e que a presença de uma interação magnetizante pode deslocar esse pico para campos $H_{c}$, relacionados à distribuição de coercividades do sistema, maiores. 

In this thesis we present a study of the behavior of a system of magnetic nanoparticles by means of experimental measurements and Monte Carlo simulations. We experimentally study the role of the interactions between particles at low temperatures in commercial samples of ferrofluids through ZFC-FC, $\Delta m$ curves, and FORC diagrams. We observed the phenomenon of supercooling and phase transitions from solid to liquid states in the ZFC-FC curves of ferrofluids. For the samples of liquid crystal doped with magnetic nanoparticles, we saw the transition between the isotropic and nematic phases. We detected in the samples of ferrofluids and in micellar solutions doped with nanoparticles an increase of the viscosity in the presence of an applied magnetic field, the so-called magnetoviscous effect, which arises due to interactions between particles. In the Monte Carlo simulations, we found that the critical temperature $\left(T_{C}\right)$ decreases with particle size, a behavior that is described well by a scaling law. The simulations also showed that a dead layer on the surface of the nanoparticles causes a slight decrease in the critical temperature value, what does not occur when we add a hard layer, which increases $T_{C}$ significantly. For simulations of a system of interacting nanoparticles, we paid special attention to interpret how the magnetizing and demagnetizing interactions manifest themselves in FORC diagrams for a set of nanoparticles with size distribution. We observed that demagnetizing interactions is associated with a displacement of the peak of the FORC diagram to positive values of the local field interaction $H_{b}$, and that the presence of a magnetizing interaction can shift this peak to larges values of the $H_{c}$ field, related to the distribution of coercivities. 

À Fapesp pela bolsa de doutorado concedida.

Ao meu orientador, Daniel Reinaldo Cornejo, que me orientou desde a iniciação científica até o doutorado, e que foi a pessoa mais importante para a minha formação acadêmica.

Ao professor Stefan Odenbach, da Technische Universität Dresden, pela sua supervisão durante o período em que usufrui da bolsa BEPE da Fapesp.

Ao professor Antônio Martins Figueiredo Neto pelas discussões e suporte na preparação das amostras.

Ao professor Carlos Alberto Ramos, do Centro Atómico de Bariloche, pelas medidas de ressonância ferromagnética.

Ao professor Luiz Nagamine pela ajuda com os ajustes dos espectros Mössbauer.

À professora Sylvia Carneiro, do Instituto Butantan, pelas imagens de microcopia eletrônica de transmissão.

Ao Tarsis, do Laboratório de Cristalografia, pelas medidas de raios X.

Aos funcionários do LMM, Sergio, Renato e Marcelo, por toda ajuda com os equipamentos, confecção dos porta-amostras e amizade.

Aos demais colegas do LMM, professores Antonio Domingues e Carmen Partiti, e todos os alunos que tive a oportunidade de conhecer durante todos esses anos.

Aos funcionários da oficina mecânica e criogenia, Paulo, Marcão, Vagner, Gilberto e Luciano.

À Rita, técnica do grupo de Fluidos Complexos, por ter me orientado no preparo das amostras de cristais líquidos.

Aos colegas da Technische Universität Dresden, Lisa Sprenger, Johannes Nowak, Julia Linke e Dmitry Borin.

Ao Renato por todo companheirismo, apoio, paciência e ajuda com problemas computacionais.

À minha família, em especial ao meu irmão Juliano, à minha mãe Irany e meu pai Paulo (in memoriam) que sempre me apoiaram e me incentivaram em todas as minhas escolhas. 

1 INTRODUÇÃO I

2 Magnetismo de nanopartículas 5

2.1 Efeitos de superfície em nanopartículas 10

2.2 Interações entre partículas magnéticas $\quad$ I4

2.3 Contribuições de simulações utilizando o método de Monte Carlo na compreensão do magnetismo de nanopartículas $\quad 16$

2.4 Fluidos magnéticos 17

2.4.1 Cristais líquidos dopados com nanopartículas magnéticas 21

2.4.2 Efeito magnetoviscoso 24

3 MÉtodos experimentais 27

3.1 Caracterização estrutural das amostras 27

3.1.1 Difratometria de raios $X \quad 27$

3.1.2 Determinação do tamanho de nanopartículas utilizando um microscópio eletrônico de transmissão 30

3.1.3 Espectroscopia Mössbauer 31

3.2 Caracterização magnética das amostras 33

3.2.1 Magnetometria SQUID 33

3.2.2 Curvas Zero Field Cooling - Field Cooling (ZFC-

FC) $\quad 35$

3.2.3 Curvas de remanência e $\Delta m \quad 37$

3.2.4 Curvas de inversão de primeira ordem (FORCs) 39

3.2.5 Medidas de suscetibilidade AC 44

3.2.6 Ressonância ferromagnética 45

3.3 Caracterização magnetoreológica de fluidos magnéti$\cos 53$

3.4 Algoritmo de Metropolis 56

4 EStudos EXPERIMENTAIs 59

4.1 Caracterização estrutural dos ferrofluidos comerciais 59

4.1.1 Microscopia de transmissão de ferrofluidos 59

4.1.2 Difratometria de raios $X \quad 63$

4.1.3 Espectroscopia Mössbauer 64

4.2 Caracterização magnética de ferrofluidos congelados 67

4.3 Curvas ZFC-FC e transição de fase do estado sólido para o líquido em ferrofluidos 80

4.3.1 Observação da transição de fase em cristais líquidos liotrópicos 83

4.4 Ressonância ferromagnética 87

4.5 Efeito magnetoviscoso em amostras micelares isotrópicas $\quad 92$ 
4.5.1 Preparação das amostras e equipamentos 93

4.5.2 Caracterização reológica das amostras isotrópicas 93

4.5.3 Ferrofluidos 95

4.5.4 Efeito magnetoviscoso em soluções isotrópicas dopadas com nanopartículas 96

5 Simulações MONTE CARLO IOI

5.1 Métodos 101

5.1.1 Partículas isotrópicas 102

5.1.2 Partículas com camada morta superficial 102

5.1.3 Partículas com uma camada superficial dura 103

5.2 Propriedades magnéticas de nanopartículas não interagentes 103

5.3 Alterando a superfície das partículas 112

5.4 Simulação Monte Carlo com interação entre partículas 114

5.4.1 Interação entre partículas usando um termo de campo médio 115

5.4.2 Interação dipolar 121

5.4.3 Aglomerados de partículas 128

6 CONCLUSÕES 131

7 ARtigos PUblicados 135

Bibliografia 135 
Sistemas formados por nanopartículas magnéticas possuem propriedades não usuais comparadas às amostras massivas (bulk), o que viabiliza seu uso em diversas aplicações, como por exemplo tratamentos médicos e de diagnóstico [1], gravação magnética [2], tratamento da água [3], entre muitos outros. Dentre essas aplicações, a que recebe mais atenção e investimento é o seu uso na área médica, cujo grau de maturidade é demonstrado, por exemplo, em um tipo de tratamento conhecido como magneto-hipertemia, que consiste em matar células cancerígenas pelo calor gerado por nanopartículas submetidas a um campo magnético alternado, e que já foi testado em ensaios pré-clínicos para alguns tipos de tumores [4]. Na área de gravação magnética, o uso de filmes finos nanoestruturados de nanopartículas foi apontado como uma possibilidade para aumentar a densidade de armazenamento de dados, porém este tipo de sistema ainda está em fase de aperfeiçoamento para que possa competir com as mídias usadas atualmente [5].

As propriedades magnéticas de sistemas de nanopartículas dependem de diversos fatores como tamanho, forma, efeitos de superfície, composição química, cristalinidade [6], interações [7] e mesmo do meio e da vizinhança ao redor das nanopartículas [8]. Em sistemas experimentais muitas vezes é difícil separar a contribuição de cada fator para certas propriedades observadas em medidas magnéticas, portanto modelos micromagnéticos e simulações que permitem estudar alguns desses aspectos contribuíram muito para sua compreensão. $\mathrm{O}$ primeiro modelo micromagnético que descreveu a histerese de partículas magnéticas não interagentes foi apresentado em 1948 por Stoner e Wohlfarth [9]. Modelos baseados na equação de Landau-LifshitzGilbert [1o], que descreve a precessão da magnetização, também são muito usados, inclusive adicionando termos estocásticos como forma de introduzir flutuações térmicas [11]. Outra possibilidade para estudar computacionalmente nanopartículas são as simulações utilizando o método de Monte Carlo [12, 13], que permitem modelar sistemas muito complexos, tais como partículas compostas por materiais diferentes, e que introduz a temperatura, um parâmetro fundamental no estudo desses sistemas.

A matriz na qual as nanopartículas estão inseridas pode ter uma contribuição nas suas propriedades magnéticas. Há na literatura relatos de um endurecimento magnético quando as nanopartículas estão dispersas em meios metálicos não magnéticos, como prata e cobre [8], mostrando que é possível um acoplamento dos orbitais atômicos 
dos átomos das partículas com os da matriz metálica. Outro exemplo é o uso de nanopartículas para dopar cristais líquidos e diminuir o campo magnético necessário para orientá-los [14]. Nesse caso temos um acoplamento mecânico entre as partículas e as unidades básicas que constituem o cristal, como micelas ou moléculas com uma anisotropia de forma, e que surge devido à orientação espacial das partículas e da matriz líquido-cristalina.

Coletivamente, nanopartículas estão sujeitas à interação dipolar, mesmo em um sistema não muito concentrado, e também à interação de troca, se estiverem suficientemente perto umas das outras. Para um sistema real de nanopartículas, estas interações, principalmente a dipolar, podem ser determinantes no comportamento magnético global da amostra, fazendo com que sua compreensão seja fundamental para aplicações, principalmente para gravação magnética, em que interações dipolares e de troca poderiam levar a ruídos de leitura [15].

Nesta tese de doutorado nosso objetivo foi estudar algumas facetas do comportamento magnético de nanopartículas. Como ponto de partida, demos continuidade a uma simulação de Monte Carlo iniciada no fim do mestrado para um sistema de partículas não interagentes [16]. Mostramos no capítulo 5 a observação a mudança de um comportamento magnético ordenado para um desordenado e de que maneira mudanças na superfície podem levar ao endurecimento magnético das partículas. Uma característica importante da simulação que apresentamos nesta tese é o tamanho do nosso sistema, já que podemos simular centenas de nanopartículas, sendo que cada uma é composta por centenas ou milhares de momentos magnéticos, dependendo do diâmetro. Até o presente momento não encontramos na literatura, em simulações semelhantes, um sistema tão grande.

O papel das interações entre partículas foi estudado experimentalmente em amostras de ferrofluido e também nas simulações com a introdução de um termo de campo médio, que mostramos nos capítulos 4 e 5. Utilizamos diversos tipos de medidas para amostras de ferrofluido com concentrações diferentes para observar o efeito destas interações. Na simulação Monte Carlo demos especial atenção a interpretar de que forma as interações magnetizantes e desmagnetizantes se manifestam em diagramas FORC, já que nem sempre é trivial interpretar este tipo de medida.

No capítulo 4 mostramos também como medidas magnéticas de nanopartículas podem dar informações sobre transições de fase do meio onde elas estão dispersas, por exemplo transições líquido-sólido ou mudanças entre diferentes fases de um cristal líquido. Neste caso temos um efeito do meio sobre a orientação das nanopartículas na direção do campo aplicado, que se reflete na medida de magnetização. Esta é uma abordagem pouco explorada, já que habitualmente transições de fase líquidas não são estudadas por meio de medidas magnéticas. 
Por fim, mostramos no mesmo capítulo a observação do efeito magnetoviscoso em soluções micelares dopadas com nanopartículas magnéticas. Neste caso verificamos que a viscosidade do meio é afetada pela interação das partículas magnéticas com o campo aplicado. Este é um tópico novo, e que em especial nunca tinha sido estudado em nosso sistema, em que observamos um grande efeito mesmo com concentrações muito baixas de nanopartículas, indicando um acoplamento mecânico entre nanopartículas e micelas que se reflete em um aumento da viscosidade. 

Uma amostra ferromagnética macroscópica na ausência de um campo aplicado possui regiões com magnetização uniforme que são chamadas de domínios magnéticos, figura 2.I (a), e que surgem para minimizar a energia interna do material. Estas regiões, que possuem magnetização com orientações diferentes entre si, são separadas por paredes de domínio, onde os momentos magnéticos possuem orientações intermediárias entre um domínio e outro. A expressão que define o comprimento característico de uma parede de domínio $l_{D W}{ }^{1}$ separando dois domínios magnéticos com magnetização oposta, isto é, de $180^{\circ}$, é dada por:

$$
l_{D W}=\pi \sqrt{\frac{A}{K}}
$$

onde $A$ é a constante de rigidez de troca, um parâmetro que representa macroscopicamente a constante de troca $\mathcal{J}$ e que tipicamente possui valores entre 1 a $2 \times 10^{-11} \mathrm{~J} / \mathrm{m}$ para a maioria dos materiais ferromagnéticos [17]. $K$ é a constante de anisotropia, que para esta derivação consideramos como sendo uniaxial. Valores típicos da constante de anisotropia cristalina estão entre $10^{3}$ e $10^{7} \mathrm{~J} / \mathrm{m}^{3}$, o que leva a comprimentos de $l_{D W}$ entre alguns $n m$ até mícrons.

Em geral, quando usamos o termo nanopartículas, estamos pensando em objetos com no máximo poucas dezenas de $n m$, uma faixa de valores um pouco menor do que a faixa de valores que compreende $l_{D W}$. Portanto, esta escala de tamanho está justamente na região onde a formação de domínios magnéticos não é mais favorável energeticamente. A expressão que nos dá o diâmetro crítico $D_{c}$ abaixo do qual temos nanopartículas esféricas monodomínios, como a representada na figura 2.1 (b), é dada por:

$$
D_{c}=\frac{72 \sqrt{A K}}{\mu_{0} M_{S}^{2}}
$$

onde $M_{S}$ é a magnetização de saturação e $\mu_{0}$ a permeabilidade magnética do vácuo. Vemos que $D_{c}$ depende da composição química da nanopartícula, já que os parâmetros $A$ e $K$ dependem do material.

Cada uma dessas partículas monodomínio pode ser considerada como um único super momento, dado pela soma dos momentos individuais dos átomos. Para estes sistemas podemos considerar uma

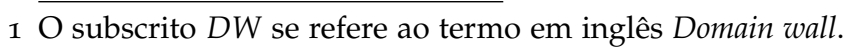


(a)
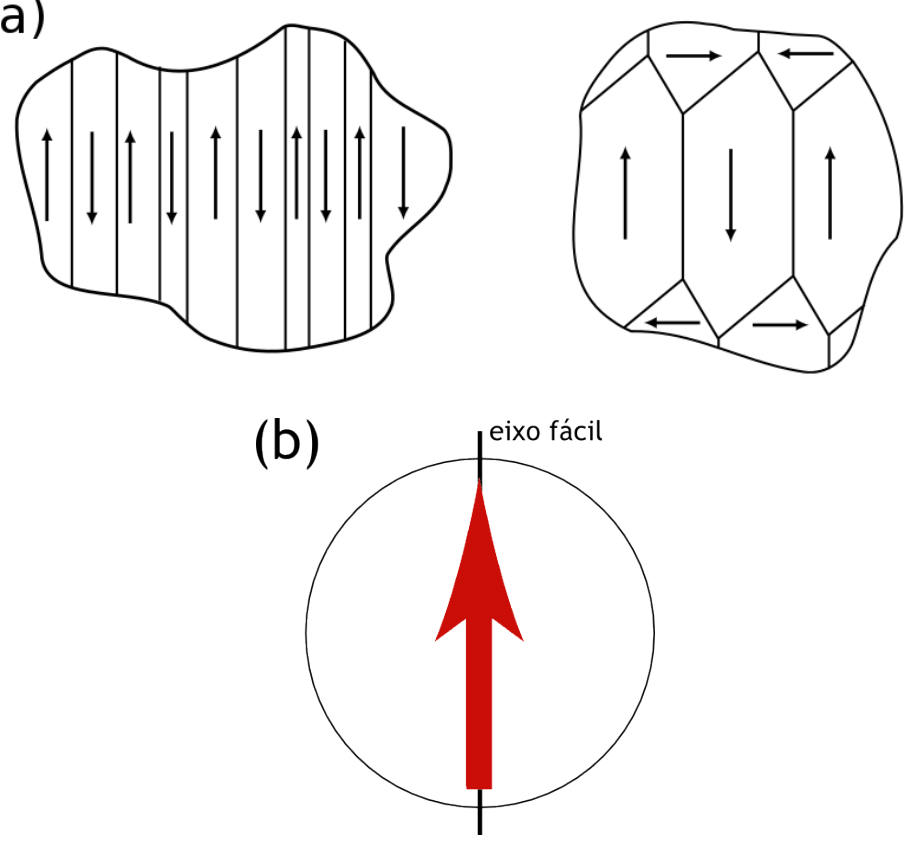

Figura 2.1: (a) Representação da estrutura de domínios magnéticos para um material com anisotropia cristalina cúbica e hexagonal. Retirado de [18]. Em (b) vemos a representação de uma nanopartícula que possui um único domínio.

anisotropia magnética uniaxial que determina um eixo de fácil magnetização onde o momento magnético da partícula está orientado. Há muitas fontes de anisotropias para uma partícula, como a magnetocristalina e de forma, mas outros fatores como campo dipolar ao redor e deformações magnetoelásticas também podem ser relevantes. Juntas, essas fontes de anisotropia determinam qual será o eixo de fácil magnetização da partícula e podem ser representadas por uma constante de anisotropia efetiva uniaxial $K_{e f}$. Podemos escrever a energia de anisotropia uniaxial nesse modelo como:

$$
E(\theta)=K_{e f} V \sin ^{2} \theta
$$

onde $\theta$ é o ângulo entre o momento magnético total da partícula e o eixo fácil, e $V$ o volume magnético da partícula. Para esta expressão temos dois mínimos de energia, um para $\theta=0^{\circ}$ e outro para $\theta=180^{\circ}$, separados por uma barreira de energia $K_{e f} V$. Na figura 2.2 vemos o gráfico desta energia de anisotropia efetiva e a direção do momento magnético nas duas configurações de mínima energia.

Para $T \neq 0$ a orientação do momento magnético da partícula pode transitar entre os dois mínimos de energia, o que ocorre com uma frequência dada pela equação de Néel-Arrhenius 2.4. Essa equação indica a probabilidade por unidade de tempo de um sistema numa 


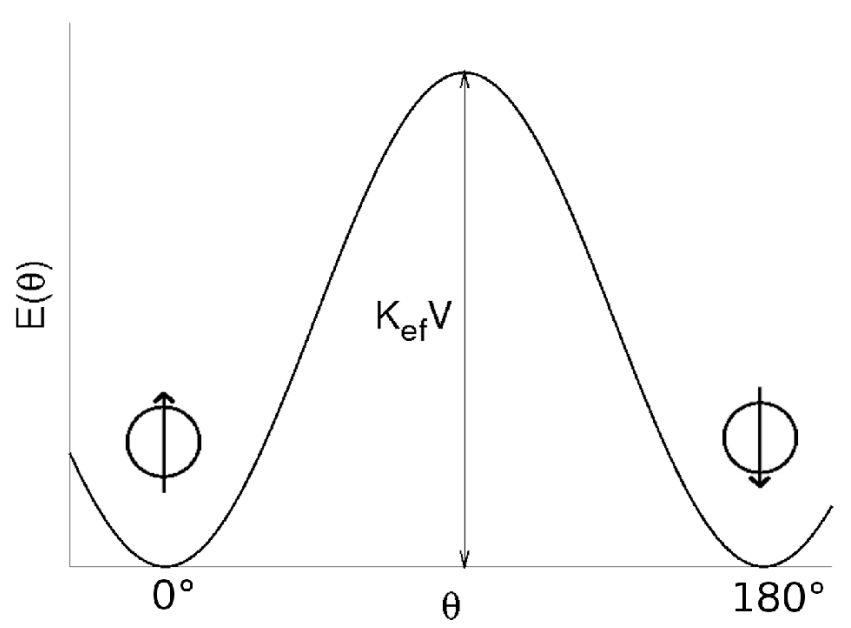

Figura 2.2: Representação da barreira de energia, $K_{e f} V$, que separa os dois mínimos de energia para uma partícula que é um monodomínio magnético.

dada temperatura sair de um estado de equilíbrio para outro. $\mathrm{Na}$ equação, $v_{0}$ é um fator cuja ordem de grandeza é, em geral, de $10^{8}-$ $10^{10} \mathrm{~Hz}$ e $k_{B}$, a constante de Boltzmann.

$$
v=v_{0} \exp \left(-\frac{K_{e f} V}{k_{B} T}\right)
$$

Dizemos que as partículas estão bloqueadas quando o tempo característico, dado pelo inverso de $v$, para que ocorra a transição entre os dois mínimos de energia é longo em comparação ao tempo de medida. Analogamente, se esse tempo for pequeno e o momento magnético da partícula seja capaz de inverter várias vezes durante a medida, dizemos que as partículas estão desbloqueadas, ou seja, estão no regime chamado de superparamagnético. Usualmente a observação experimental do superparamagnetismo se dá quando a energia térmica da partícula é da ordem da barreira $K_{e f} V$. Rearranjando a equação 2.4 podemos obter a expressão para a temperatura de bloqueio $T_{B}$, acima da qual as partículas estão no regime superparamagnético:

$$
T_{B}=\frac{K_{e f} V}{k_{B} \ln \left(v_{0} / v_{m}\right)},
$$

sendo que $1 / \nu_{m}$ é o tempo característico da medida.

Uma característica de um conjunto de partículas superparamagnéticas é que na ausência de um campo aplicado a magnetização total do sistema será nula devido à flutuação térmica da magnetização. Outra característica destes sistemas é a ausência de coercividade no ciclo de 
histerese, pois a desmagnetização não é devida ao campo magnético, mas sim à temperatura. Assim, quando o campo magnético é invertido, a magnetização da amostra também inverte, já que a barreira de energia que ela precisa superar é da mesma ordem de grandeza da energia térmica.

Ao contrário, quando estamos abaixo da temperatura de bloqueio, as nanopartículas voltam a mostrar coercividade. Um modelo que descreve bem a histerese magnética destes sistemas é o modelo de Stoner e Wohlfarth [9, 18] com rotação coerente da magnetização. Neste modelo temos um elipsoide com anisotropia uniaxial de constante $K$ sujeito a um campo magnético aplicado $H$ com ângulo $\alpha$ em relação ao eixo fácil, figura 2.3. Para este sistema a densidade de energia magnética $\mathcal{E}$ pode ser escrita como:

$$
\frac{E}{V}=\mathcal{E}=K \sin ^{2}(\theta)-\mu_{0} M H \cos (\alpha-\theta)
$$

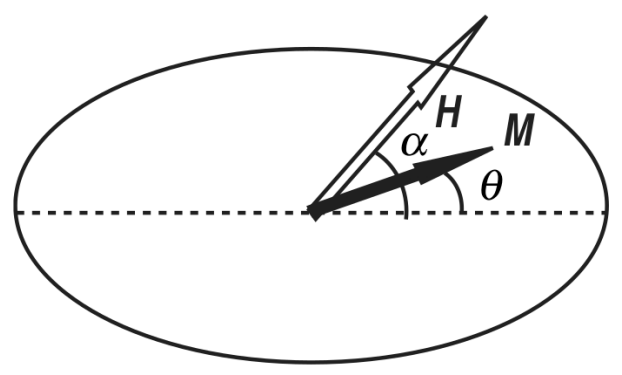

Figura 2.3: Esquema de uma partícula magnética no modelo de Stoner e Wohlfarth [9]. A partícula possui um formato de elipsoide com anisotropia uniaxial, onde o eixo fácil é representado pela linha tracejada. Retirada de [18].

A equação 2.6 deve ser minimizada em relação ao ângulo $\theta$ da magnetização $M$ em relação ao eixo fácil, de forma que $d \mathcal{E} / d \theta=0$. Resolvendo esta equação vemos que há uma região de valores de $H$ onde temos dois mínimos possíveis para $\theta$, que é justamente a região onde a histerese aparece. Na figura 2.4 (a) vemos a solução para valores de $\alpha$ entre 0 e $90^{\circ}$. Para $\alpha=0^{\circ}$ temos um ciclo quadrado com coercividade igual ao campo de anisotropia $H_{A}=H_{c}(\alpha=0)=$ $2 K / \mu_{0} M_{S}$, já para $\alpha=90^{\circ}$ não temos mais histerese. Para valores de $\alpha$ menores do que $45^{\circ}$, a coercividade é igual ao campo de inversão de um mínimo para o outro $H_{S}{ }^{2}$, já para $\alpha>45^{\circ}$, temos $H_{S}>H_{c}$.

2 O subscrito $S$ vem do termo em inglês switiching field. 

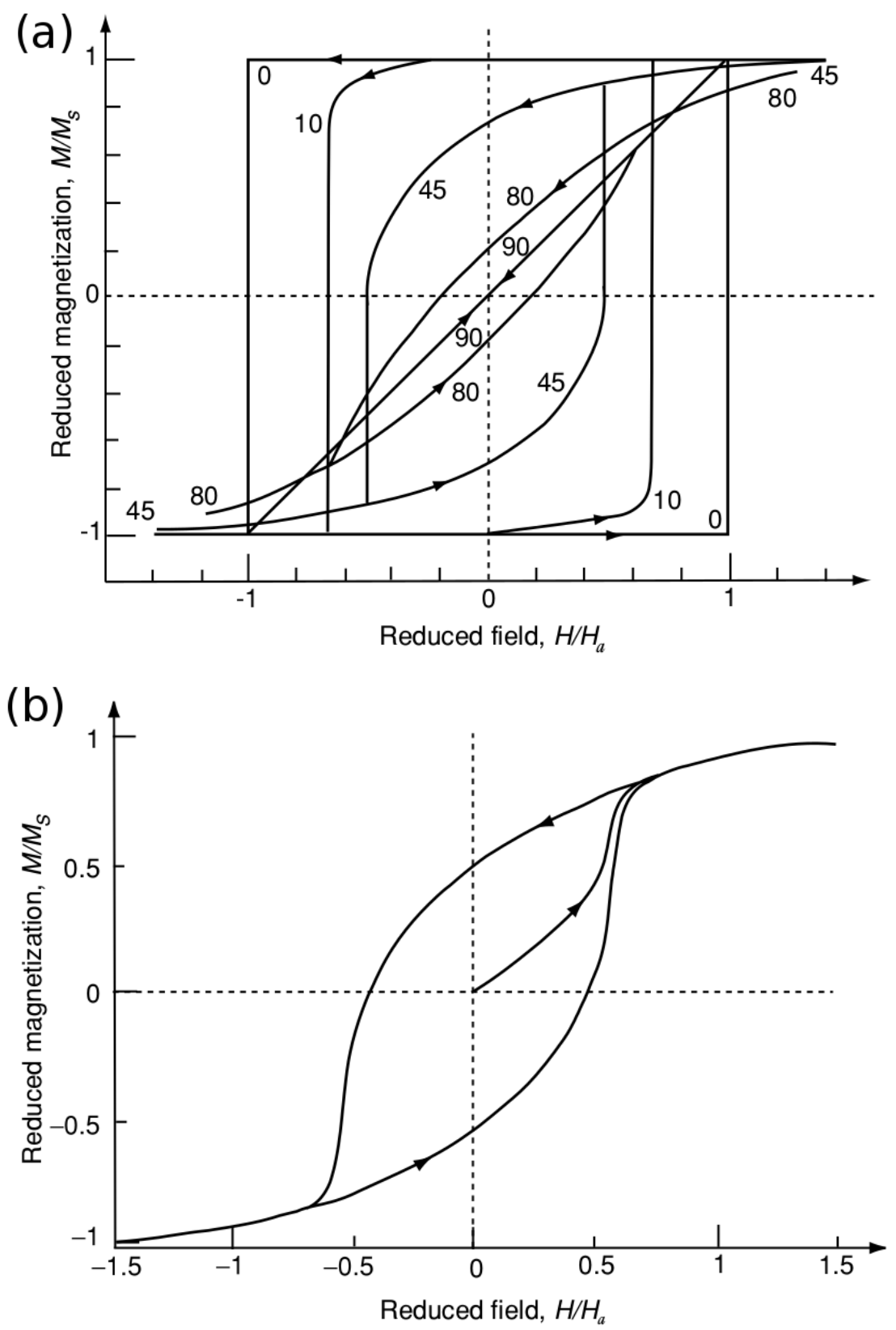

Figura 2.4: (a) Ciclos de histerese para vários ângulos $\alpha$ entre o campo aplicado e o eixo fácil. Em (b) vemos o ciclo para um conjunto de nanopartículas com orientações entre o eixo fácil e o campo aplicado distribuídas aleatoriamente. Figuras retiradas de [18]. 
O campo $H_{S}$ é dado justamente quando $d^{2} \mathcal{E} / d \theta^{2}=0$, na passagem irreversível de um mínimo para outro, e possui a seguinte expressão:

$$
H_{S}(\theta)=\frac{H_{A}}{\left[\sin (\theta)^{2 / 3}+\cos (\theta)^{2 / 3}\right]}
$$

Para um conjunto de partículas com distribuição aleatória de orientação entre o campo magnético e o eixo fácil, dada pelo ângulo $\alpha$, obtemos o ciclo de histerese mostrado na figura 2.4 (b). Neste caso a remanência do conjunto de partículas é igual a $M_{R}=M_{S} / 2$ e a coercividade $H_{c}=0.482 H_{A}$. Com os avanços nos métodos de síntese de nanopartículas foi possível obter sistemas com um comportamento muito próximo ao previsto neste modelo, principalmente a baixas temperaturas, como vemos na figura 2.5 para amostras de nanopartículas de ferrita de bário recobertas com sílica, que possui a função de diminuir as interações entre partículas [19].

\subsection{EFEITOS DE SUPERFÍCIE EM NANOPARTÍCULAS}

A razão entre o número de átomos que se encontram na superfície em relação ao número de átomos internos é maior quanto menor for o tamanho das nanopartículas. Para nanopartículas onde uma fração considerável dos átomos se encontra na superfície, os efeitos ligados ao menor número de coordenação desses átomos, que possuem uma energia de troca total menor, pode ser detectado experimentalmente. Em um trabalho de 1996, Kodama et. al. [20] observaram um decréscimo da magnetização para nanopartículas de $\mathrm{NiFe}_{2} \mathrm{O}_{4}$ em relação a uma amostra bulk, figura 2.6. Para explicar seus resultados, os autores mostram um modelo onde a baixas temperaturas os spins superficiais estão orientados em múltiplas direções em relação aos spins do núcleo, em uma configuração conhecida como vidro de spin (spinglass). Portanto, a irreversibilidade magnética observada no ciclo de histerese até o campo de $160 \mathrm{kOe}$ seria devido a uma mudança de orientação dos spins superficiais e não a uma reversão coerente da magnetização das partículas. Podemos encontrar resultados similares em nanopartículas com composições químicas diferentes, como por exemplo $\mathrm{CoFe}_{2} \mathrm{O}_{4}$ [21] e $\gamma-\mathrm{Fe}_{2} \mathrm{O}_{3}$ [22].

Nanopartículas, em comparação à amostras bulk, necessitam de campos mais intensos para saturarem, o que pode ser explicado pela diminuição do número de coordenação dos átomos superficiais. No entanto é importante que a cristalinidade da partícula se mantenha a mesma em relação ao observado em uma amostra bulk para que a comparação seja válida. Batlle et. al. [6] mostram que, dependendo do método de síntese, podemos ter nanopartículas com uma cristalinidade muito baixa, que possuem propriedades magnéticas, como irreversibilidade a altos campos, que poderiam ser associadas aos efei- 

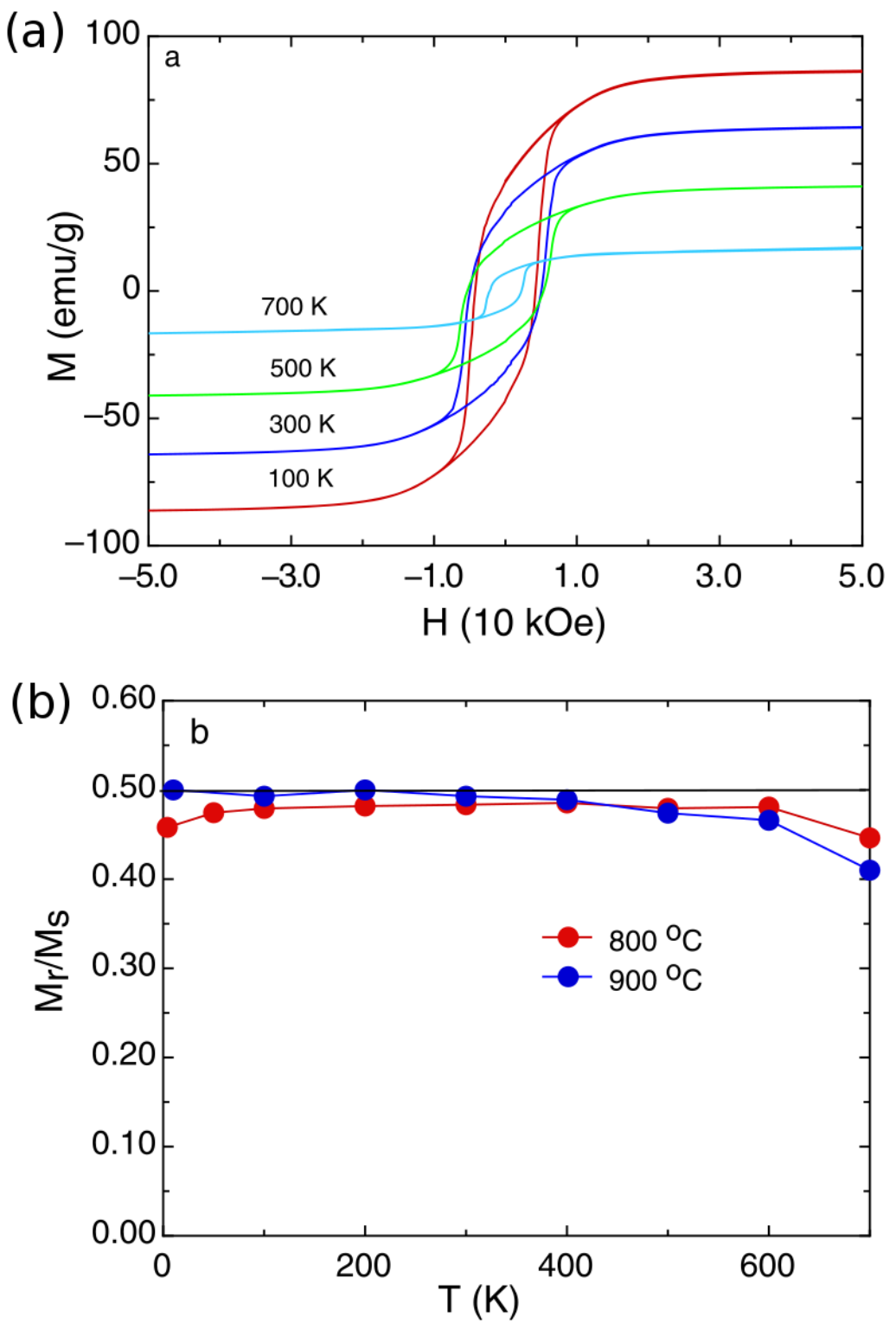

Figura 2.5: (a) Ciclos de histerese para nanopartículas de ferrita de bário recobertas com sílica para diminuir interações. Em (b) vemos a dependência da remanência normalizada com a temperatura para duas amostras diferentes. Abaixo de $400 \mathrm{~K}$ o valor obtido é compatível com o previsto no modelo de Stoner e Wohlfarth. Retirado de [19]. 


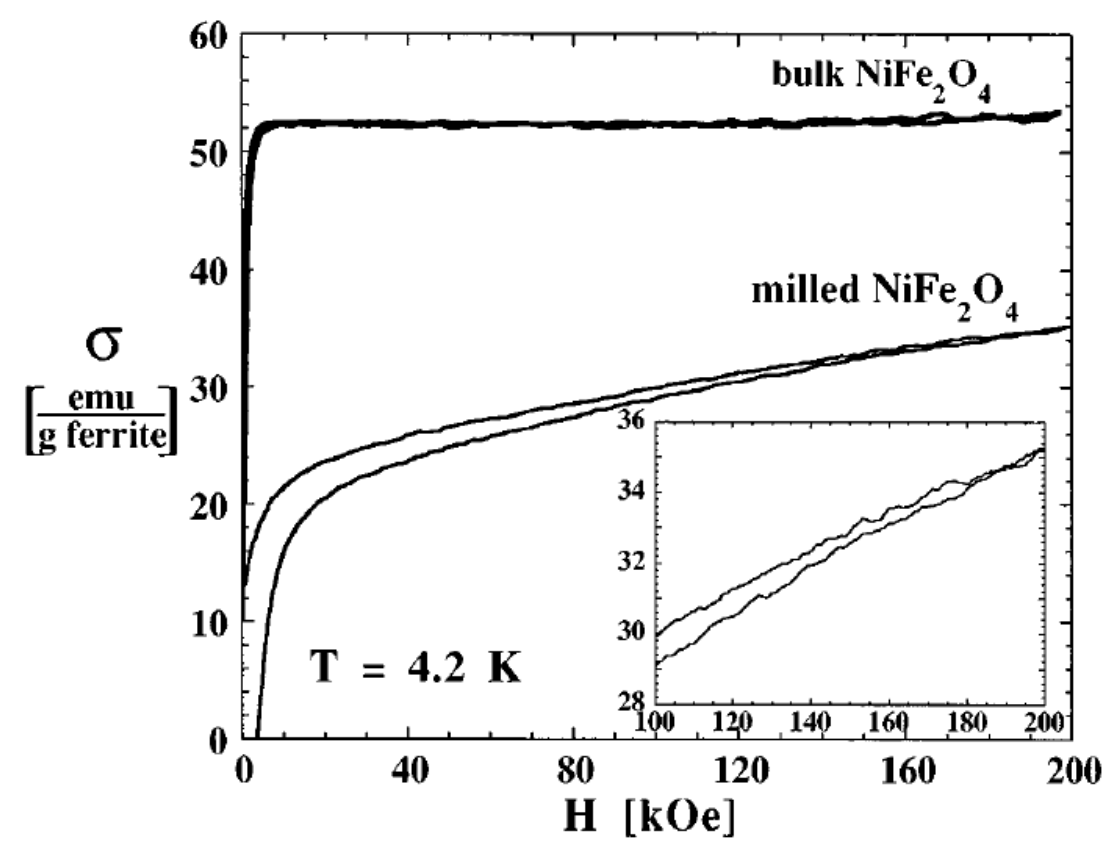

Figura 2.6: Ciclos de histerese para nanopartículas de $\mathrm{NiFe}_{2} \mathrm{O}_{4}$ (milled) e para uma amostra bulk com a mesma composição. Vemos que as nanopartículas necessitam de campos mais intensos para saturarem. No painel interno vemos em detalhes a região de campos mais intensos para as nanopartículas. Retirado de [20]. 
tos de superfície, mas que na verdade são efeitos devido à baixa cristalinidade. Os autores mostram que para nanopartículas de $\mathrm{Fe}_{3-x} \mathrm{O}_{4}$ efeitos de superfície podem ser observados para nanopartículas com alta cristalinidade apenas com diâmetros menores do que $5 \mathrm{~nm}$.

Para nanopartículas, a constante de anisotropia $K$ também depende do tamanho. Uma expressão fenomenológica que descreve a dependência da constante de anisotropia efetiva $K_{e f}$ com o diâmetro $D$ de nanopartículas esféricas é dada por [23]:

$$
K_{e f}=K_{V}+\frac{6}{D} K_{\text {sup }}
$$

onde $K_{V}$ é a constante de anisotropia de uma amostra volumétrica e $K_{\text {sup }}$ a constante de anisotropia superficial.

Os avanços recentes no método de síntese dessas amostras também tornou possível a obtenção de nanopartículas heterogêneas, onde o núcleo e a superfície são compostos por materiais magnéticos diferentes, levando à observação de efeitos como exchange bias [24] e a um aumento da magnetização, como vemos na figura 2.7 [25]. Alguns trabalhos experimentais também mostram que o recobrimento de partículas magnéticas com ácidos orgânicos, como o ácido oleico, é capaz de aumentar a magnetização destes sistemas, apesar desse fenômeno ainda não ser totalmente compreendido [26].
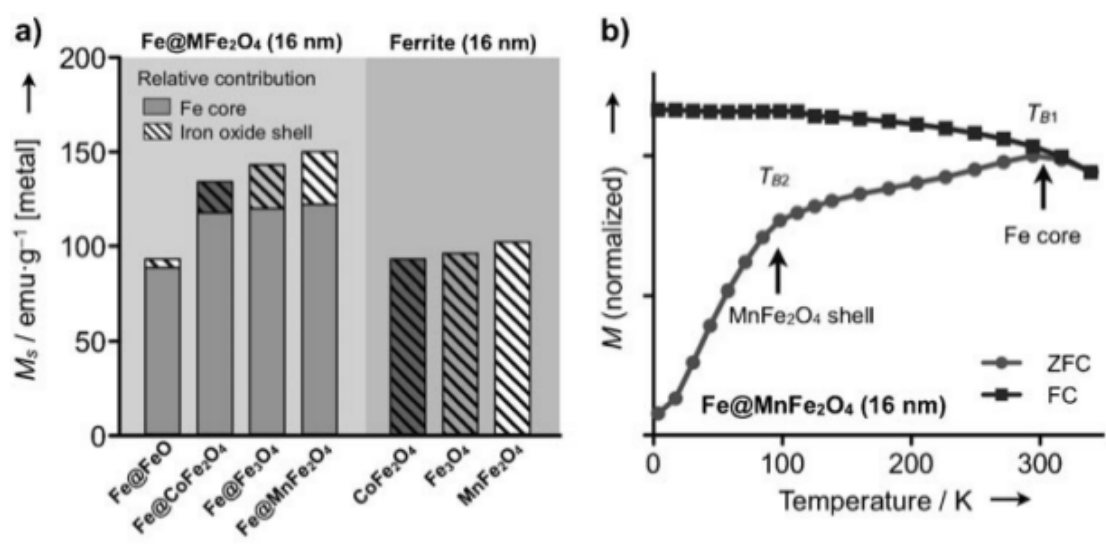

Figura 2.7: Magnetização de saturação para nanopartículas com um núcleo de ferro e superfície de ferritas. Em (a) vemos que o recobrimento destas nanopartículas com as ferritas é capaz de aumentar $M_{S}$. Em (b) vemos as curvas ZFC-FC, onde cada fase da nanopartícula tem uma temperatura de bloqueio diferente. Retirado de [25]. 


\subsection{INTERAÇÕES ENTRE PARTÍCULAS MAGNÉtiCAS}

Uma característica quase sempre marcante em amostras de nanopartículas é a presença de interações entre elas. A interação de troca é importante para amostras onde as nanopartículas estão em contato uma com as outras, já que essa é uma interação de curto alcance, com comprimento característico da ordem de alguns $n m$. Por sua vez, a interação dipolar pode ser relevante para boa parte das amostras, já que é uma interação de longo alcance em comparação à de troca, que caí com a distância ao cubo, como vemos na equação abaixo para a expressão do campo dipolar na posição $\vec{r}$ criado por um momento magnético $\vec{\mu}$ colocado na origem do sistema de coordenadas:

$$
\vec{H}_{d}=\frac{1}{4 \pi}\left(\frac{3 \vec{r}(\vec{\mu} \cdot \vec{r})}{r^{5}}-\frac{\vec{\mu}}{r^{3}}\right)
$$

Assim como efeitos de superfície, as interações entre partículas também podem alterar algumas propriedades magnéticas destes sistemas, como coercividade, temperatura de bloqueio e a barreira de energia [27]. Por exemplo, em um trabalho recente, vemos o comportamento magnético de nanopartículas de $\mathrm{SmCo}_{5}$ com diâmetro médio de $3.5 \mathrm{~nm}$ dispersas em matrizes de carbono [28]. Os autores observam que para as amostras onde as partículas estavam mais separadas dentro da matriz, a coercividade (que vemos na figura 2.8) e a temperatura de bloqueio eram maiores. Os autores atribuem isso à diminuição da interação de troca entre partículas, que seria menor para a amostra $S 5$ que possui uma maior espessura da camada de carbono que separa as nanopartículas. Os autores argumentam que para um sistema de nanopartículas sem interações, a reversão da magnetização é por rotação coerente, enquanto que na presença de interações a reversão da magnetização é incoerente, o que leva a uma diminuição da coercividade.

Para nanopartículas de níquel foi observado que a barreira de energia tem um aumento considerável quando a concentração de nanopartículas aumenta, como vemos na figura 2.9 [7]. Esse fato está diretamente relacionado ao aumento da interação dipolar para as amostras mais concentradas, já que nas amostras preparadas neste trabalho as nanopartículas eram isoladas por uma matriz de $\mathrm{SiO}_{2}$. Como a interação dipolar aumenta a barreira de energia das nanopartículas, podemos esperar que sistemas mais concentrados mostrem uma temperatura de bloqueio maior.

Outra característica da interação dipolar, é que sua energia é minimizada em configurações onde as nanopartículas se organizam em linhas, como cadeias lineares e anéis. Na figura 2.10 vemos uma imagem de nanopartículas de magnetita, $\mathrm{Fe}_{3} \mathrm{O}_{4}$, que se organizam em cadeias [29]. Na figura B, vemos que a formação destas cadeias leva a 


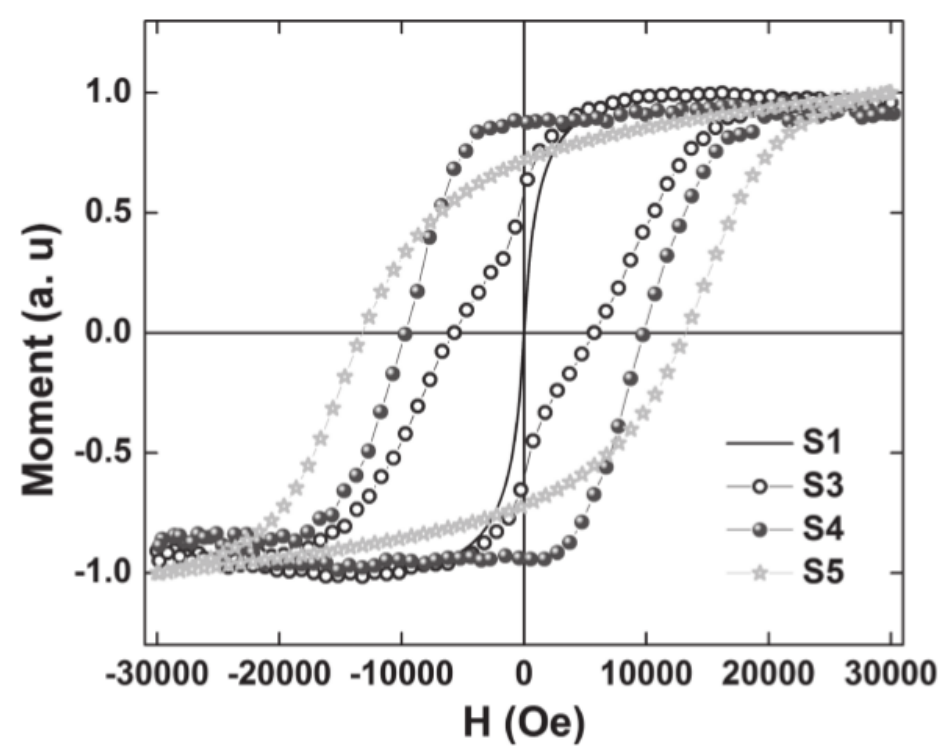

Figura 2.8: Ciclos de histerese para nanopartículas de $\mathrm{SmCo}_{5}$ dispersas em matrizes de carbono. A amostra $\mathrm{S}_{5}$ possui uma espessura da camada de carbono de $52 \mathrm{~nm}$, enquanto que $S 1$ não possui essa camada. As demais amostras possuem espessuras com valores intermediários. Retirado de [28].

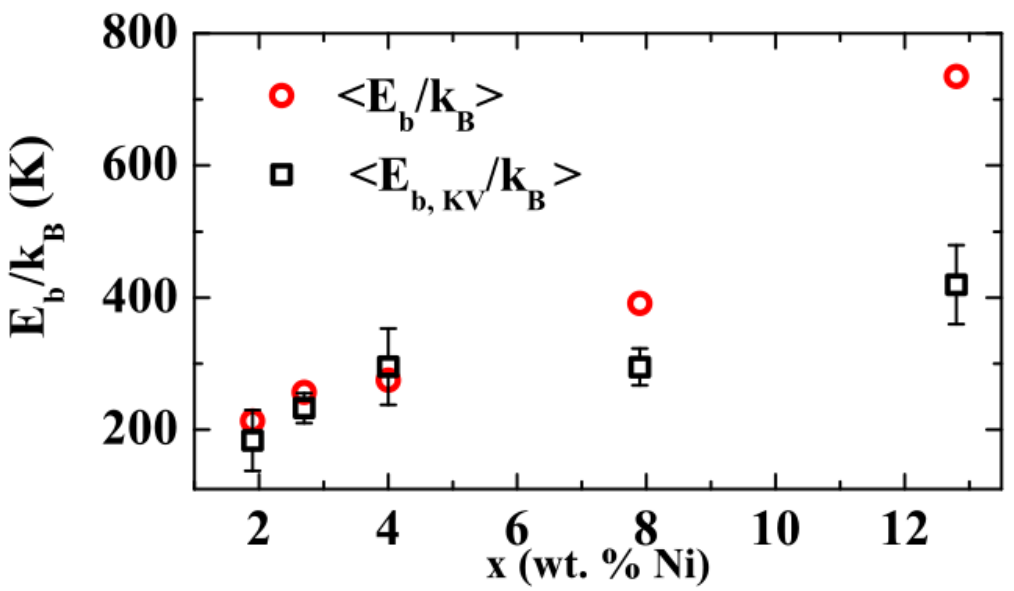

Figura 2.9: Dependência da barreira de energia intrínseca $E_{b}=K V$ com a média $\left\langle E_{b}\right\rangle$, esta última extraída de medidas de suscetibilidade AC, com a concentração de nanopartículas de níquel. Retirado de [7]. 
um aumento da coercividade do sistema. Na seção 2.4.2 veremos que a formação destas estruturas pode levar a aumento da viscosidade de um fluido magnético.
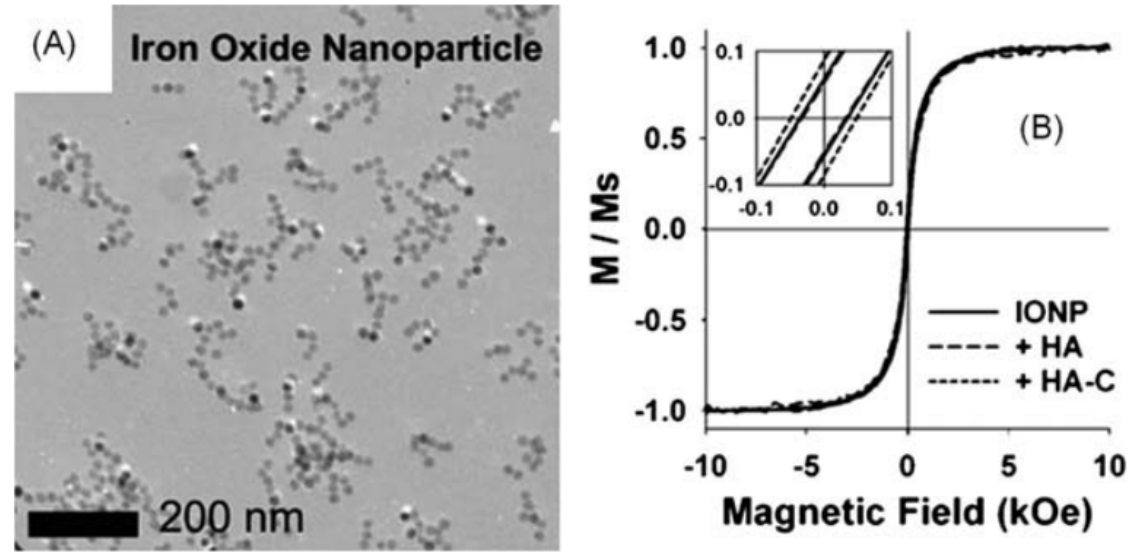

Figura 2.10: Na figura A vemos imagens obtidas com um microscópio eletrônico de transmissão mostrando nanopartículas de $\mathrm{Fe}_{3} \mathrm{O}_{4}$ organizadas em cadeias. Em $\mathrm{B}$ os autores mostram que a amostra onde as partículas se organizaram em cadeias possuíam uma maior coercividade. Retirado de [29].

2.3 CONTRIbUiÇÕEs de SimulaÇÕes utilizando o método DE MONTE CARLO NA COMPREENSÃO DO MAGNETISMO DE NANOPARTÍCULAS

Utilizando o modelo de Ising ou de Heisenberg podemos construir uma rede de spins que interagem entre si via interação de troca [30]. No caso do modelo de Ising, temos spins $S_{i}$ que podem estar em dois estados possíveis, $S_{i}= \pm 1$. Já no modelo de Heisenberg os spins $S_{i}$ são vetores tridimensionais, com $\left|\vec{S}_{i}\right|=1$. Para os dois modelos, considerando apenas a energia de troca, podemos construir uma hamiltoniana do tipo:

$$
\mathcal{H}=-\sum_{i, j} \mathcal{J}_{i j} \vec{S}_{i} \cdot \vec{S}_{j}
$$

sendo que $\mathcal{J}_{i j}=J$ se os spins $i$ e $j$ são primeiros vizinhos, e $\mathcal{J}_{i j}=0$ caso contrário.

Como a interação de troca é a chave para a compreensão do ordenamento magnético, é natural pensar que os modelos acima sejam ferramentas poderosas para representar nanopartículas magnéticas. De fato, há inúmeros trabalhos [31, 32, 33, 34] que utilizam algum dos modelos acima para representar os spins das nanopartículas junto 
com algum algoritmo Monte Carlo, como o Metropolis [35], para introduzir a temperatura como um parâmetro do sistema.

Em geral, construímos uma rede de spins com um formato esférico e adicionamos à equação 2.10 outros termos de energia, como o de interação entre o spin com o campo magnético, anisotropia e interação entre partículas. Variando os parâmetros de cada termo de energia, é possível observar o efeito de cada um no ordenamento magnético das nanopartículas. Por exemplo, considerando uma anisotropia superficial $K_{S}$ para os spins da superfície, Berger et. al. [33] observaram fases onde o ordenamento dos spins podiam ter uma configuração homogênea para $K_{S}=0$ até uma fase com um ordenamento radial, que eles chamaram de hedgehog. Segundo as simulações, este tipo de ordenamento pode levar a uma mudança no mecanismo de reversão da magnetização nas nanopartículas [36].

Com este tipo de representação das nanopartículas também podemos observar efeitos do tamanho nas propriedades magnéticas, como redução do campo coercivo, da temperatura de ordenamento e magnetização espontânea para partículas menores [12, 36, 37]. Outra possibilidade é representar as nanopartículas com uma estrutura coreshell, mudando o sinal da constante de troca $\mathcal{J}$ que é positiva para amostras ferromagnéticas e negativa para antiferromagnéticas [38]. Neste tipo de sistemas, os autores puderam observar que o aparecimento de um campo de exchange bias é dependente do surgimento de um momento magnético não nulo na interface antiferromagnética $[39,40]$.

Para estudar interações entre partículas muitos autores preferem uma abordagem diferente da mencionada acima. Neste caso podemos considerar cada partícula como um super momento que interage com as demais via interação dipolar, como por exemplo nos trabalhos de $[41,42]$. Com esta representação é mais fácil simular grandes quantidades de nanopartículas, já que que não é preciso levar em conta os spins dos átomos que constituem uma partícula, no entanto é preciso simular uma caixa e definir a posição espacial de cada partícula, já que a interação dipolar depende da distância. Estudos mostram que a distribuição espacial das nanopartículas tem um forte efeito no seu comportamento magnético em função da temperatura [43].

\subsection{FLUIDOS MAGNÉTICOS}

Fluidos magnéticos são materiais formados por uma suspensão de partículas magnéticas dispersas em um líquido, que pode ser água, óleo ou materiais mais complexos, como cristais líquidos. A possibilidade de um material ser controlado por campos magnéticos moderados é uma característica única que fez com que uma grande variedade de aplicações, indo de biológicas [44] a tecnológicas [45], fossem atribuídas a esses sistemas. 
Um aspecto importante do estudo dos fluidos magnéticos é a forma de obtenção desse tipo de amostra. Atualmente a síntese de fluidos magnéticos coloidais se tornou um campo de pesquisa importante, já que para obter determinadas propriedades magnéticas de interesse, como por exemplo uma baixa temperatura de bloqueio, características como a cristalinidade, forma e distribuição de tamanho das partículas são fatores determinantes [6]. Já para a utilização desses materiais como fármacos, a incorporação de um surfactante à superfície das partículas que não seja tóxico e ao mesmo tempo seja capaz de guiar as partículas até um determinado local de interesse (por exemplo, um tumor localizado em um órgão) se torna tão ou mais importante que o núcleo magnético das partículas [46].

As inúmeras aplicações desses fluidos, principalmente as ligadas às áreas médicas, foram responsáveis por esse campo ter recebido muito investimento financeiro nos últimos anos. No entanto, além do interesse mais aplicado, esses materiais possuem diversas propriedades físicas que fazem com que eles sejam ótimos sistemas para o estudo de propriedades físicas básicas. Por exemplo, fluidos magnéticos são capazes de ter suas propriedades mecânicas alteradas devido à aplicação de um campo magnético, como é o caso da viscosidade [47]. Sob determinadas condições, e com um campo magnético aplicado, ferrofluidos (nome usualmente dado aos fluidos magnéticos com partículas da ordem de nanômetros) são capazes de formar estruturas com protuberâncias em sua superfície que lembram espinhos, como vemos na figura 2.11. Essa área é conhecida como instabilidade de ferrofluidos $[48,49]$.

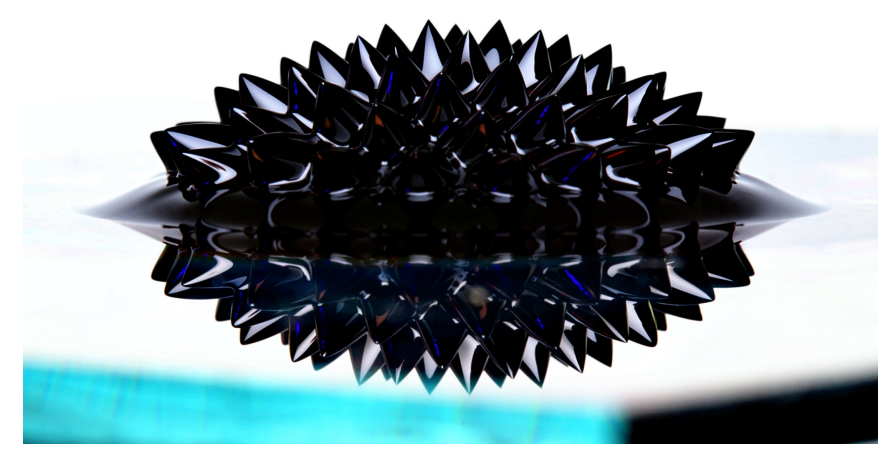

Figura 2.11: Observação de uma instabilidade em ferrofluido, que acontece quando a energia magnética é grande o suficiente para superar efeitos da gravidade e de tensões superficiais. Imagem retirada de $[50]$. 
Em relação às propriedades magnéticas, podemos observar algumas propriedades diferentes quando as mesmas partículas estão dispersas em um meio líquido, ou imobilizadas em uma matriz. Na figura 2.12, por exemplo, vemos o comportamento da parte imaginária da suscetibilidade, $\chi^{\prime \prime}$, com a frequência para as mesmas partículas quando elas estão dispersas em um meio fluido ou quando estão imobilizadas em um gel [51]. Vemos que existe na curva do fluido um pico que não existe nas partículas imobilizadas. Isso está associado à relaxação magnética devido ao movimento browniano das partículas.

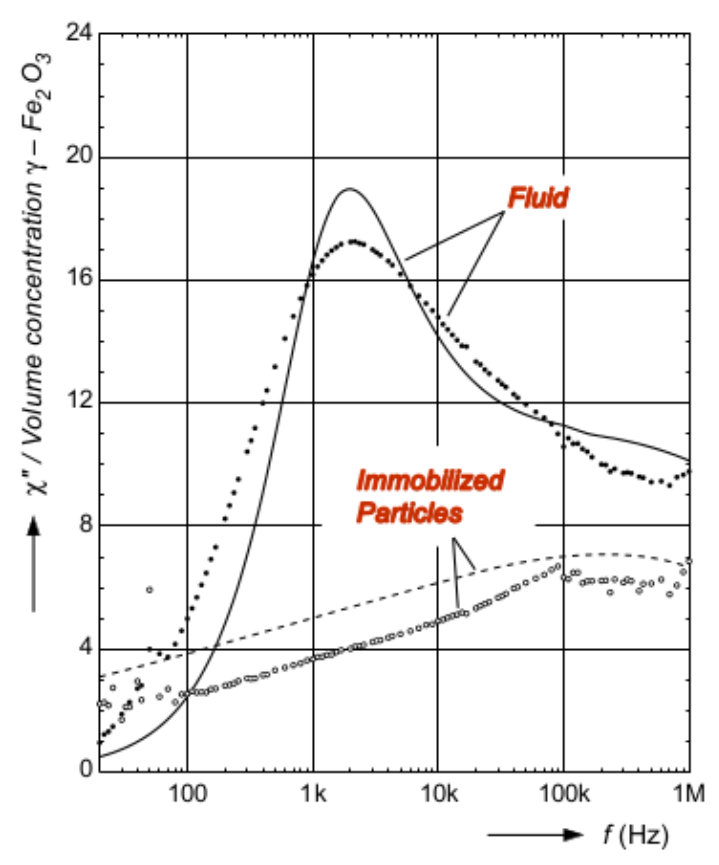

Figura 2.12: Componente imaginária da suscetibilidade magnética para partículas de maguemita dispersas em um fluido e para as mesmas partículas imobilizadas em um gel. Retirado de [51].

Quando as partículas magnéticas estão dispersas em um meio líquido elas podem rotacionar e transladar dentro desse meio. Se um campo magnético é aplicado nessa amostra, o momento magnético dessas partículas poderá se orientar de duas maneiras: com a partícula rotacionando dentro do líquido de modo que seu eixo fácil fique na direção do campo aplicado, ou com o momento magnético da partícula rotacionando para se alinhar com esse campo. O primeiro processo é conhecido como relaxação magnética de Brown e o segundo como relaxação magnética de Néel.

O tempo típico $\tau_{B}$ para que uma partícula gire dentro do líquido e se oriente com o campo depende do volume hidrodinâmico $V_{h}{ }^{3}$

3 Esse é o volume total da partícula, incluindo seu núcleo magnético e o surfactante na superfície. 
dessa partícula, da viscosidade $\eta$ do meio e da temperatura $T$ do sistema. Sua expressão foi deduzida em um artigo de W. F. Brown de 1963 [52] e é dada por:

$$
\tau_{B}=\frac{3 V_{h} \eta}{k_{B} T}
$$

Já para partículas que são monodomínios magnéticos, o tempo típico para ocorrer uma relaxação de Néel é simplesmente dado pelo inverso da equação 2.4:

$$
\tau_{N}=v_{0}^{-1} \exp \left(\frac{K_{e f} V}{k_{B} T}\right)
$$

Para partículas pequenas, a relaxação magnética é dada predominantemente por processos de Néel. No entanto temos que $\tau_{N}$ cresce exponencialmente com o volume magnético da partícula, portanto em uma amostra de ferrofluido com uma distribuição de volumes de partículas pode ocorrer que existam partículas que se alinhem com o campo magnético pela relaxação de Néel e outras maiores que relaxem pelo processo de Brown. Na figura 2.13 vemos os tempos de relaxação em função do diâmetro das partículas para uma amostra de ferrofluido a base de óleo com viscosidade $\eta=0,05 \mathrm{~kg} / \mathrm{ms}$ e partículas de magnetita (retirado de [53]). Quando $\tau_{B}$ e $\tau_{N}$ são da mesma ordem, podemos aproximar o tempo de relaxação por um tempo efetivo $\tau_{e f}$ dado pela média geométrica de $\tau_{B}$ e $\tau_{N}[54]$ :

$$
\tau_{e f}=\frac{\tau_{N} \tau_{B}}{\tau_{N}+\tau_{B}}
$$

Em amostras de ferrofluido as partículas podem formar estruturas como cadeias, agulhas e outras estruturas magnéticas. Em geral esse efeito é mais pronunciado em fluidos com uma fração significativa de partículas maiores [55] e quando um campo magnético é aplicado [56], no entanto essas estruturas já foram observadas em amostras sem a aplicação de um campo [57]. Um exemplo onde a formação dessas estruturas é importante é na mudança de viscosidade que ocorre em fluidos magnéticos sob a ação de um campo. Em geral esse efeito depende da intensidade e orientação do campo aplicado e das propriedades internas do fluido, como tamanho, distribuição e concentração das partículas $[45,47]$.

Um fenômeno interessante observado em amostras de ferrofluido é ver como a magnetização se comporta com a transição entre o estado sólido e líquido $[58,59]$. Na figura 2.14 vemos curvas de magnetização em função da temperatura para nanopartículas de cobalto dispersas em DCB (1,2 diclorobenzeno) (retirado de [58]) para vários valores 


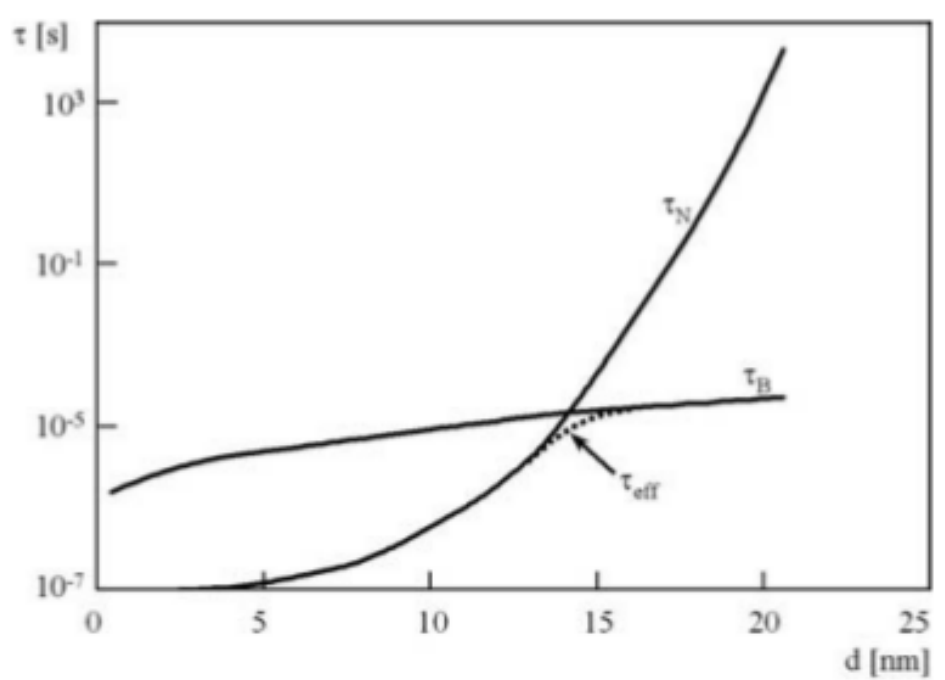

Figura 2.13: Gráfico mostrando os tempos de relaxação de Brown $\tau_{B}$ e Néel $\tau_{N}$ em função do diâmetro para partículas de magnetita imersar em um óleo de viscosidade $\eta=0,05 \mathrm{~kg} / \mathrm{ms}$. Retirado de [53].

de campo aplicado, sendo as curvas vermelhas a magnetização medida enquanto a amostra era aquecida e azul enquanto a amostra era resfriada. Nas curvas vermelhas a transição do estado sólido para o líquido pode ser observada com o súbito aumento da magnetização em torno de $250 \mathrm{~K}$. Para as curvas azuis vemos um degrau a uma temperatura menor que $250 \mathrm{~K}$, que é justamente quando a amostra passa do estado líquido para o sólido. $\mathrm{O}$ interessante dessas medidas é que a temperatura da passagem do estado líquido para o sólido é menor do que a de liquefação, um fenômeno conhecido como superresfriamento. A observação dessas transições são discutidas em mais detalhes na seção $4 \cdot 3$, já que pudemos observar esse efeito nas nossas amostras.

\subsubsection{Cristais líquidos dopados com nanopartículas magnéticas}

Em 1970 Brochard e De Gennes [14] publicaram um artigo prevendo que a introdução de pequenos grãos magnéticos em cristais líquidos poderia reduzir o campo magnético necessário para alinhar esses sistemas de aproximadamente 100000 e para algumas dezenas de Oe. Desde então o uso de nanopartículas para dopar cristais líquidos é amplamente utilizado, principalmente em cristais líquidos liotrópicos que são formados por micelas que se ordenam espacialmente.

No meu trabalho de mestrado [16], onde alguns resultados foram publicados no artigo [6o], observamos que medidas magnéticas podiam dar informações sobre as transições de fase de uma amostra de cristal líquido liotrópico com a temperatura. A amostra de cristal líquido estudada apresentava uma transição entre a fase isotrópica 


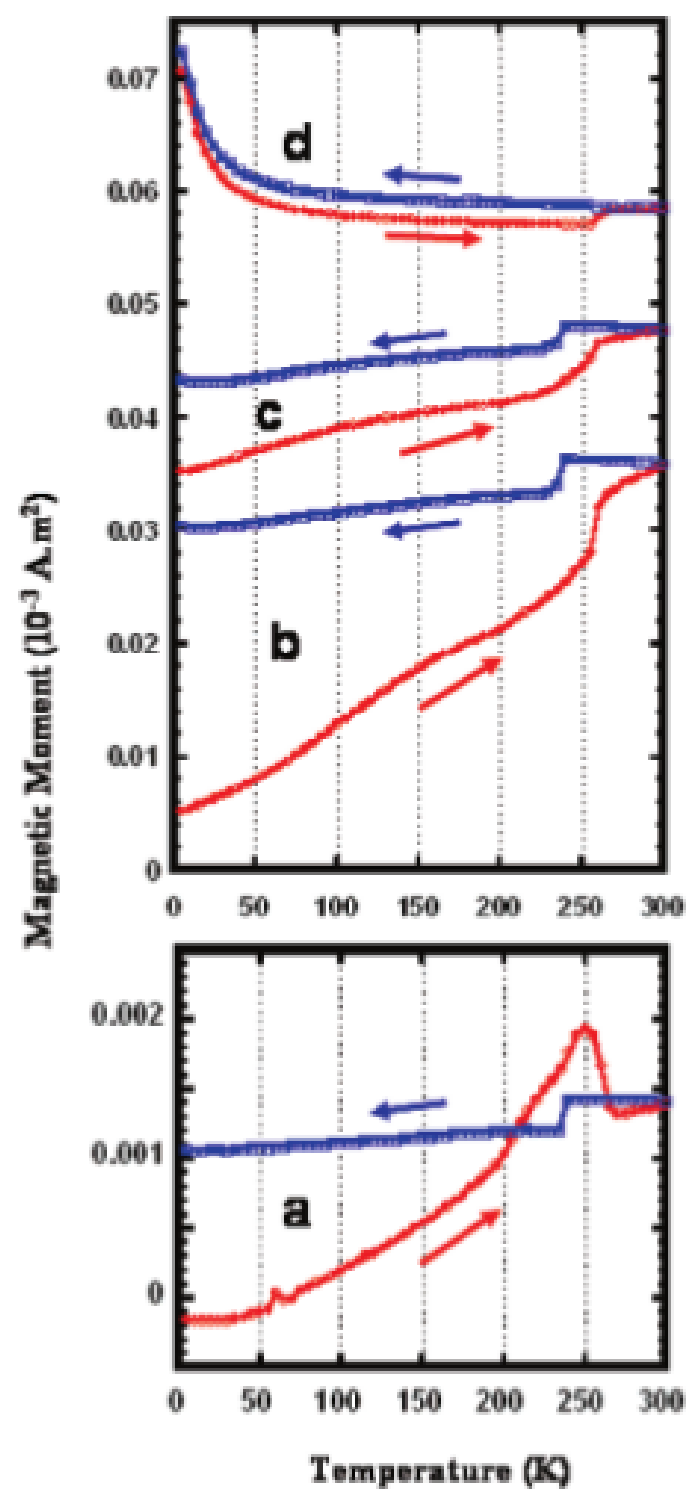

Figura 2.14: Curvas de magnetização versus temperatura para amostras de nanopartículas de cobalto com $10 \mathrm{~nm}$ imersas em DCB com campo aplicado de (a) 0, (b) 200, (c) 500 e (d) 50000Oe. Retirado de $[58]$. 


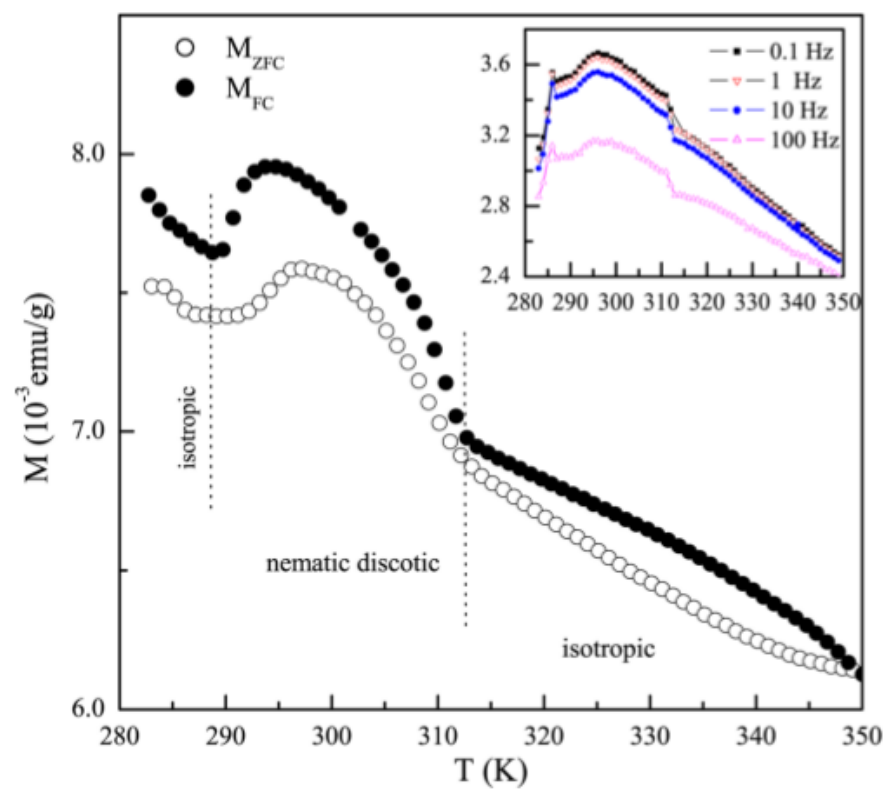

Figura 2.15: Curvas ZFC-FC e medidas de suscetibilidade (painel interno) para uma amostra de cristal líquido dopada com nanopartículas de magnetita. Vemos que a medida de magnetização indica as temperaturas de transição de fase da amostra. Retirado de [6o].

(quando não temos um ordenamento das micelas e elas possuem uma baixa anisotropia de forma) e a nemática (quando as micelas estão ordenadas espacialmente e possuem uma alta anisotropia de forma) [61, 16]. Na figura 2.15 vemos a curva ZFC-FC e a medida de suscetibilidade (painel interno) que obtivemos para uma das amostras, e as respectivas fases isotrópica e nemática indicadas. Vemos que as temperaturas onde ocorre uma mudança de comportamento da magnetização nas curvas ZFC-FC coincidem com as mudanças de comportamento da suscetibilidade.

O resultado mais surpreendente apresentado nesse artigo é o comportamento na forma de sino da magnetização na fase nemática. Esse é o comportamento do parâmetro de ordem com a temperatura nessa fase e que pode ser determinado experimentalmente por meio de medidas óticas e de raios $X$, como vemos na figura 2.16 (retirada de [62]). Foi justamente esse comportamento que fez com que pudéssemos ter certeza que as medidas de magnetização podiam dar informações sobre as transições de fase em amostras de cristal líquido. Esse resultado é surpreendente porque vemos que as nanopartículas podem se ancorar com as micelas do cristal líquido e se ordenarem com o campo magnético quando essas também o estão. Temos então um claro exemplo onde o comportamento magnético das partículas é alterado de acordo com o meio onde elas estão dispersas. 

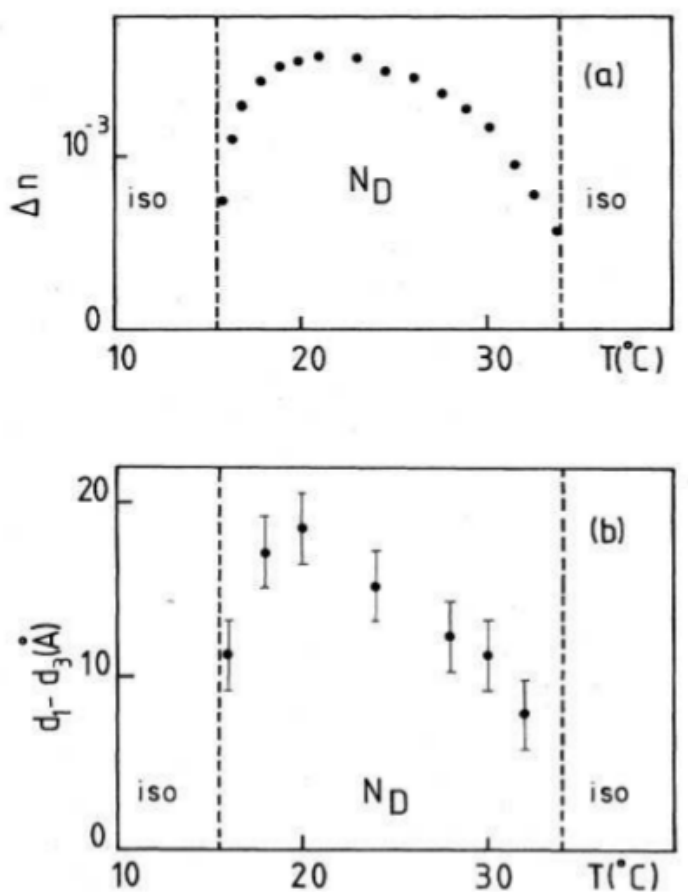

Figura 2.16: Medidas (a) óticas e (b) de raio X que mostram o comportamento do parâmetro de ordem com a temperatura para uma amostra nemática. Retirado de [62].

\subsubsection{Efeito magnetoviscoso}

A mudança na viscosidade de um fluido magnético devido à aplicação de um campo externo tem sido estudada há mais de quarenta anos, desde sua primeira observação nos trabalhos de Rosensweig [63] e McTague [64] em 1969. Usualmente observado em ferrofluidos, este efeito pode ser explicado em uma primeira abordagem considerando que as partículas magnéticas que não estão no estado superparamagnético são impedidas pelo campo de rotacionar livremente dentro do líquido $[65,47]$, um efeito conhecido como viscosidade rotacional. Estudos nos últimos quinze anos mostraram, no entanto, que as interações entre partículas e as cadeias que aparecem no ferrofluido quando o campo é aplicado em geral dominam este efeito [47, 66, 67]. A mudança na viscosidade devido às interações entre partículas é conhecido como efeito magnetoviscoso, ou simplesmente MVE do acrônimo em inglês magnetoviscous effect, e as propriedades que potencializam as interações magnéticas, como o tamanho das partículas e a composição química, são as características importantes que determinam a magnitude do MVE [68]. Na figura 2.17 vemos o aumento relativo da viscosidade em função do campo aplicado para diversas taxas de cisalhamento para um ferrofluido comercial [69]. Para esse ferrofluido em particular observamos um aumento da vis- 


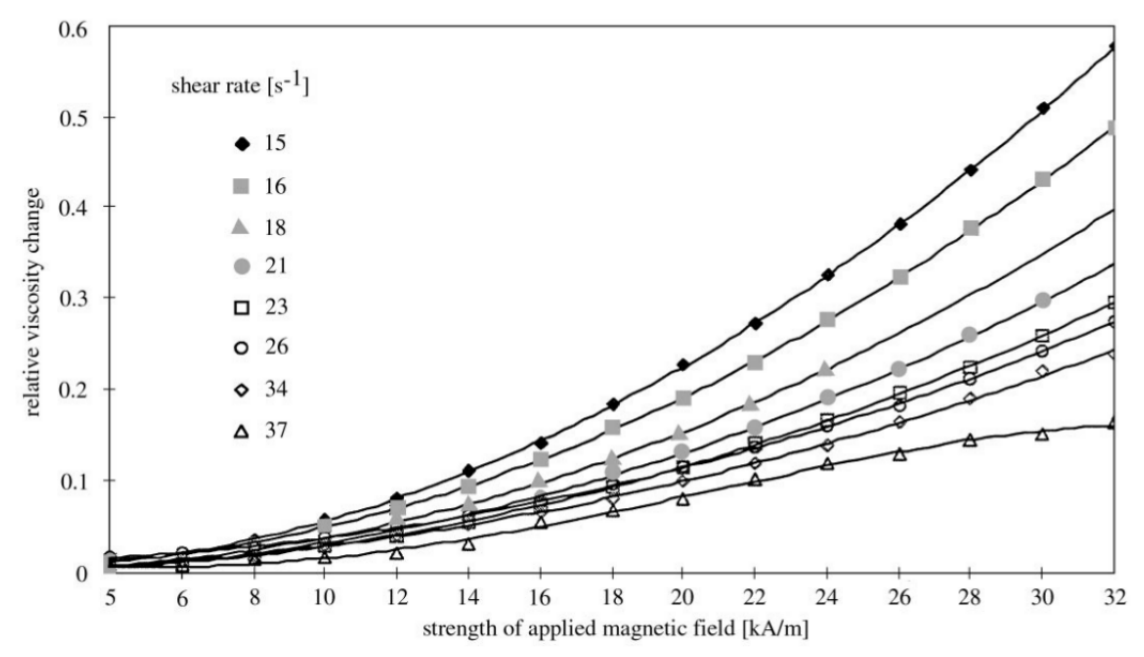

Figura 2.17: Aumento relativo da viscosidade em função do campo aplicado para diversas taxas de cisalhamento para um ferrofluido comercial. Retirado de [69].

cosidade de quase $60 \%$ para o campo mais intenso e a menor taxa de cisalhamento.

Como em um ferrofluido as partículas magnéticas estão dispersas em líquido comum, como água e óleo, esperamos que todas as propriedades magnéticas que aparecem devido à aplicação de um campo magnético são devido a presença e interações destas partículas, o que faz com que a concentração seja um fator importante para observar o efeito magnetoviscoso. No entanto isto não é mais verdadeiro quando as partículas magnéticas estão diluídas em um meio que pode ser afetado pela sua presença e sua interação com o campo magnético, como soluções anfifílicas de surfactantes [70], ferronemáticos [14, 60] e cristais líquidos. Estas interações dinâmicas das partículas magnéticas com o meio e com o campo aplicado levam à diferentes propriedades físicas na presença do campo aplicado, como mudanças no comportamento ótico [71] e reológico [70], mesmo em concentrações de partículas tão pequenas quanto uma a quatro ordens de grandezas menores do que a concentração típica de ferrofluidos.

No caso de soluções micelares, agregados de moléculas anfifílicas em um solvente, a maioria dos estudos são dedicados ao uso de nanopartículas para orientar sistemas que mostram um ordenamento espontâneo líquido cristalino, como fases nemáticas [72, 73] e hexagonais [74]. Seu comportamento reológico, com ou sem ordenamento espontâneo, é caracterizado por uma mudança microscópica estrutural no líquido quando a amostra é cisalhada $[75,76]$, porque micelas são estruturas dinâmicas que mudam sua forma e alinhamento durante o cisalhamento [77]. No entanto, como pequenas quantidades de partículas magnéticas podem mudar as propriedades óticas e magnéticas destes sistemas, podemos esperar que a dopagem de soluções 
micelares com partículas magnéticas também poderá influenciar sem comportamento reológico na presença de um campo aplicado. 
Neste capítulo reunimos uma descrição de todos os métodos e técnicas que utilizamos neste trabalho. Dividimos esse capítulo em quatro seções, com as técnicas de caracterização estrutural, magnética, reológica e por fim uma seção explicando o algoritmo de Metropolis. Como o enfoque deste trabalho é no comportamento magnético de nanopartículas, a seção 3.2 é a mais completa entre as três e contém uma grande parte das técnicas utilizadas tradicionalmente para caracterizar materiais magnéticos. Nas seções referentes à caracterização estrutural das amostras e às técnicas de reologia, comentamos apenas o necessário para poder acompanhar os resultados experimentais apresentados nos próximos capítulos. Devemos ter em mente, no entanto, que as técnicas de difratometria de raios $X$, microscopia de transmissão, espectroscopia Mössbauer e reologia possuem muito mais peculiaridades e sofisticação do que apresentamos aqui.

\subsection{CARACTERIZAÇÃO ESTRUTURAL DAS AMOSTRAS}

\subsubsection{Difratometria de raios $X$}

A difratometria de raios $X[78]$ é uma técnica com a qual podemos obter muitas informações de uma determinada amostra, como sua estrutura cristalina, presença de determinados elementos químicos, tamanho de grão, entre outras. Nesta técnica, temos um feixe de raios $X$ colimado e em geral monocromático (com um único comprimento de onda) que atinge o material de interesse. As ondas de raios $X$ são espalhadas pelos átomos da amostra, mas como os espaços interatômicos são da ordem de décimos de nanômetros e o comprimento de onda para raios $X$ está entre cerca de $10 \mathrm{~nm}$ e $1 \mathrm{pm}$, temos então processos de interferência entre as ondas da radiação espalhada. Essas interferências, portanto, levam à difração dos raios $X$ que é a característica desta técnica.

Neste trabalho utilizamos a técnica conhecida como varredura $\theta-$ $2 \theta$, esquematizada na figura 3.I. Nesta geometria a radiação incidente atinge a amostra formando um ângulo $\theta$ com seus planos cristalográficos. As ondas difratadas atingem o detetor posicionado com um ângulo $2 \theta$ em relação à radiação incidente, como vemos na figura 3.I. Fazendo a varredura dos ângulos $2 \theta$, com a ajuda de um goniômetro, podemos construir um gráfico da intensidade da radiação detectada pelo ângulo $2 \theta$, conhecido como difratograma. Na figura 3.2 vemos por exemplo alguns difratogramas para nanopartículas de magnetita. 


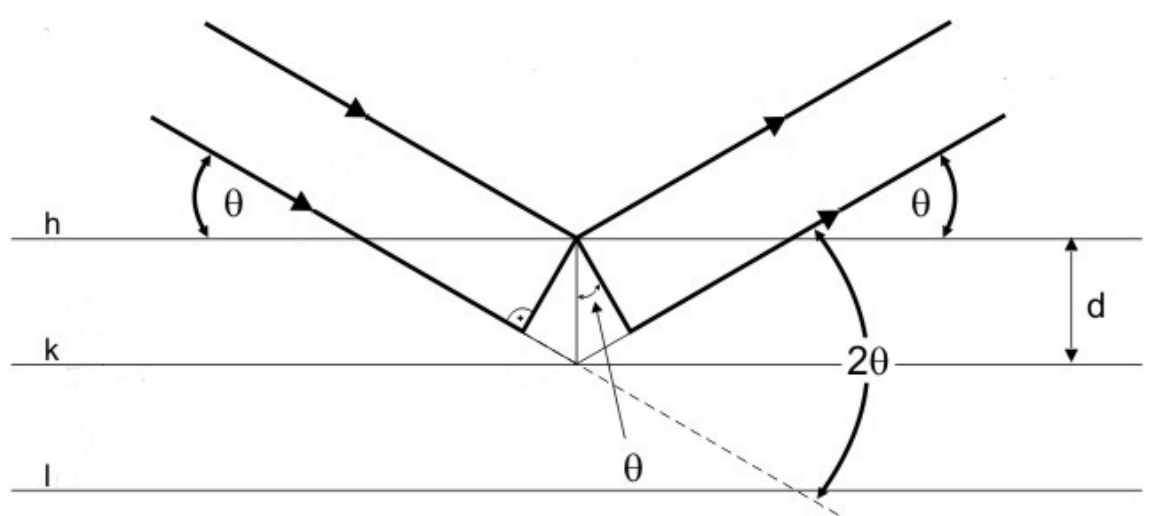

Figura 3.1: Figura indicando a geometria $\theta-2 \theta$ e os planos cristalográficos da amostra.

A partir dos ângulos onde ocorrem os picos de intensidade, podemos determinar o parâmetro de rede $a$ da estrutura cristalina usando a lei de Bragg, equação 3.I, que fornece a condição onde se dão as interferências construtivas da radiação espalhada, e também da equação 3.2 que fornece a distância $d$ entre os planos atômicos para uma amostra com simetria cristalina cúbica. Nestas equações $\lambda$ é o comprimento de onda da radiação e $h, k$ e $l$ são os índices de Miller.

Em sistemas simples as fases cristalinas de uma amostra podem ser determinadas comparando o difratograma obtido com difratogramas padrões disponíveis em bancos de dados. Na figura 3.2 [79] os traços representados em $\mathrm{d}$ foram retirados do The International Centre for Diffraction Data (JCPDS) e foram usados para comparar com os difratogramas obtidos para as amostras sintetizadas pelos autores.

$$
\begin{aligned}
& n \lambda=2 d \sin \theta \\
& d_{h k l}=\left[\frac{1}{a^{2}}\left(h^{2}+k^{2}+l^{2}\right)\right]^{-1 / 2}
\end{aligned}
$$

Neste trabalho utilizamos o equipamento D8 Advance da Bruker do Laboratório de Cristalografia do Instituto de Física da USP. Este equipamento possui fonte de radiação $\mathrm{C} u-K_{\alpha}$, com comprimento de onda $\lambda=1.5418 \AA$, corrente no filamento de $30 \mathrm{~m} A$ e ddp. de $40 \mathrm{kV}$. Um filtro de níquel foi utilizado para eliminar parte da radiação $C u-K_{\beta}$. 


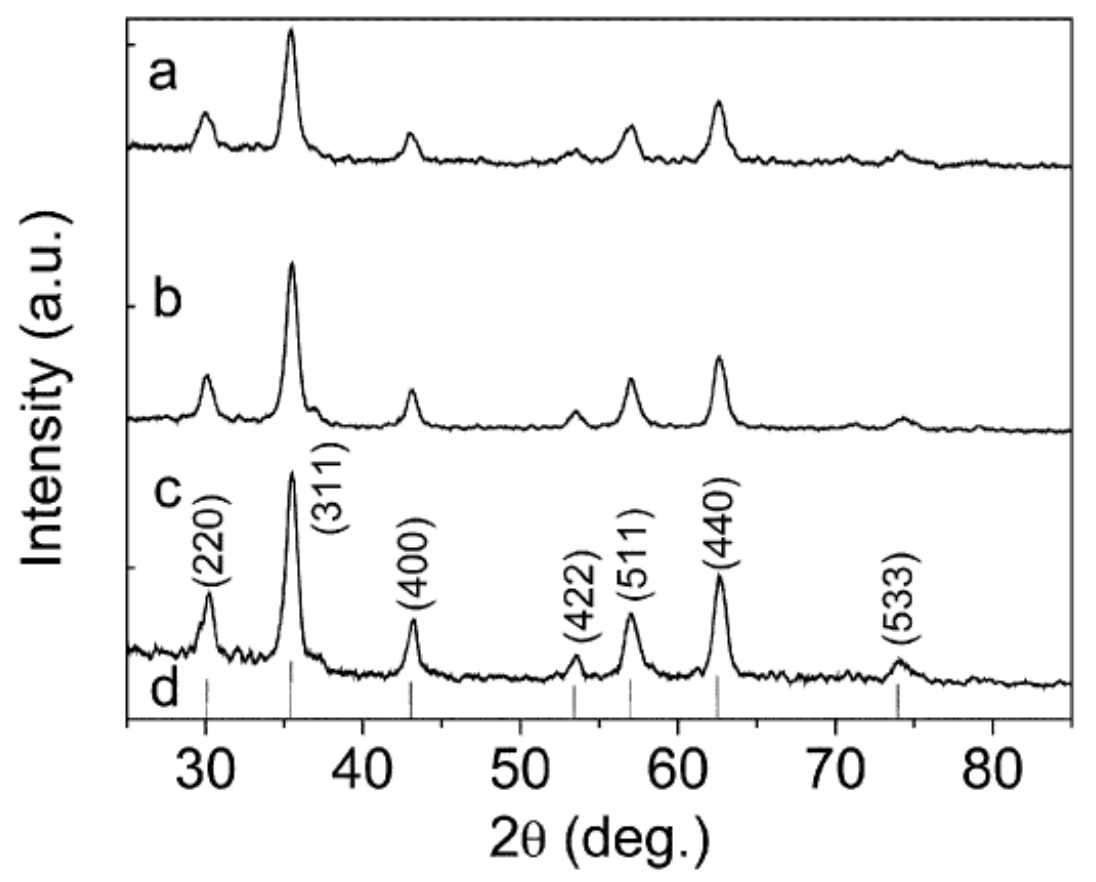

Figura 3.2: Difratogramas de raios $X$ para amostras de nanopartículas de magnetita com tamanhos entre 8 e $11 \mathrm{~nm}$, recobertas com diferentes surfactantes, sendo a (TOPO e PVP), b (HDA e PVP) e c (PVP). Em d é mostrado um difratograma padrão para a magnetita retirado do The International Centre for Diffraction Data (JCPDS). Retirado de [79]. 
3.1.2 Determinação do tamanho de nanopartículas utilizando um microscópio eletrônico de transmissão

Em um microscópio eletrônico de transmissão [8o] temos um feixe de elétrons, em geral obtido por efeito termoiônico ou pela técnica de emissão de elétrons por campo, que é acelerado por um potencial elétrico em direção à amostra depois de ter sido focalizado por lentes eletromagnéticas. O feixe de elétrons é espalhado pela amostra, que se for cristalina criará padrões de difração, e emerge pela sua superfície inferior. $O$ feixe espalhado pela amostra passa então por uma lente objetiva para formar uma primeira imagem e depois por outras lentes, dependendo da configuração do microscópio. Por fim o feixe atinge uma tela sensível que criará a imagem final da amostra.

Para utilizar o microscópio eletrônico de transmissão é necessário que a amostra seja transparente ao feixe de elétrons, o que pode ser um fator limitante para vários tipos de amostra. Uma vantagem desta técnica é a sua resolução, na faixa de alguns Å, já que o comprimento de onda dos elétrons se situa na faixa de 0.001 a $0.01 \mathrm{~nm}$. Como os elétrons podem ser espalhados em um meio gasoso, é necessário um alto vácuo para a obtenção das imagens.

A microscopia eletrônica de transmissão é uma técnica muito útil para obter imagens de nanopartículas devido à sua resolução. No caso de ferrofluidos a condição de ser transparente ao feixe de elétrons pode ser facilmente obtida colocando uma pequena quantidade da amostra líquida em uma grade de carbono. Se o ferrofluido for muito concentrado é importante que ele seja diluído previamente.

Usualmente vemos em amostras de nanopartículas uma distribuição de tamanhos dada por uma função log-normal:

$$
f(d ; \mu, \sigma)=\frac{1}{d \sigma \sqrt{2 \pi}} \exp \left(-\frac{\ln ^{2}(d / \mu)}{2 \sigma^{2}}\right)
$$

onde $d$ é o diâmetro das partículas, $\mu$ a mediana e $\sigma$ o chamado parâmetro de escala. Nessa distribuição, o valor médio $\bar{d}$ e o valor mais provável $d_{m p}$ são dados por:

$$
\bar{d}=\mu e^{\sigma^{2} / 2} \quad d_{m p}=\mu e^{-\sigma^{2}}
$$

Com um histograma dos diâmetros das nanopartículas, que pode ser obtido pela imagem da microscopia, podemos ajustar a equação 3.3 usando a função:

$$
L(d ; \mu, \sigma)=N \Delta d f(d ; \mu, \sigma)
$$




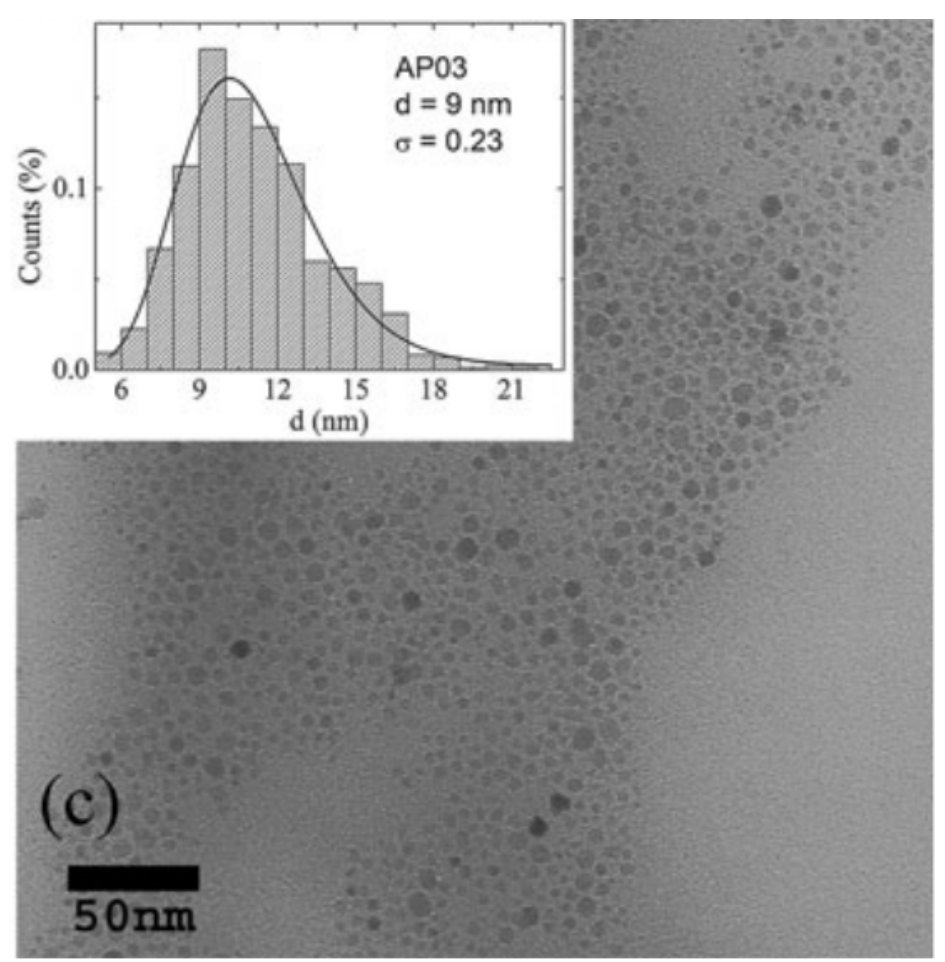

Figura 3.3: Imagem utilizando um microscópio eletrônico de transmissão e um ajuste log-normal para determinar a distribuição de tamanhos de nanopartículas de óxido de ferro. Retirado de [81].

onde $N$ é o número de partículas, $\Delta d$ a largura do bin do histograma e $f(d ; \mu, \sigma)$ a função log-normal dada pela equação 3.3. Na figura 3.3 vemos um exemplo de uma imagem utilizando um microscópio eletrônico de transmissão e um ajuste log-normal para determinar a distribuição de tamanhos de nanopartículas de óxido de ferro [81].

Neste trabalho utilizamos o microscópio MET LEO 906E (Zeiss) do Laboratório de Biologia Celular do Instituto Butantan.

\subsubsection{Espectroscopia Mössbauer}

A espectroscopia Mössbauer [82, 83] é uma técnica por meio da qual podemos obter informações sobre a magnitude dos campos internos de uma amostra, assim como sobre sua composição química e estrutural. Comparada à difratometria de raios $\mathrm{X}$, esta técnica tem a vantagem de ser aplicável também a amostras sem ordenamento estrutural, tais como sólidos amorfos. Uma desvantagem da técnica é que o núcleo atômico que emite a radiação $\gamma$ deve ser o mesmo de algum dos núcleos atômicos dos constituintes da amostra. A razão disso ficará clara a seguir quando explicarmos o efeito Mössbauer.

Um núcleo atômico em um estado excitado com energia $E_{e}$ decai para o estado de menor energia $E_{0}$ emitindo um quantum de radiação. Esta radiação emitida poderia ser absorvida por outro núcleo atômico 
do mesmo tipo com energia $E_{0}$, que passaria então ao estado excitado com energia $E_{e}$. Nesta explicação devemos também considerar a conservação de momento do sistema, de forma que o fóton emitido deve ter energia $E_{\gamma}=E_{e}-E_{0}-E_{R}$, onde $E_{R}$ é a energia cinética de recuo do átomo ao emitir o fóton, que é dada por:

$$
E_{R}=\frac{p^{2}}{2 M}=\frac{\left(E_{\gamma} / c\right)^{2}}{2 M}
$$

sendo $M$ a massa do átomo emissor. Como a energia do fóton emitido é menor que a energia necessária para outro átomo ser excitado do estado de energia $E_{0}$ para o estado de energia $E_{e}$, a absorção neste caso não seria possível. Na prática, esta absorção ocorre devido ao princípio de incerteza de Heisenberg, que garante que as energias dos átomos das amostras estão distribuídas ao redor de $E_{0}$. Dessa forma, existe uma região onde a distribuição de energias da amostra que emite a radiação e da amostra que absorve a radiação se sobrepõem.

Quando os núcleos atômicos, tanto da fonte que emite a radiação $\gamma$ quanto da amostra, estão em uma matriz sólida o recuo dos núcleos atômicos devido à emissão e absorção dos fótons pode ser absorvido pelo sólido, que pode ser considerado como tendo uma massa infinita. Nesta situação, a energia $E_{R}$, equação 3.6 , tende a zero e a emissão e absorção da radiação $\gamma$ pode ocorrer sem recuo. Este efeito é conhecido como absorção ressonante nuclear sem recuo, ou simplesmente como efeito Mössbauer.

Para a tomada de um espectro utilizando o efeito Mössbauer, temos uma fonte radioativa, em geral ${ }^{57} \mathrm{Co}$ que decai para ${ }^{57} \mathrm{Fe}$, que por sua vez emite radiação $\gamma$; uma amostra com o mesmo tipo de núcleo da fonte radioativa e um detetor que contará o número de fótons transmitidos pela amostra. A ressonância é observada variando a energia dos fótons emitidos pela fonte. A variação desta energia se dá com a variação da velocidade relativa $v$ entre a fonte e a amostra, de acordo com o efeito Doppler, que dá a energia em função da velocidade $v$ :

$$
E(v)=E(0)\left(1+\frac{v}{c}\right)
$$

Quando variamos $v$, a contagem $N(v)$ de fótons transmitidos pela amostra deve ser zero na ressonância e constante para outros valores de $v$. Em um sistema real esta ressonância não ocorre a $v=0$, pois temos interações hiperfinas e também porque a equação 3.7 só considera o termo de primeira ordem.

Quando utilizamos a espectroscopia Mössbauer, em geral temos o núcleo atômico que compõe a fonte e a amostra em ambientes diferentes. Esta diferença, que se dá em geral devido à estrutura cristalina, átomos vizinhos e etc, faz com que os níveis de energia atômicos se- 
jam ligeiramente diferentes entre os núcleos que estão na fonte e na amostra. Em experimentos de espectroscopia Mössbauer usualmente olhamos para as chamadas interações hiperfinas, que surgem devido às perturbações induzidas pelas vizinhanças do núcleo na forma de campos elétricos e magnéticos. A presença destas interações levam à mudanças no espectro Mössbauer, que são quantificadas pela posição da linha $\delta$, pela constante de acoplamento quadrupolar $\Delta$ e pelo campo hiperfino $B_{h f}$.

O deslocamento $\delta$ da energia onde ocorre a absorção ressonante, figura 3.4 (a), também conhecido como deslocamento isomérico, surge devido à presença da nuvem eletrônica no interior do núcleo. Se a vizinhança do núcleo for diferente na amostra e na fonte, a densidade da nuvem eletrônica no interior do núcleo também será diferente, o que leva a esta diferença no valor da energia ressonante.

Outro tipo de interação hiperfina é a que surge devido à interação entre o momento de quadrupolo elétrico do núcleo com o gradiente de campo elétrico gerado pela forma da distribuição da nuvem eletrônica. Esta interação hiperfina se manifesta no espectro Mössbauer como um desdobramento do pico de ressonância, separados pela constante de acoplamento quadrupolar $\Delta$, como vemos na figura 3.4 (b).

Por fim temos a interação magnética hiperfina, devida aos campos magnéticos internos do núcleo $B_{h f}$. Esse desdobramento dos níveis de energia é conhecido como efeito nuclear Zeeman, e se manifesta nos espectros com o surgimento de um sexteto, como vemos na figura 3.4 (c).

Os valores dos parâmetros $B_{h f}, \Delta$ e $\delta$ podem ser extraídos de ajustes que utilizam combinações de funções lorentzianas que representam o pico de absorção da radiação pela amostra. Em geral, para amostras magnéticas, as três interações hiperfinas são relevantes, e portanto vemos a superposição de todas as interações no espectro.

\subsection{CARACTERIZAÇÃO MAGNÉTICA DAS AMOSTRAS}

\subsubsection{Magnetometria SQUID}

Um magnetrômetro SQUID (Superconducting Quantum Interference Device) é um equipamento de grande sensibilidade, capaz detectar pequenos campos magnéticos da ordem de $10^{-14} \mathrm{~T}$. Ele é formado por um circuito supercondutor fechado com uma ou mais junções de Josephson [85]. Em um sistema de aquisição de dados, o SQUID está conectado a um sistema de bobinas supercondutoras de detecção, por onde a amostra se move induzindo uma corrente elétrica na bobina. Essa variação da corrente nas bobinas de detecção produzem variações na tensão de saída do SQUID que são proporcionais ao momento magnético da amostra [85]. 

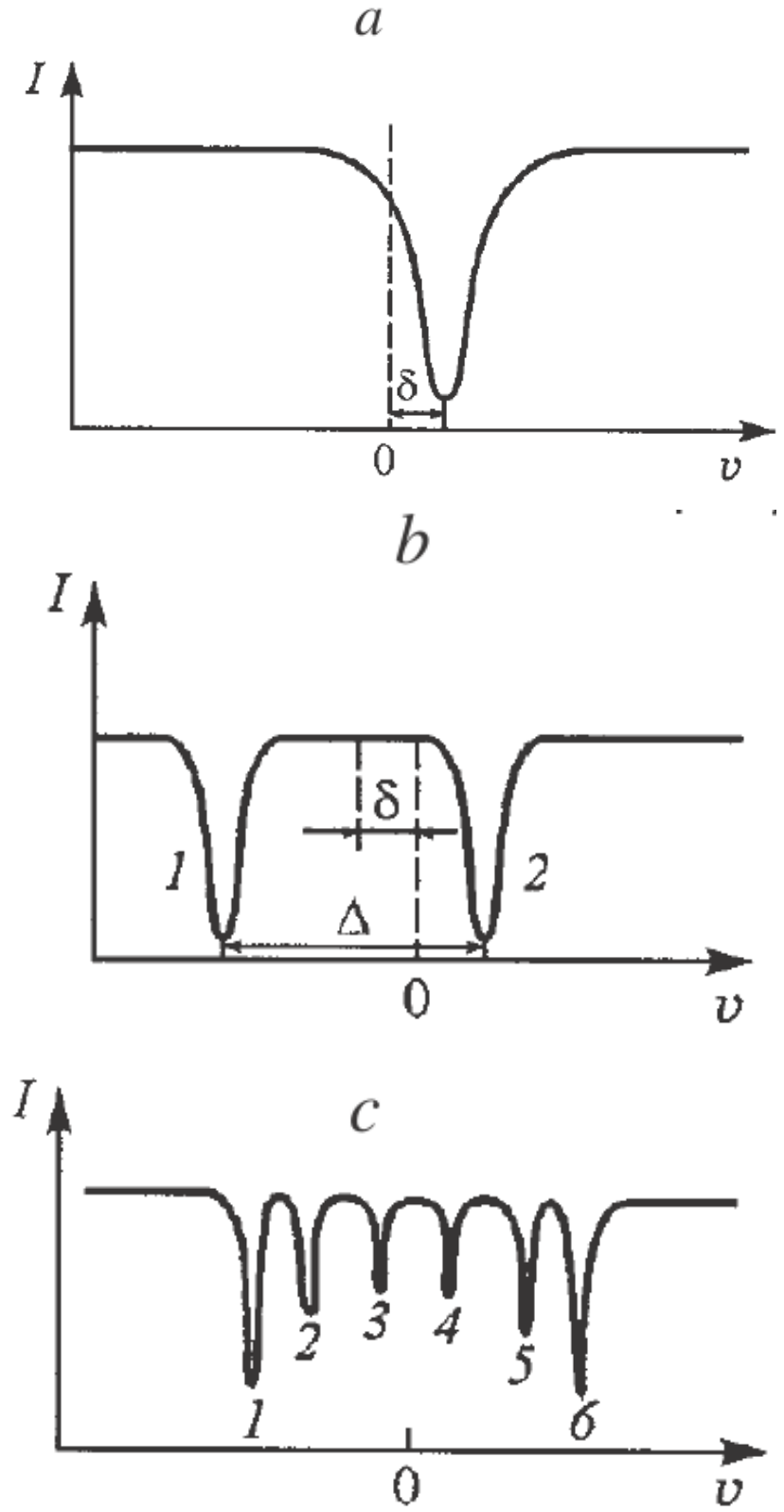

Figura 3.4: Espectros Mössbauer representando (a) o deslocamento isomérico $\delta,(b)$ a constante de acoplamento quadrupolar $\Delta$ e (c) o sexteto devido ao campo magnético hiperfino $B_{h f}$. Retirado de [84]. 
Nesta tese todas as medidas de magnetização foram obtidas com o modelo MPMS da empresa Quantum Design, com campo máximo de $7 T$ e variação de temperatura na região da amostra entre 1.8 e $400 K$. Utilizamos porta amostras de quartzo vedados com resina de dentista com comprimento total da ordem de $1 \mathrm{~cm}$ e diâmetro interno de $2.2 \mathrm{~mm}$.

\subsubsection{Curvas Zero Field Cooling - Field Cooling (ZFC-FC)}

Uma das principais técnicas utilizadas para caracterizar o comportamento magnético de nanopartículas, e que fornece informações como a temperatura de bloqueio desses sistemas ou temperaturas relacionadas à outras mudanças de comportamento magnético, são as curvas Zero Field Cooling - Field Cooling (ZFC-FC).

Neste tipo de medida a amostra é resfriada em campo nulo e então um pequeno campo magnético, tipicamente entre dezenas e centenas de Oe, é aplicado. Uma vez que o campo é aplicado, a temperatura é aumentada e a magnetização medida para cada novo valor de $T$ até chegar a uma dada temperatura máxima de interesse. Essa primeira etapa é conhecida como a curva ZFC. Após chegar na temperatura máxima, começamos a resfriar o sistema até chegar novamente na temperatura inicial. Essa é a curva FC. Na figura 3.5 vemos uma representação de uma medida típica obtida com esta técnica. Vemos que a curva ZFC é caracterizada por um comportamento inicialmente crescente da magnetização com o aumento da temperatura, seguido por um decréscimo de $M$ com $T$. Isso acontece pois como resfriamos o sistema antes de aplicar o campo, as nanopartículas só adquirem energia suficiente para se alinhar com o pequeno campo aplicado quando ganham energia térmica. Portanto temos essa fase inicial de aumento da magnetização seguido por um decréscimo, que é quando a energia térmica é grande o suficiente para impedir que a magnetização continue a se alinhar na direção do campo. Essa é a temperatura onde se inicia a observação do comportamento superparamagnético das nanopartículas.

Nem sempre a resposta magnética de um conjunto de nanopartículas em medidas ZFC-FC é exatamente como o representado na figura 3.5. Muitas vezes podemos encontrar nas curvas ZFC outras temperaturas onde ocorrem transições magnéticas, como mostramos na figura 3.6 (Retirado de [86]), além da mudança de um regime com ordenamento magnético para o superparamagnético. Neste exemplo em particular, os autores argumentam que a primeira transição poderia ser devido a um ordenamento magnético de curto alcance.

Outro aspecto importante é que as curvas ZFC-FC representam a resposta de um conjunto de partículas magnéticas que podem ter diferentes tamanhos e diferentes orientações em relação ao campo aplicado, portanto temos que interpretar seu resultado como uma 


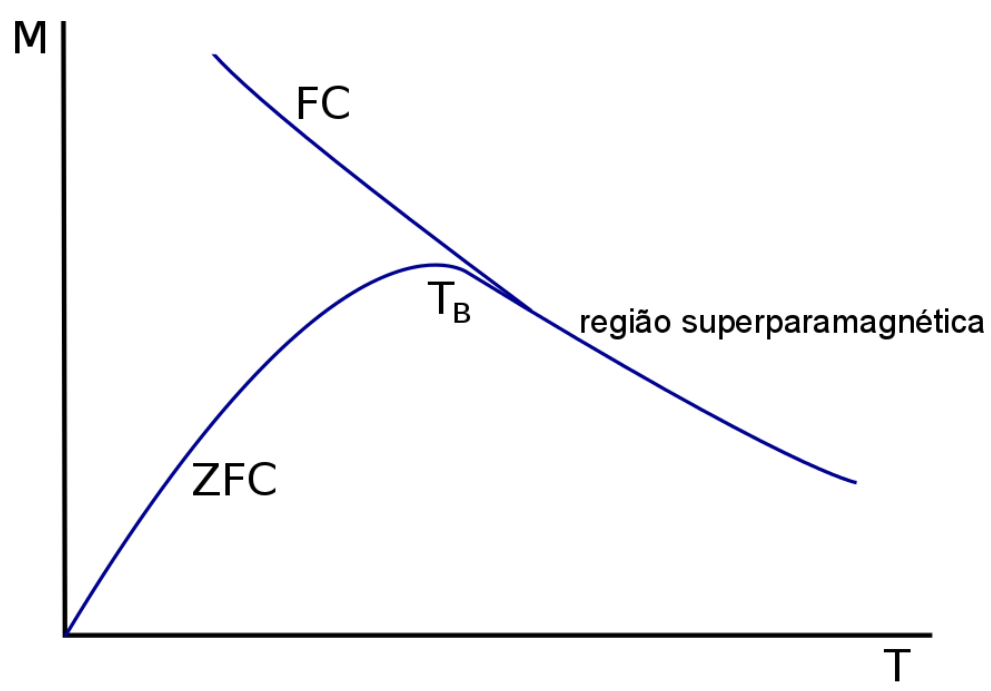

Figura 3.5: Figura esquemática de uma medida ZFC-FC. A temperatura de bloqueio $T_{B}$ é dada pelo máximo da curva $Z F C$, e a região superparamagnética é onde temos uma reversibilidade térmica.

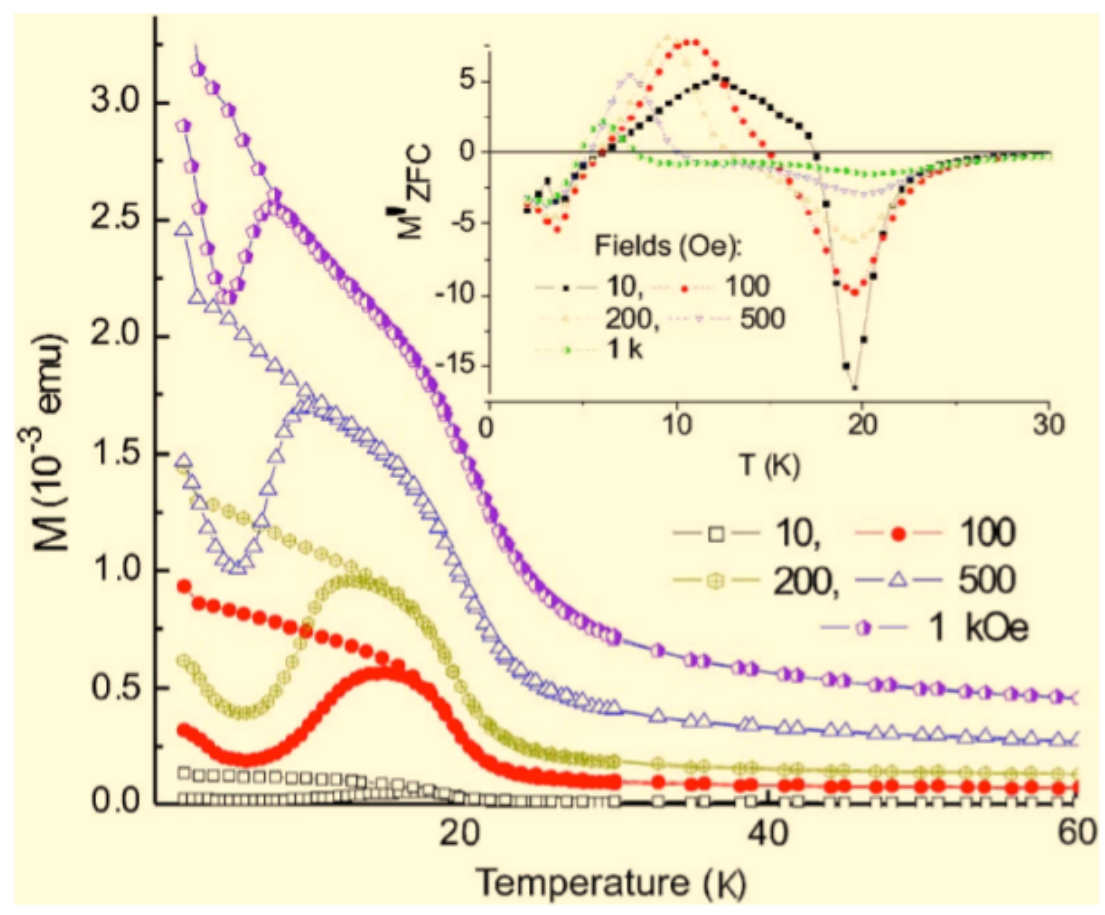

Figura 3.6: Curvas ZFC-FC de nanopartículas de níquel com diversos valores de campo aplicado. Para este sistema vemos duas regiões de transição de fase magnética. Retirado de [86]. 
resposta do conjunto como um todo. A temperatura de bloqueio é a temperatura onde as curvas ZFC e FC se separam, ou, quando a distribuição de tamanhos de partículas é relevante, é a temperatura na qual a curva ZFC atinge seu valor máximo. Se a amostra medida possuir nanopartículas com tamanhos muito diferentes, cada uma deve ter um valor de $T_{B}$ diferente, por isso, nesse caso, o máximo da curva ZFC não ocorre na mesma temperatura onde as curvas ZFC e FC se separam.

Em sistemas formados por nanopartículas magnéticas é muito comum que haja uma distribuição espacial uniforme do eixo fácil em relação à direção do campo aplicado, por exemplo nos casos em que essas amostras são na forma de pó ou de ferrofluidos. No entanto, se pensarmos em um sistema onde todas as partículas possuam seu eixo fácil perfeitamente orientados na direção do campo e com magnetização positiva, podemos esperar que a histerese térmica característica das curvas ZFC-FC desapareça nesse caso, uma vez que a medida já se inicia com a magnetização das nanopartículas orientada na direção do campo. Analogamente, se em uma determinada amostra todas as nanopartículas possuírem uma mesma orientação do eixo fácil em relação ao campo aplicado, devemos considerar esse fato na interpretação das curvas ZFC-FC.

$\mathrm{Na}$ figura 3.6 vemos que a magnitude do campo aplicado também altera a temperatura onde ocorre o pico da curva ZFC. Isso é esperado, uma vez que quanto mais intenso for o campo aplicado, mais facilmente a magnetização da amostra se orientará em sua direção. Campos muito intensos não são recomendados para determinar a temperatura de bloqueio de uma amostra, pois podemos esperar uma maior alteração na barreira de energia desses sistemas (figura 2.2) quanto mais intenso for o campo aplicado.

Experimentalmente as curvas ZFC-FC podem ser medidas utilizando um magnetômetro SQUID, já que neste tipo de equipamento é possível variar a temperatura facilmente. Outra possibilidade é usar o magnetômetro de amostra vibrante (VSM) com um criostato acoplado.

\subsubsection{Curvas de remanência e $\Delta m$}

Uma técnica muito utilizada para determinar se o comportamento magnético de uma amostra é dominado por interações magnetizantes ou desmagnetizantes são as curvas de remanência e $\Delta m$. Para um sistema de partículas não interagentes, uniaxiais e monodomínios, temos que é válida a relação 3.8 deduzida por Wohlfarth [87]:

$$
m_{d}(H)=1-2 m_{r}(H)
$$


sendo que $m_{r}(H)$ são as remanências isotérmicas e $m_{d}(H)$ as remanências desmagnetizantes. Obtemos as remanências $m_{r}(H)$ a partir de uma amostra inicialmente desmagnetizada, em seguida aplicando um pequeno campo magnético e medindo sua remanência após a remoção desse campo. Isso é feito repetidamente até chegar ao campo de saturação positivo. Já as remanências desmagnetizantes $m_{d}(H)$ são obtidas após a saturação da amostra com um campo positivo, quando subsequentes campos negativos são aplicados e removidos, até chegar na saturação negativa da amostra. Devemos lembrar que na equação $3.8 m_{r}(h)$ e $m_{d}(h)$ estão normalizadas pela remanência obtida após a saturação do sistema.

Sendo válida essa relação, podemos definir a quantidade $\Delta m$ dada por:

$$
\Delta m(H)=m_{d}(H)-\left(1-2 m_{r}(H)\right)
$$

que quantifica os desvios do comportamento previsto por 3.8. Como na derivação de 3.8 foram consideradas partículas uniaxiais, não interagentes e monodomínios, qualquer sistema que não satisfaça uma dessas condições pode apresentar a quantidade $\Delta m(H)$ não nula. Além da curva $\Delta m$, também podemos construir o gráfico $m_{d}(H) \times$ $m_{r}(H)$, conhecido como gráfico de Henkel, e observar os desvios do comportamento linear previsto pela equação 3.8 .

Quando observamos desvios do comportamento previsto por 3.8 em amostras de nanopartículas, tipicamente atribuímos isso às interações que usualmente existem nesses sistemas. Neste caso, quando $\Delta m<0$, temos sistemas com interações predominantemente desmagnetizantes, já que após a saturação positiva da amostra a aplicação de um campo negativo leva a desmagnetização do sistema mais facilmente do que foi para magnetizá-lo, indicando a existência de campos internos da amostra que tendem a desmagnetizá-la. Já com $\Delta m>0$, temos sistemas com interações magnetizantes. Podemos então usar essa técnica para analisar os tipos de interações presentes em uma determinada amostra a uma dada temperatura [88, 89, 90].

Na figura 3.7 vemos o comportamento de curvas $\Delta m$ para nanopartículas de $\mathrm{SmCo}_{5}$ dispersas em matrizes de carbono. Vemos que para a amostra $S 5$, que possui uma maior separação entre as partículas, a curva possui uma forte componente desmagnetizante, que podemos atribuir à interação dipolar que é de longo alcance. Já para as demais amostras, onde as partículas estão mais próximas, a magnetização é governada pela interação de troca que é magnetizante e de curto alcance. 


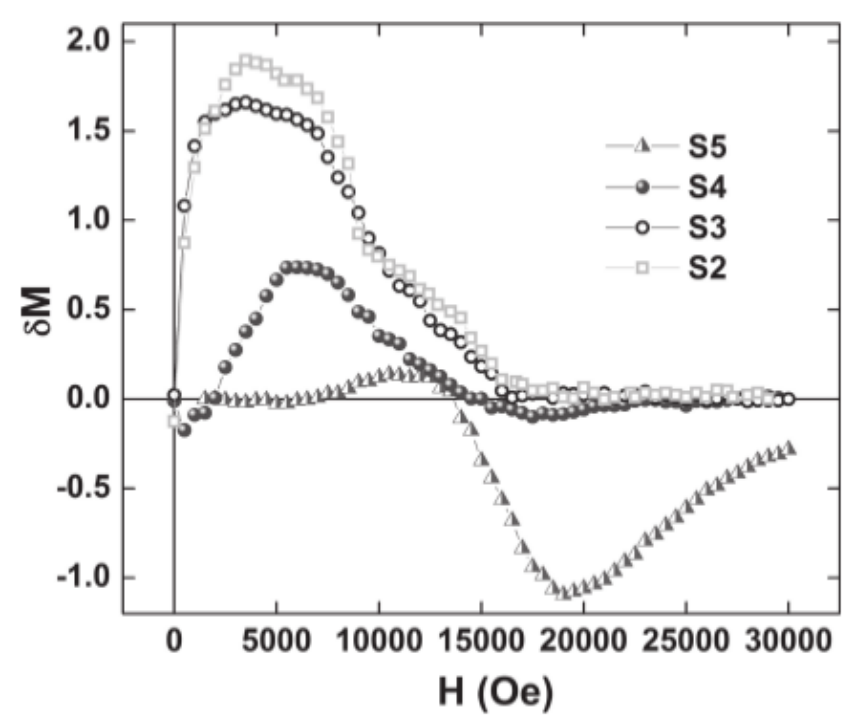

Figura 3.7: Curvas $\Delta m$ para nanopartículas de $\mathrm{SmCo}_{5}$ dispersas em matrizes de carbono. A amostra $S_{5}$ possui uma espessura da camada de carbono de $52 \mathrm{~nm}$, enquanto que $S 2$ possui uma camada de $6.5 \mathrm{~nm}$. As demais amostras possuem espessuras com valores intermediários. Retirado de [28].

\subsubsection{Curvas de inversão de primeira ordem (FORCs)}

A magnetização de um material depende, em geral, do valor instantâneo do campo magnético aplicado, e da história do campo até chegar nesse valor. Em materiais ferromagnéticos este comportamento pode ser observado em medidas de ciclo de histerese, como vemos na figura 3.8 (a). A princípio, todo ponto interno do ciclo de histerese principal deve ser um estado acessível, sendo que uma maneira de acessar esses pontos é a partir das chamadas curvas de inversão de primeira ordem, ou simplesmente FORCs, do acrônimo em inglês First Order Reversal Curves, ilustrada também na figura 3.8 (a).

Obtemos as curvas de inversão de primeira ordem partindo de um campo positivo máximo $H_{\max }$ na região reversível do ciclo de histerese e levando para um determinado campo de inversão $H_{r}$. A curva FORC é a curva de magnetização obtida partindo de $H_{r}$ e aumentando o campo até chegar ao campo máximo inicial $H_{\text {max }}$, já um conjunto de FORCs é obtido para diferentes valores de $H_{r}$, como vemos na figura $3.8(\mathrm{~b})$.

A principal dificuldade desta técnica é como interpretar as curvas FORCs. Podemos fazer isto de duas maneiras, utilizando o modelo de Preisach, que explicaremos a seguir, ou a partir da análise FORC que considera as limitações do modelo de Preisach. 

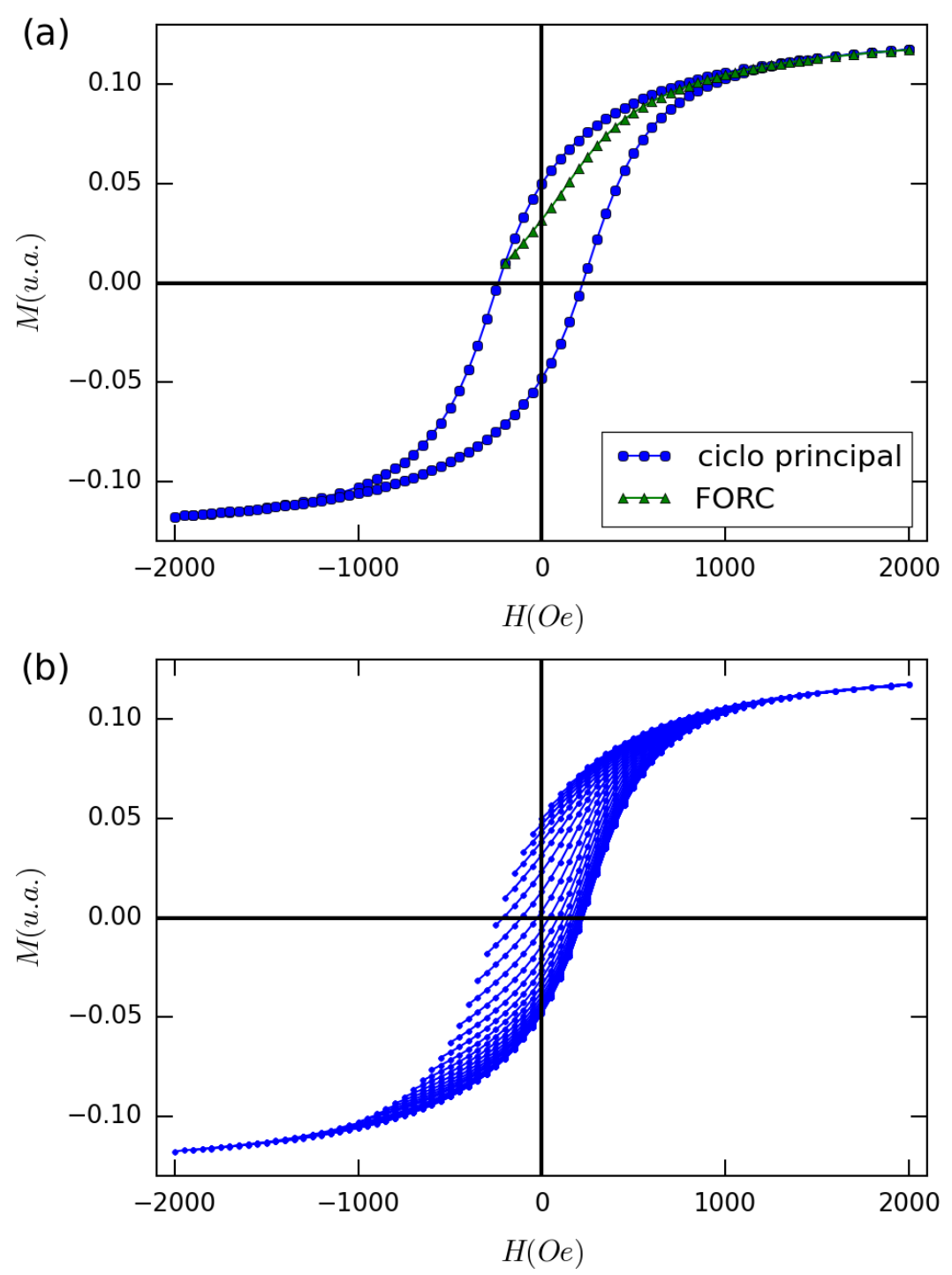

Figura 3.8: Exemplo de (a) um ciclo de histerese com uma curva de inversão de primeira ordem (FORC). Em (b) vemos uma coleção de FORCs, que acessa vários pontos dentro do ciclo principal. 


\section{Modelo de Preisach}

Em seu trabalho de 1935 [91], F. Preisach propôs um modelo com hipóteses sobre as bases físicas dos mecanismos de magnetização. Neste modelo, que posteriormente ganhou bases matemáticas e uma fundamentação termodinâmica a partir de trabalhos de Issak D. Mayergoyz [92] e Giorgio Bertotti [93, 94], respectivamente, consideramos que a amostra é constituída de unidades básicas chamadas de hysterons. Cada hysteron é um ciclo de histerese retangular de coercividade $h_{c}$ e magnetizações $\pm \Delta m$, dependendo da direção do campo $H$ aplicado. Podemos ver a representação de um hysteron na figura 3.9, retirada de [95]. O campo $h_{b}$ é o campo de interação que representa às interações entre os hysterons.

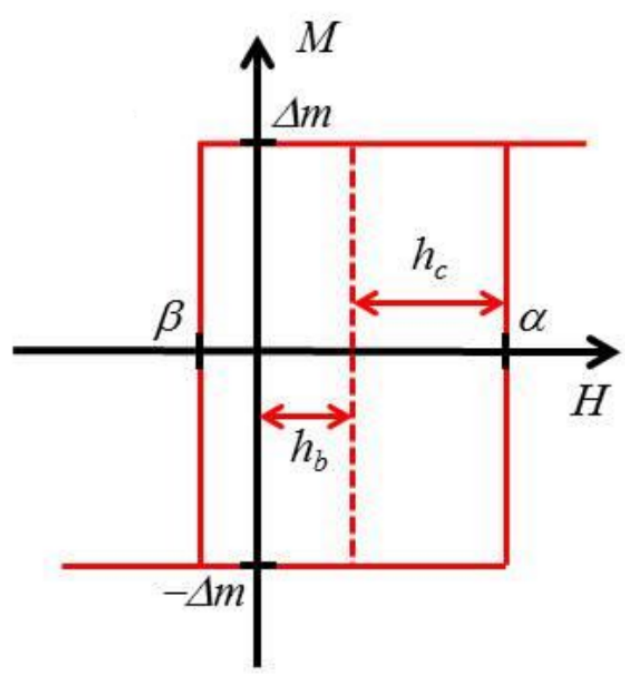

Figura 3.9: Ciclo de histerese quadrado, chamado de hysteron, com coercividade $h_{c}$ e campo de interação $h_{b}$. Retirada de [95].

Como vemos na figura 3.9, os hysterons possuem dois campos críti$\cos , \alpha$ e $\beta \operatorname{com} \alpha>\beta$, que satisfazem a relação:

$$
\alpha=h_{b}+h_{c} \quad \beta=h_{b}-h_{c}
$$

O valor da magnetização $M$ dependerá do valor do campo $H$ e da história prévia do campo, satisfazendo as seguintes condições:

$$
\begin{gathered}
\frac{\Delta m}{|\Delta m|}= \begin{cases}+1, & H>\alpha \\
-1, & H<\beta\end{cases} \\
\frac{\Delta m}{|\Delta m|}= \begin{cases}+1, & \dot{H}<0 \\
-1, & \dot{H}>0\end{cases}
\end{gathered}
$$


A distribuição Preisach de hysterons, normalizada, com coercividades $h_{c}$ e campos de interação $h_{b}$ é dada por:

$$
p\left(h_{b}, h_{c}\right)=\frac{n\left(h_{c}, h_{b}\right)}{N}
$$

onde $N$ é o número de hysterons e $n\left(h_{c}, h_{b}\right)$ a distribuição normalizada do número de hysterons com coercividades entre $\left(h_{c}, h_{c}+d h_{c}\right)$ e campos de interação entre $\left(h_{b}, h_{b}+d h_{b}\right)$.

A magnetização total do sistema será dada pela soma dos hysterons que se encontram com magnetização $+\Delta m \mathrm{e}-\Delta m$. A separação entre estes dois estados possíveis pode ser visto no diagrama de Preisach, figura 3.10, e é representada pela linha $h_{b}=H+f\left(h_{c}\right)$. Para este estado, a magnetização do sistema é dada por:

$$
M(H, f)=M_{S} \int_{0}^{\infty} d h_{c}\left[\int_{-\infty}^{H+f\left(h_{c}\right)} p\left(h_{c}, h_{b}\right) d h_{b}-\int_{H+f\left(h_{c}\right)}^{+\infty} p\left(h_{c}, h_{b}\right) d h_{b}\right]
$$

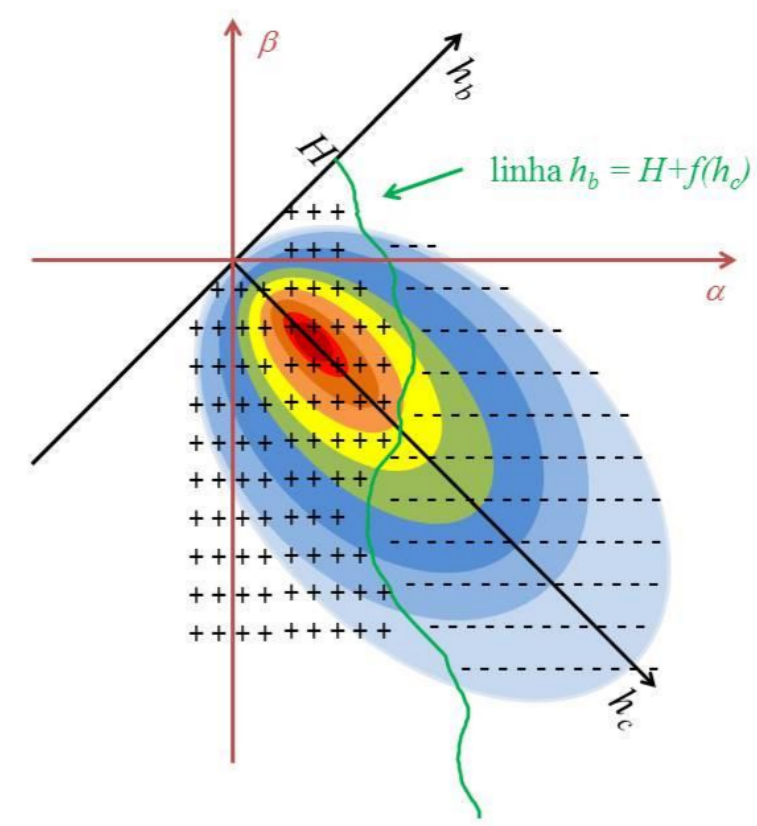

Figura 3.10: Representação de um plano e diagrama de Preisach. A linha $h_{b}=H+f\left(h_{c}\right)$ separa os estados com magnetização $+\Delta m$ e $-\Delta m$. Retirada de [95].

Para uma FORC genérica, obtida a partir da amostra saturada e levando a um campo de retorno $H_{r}$, essa magnetização pode ser escrita como [95]: 


$$
\begin{gathered}
M\left(H_{r}, H\right)=2 M_{S}\left[\int_{0}^{\frac{1}{2}\left(H-H_{r}\right)} d h_{c} \int_{0}^{H-h_{c}} p\left(h_{c}, h_{b}\right) d h_{b}+\right. \\
\left.+\int_{\frac{1}{2}\left(H-H_{r}\right)}^{+\infty} d h_{c} \int_{0}^{H_{r}+h_{c}} p\left(h_{c}, h_{b}\right) d h_{b}\right]
\end{gathered}
$$

Derivando a relação acima em relação a $H$ e $H_{r}$ encontramos uma expressão para a distribuição Preisach, dada por:

$$
p\left(\frac{1}{2}\left(H-H_{r}\right), \frac{1}{2}\left(H+H_{r}\right)\right)=-\frac{1}{M_{S}} \frac{\partial^{2} M\left(H_{r}, H\right)}{\partial H_{r} \partial H}
$$

Os valores desta distribuição podem ser obtidos por meio de dados experimentais de curvas FORCs, a partir de sua derivada numérica.

\section{Distribuição FORC}

Para amostras reais, a distribuição que obtemos a partir dos valores de magnetização em função dos campos $H$ e $H_{r}$ não podem ser inteiramente descritas pelo modelo de Preisach e sua distribuição, dada pela equação 3.14. Neste modelo $p\left(\frac{1}{2}\left(H-H_{r}\right)\right)$ não assume valores negativos, enquanto que isso é frequentemente visto com a análise de dados experimentais. Isto acontece porque o modelo de Preisach assume uma independência entre os campos $h_{b}$ e $h_{c}$, o que em geral não é válido para sistemas físicos.

$\mathrm{Na}$ análise de dados experimentais, é conveniente definir uma nova distribuição dada por:

$$
\rho\left(H_{r}, H\right)=-\frac{1}{2} \frac{\partial^{2} M\left(H_{r}, H\right)}{\partial H_{r} \partial H}
$$

onde $H$ são os valores de campo entre $H_{r}$ e $H_{\text {max }}$. A partir do cálculo de $\rho\left(H_{r}, H\right)$ podemos obter um mapa das distribuições de coercividade e campos de interação do sistema. Esta distribuição é usualmente representada em um gráfico bidimensional de $\rho\left(H_{c}, H_{b}\right)$ em função dos campos $H_{c}$ e $H_{b}$, sendo que para isso estamos usando um sistema de coordenadas dado por $H_{c}=\left(H-H_{r}\right) / 2$ e $H_{b}=$ $\left(H+H_{r}\right) / 2$. O campo $H_{c}$ seria equivalente à coercividade das partículas e $H_{b}$ ao campo local de interação [96]. Usando essa representação encontramos um diagrama da forma mostrada na figura 3.11. É importante mencionar que na figura 3.11 e nos diagramas FORC que apresentamos nesta tese, a densidade $\rho\left(H_{r}, H\right)$ foi obtida a partir do algoritmo proposto por Heslop e Muxworthy [97]. 


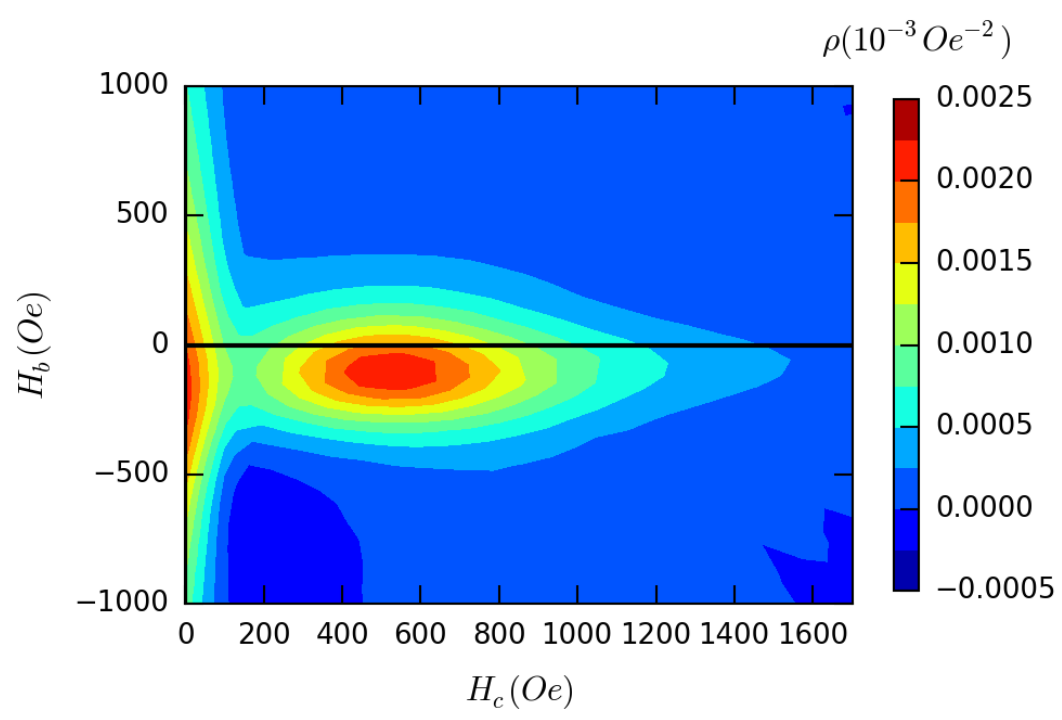

Figura 3.11: Diagrama FORC para um conjunto de nanopartículas, a $5 K$. Vemos a existência de uma região reversível, na região com $H_{c}=0$, e outra irreversível em $H_{c}=3000$ e devido às partículas com maior coercividade.

\subsubsection{Medidas de suscetibilidade AC}

Um tipo de medida alternativa para determinar a temperatura de bloqueio e a constante de anisotropia efetiva para uma amostra de nanopartículas são as medidas de suscetibilidade AC. Neste arranjo temos um pequeno campo DC, tipicamente algumas dezenas de $O e$, que permanece constante durante a medida, e outro AC que varia com o tempo com frequência $\omega$ e com amplitude $H_{A C}$ de poucos $O e$. Este campo AC induz na amostra uma magnetização $\mathrm{AC}, M_{A C}$, que pode ser escrita como:

$$
M_{A C}=\frac{d M}{d H} H_{A C} \sin (\omega t),
$$

sendo que $\chi=d M / d H$ é a suscetibilidade magnética na medida AC. Esta magnetização pode ser decomposta em uma componente em fase e outra fora de fase com o campo em termos de $\chi$.

Nas medidas AC medimos a variação da magnetização com o campo aplicado, ou seja, a suscetibilidade AC. Como nesse caso temos uma fase associada ao valor da suscetibilidade, é conveniente escrever uma suscetibilidade complexa com uma parte real, em fase, e outra imaginária, fora de fase. Essa representação é dada nas equações $3.17 \mathrm{e}$ 3.18 , onde $\chi^{\prime}$ é a parte real, $\chi^{\prime \prime}$ a parte complexa e $\phi$ é a fase entre a magnetização e o campo magnético aplicado. 


$$
\begin{array}{r}
\chi^{\prime}=\chi \cos (\phi) \\
\chi^{\prime \prime}=\chi \operatorname{sen}(\phi) \\
\chi=\sqrt{\chi^{\prime 2}+\chi^{\prime \prime 2}} \\
\phi=\arctan \left(\chi^{\prime \prime} / \chi^{\prime}\right)
\end{array}
$$

Tipicamente em sistemas de nanopartículas medimos $\chi^{\prime}$ e $\chi^{\prime \prime}$ em função da temperatura e a partir da medida desta última podemos estimar o valor da constante de anisotropia efetiva do sistema. Podemos usar a componente $\chi^{\prime \prime}$ para determinar a temperatura de bloqueio, pois no regime bloqueado a ativação térmica não deve induzir histerese, no entanto no regime superparamagnético a componente $\chi^{\prime \prime}$ deve ser pequena, de modo que o máximo da curva de $\chi^{\prime \prime}(T)$ deve ser o valor de $T_{B}$ naquela frequência.

Para um sistema de partículas monodomínios a componente imaginária da suscetibilidade pode ser escrita como:

$$
\chi^{\prime \prime}=\frac{\chi_{T} \omega \tau}{1+\omega^{2} \tau^{2}}
$$

onde $\chi_{T}$ é a componente da suscetibilidade associada à fração de partículas que estão no estado bloqueado e desbloqueado [98], $\omega$ a frequência angular do campo aplicado e $\tau$ é dado pelo inverso da equação 2.4. Minimizando esta equação, $\partial \chi^{\prime \prime} / \partial T=0$, encontramos que $\omega \tau=1$ de forma que, utilizando a equação 2.4, temos uma relação linear entre $\frac{1}{\omega} \mathrm{e} \frac{1}{T_{\max }}$, dada por:

$$
\ln \left(\frac{1}{\omega}\right)=\ln \left(\tau_{0}\right)+\frac{E_{a}}{k_{B} T_{\max }}
$$

Usando essa relação e os valores máximos de temperatura extraídos das curvas na figura 4.10 podemos fazer um ajuste linear para estimar o valor dessa barreira de energia e a constante média $<1 / \nu_{0}=$ $\tau_{0}>$ de uma amostra de nanopartículas. Na figura 3.12 vemos um exemplo da obtenção da energia de ativação representativa de um conjunto de nanopartículas de magnetita por meio de medidas AC [99].

\subsubsection{Ressonância ferromagnética}

Desde sua descoberta no começo do século XX, técnicas de ressonância magnética são usadas até hoje para obter informações a respeito da estrutura microscópica dos materiais e suas propriedades magnéticas. Em materiais formados por íons ou radicais livres paramagné- 


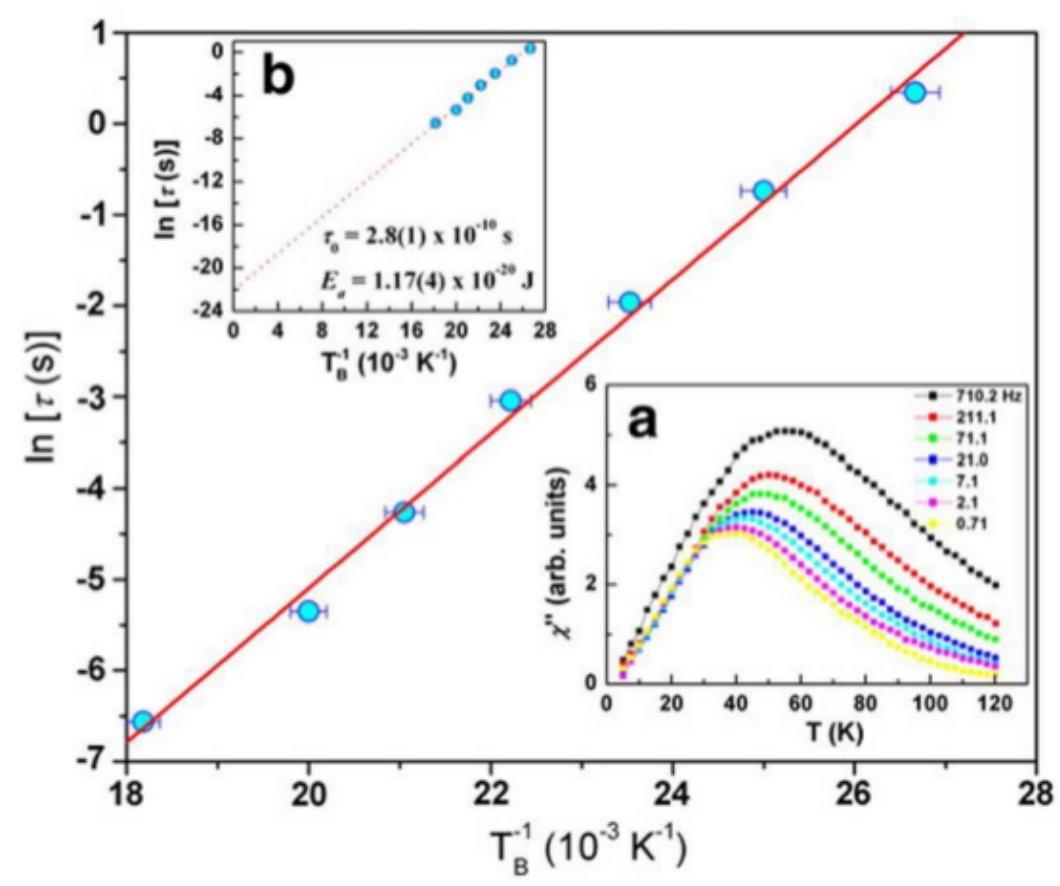

Figura 3.12: Vemos no gráfico principal a dependência do logaritmo do inverso da frequência de oscilação do campo AC com o inverso da temperatura de bloqueio, extraída das curvas do painel interno (a). A energia de ativação $E_{a}$ é proporcional a barreira $K_{e f}$, e pode ser extraída do ajuste linear. Retirado de [99]. 
ticos essa ressonância é conhecida como EPR (Electron Paramagnetic Resonance), já quando a ressonância ocorre em materiais ferromagnéticos chamamos de FMR (Ferromagnetic Resonance). Essa distinção é feita pois podemos considerar os materiais paramagnéticos como um conjunto de paramagnetos independentes e não interagentes, já para os ferromagnéticos isto não é possível pois os elétrons são fortemente interagentes. Nesta seção explicaremos a física por trás desse fenômeno com ênfase na análise FMR, no entanto mais informações podem ser obtidas em [100, 101, 102, 18].

\section{Condições para se observar a ressonância}

Os níveis de energia acessíveis a um sistema formado por um conjunto de elétrons podem ser determinados resolvendo a equação de Schrödinger desse sistema, o que geralmente é um problema muito difícil já que estamos lidando com muitos corpos. Uma vez que esse problema é resolvido, vemos que pode existir mais de um estado possível com a mesma energia. Esses estados são conhecidos como estados degenerados.

Quando um campo magnético uniforme é aplicado observamos uma quebra da degenerescência desses níveis de energia, conhecido como efeito Zeeman ${ }^{1}$. Para entender melhor vamos considerar o caso de um momento magnético $\vec{m}$, dado por ${ }^{2}$ :

$$
\vec{m}=\gamma \hbar \vec{S}
$$

onde $\gamma$ é conhecido como raio giromagnético, $\hbar$ é a constante de Planck e $\vec{S}$ o spin. Se um campo externo uniforme $\overrightarrow{B_{0}}=B_{0} \hat{z}$ é aplicado, temos uma hamiltoniana Zeeman dada por:

$$
\mathcal{H}_{Z}=-\vec{m} \cdot \overrightarrow{B_{0}}=-\gamma \hbar B_{0} S_{z}
$$

Por exemplo, no caso de $S=1$, os estados $m_{S}=-1,0,1$ tem três autovalores distintos, o que leva a três autovalores de energia distintos para a hamiltoniana acima: $E_{Z}=\gamma \hbar B_{0}, 0,-\gamma \hbar B_{0}$. Se antes da aplicação do campo magnético tínhamos três estados degenerados com energia $E_{0}$, agora temos três estados com três energias distintas $E_{0}+E_{Z}$, como esquematizado na figura 3.13.

Vemos que as novas energias desses estados são separadas por uma quantidade $\gamma \hbar B_{0}$, assim, com a absorção (ou emissão) de um quantum de radiação eletromagnética $\hbar \omega_{0}$, a transição entre dois estados adja-

1 O mesmo acontece com a aplicação de um campo elétrico uniforme, nesse caso chamado de efeito Stark.

2 Aqui estamos considerando que a carga do elétron é $-e$. 


$$
B=0 \quad B=B_{0}
$$

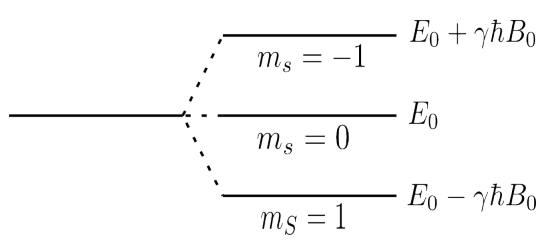

Figura 3.13: Figura ilustrando a quebra de degenerescência dos estados $m_{S}=-1,0,1$ devido à aplicação de um campo magnético $\vec{B}=B_{0} \hat{z}$.

centes é possível ${ }^{3}$. Com isso chegamos a uma condição de ressonância, dada por:

$$
\begin{gathered}
\gamma \hbar B_{0}=\hbar \omega_{0} \\
B_{0}=\omega_{0} / \gamma
\end{gathered}
$$

Nesse caso podemos determinar o valor do fator $g$, uma quantidade adimensional associado ao momento magnético de uma partícula subatômica ou um núcleo, a partir da expressão:

$$
g=\frac{\omega \hbar}{\mu_{B} B}=\frac{2 \pi \hbar f}{\mu_{B} B}
$$

onde $\omega$ é a frequência angular da radiação aplicada.

$\mathrm{O}$ interessante é que a condição de ressonância 3.25 poderia ser obtida também classicamente considerando o torque $\vec{\Gamma}$ que o campo $\vec{B}_{0}$ aplica em $\vec{m}$ :

$$
\vec{\Gamma}=\vec{m} \times \vec{B}_{0}
$$

Como o torque é igual a variação temporal do momento angular $\frac{\vec{m}}{\gamma}$ temos que:

$$
\frac{d \vec{m}}{d t}=\gamma \vec{m} \times \vec{B}_{0}
$$

que tem solução com o momento magnético $\vec{m}$ precessionando com frequência $\omega_{0}=\gamma B_{0}$ em torno de $\vec{B}_{0}$, que é justamente a condição encontrada em 3.25. A frequência $\omega_{0}$ é conhecida como frequência de Larmor.

3 Só são permitidas transições entre estados adjacentes devido às regras de seleção $\Delta L= \pm 1$ e $\Delta J=0, \pm 1$ (sendo $\vec{J}=\vec{L}+\vec{S}$ ) provenientes da conservação de momento angular e da simetria de paridade dos orbitais. 
A equação 3.25 mostra que para um campo magnético uniforme de magnitude $B_{0}$ temos uma frequência $\omega_{0}$ onde a transição entre estados adjacentes é possível. Assim, para observarmos a ressonância em uma amostra, além do campo externo $\vec{B}_{0}$ também devemos aplicar uma radiação externa. Usualmente o que se faz é aplicar uma onda eletromagnética com uma frequência bem determinada e variar o campo magnético externo até encontrar a condição de ressonância, no entanto também é possível fixar $B_{0}$ e variar $\omega_{0}$. Devemos notar também que para ocorrer a transição entre estados adjacentes a radiação externa deve ser aplicada na direção perpendicular ao campo uniforme $\vec{B}_{0}$, pois se aplicarmos um campo AC paralelo a $\vec{B}_{0}$ teremos somente uma mudança nos autovalores de 3.24 e não uma transição de estados.

\section{Campo magnético efetivo sentido por uma amostra ferromagnética}

Em uma amostra ferromagnética, além do campo magnético externo aplicado em um experimento de ressonância, também temos que levar em contar os campos magnéticos internos da própria amostra. Assim, na equação 3.28 vamos substituir $\vec{B}_{0}$ por um campo magnético efetivo $\vec{B}_{e f}$ :

$$
\frac{d \vec{m}}{d t}=\gamma \vec{m} \times \vec{B}_{e f}
$$

sendo que agora a frequência de ressonância não é mais a frequência de Larmor $\omega_{0}$. Para encontrar a frequência de ressonância $\omega$ para amostras ferromagnéticas é conveniente usar o formalismo de Smit e Beljers [101, 103], dado pela equação:

$$
\omega=\gamma B_{e f}=\frac{\gamma}{M \sin \theta_{0}}\left(F_{\theta \theta} F_{\phi \phi}-F_{\theta \phi}^{2}\right)^{1 / 2}
$$

onde $F$ é a energia livre associada a esse sistema.

Considerando o caso de partículas com energia Zeeman e anisotropia de forma, $F$ é dada por 4 :

$$
\begin{aligned}
F=- & M_{S} H \mathcal{L}_{1}(x) \sin \theta \cos \phi \\
& +\frac{1}{2}\left(\mathcal{N}_{\|}-\mathcal{N}_{\perp}\right) M^{2} \mathcal{L}_{2}(x)\left(\sin ^{2} \theta \cos ^{2}\left(\phi-\phi_{n}\right)-\frac{1}{3}\right)
\end{aligned}
$$

onde $x=\frac{\mu H}{k_{B} T}$ é o momento da partícula, $\mathcal{L}_{1}(x)$ é a função de Langevin, $\mathcal{L}_{2}(x)=1-\frac{3}{x} \mathcal{L}_{1}(x)$ e $\phi_{n}$ é o ângulo entre o eixo fácil e o eixo de referência. Com essa expressão para $F$ a equação 3.30 se reduz a:

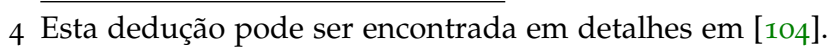




$$
\begin{aligned}
\left(\frac{\omega}{\gamma}\right)^{2}=\left[H_{r} \cos \phi+\right. & \left.H_{A}^{e f f} \cos ^{2}\left(\phi-\phi_{n}\right)\right] \times \\
& {\left[H_{r} \cos \phi+H_{A}^{e f f} \cos \left(2\left(\phi-\phi_{n}\right)\right)\right] }
\end{aligned}
$$

onde $H_{r}$ é o campo de ressonância e $H_{A}^{e f f}$ é o campo de anisotropia efetiva dado por $H_{A}^{\text {eff }}=\left(\mathcal{N}_{\perp}-\mathcal{N}_{\|}\right) M_{S} \mathcal{L}_{2}(x) / \mathcal{L}_{1}(x)$. Quando a anisotropia da partícula é muito pequena $\vec{M}$ é paralelo ao campo aplicado, assim 3.32 se reduz simplesmente a:

$$
H_{r}=\frac{\omega}{\gamma}-\frac{H_{A}^{e f f}}{2}\left(3 \cos ^{2} \phi_{n}-1\right)
$$

\section{Ressonância ferromagnética em fluidos magnéticos}

Medidas de ressonância ferromagnética são muito utilizadas para estudar amostras sólidas, no entanto existe na literatura alguns poucos trabalhos que mostram o uso dessa técnica para estudar amostras de ferrofluidos. Em geral esses trabalhos se concentram em analisar a influência da temperatura [105, 106, 107] e formação de agregados de partículas [108] nos espectros de ressonância.

Em um espectro de ressonância, a sua largura de linha (nesse caso vamos representar por $\Delta H_{p p}$ para manter a notação da referência) é definida como sendo a distância entre os picos do espectro. $\mathrm{Na}$ figura 3.14 vemos o espectro medido a temperatura ambiente para uma amostra de ferrofluido com nanopartículas de maguemita com diâmetro de $7 \mathrm{~nm}$. Vemos também indicado o campo de ressonância e a razão $\omega / \gamma$.

Em qualquer amostra ferromagnética o campo de ressonância dependerá da orientação relativa entre a magnetização da amostra e o campo DC aplicado [109]. Para uma amostra onde existem várias regiões com diferentes orientações de magnetização, como por exemplo uma amostra de nanopartículas em um ferrofluido, temos uma condição para um alargamento da largura de linha $\Delta H_{p p}$, já que existe uma distribuição de campos de ressonância. Se por exemplo quisermos acabar com esse efeito de distribuição de orientações em amostras de fluidos magnéticos, basta congelar a amostra com um campo aplicado e tomar o espectro na direção de interesse.

Em amostras de ferrofluidos, a dependência da largura de linha com a temperatura, além de ser influenciada por essa distribuição de eixos, também pode ser afetada pelas flutuações da magnetização no regime superparamagnético. Nessa situação temos dois efeitos com dependências opostas com a temperatura. O primeiro está relacionado ao movimento das partículas dentro do fluido, que aumenta 


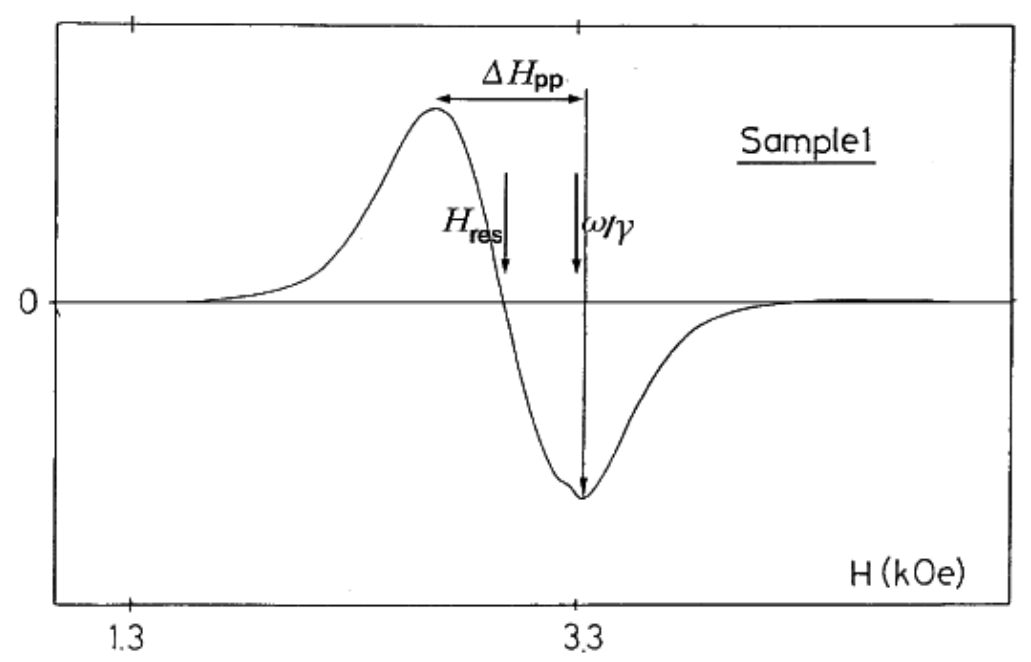

Figura 3.14: Espectro de ressonância a temperatura ambiente para uma amostra de ferrofluido de maguemita. Retirado de [105].

quando aumentamos a temperatura, e na média diminuem os efeitos de anisotropia no espectro e portanto contribuem para um menor valor de $\Delta H_{p p}$ [105]. Já o mecanismo que levaria a um aumento da largura de linha com o aumento da temperatura, atribuído por Gazeau et. al. [105], pode ser entendido como uma perda de fase devido a desvios da magnetização em relação à sua precessão regular. Na figura 3.15 vemos o decréscimo de $\Delta H_{p p}$ com a temperatura obtido por esses autores em uma situação onde o primeiro efeito é dominante. Além desse trabalho, também existem outros teóricos apontando para determinadas situações onde temos um aumento e outras uma diminuição de $\Delta H_{p p}$ com a temperatura [106]. Na verdade vemos que existe um balanço delicado entre interação, tamanho de partículas e região de temperatura onde pode ocorrer uma mudança de comportamento da largura de linha com a temperatura.

Outro fato que provoca um alargamento do espectro é a interação entre as partículas e a formação de cadeias e agregados, como mostrado em [108, 110]. Na figura 3.16 vemos a dependência da largura do espectro, representada por $\Delta H$, em função da concentração de partículas $\rho$ feita por meio de simulações computacionais considerando que as partículas magnéticas sofrem influência do campo dipolar gerado por suas vizinhas e que pertencem à mesma cadeia (retirado de [108]). Alguns trabalhos experimentais mostram evidências da formação de pequenos aglomerados de partículas por meio da análise dos espectros de ressonância desses sistemas [111, 112]. 


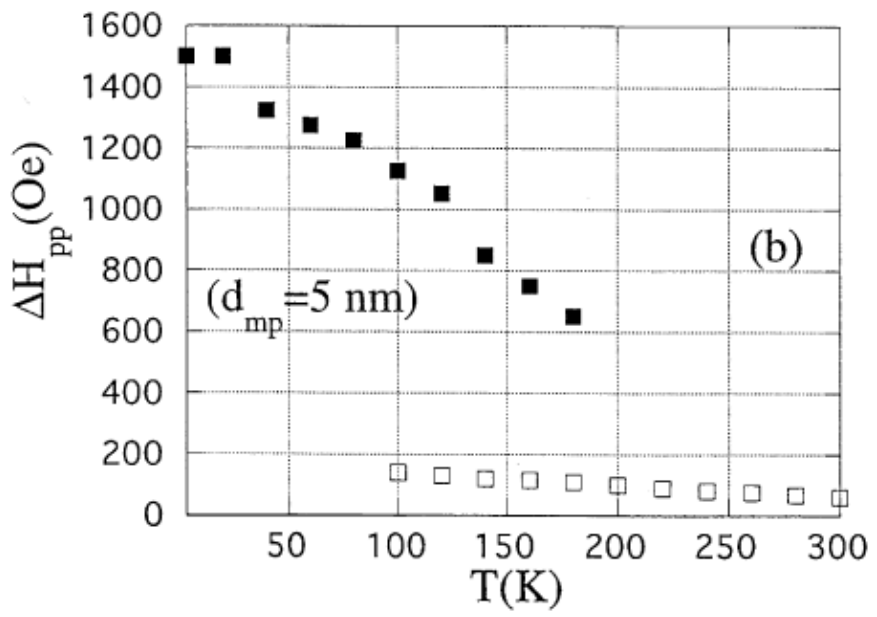

Figura 3.15: Dependência da largura do espectro $\Delta H$ com a temperatura. Retirado de [105].

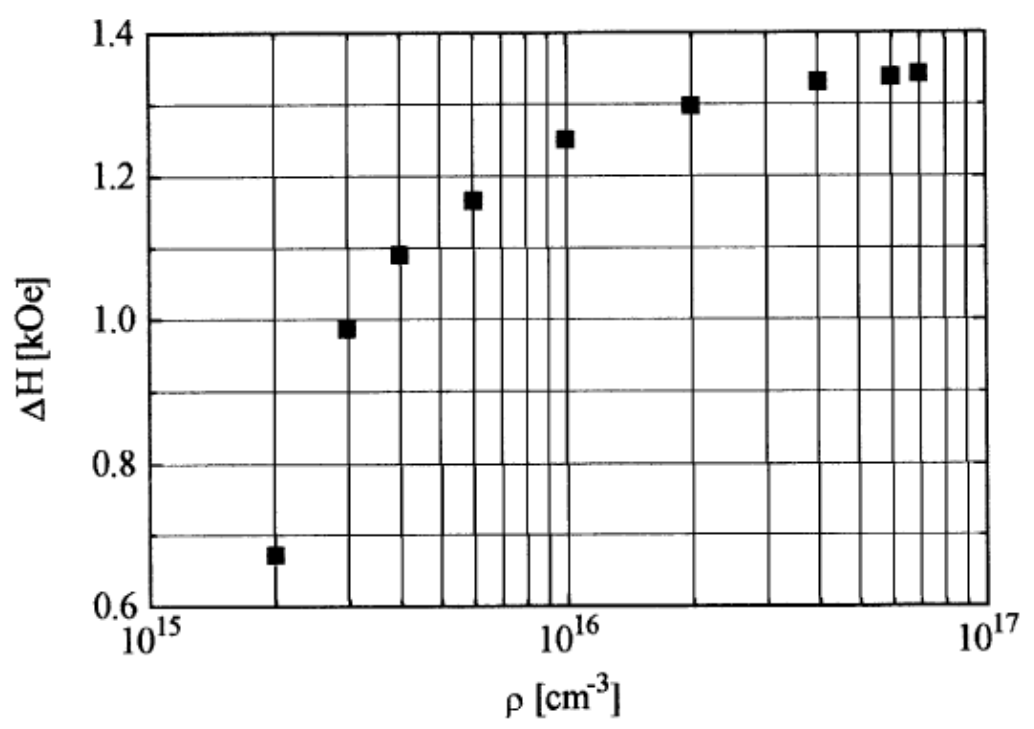

Figura 3.16: Dependência da largura do espectro $\Delta H$ com a concentração de partículas $\rho$. Retirado de [108]. 


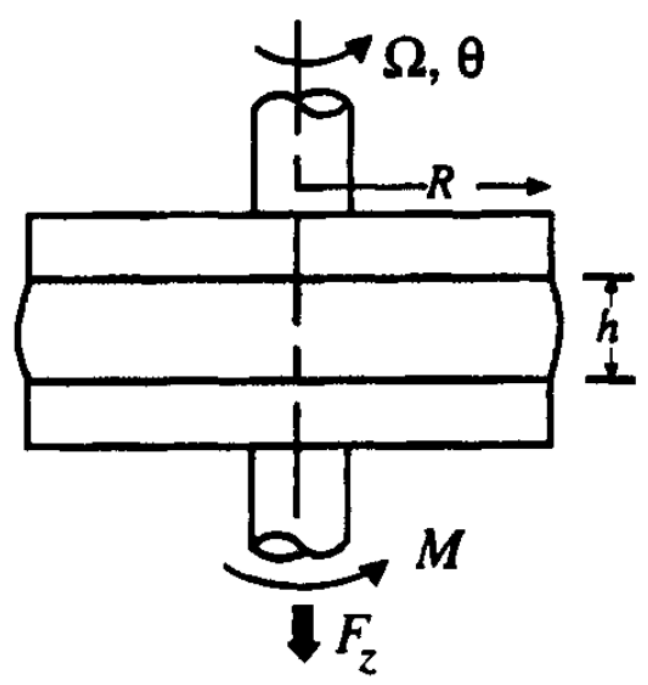

Figura 3.17: Esquema de um reômetro com placas paralelas de raios $R$, separadas por uma distância $h$. Retirado de [113].

\subsection{CARACTERIZAÇÃo MAGNETOREOLÓGiCA DE FLUIDOS MAG- NÉTICOS}

Nesta tese estudamos a variação da viscosidade de ferrofluidos e soluções micelares na presença de um campo magnético aplicado. Este estudo foi feito utilizando um reômetro, que é um equipamento usado para quantificar a resposta de um fluido submetido a uma força, sendo que com ele podemos extrair valores da viscosidade de uma amostra. Para os resultados que apresentamos nesta tese, utilizamos um reômetro rotacional com geometria de placas paralelas, que explicamos a seguir. Mais detalhes sobre a derivação destas equações se encontram na referência [113].

Para um reômetro rotacional com placas paralelas, figura 3.17 [113], a amostra é confinada entre duas placas circulares de raio $R$ paralelas e separadas por uma distância $h$, sendo que uma das placas permanece fixa e a outra gira com velocidade angular $\Omega$. Acoplado a uma das placas há um sensor de torque, que mede o torque $M$ que o fluido aplica em uma das placas. Nesta geometria, as equações de movimento do fluido levam a seguinte expressão para a taxa de cisalhamento $\dot{\gamma}$ na borda da placa $(r=R)$ :

$$
\dot{\gamma}(r=R)=R \frac{\Omega}{h}
$$

A taxa de cisalhamento $\dot{\gamma}$ é a taxa com a qual a deformação de cisalhamento é aplicada no material. Esta deformação no fluido surge devido à rotação de uma das placas enquanto a outra permanece parada. Já a expressão para a tensão de cisalhamento, que é a força 
por unidade de área necessária para o movimento do fluido, na borda da placa é dada por:

$$
\tau_{\theta z}(R)=\frac{M}{2 \pi R^{3}}\left[3+\frac{d \ln (M)}{d \ln \left(\dot{\gamma}_{R}\right)}\right]
$$

Para fluidos newtonianos, é válida a relação $d \ln (M) / d \ln \left(\dot{\gamma}_{R}\right)=1$, portanto neste caso podemos usar a taxa de cisalhamento aparente $\tau_{a}$ :

$$
\tau_{a}(R)=\frac{2 M}{\pi R^{3}}
$$

A viscosidade $\eta$ do fluido pode ser determinada pela razão $\tau / \dot{\gamma}$, portanto para um fluido newtoniano a viscosidade aparente $\eta_{a}$ nesta geometria é dada por:

$$
\eta_{a}=\frac{2 M h^{3}}{3 \pi R^{4} \Omega}
$$

A partir das medidas de viscosidade, ou primariamente do torque, podemos quantificar o efeito magnetoviscoso a partir da variação percentual da viscosidade na ausência e presença de um campo $H$ aplicado. $\mathrm{O}$ fator $R(\%)$ que quantifica este efeito é dado por:

$$
R=\frac{\eta(H)-\eta(0)}{\eta(0)} \times 100
$$

Como a viscosidade é proporcional ao torque $M$, é possível achar a porcentagem $R$ a partir da variação percentual do torque. Nas figuras 3.18 (a) e (b) vemos a medida do torque em função do tempo para uma amostra de ferrofluido e de uma solução micelar dopada com ferrofluido. Inicialmente medimos o torque sem campo aplicado durante um tempo suficiente para que haja uma boa estatística para calcular o torque médio para $H=0$. Depois o campo é ligado e vemos o aumento do torque, e consequentemente da viscosidade, até atingir um valor constante na média. Vemos que esse fenômeno ocorre mais rapidamente para a amostra de ferrofluido do que para a amostra micelar, já que no primeiro a quantidade de partículas magnéticas é maior. Assim que o campo é desligado, o torque volta ao seu valor inicial. Para os resultados mostrados na seção 4.5 todas as medidas na presença de campo aplicado foram realizadas da maneira mostrada na figura 3.18. 

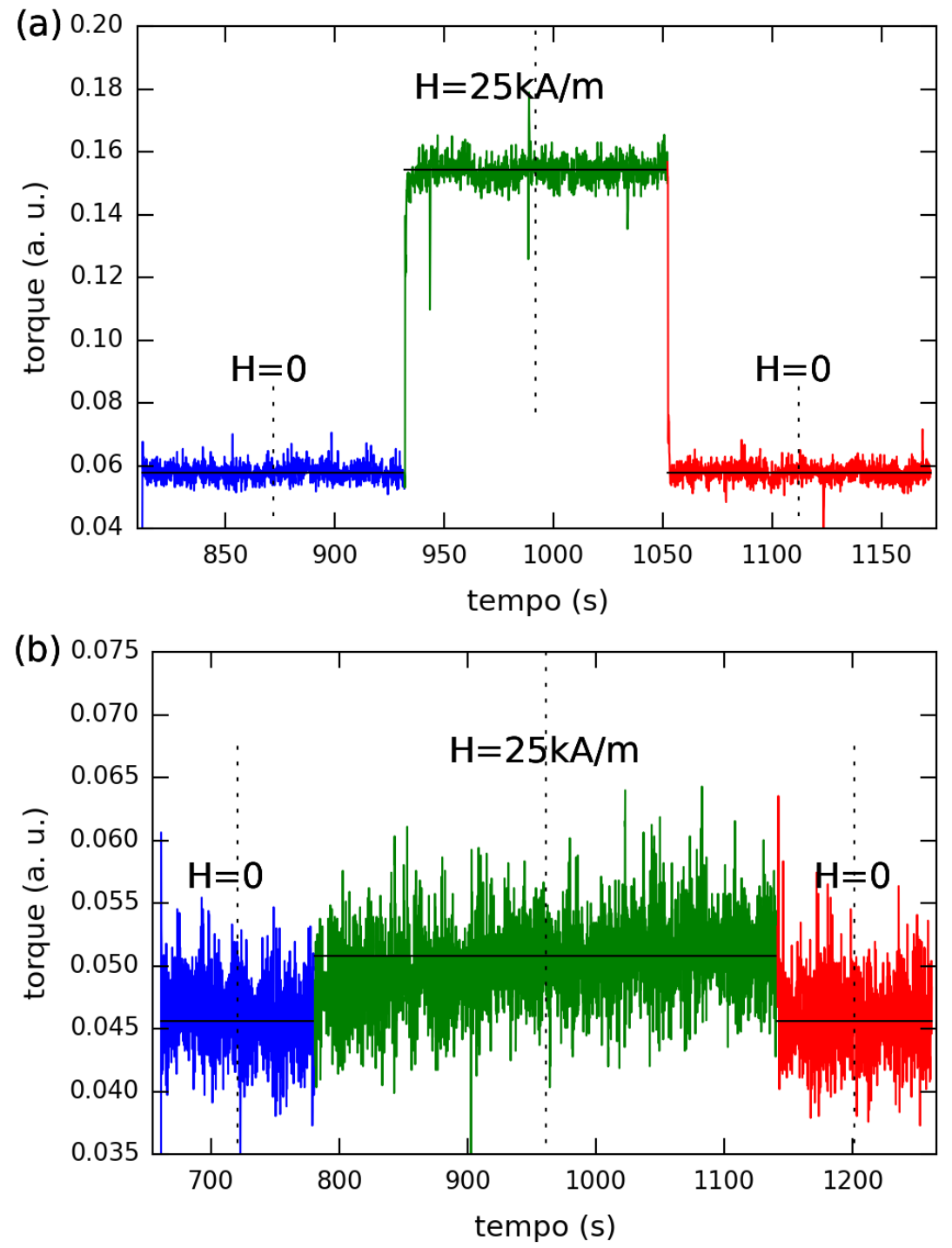

Figura 3.18: Torque em função do tempo para (a) o ferrofluido comercial EMG605 e (b) uma solução micelar com $27 \%$ de laurato de potássio dopada com o mesmo ferrofluido. A linha preta representa a média calculada considerando os dados a direita da linha tracejada para as três situações de campo aplicado. 


\subsection{AlgoritMo DE METROPOLIS}

As simulações que mostramos nesta tese foram feitas utilizando o algoritmo de Metropolis [35, 30], que é um método de Monte Carlo de cadeias markovianas. Uma cadeia de Markov é uma sequência de estados discretos, onde cada estado depende apenas do estado imediatamente anterior. Portanto o próximo estado é determinado apenas pelo estado atual, sendo que as taxas de transição não dependem da história prévia.

No algoritmo de Metropolis, a cadeia de Markov é obtida a partir da geração estocástica de sucessivos estados, que possuem uma probabilidade de transição que depende da probabilidade dos estados inicial e final no equilíbrio. Essa distribuição de probabilidades, em Física, geralmente é dada pela distribuição de Boltzmann, $Z^{-1} \exp \left(-E /\left(k_{B} T\right)\right)$. Nesse caso, a razão entre as probabilidades de ocupação dos estados inicial e final é dada pelo fator de Boltzmann $\exp \left(-\Delta E /\left(k_{B} T\right)\right)$.

De maneira prática, a implementação do algoritmo de Metropolis para um sistema composto por momentos magnéticos $\mu_{i}$ com orientação determinada pelos ângulos $\left(\theta_{i}, \phi_{i}\right)$, segundo o modelo de Heisenberg, pode ser descrita pelos seguintes passos:

1. Inicializar a configuração de cada momento $\mu_{i}$, determinada pelos ângulos $\left(\theta_{i}, \phi_{i}\right)$,

2. escolher um momento magnético $\mu_{i}$ e sortear dois novos ângu$\operatorname{los}\left(\theta_{i}^{\prime}, \phi_{i}^{\prime}\right)$,

3. calcular a variação de energia $\Delta E$ devida à rotação do momento magnético $\mu_{i}$,

4. gerar um número aleatório $r$ tal que $0<r<1$,

5. se $r<\exp \left(-\Delta E /\left(k_{B} T\right)\right)$ os novos valores $\left(\theta_{i}^{\prime}, \phi_{i}^{\prime}\right)$ são aceitos, caso contrário o estado anterior é mantido,

6. voltar para o passo 2 .

O sorteio dos ângulos $\left(\theta_{i}^{\prime}, \phi_{i}^{\prime}\right)$ pode ser tanto aleatório (uniforme), dentro do intervalo de valores que eles podem assumir, como ser da forma $\left(\theta_{i}^{\prime}, \phi_{i}^{\prime}\right)=\left(\theta_{i}+\delta_{1}, \phi_{i}+\delta_{2}\right)$, onde $\delta_{1}$ e $\delta_{2}$ são pequenas pertubações aleatórias que são somadas aos valores atuais dos ângulos $\left(\theta_{i}, \phi_{i}\right)$. Depois que todos os momentos $\mu_{i}$ foram acessados seguindo a sequência de passos descrita acima, dizemos que um passo de Monte Carlo foi completado. Este algoritmo é repetido até que o equilíbrio a uma dada temperatura seja obtido para o sistema, como podemos ver na figura 3.19 da energia em função do número de passos de Monte Carlo. 


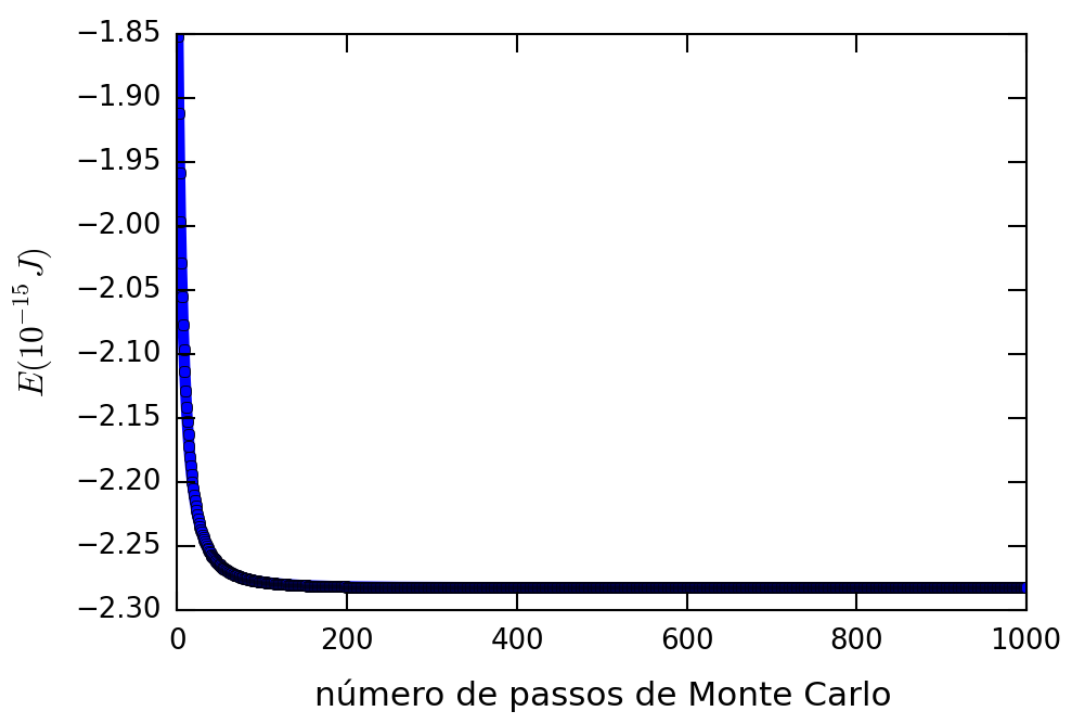

Figura 3.19: Energia em função do número de passos de Monte Carlo. Vemos que após um transiente, o sistema atinge o equilíbrio energético.

Quando fazemos simulações seguindo esse algoritmo é prudente partir de configurações iniciais e de sequências de números aleatórios diferentes para ver se o sistema chega no mesmo estado de equilíbrio. Para sistemas muito complexos, pode haver mínimos de energia locais que o sistema pode acessar antes de ir para o mínimo global, e muitas vezes isso pode ser observado partindo de configurações iniciais distintas. 

Neste capítulo mostramos a caracterização magnética de ferrofluidos e soluções micelares dopadas com ferrofluidos. Iniciamos com a caracterização estrutural das amostras. A caracterização magnética está dividida em três seções, uma com os resultados obtidos a baixas temperaturas, com os ferrofluidos congelados, outra com os ferrofluidos no estado líquido e por fim o estudo magnetoreológico das soluções micelares, que corresponde ao trabalho de doutorado sanduíche desenvolvido na Technische Universität Dresden.

\section{I CARACTERIZAÇÃO ESTRUTURAL DOS FERROFLUIDOS COMER- CIAIS}

Neste trabalho utilizamos dois ferrofluidos comerciais: EMG909 (a base de óleo) e EMG6o5 (a base de água), ambos da empresa Ferrotec. Esses ferrofluidos possuem uma concentração de partículas magnéticas da ordem de 3 Vol.\%, que como veremos, é suficiente para que as interações dipolares possam se manifestar em algumas medidas magnéticas a temperaturas inferiores à temperatura ambiente. Começamos esta seção com imagens de microscopia, difratometria de raios X e espectroscopia Mössbauer dos dois ferrofluidos e em seguida apresentamos a caracterização magnética desses sistemas.

\subsubsection{Microscopia de transmissão de ferrofluidos}

Para caracterizar o tamanho das partículas presentes nos ferrofluidos EMG605 e EMG909, foram feitas imagens no Microscópio Eletrônico de Transmissão LEO 906E (Zeiss) do Laboratório de Biologia Celular do Instituto Butantan. A figura 4.I mostra as imagens obtidas para os ferrofluidos (a) EMG605 e (b) EMG9o9. Nessas imagens observamos que as partículas apresentam uma distribuição de tamanhos e formatos ligeiramente alongados, de forma que achamos conveniente definir dois diâmetros, o maior, dado por $d+$, e o menor, $d-$. Para cada ferrofluido medimos os diâmetros $d+$ e $d-$ de 200 partículas. As figuras 4.2 e 4.3 mostram os histogramas para $d+$ e $d-$ de cada ferrofluido, assim como a função log-normal ajustada.

$\mathrm{Na}$ tabela 4.I vemos os parâmetros obtidos com os ajustes. Vemos que as partículas de fato apresentam uma ligeira anisotropia de forma, sendo os diâmetros médios obtidos para o ferrofluido EMG605 iguais a $\bar{d}+=12.8(2) n m$ e $\bar{d}-=11.7(2) n m$, e para o ferrofluido EMG9o9 $\bar{d}+=7.0(1) n m$ e $\bar{d}-=6.2(1) n m$. 


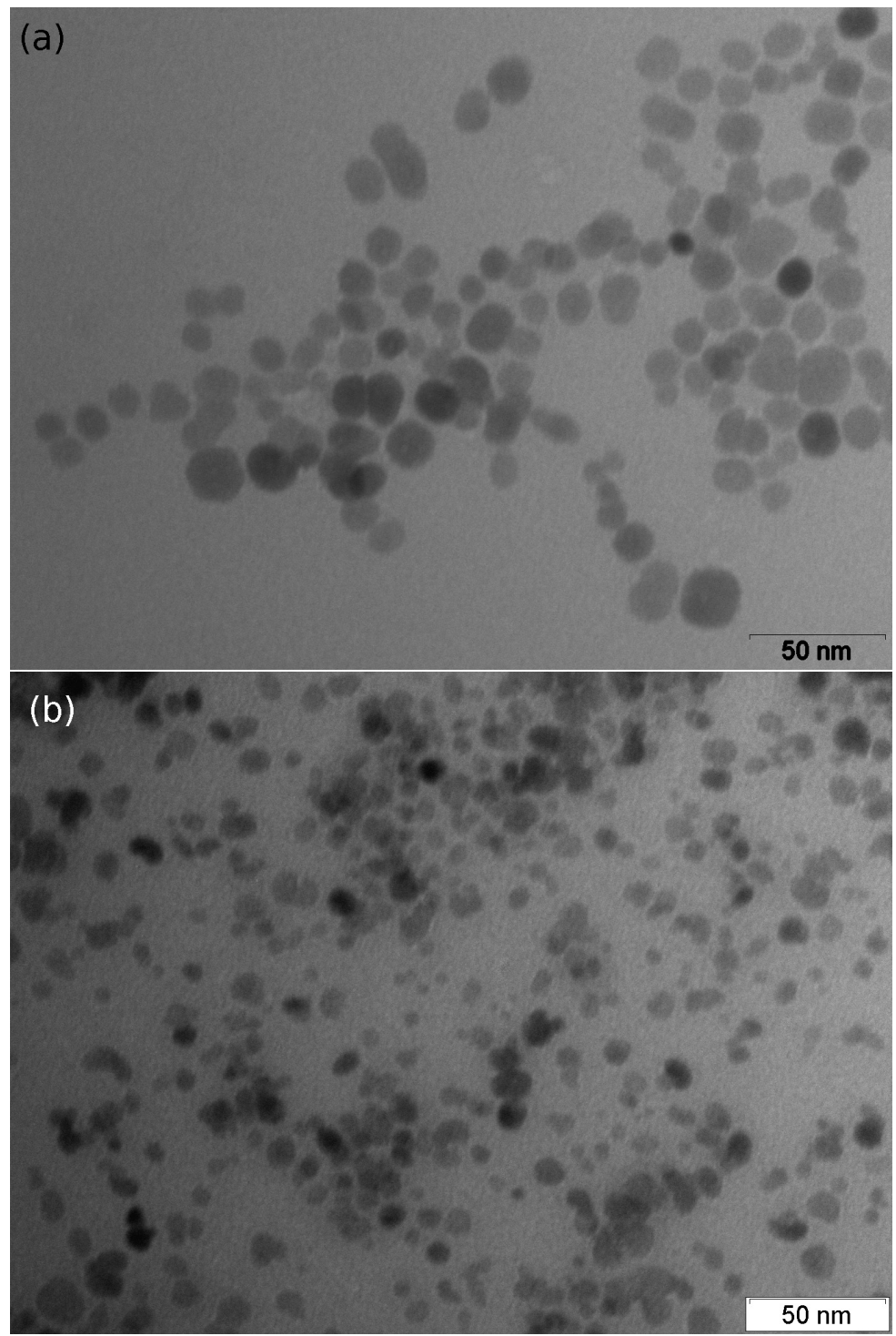

Figura 4.1: Imagens obtidas com o microscópio de transmissão para os ferrofluidos (a) EMG605 e (b) EMG9o9. 
(a)

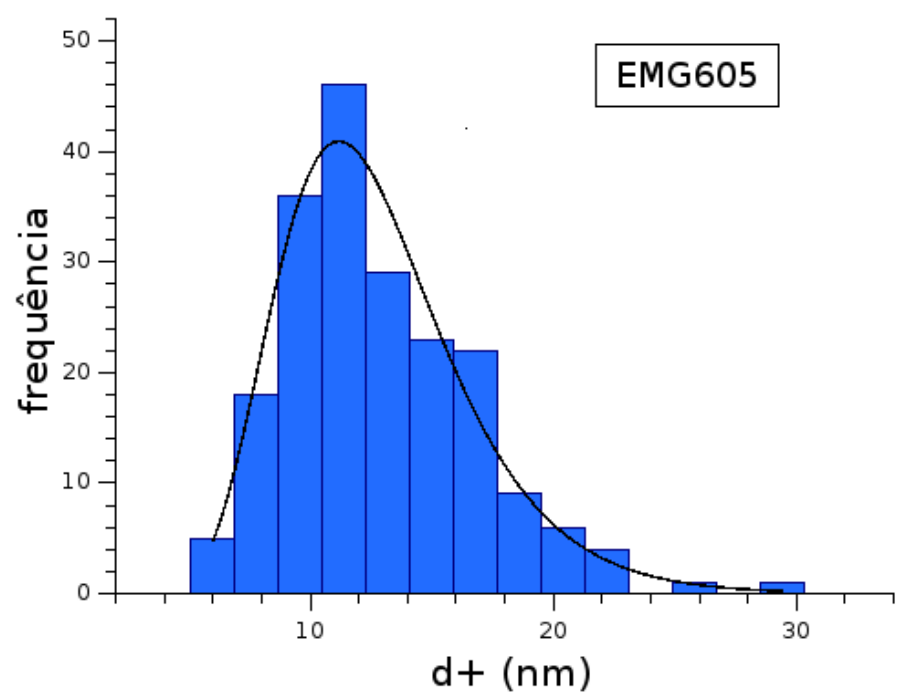

(b)

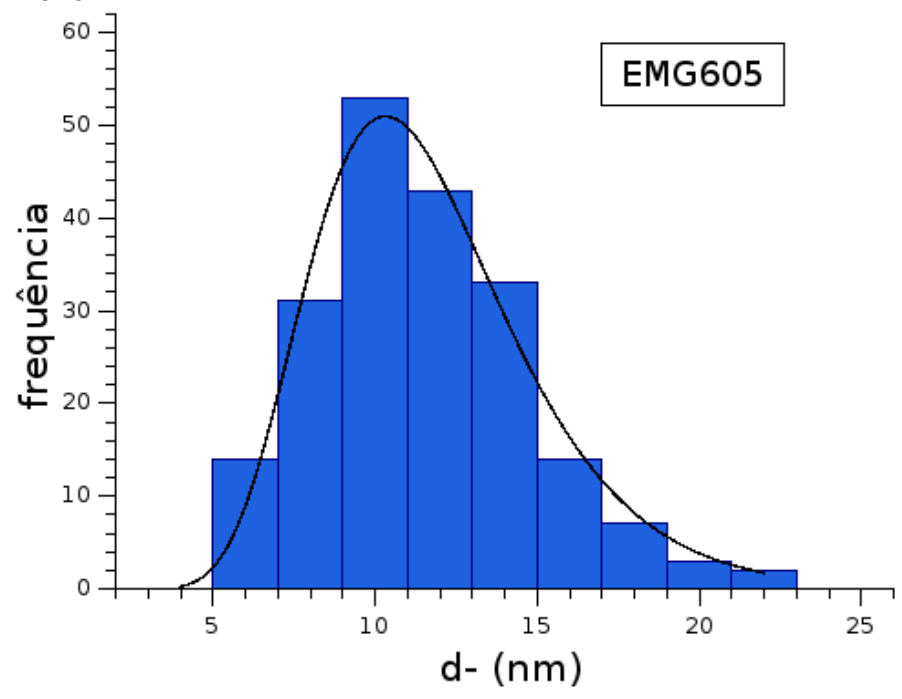

Figura 4.2: Histograma dos (a) diâmetros maiores $(d+)$ e (b) menores $(d-)$ para o ferrofluido EMG605. As linhas sólidas mostram os melhores ajustes obtidos usando uma função log-normal. 


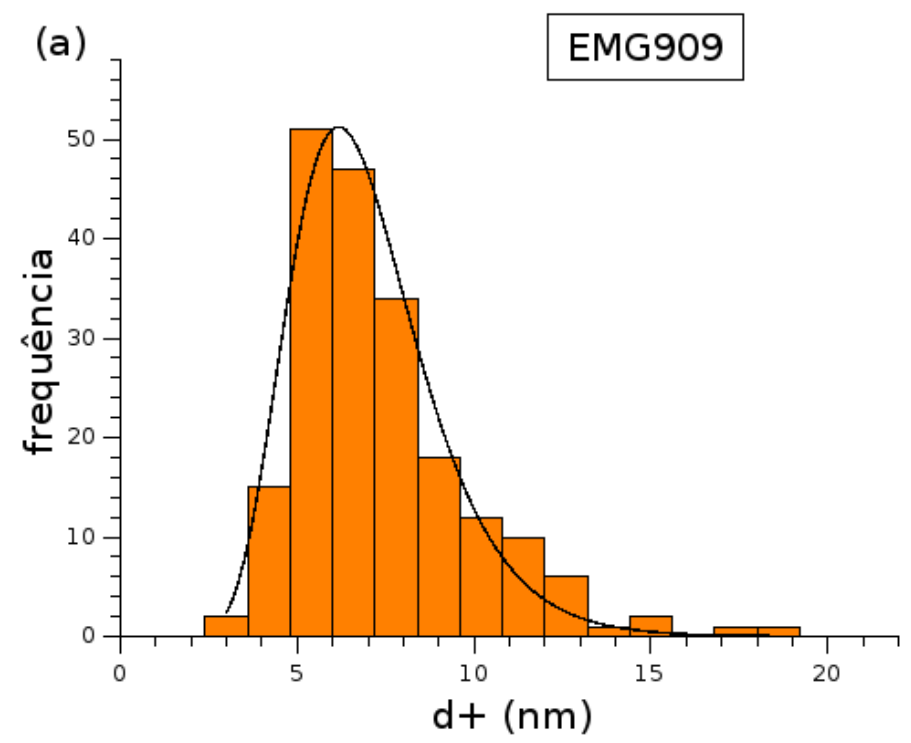

(b)

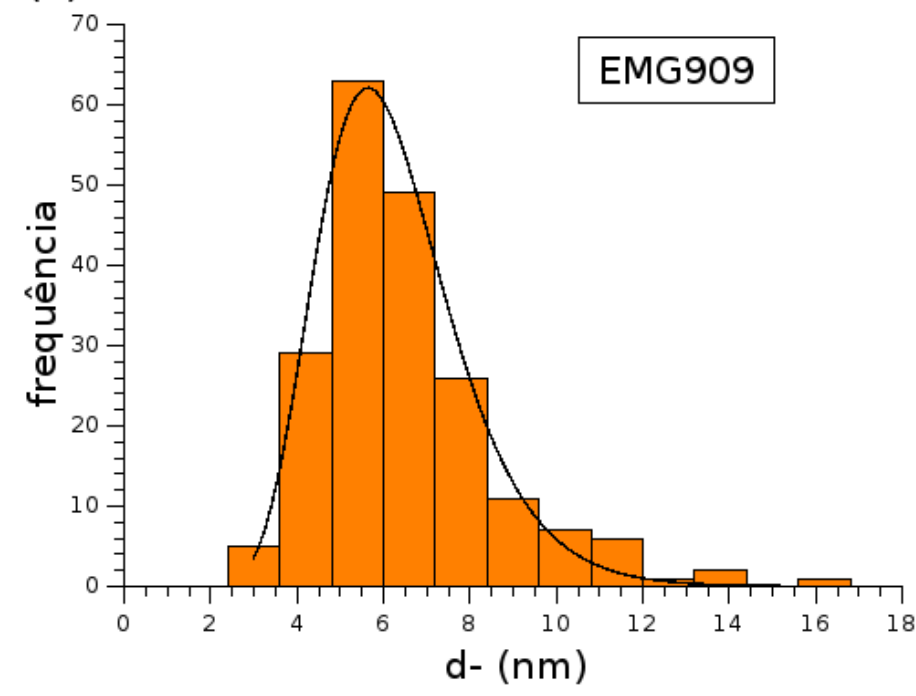

Figura 4.3: Histograma dos (a) diâmetros maiores $(d+)$ e (b) menores $(d-)$ para o ferrofluido EMG9og. As linhas sólidas mostram os melhores ajustes obtidos usando uma função log-normal. 


\begin{tabular}{c|c|c|c|c}
\hline \hline Ajuste & $\sigma$ & $\mu(n m)$ & $\bar{d}(n m)$ & $d_{m p}(n m)$ \\
\hline EMG605 d+ & $0.300(14)$ & $12.2(2)$ & $12.8(2)$ & $11.2(2)$ \\
EMG605 d- & $0.291(12)$ & $11.2(2)$ & $11.7(2)$ & $10.3(2)$ \\
EMG909d+ & $0.290(13)$ & $6.7(1)$ & $7.0(1)$ & $6.2(1)$ \\
EMG909d- & $0.264(9)$ & $6.0(1)$ & $6.2(1)$ & $5.7(1)$ \\
\hline \hline
\end{tabular}

Tabela 4.1: Parâmetros extraídos do ajuste da curva log-normal para os ferrofluidos EMG605 e EMG909, sendo $\sigma$ o parâmetro de escala, $\mu$ a mediana, $\bar{d}$ o valor médio e $d_{m p}$ o valor mais provável da distribuição.

\subsubsection{Difratometria de raios $X$}

Aplicamos a técnica de difratometria de raios $X \operatorname{com}$ geometria $\theta-2 \theta$ para as amostras EMG605 e EMG909. Utilizamos o equipamento D8 Advance da Bruker com fonte de radiação $\mathrm{Cu}-K_{\alpha}$, que possui comprimento de onda $\lambda=1.5418 \AA$, corrente no filamento de $30 \mathrm{~mA}$ e ddp. de $40 \mathrm{kV}$. Para a varredura dos difratogramas entre 20 e $80^{\circ}$ utilizamos um passo de $0.05^{\circ}$ e tempo de exposição de $3 s$ para a amostra EMG605 e de 5 s para EMG909. Para os três picos principais de cada amostra, realizamos uma medida mais detalhada, com passo $0.02^{\circ} \mathrm{e}$ tempos de exposição entre 15 e 50 s, dependendo da intensidade do pico.

Segundo o fabricante, os ferrofluidos EMG6o5 e EMG9o9 são compostos por nanopartículas de magnetita, portanto guiamos nossa análise comparando os resultados com os valores padrões da literatura tanto para a magnetita $\left(\mathrm{Fe}_{3} \mathrm{O}_{4}, a=0.8396 \AA\right)$, quanto para outra possível fase de óxido de ferro, a maguemita $\left(\gamma-\mathrm{Fe}_{3} \mathrm{O}_{4}, a=0.83474 \AA\right)$. Esses dois óxidos de ferro possuem uma estrutura cristalina cúbica do tipo spinel que possuem a forma $\mathrm{A}^{+2} \mathrm{~B}_{2}^{+3} \mathrm{O}_{4}^{-2}$. Nesta estrutura os ânions se arranjam em uma rede cúbica e os cations ocupam sítios octaédricos e tetraédricos. Podemos distinguir esses dois óxidos de ferro lembrando de algumas de suas características. A maguemita possui apenas íons $\mathrm{Fe}^{+3}$, enquanto que a magnetita, figura 4.4, possui íons $\mathrm{Fe}^{+3}$ e $\mathrm{Fe}^{+2}$. Para a magnetita, a cada fórmula unitária $\mathrm{Fe}_{3} \mathrm{O}_{4}$, um sítio tetraédrico (A) é ocupado a cada dois octaédricos (B). Para a maguemita, temos a disposição dos íons $\mathrm{Fe}^{+3}$ entre os sítios $A$ e $B$ da forma $\left(F e_{8}^{I I I}\right)_{A}\left[F e_{40 / 3}^{I I I} \square_{8 / 3}\right]_{B} O_{32}$, onde $\square$ representa uma vacância.

Os difratogramas para a magnetita e a maguemita possuem picos muito próximos, tabela 4.2 , de forma que muitas vezes é difícil distinguir as duas fases utilizando apenas a difratometria de raios $\mathrm{X} . \mathrm{Na}$ próxima seção mostramos medidas utilizando espectroscopia Mössbauer para complementar os resultados que apresentamos aqui.

Nos painéis principais da figura 4.5, vemos os difratogramas obtidos para as amostras (a) EMG605 e (b) EMG909, já com a intensidade 
(a)

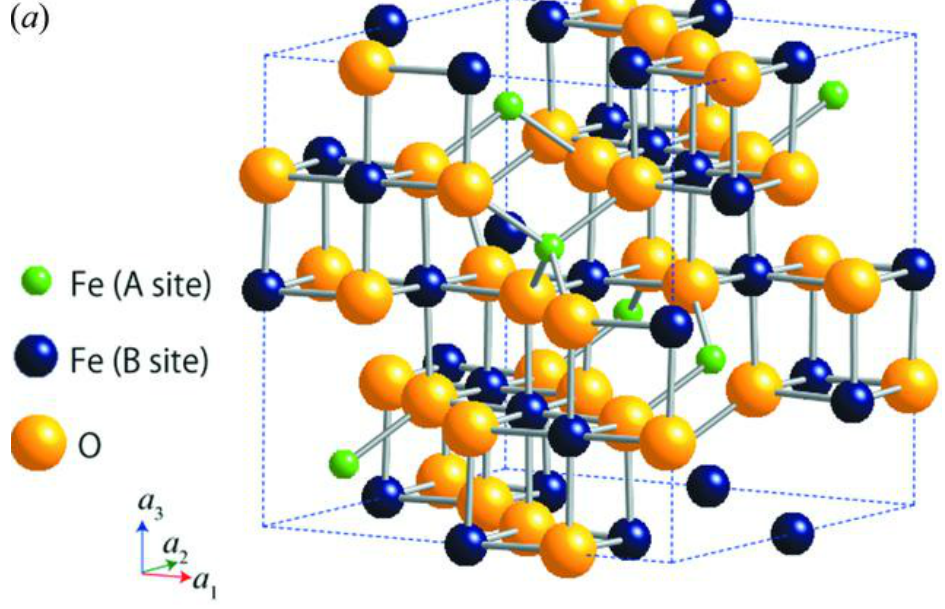

Figura 4.4: Estrutura cristalina da magnetita. Retirado de [114].

de fundo subtraída do sinal da amostra, com os respectivos planos cristalográficos de cada pico. Nos painéis internos vemos os ajustes utilizando as funções gaussiana e lorentziana para o pico correspondente a $2 \theta_{p}=35.68^{\circ}$. Na tabela 4.2 , que também mostra os valores da literatura para a magnetita e a maguemita, vemos os valores obtidos para os picos principais dos difratogramas mostrados na figura 4.5. Os ajustes obtidos com as funções gaussiana e lorentziana forneceram valores de $2 \theta_{p}$ equivalentes, portanto mostramos apenas um resultado.

\begin{tabular}{c|c|c|c}
\hline \hline $\mathrm{Fe}_{3} \mathrm{O}_{4}$ & $\gamma-\mathrm{Fe}_{3} \mathrm{O}_{4}$ & $2 \theta_{p}\left({ }^{o}\right)$ EMG605 & $2 \theta_{p}\left(^{o}\right)$ EMG9o9 \\
\hline 35.46 & 35.75 & $35.68(2)$ & $35.67(2)$ \\
56.99 & 57.49 & $57.35(2)$ & $57.34(2)$ \\
62.58 & 63.14 & $62.99(2)$ & $62.96(2)$ \\
\hline \hline
\end{tabular}

Tabela 4.2: Tabela com os valores obtidos para os ângulos onde ocorrem os picos principais dos difratogramas mostrados na figura $4.5 \mathrm{e}$ valores da literatura [115].

Com os dados mostrados na tabela 4.2 vemos que não é possível distinguir se nossas amostras possuem nanopartículas compostas por magnetita ou maguemita. Utilizando esses valores e as equações $3.1 \mathrm{e}$ 3.2 , encontramos um valor para o parâmetro de rede $a=8.35 \AA$ para as duas amostras.

\subsubsection{Espectroscopia Mössbauer}

Além da difratometria de raios $X$, outra técnica que pode fornecer informações sobre a composição química de uma amostra é a espec- 

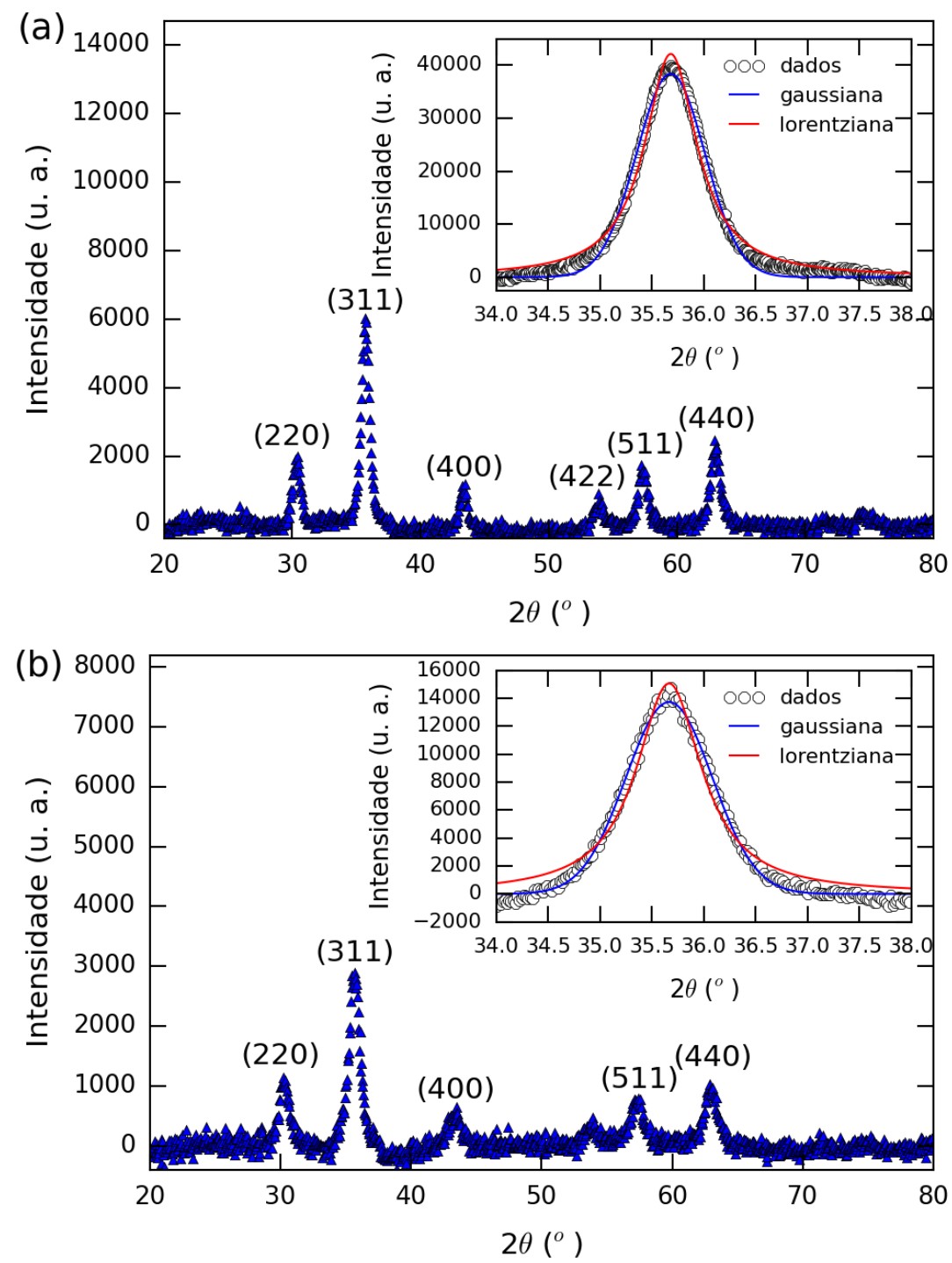

Figura 4.5: Difratogramas obtidos para os ferrofluidos comerciais (a) EMG605 e (b) EMG9o9. Nas figuras principais estão indicados os picos correspondentes a cada plano cristalográfico e nos painéis internos temos os ajustes obtidos para o pico correspondente a $2 \theta=35.68^{\circ}$. 
troscopia Mössbauer. Para os nossos ferrofluidos, as medidas foram feitas a $4.2 \mathrm{~K}$ sem campo magnético aplicado e utilizando ${ }^{57} \mathrm{Fe}$ como fonte radioativa. Na figura 4.6 vemos os espectros obtidos para os dois ferrofluidos, assim como os respectivos ajustes.
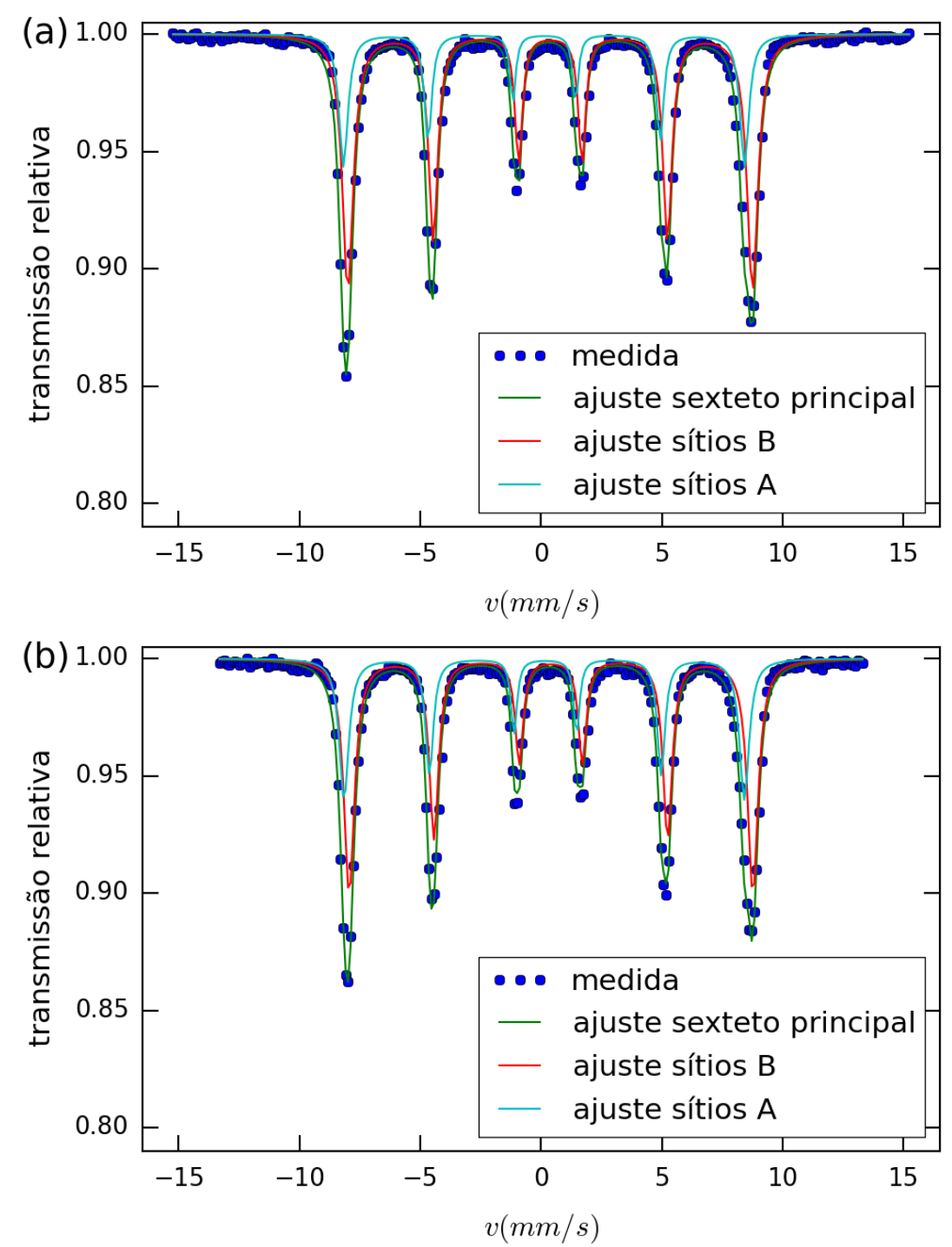

Figura 4.6: Espectros Mössbauer a 4.2K, sem campo aplicado, para os ferrofluidos (a) EMG605 e (b) EMG9o9.

Assim como nos difratogramas de raios X, os espectros Mössbauer da magnetita e maguemita podem ser um pouco semelhantes. No entanto a população de átomos de ferro nos sítios $A$ e $B$ deve seguir a proporção de 1:2 para a magnetita e 1:5/3 para a maguemita. Utilizando esta proporção de população de ferro em cada sítio e as áreas obtidas com o ajuste, pudemos atribuir o ajuste da curva azul clara na figura 4.6 ao sítio A e a curva vermelha ao sítio B. Outra característica entre os sítios $\mathrm{A}$ e $\mathrm{B}$ para ferritas é que $\delta$ é menor para os sítios A tetraédricos, como observamos nas nossas amostras. 


\begin{tabular}{c|c|c|c|c}
\hline \hline ferrofluido & $\delta(\mathrm{mm} / \mathrm{s})$ & $\Delta(\mathrm{mm} / \mathrm{s})$ & $B_{h f}(T)$ & Área (\%) \\
\hline EMG605 sítio A & $0.28(2)$ & $-0.05(1)$ & $51.4(5)$ & $29.5(2)$ \\
EMG605 sítio B & $0.54(2)$ & $-0.01(1)$ & $51.9(5)$ & $70.5(2)$ \\
EMG909 sítio A & $0.28(2)$ & $-0.05(1)$ & $51.3(5)$ & $35.2(2)$ \\
EMG909 sítio B & $0.54(2)$ & $0.01(1)$ & $51.7(5)$ & $64.8(2)$ \\
\hline \hline
\end{tabular}

Tabela 4.3: Tabela com os valores obtidos nos ajustes dos espectros Mössbauer para a posição da linha $(\delta)$, constante de acoplamento quadrupolar $(\Delta)$ e o campo hiperfino $B_{h f}$ para os ferrofluidos EMG605 e EMG909. Na tabela mostramos os ajustes correspondentes aos sítios A (tetraédrico) e B (octaédrico).

Comparando a proporção entre áreas na tabela $4 \cdot 3$, temos para o ferrofluido EMG605 a relação A:B de 1:2.39 e de 1:1.84 para o ferrofluido EMG909. Estes valores são mais próximos dos valores da magnetita, que é de 1:2, no entanto somente com esses valores a distinção entre magnetita e maguemita não pode ser feita. Com esses resultados, e a informação fornecida pelo fabricante, assumimos que nossos ferrofluidos são compostos por nanopartículas de magnetita.

\subsection{CARACTERIZAÇÃO MAgNéticA DE FERROFLUidos CONGE- LADOS}

Uma vantagem dos ferrofluidos é a facilidade de obter amostras com diversas concentrações de nanopartículas a partir de uma amostra mais concentrada e assim estudar o efeito de interações no comportamento magnético desses sistemas. Na prática, quando diluímos uma amostra de ferrofluido, alteramos a concentração dos componentes que garantem a estabilidade dos mesmos, de forma que nossa amostra resultante pode conter aglomerados de nanopartículas. Em geral, ferrofluidos a base de água são mais instáveis e suscetíveis a formar aglomerados, enquanto que os ferrofluidos a base de óleo toleram melhor esse tipo de diluição.

Nesta seção apresentamos a caracterização magnética dos ferrofluidos EMG605 e EMG909. Para observar possíveis efeitos de interações entre partículas em nossas amostras, fizemos medidas usando os ferrofluidos em seu estado puro, que vamos chamar de EMG909-100\% e EMG605-100\%, e em mais duas diluições: EMG9o9-15\%, EMG605-15\%e EMG909-1\%, EMG605-1\%, com composições mostradas nas tabelas 4.4 e 4.5. As amostras a base do ferrofluido EMG605 foram diluídas em água destilada, enquanto que as amostras obtidas com o ferrofluido EMG9og foram diluídas com um solvente próprio da empresa Ferrotec. Para essas amostras mostramos medidas de ciclos de histerese, curvas ZFC-FC, $\Delta m$, medidas de suscetibilidade AC e curvas de inversão de primeira ordem. 


\begin{tabular}{c|c|c|c}
\hline \hline Amostra & $m_{\text {EMG909 }(g)}$ & $m_{\text {sol }}(g)$ & conc. part. $10^{14}\left(\mathrm{~cm}^{-3}\right)$ \\
\hline EMG909-100\% & 1,0000 & - & 1000 \\
EMG909-15\% & 0,1653 & 0,8459 & 100 \\
EMG909-1\% & 0,01 & 1,0020 & 1 \\
\hline \hline
\end{tabular}

Tabela 4.4: Tabela com a composição em massa do ferrofluido EMGgog e do solvente para as amostras EMG909-100\%, EMG909-15\% e EMG909$1 \%$. Mostramos também uma estimativa da concentração do número de partículas magnéticas por volume de amostra.

\begin{tabular}{c|c|c|c}
\hline \hline Amostra & $m_{E M G 605}(g)$ & $m_{\mathrm{H}_{2} \mathrm{O}}(\mathrm{g})$ & conc. part. $10^{14}\left(\mathrm{~cm}^{-3}\right)$ \\
\hline EMG605-100\% & 1,00 & - & 1000 \\
EMG605-15\% & 0,15 & 0,85 & 100 \\
EMG605-1\% & 0,01 & 1,00 & 1 \\
\hline \hline
\end{tabular}

Tabela 4.5: Tabela com a composição em massa do ferrofluido EMG6o5 e de água para as amostras EMG605-100\%, EMG605-15\% e EMG605-1\%. Mostramos também uma estimativa da concentração do número de partículas magnéticas por volume de amostra.

Como vimos no capítulo 3, um tipo de medida que nos dá informação sobre efeitos magnetizantes e desmagnetizantes nas amostras são as chamadas curvas $\Delta m$. Para determinar o tipo de efeito predominante em ferrofluidos congelados, medimos a remanência isotérmica $m_{r}(H)$ e a remanência desmagnetizante $m_{d}(H)$ para as amostras apresentadas nas tabelas 4.5 e 4.5 . Na figura 4.7 vemos o gráficos de $m_{r}(H)$ para as amostras (a) EMG909-100\%, EMG909-15\% e EMG909-1\%, e (b) EMG605-100\%, EMG605-15\% e EMG605-1\% medidos a uma temperatura de $5 K$. Nas figuras 4.8 (a) e (b) mostramos as curvas $\Delta m$ obtidas com os dados da figura 4.7. Vemos que em todas as amostras temos claramente uma interação desmagnetizante predominante, que podemos atribuir à interação dipolar entre as partículas. Para as amostras obtidas com o ferrofluido EMG909, figura (a), vemos que a interação desmagnetizante é mais marcante quanto maior for a concentração de nanopartículas, de acordo com o que esperamos quando temos uma interação dipolar mais forte. Já para as amostras obtidas com o ferrofluido EMG605, a base de água, não há uma diferença marcante entre as curvas. Podemos atribuir esse fato a forte tendência que os ferrofluidos aquoso têm de formar aglomerados de partículas. Apesar de a amostra EMG605-1\% possuir uma concentração de partículas menor do que EMG605-100\%, ela deve conter aglomerados maiores, já que a diluição em água propicia a aglomeração das partículas.

Para as amostras EMG909-15\% e EMG909-100\% o mínimo da curva $\Delta m$ ocorre em um campo de 260(10)Oe, enquanto que para a amostra 

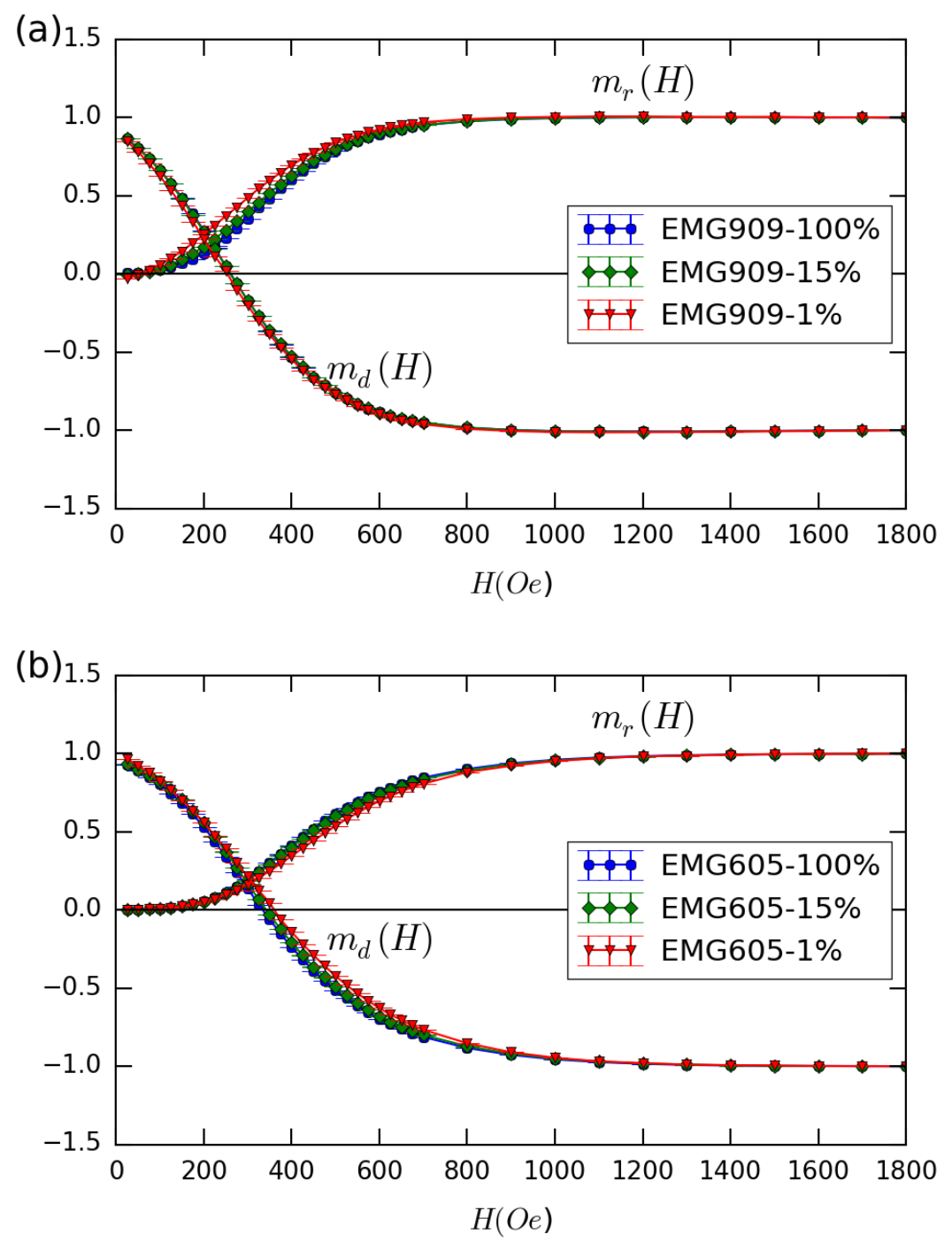

Figura 4.7: Curvas $m_{r}(H)$ e $m_{d}(H)$ a $5 K$ para as amostras (a) EMG909-100\%, EMG909-15\% e EMG909-1\%, e (b) EMG605-100\%, EMG605-15\% e EMG605-1\%. 

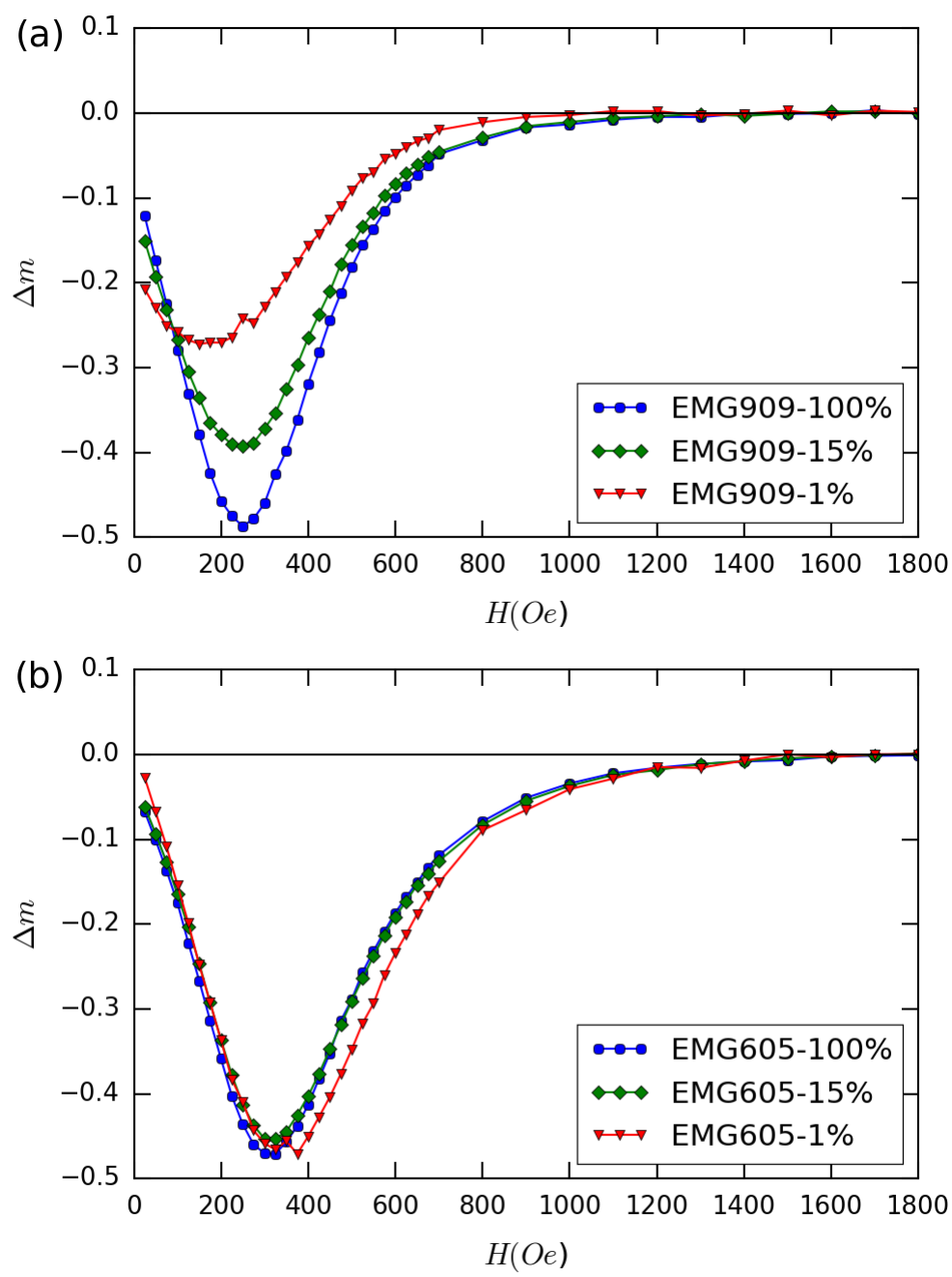

Figura 4.8: Curvas $\Delta m(H)$ a $5 K$ para as amostras (a) EMG909-100\%, EMG9o915\% e EMG909-1\%, e (b) EMG605-100\%, EMG605-15\% e EMG605$1 \%$. 
EMG909-1\% esse campo é de 230(10)Oe. Já para as amostras EMG605 esse mínimo ocorre em um campo de 325(10)Oe. Podemos esperar por esses resultados, assim como pelas imagens de microscopia eletrônica que mostraram que o ferrofluido EMG605 é constituído por partículas maiores do que o EMG909, que as amostras da série EMG605 sejam magneticamente mais duras do que as da série EMG909. De fato observamos que a uma temperatura de $10 \mathrm{~K}$ o ferrofluido EMGgog possui uma coercividade de 115(2)Oe (figura 4.9 (a)), enquanto que para o ferrofluido EMG605 esta coercividade é de 222(2)Oe.

Na figura 4.9(a) vemos o ciclo de histerese a $10 \mathrm{~K}$ para as amostras EMG909-100\%, EMG909-15\% e EMG909-1\%. Para as amostra EMG909$100 \%$ e EMG909-15\% a magnetização de saturação foi estimada pelo coeficiente linear do ajuste de $m \times(1 / H)$, já que mesmo com um campo de $4.5 \mathrm{~T}$ as amostras ainda não estavam saturadas, já para a amostra EMG909-15\% (curva vermelha) a componente diamagnética do solvente onde as partículas estão dissolvidas teve que ser subtraída, já que era dominante em relação à ferromagnética para campos intensos. Nesta última medida também vemos uma descontinuidade nos pontos na região de $2 T$, devido a problemas na aquisição de dados com o SQUID nessa região de campo. No gráfico 4.9 (b) vemos que as coercividades das três amostras são similares, sendo 115(2), 112(2) e 116(2)Oe para as amostras EMG909-100\%, EMG909-15\% e EMG909-1\%, respectivamente. Alguns trabalhos preveem um decréscimo no valor da coercividade para sistemas com uma forte interação dipolar [116], já que esse tipo de interação é desmagnetizante, no entanto, nas nossas amostras, não pudemos observar nenhum efeito de interações no valor da coercividade. No entanto, comparando o valor da coercividade de 115(2)Oe obtida para a amostra EMG909-100\% com o valor do campo onde ocorre o mínimo da curva $\Delta m$ que foi de 260(10)Oe a $5 K$ e $220(10)$ Oe a $10 K$ (medida não mostrada aqui), podemos esperar que esta diferença possa ser explicada devido a um campo efetivo da forma $H_{e f}=H+\alpha M$ na amostra, que iremos discutir também no próximo capítulo com a simulação Monte Carlo.

Como vimos na seção 3.2.5, podemos estimar o valor da constante de anisotropia magnética efetiva de um sistema de nanopartículas por meio de medidas de suscetibilidade AC. Para as amostras EMGgog100\%, EMG909-15\% e EMG909-1\% realizamos essas medidas em função da temperatura utilizando frequências para o campo AC aplicado entre 0.21 e $710.23 \mathrm{~Hz}$. O campo DC utilizado foi de 250 e. Não realizamos essas medidas para as amostras a base do ferrofluido EMG605, pois ele possui uma temperatura de bloqueio maior e não era possível obter os máximos das curvas de suscetibilidade antes do gelo passar para o estado líquido.

Na figura 4.10 vemos as curvas da componente imaginária da suscetibilidade AC para as amostras EMG909-100\%, EMG909-15\% e EMG9091\%. Essa é a componente que está fora de fase com o campo aplicado, 

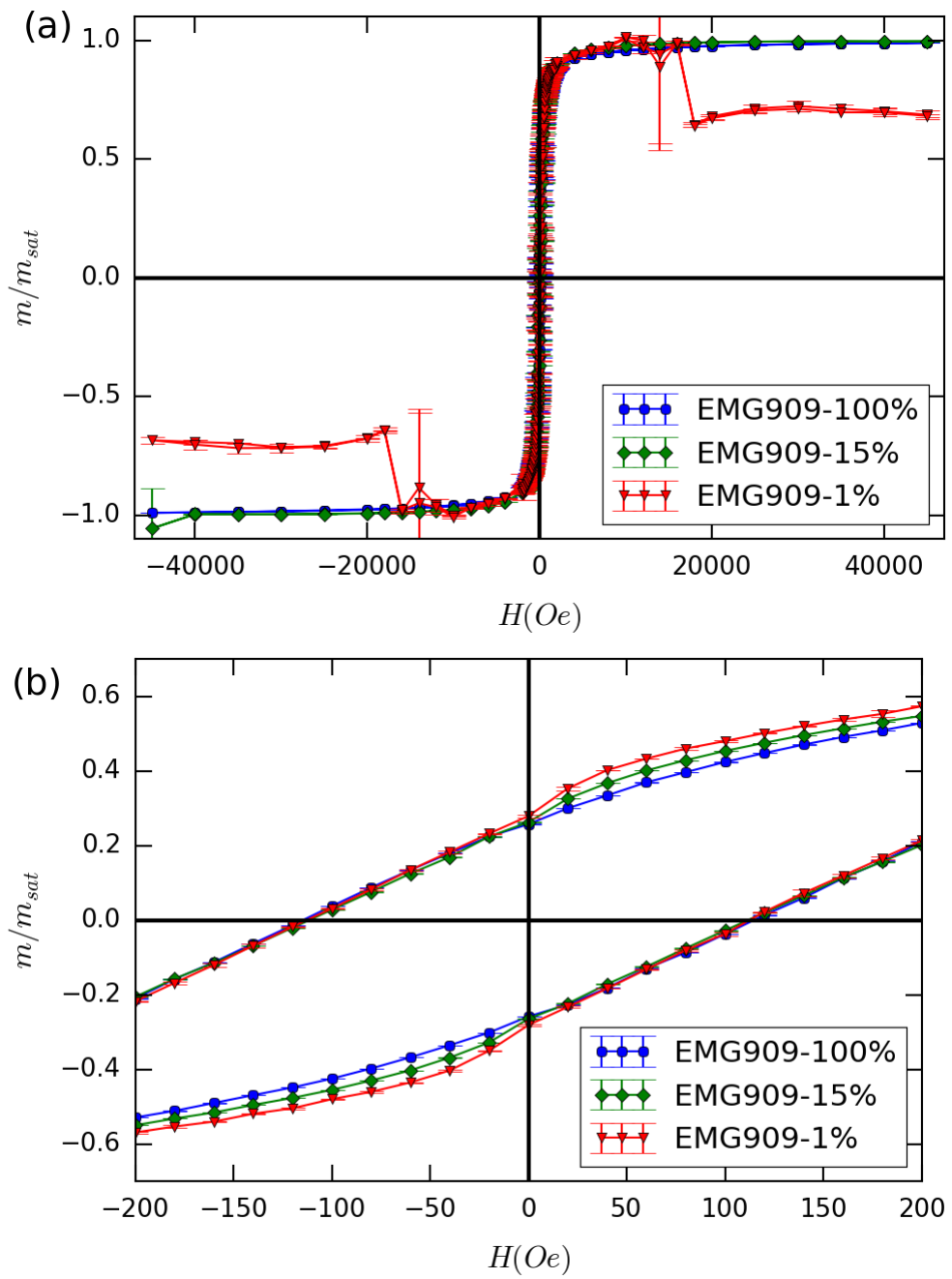

Figura 4.9: (a) Ciclos de histerese a $10 \mathrm{~K}$ para as amostras EMG909-100\%, EMG909-15\% e EMG909-1\%. Na figura (b) vemos em detalhe a região de coercividade dos ciclos. 

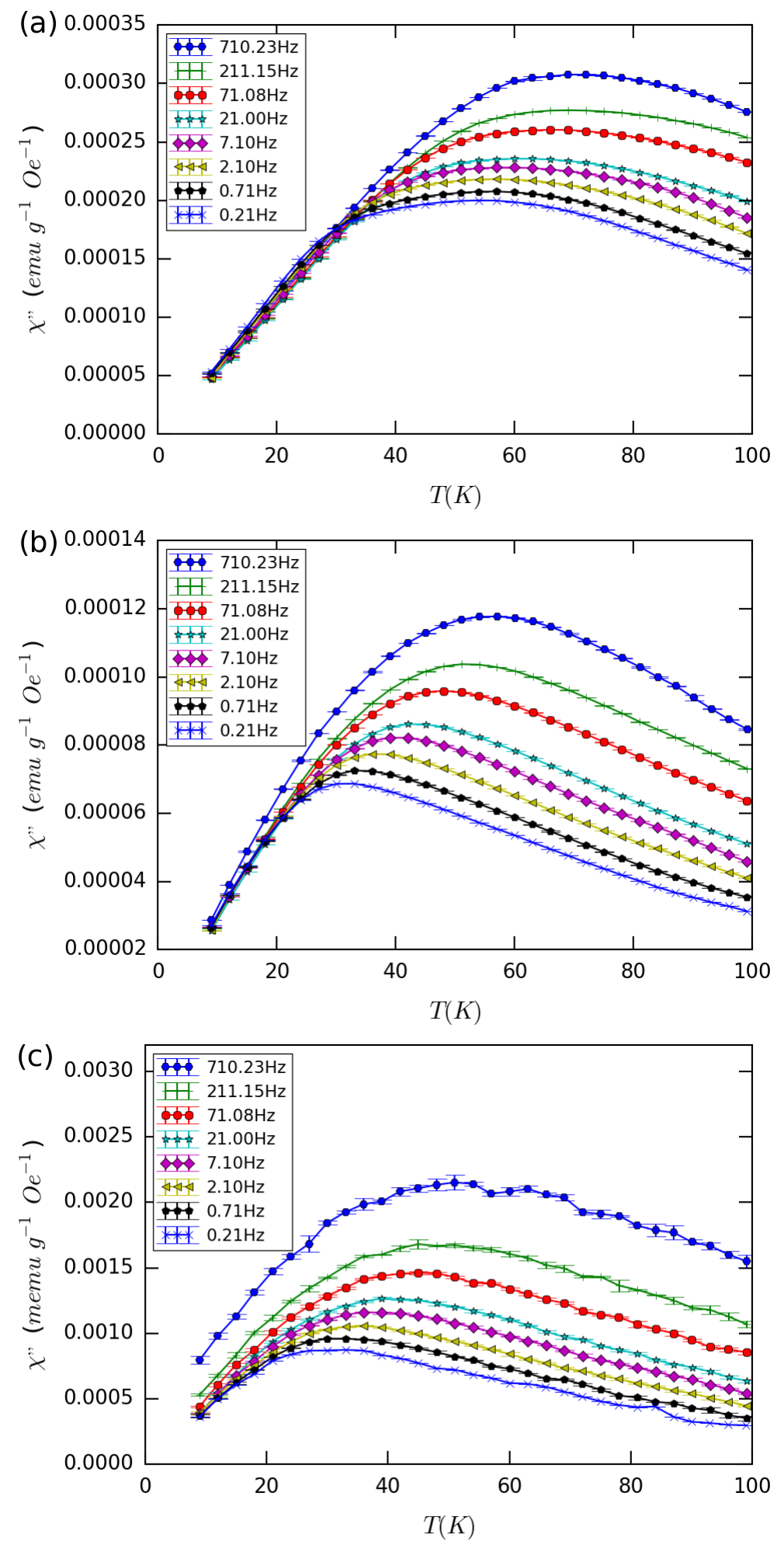

Figura 4.10: Curvas da componente imaginária da suscetibilidade para as amostras (a) EMG909-100\%, (b) EMG909-15\% e (c) EMG909-1\%. 
portanto quanto maior for a frequência de oscilação maior será o sinal de $\chi^{\prime \prime}$. Outro fato é que a temperatura de máximo da curva aumenta com o valor da frequência, pois como vimos no capítulo 1 , para uma partícula que é um monodomínio magnético existe uma relação entre a frequência com que ocorre a inversão de seu momento, a temperatura e a barreira de energia da partícula, dada pela equação 2.4. Essa relação mostra que para um dado valor da barreira de energia, a inversão da magnetização ocorre em tempos maiores (ou frequências menores) para temperaturas menores. Usando a relação 3.22, e os valores máximos de temperatura extraídos das curvas na figura 4.10, podemos fazer um ajuste linear para estimar o valor dessa barreira de energia e a constante média $\left\langle v_{0}\right\rangle$ da amostra.

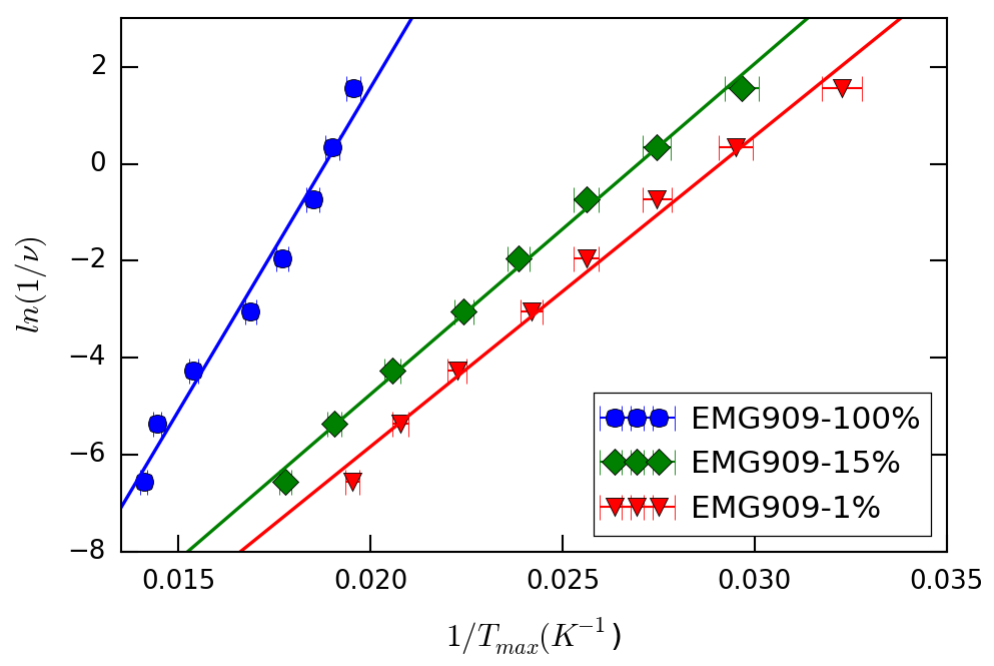

Figura 4.11: Ajustes para as amostras EMG909-100\%, EMG909-15\% e EMG909-1\% obtidos para determinar o valor médio da constante de anisotropia efetiva $<K_{e f}>$ e a constante $v_{0}$.

Na figura 4.11 vemos os ajustes lineares obtidos para as amostras EMG909-100\%, EMG909-15\% e EMG909-1\% pela linearização da equação 2.4, e na tabela 4.6 temos os resultados obtidos para a barreira de energia de anisotropia que é dada por $\left.\left\langle E_{a}\right\rangle=<K_{e f}\right\rangle V$. Nesta tabela também temos $\left\langle v_{0}>\right.$ e a estimativa da constante de anisotropia efetiva média $\left\langle K_{e f}\right\rangle=\langle E a\rangle /\langle V\rangle$, usando o diâmetro médio obtido por meio dos dados da tabela 4.1.

Esses resultados nos mostram que temos uma anisotropia efetiva média para as partículas cerca de nove vezes maior do que o valor de $K$ para a magnetita em sua forma massiva $\left(1.35 \times 10^{5} \mathrm{erg} / \mathrm{cm}^{3}\right.$ $[117,17])$ para a amostra EMG909-100\%, e quatro vezes maior para as amostras EMG909-15\% e EMG909-1\%. Podemos atribuir esse aumento de $K$ tanto devido à efeitos de superfície nas partículas, a uma baixa cristalinidade [6], e também às interações entre partículas. Para a amostra EMG909-100\%, em particular, é bastante sugestivo que um valor de $<K_{e f}>$ maior em relação as outras duas amostras esteja 


\begin{tabular}{c|c|c|c}
\hline \hline Amostra & $\left\langle E_{a}>\left(10^{-20} \mathrm{~J}\right)\right.$ & $\left\langle v_{0}>\left(10^{8} \mathrm{~Hz}\right)\right.$ & $\left\langle K_{e f}>\left(10^{5} \mathrm{erg} / \mathrm{cm}^{3}\right)\right.$ \\
\hline EMG909-100\% & $1.84(11)$ & $800(1000)$ & $12.2(8)$ \\
EMG909-15\% & $0.94(3)$ & $1.0(4)$ & $6.3(2)$ \\
EMG909-1\% & $0.88(4)$ & $1.2(9)$ & $5.9(3)$ \\
\hline \hline
\end{tabular}

Tabela 4.6: Valores obtidos por meio dos ajustes lineares mostrados na figura 4.11 para $\left\langle E_{a}\right\rangle$, $\left.\left\langle v_{0}\right\rangle \mathrm{e}<K_{e f}\right\rangle$ para as amostras EMGgog$100 \%$, EMG $909-15 \%$ e EMG909-1\%.

relacionado a uma maior interação dipolar desse sistema. Vale lembrar que neste trabalho consideramos a interação dipolar como sendo desmagnetizante devido aos resultados de $\Delta m<0$, figura 4.8, em acordo com resultados obtidos por outros autores [28, 89], e não devido ao aumento da constante de anisotropia $\left\langle K_{e f}>\right.$ em amostras mais concentradas, que estaria relacionado a um endurecimento das partículas, o que neste contexto poderia ser interpretado como uma interação magnetizante.

Vamos agora observar o comportamento dessas três amostras em medidas ZFC-FC. Na literatura existem resultados que apontam tanto um aumento da temperatura de bloqueio, quanto uma diminuição em sistemas com interações dipolares. Na simulação que apresentamos no próximo capítulo quando consideramos um campo desmagnetizante vemos que o máximo da curva $\mathrm{ZFC}$, que tomamos como a temperatura de bloqueio, aumenta quanto mais desmagnetizante for o campo, o que sugere que para sistemas com mais interação dipolar $T_{B}$ aumenta. Na figura 4.12 mostramos as curvas ZFC-FC normalizadas pela magnetização máxima da curva ZFC, escolhemos essa normalização para poder comparar as curvas que possuem magnetização com ordens de grandezas diferentes. Vemos que para a amostra EMG909-100\%, que é o ferrofluido sem diluição, $T_{B}$ é de $86(1) K$, enquanto que as amostras EMG909-15\% e EMG909-1\% possuem temperaturas de bloqueio equivalentes e iguais a 62(1)K. Vemos assim que o sistema mais concentrado e que consequentemente possui uma maior interação dipolar entre as partículas também possui uma temperatura de bloqueio maior. Possivelmente após uma certa diluição a interação dipolar não é mais determinante para $T_{B}$ e por isso vemos duas curvas equivalentes para as amostras EMG909-15\% e EMG909-1\%

Vimos no capítulo 3 que as curvas ZFC-FC possuem um comportamento fortemente dependente da intensidade do campo magnético aplicado. Podemos observar esse efeito para as amostras EMG9o9$100 \%$ e EMG909-1\% nas figuras 4.13 (a) e (b), respectivamente, mostrando as curvas ZFC com campos de 50, 300, 500 e 8000 e. Vemos que com campos mais intensos a temperatura de bloqueio obtida pelo máximo da curva ZFC é menor, já que as partículas ganham mais energia para se alinhar com o campo magnético. Na figura (c) vemos 


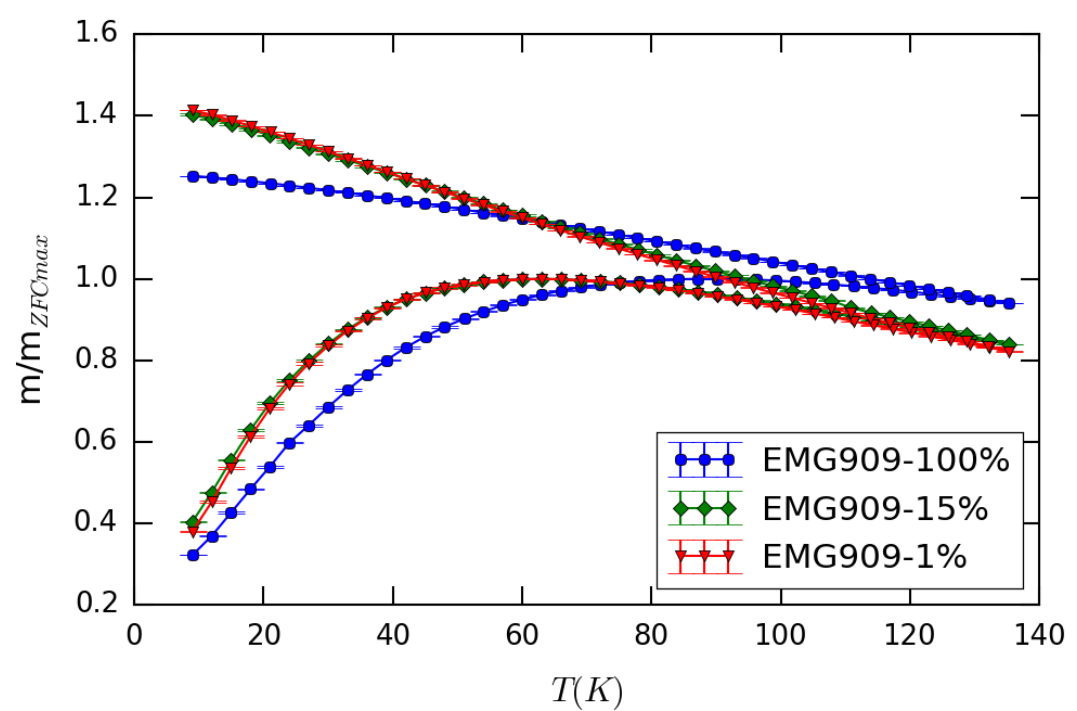

Figura 4.12: Curvas ZFC-FC normalizadas pelo máximo da ZFC com campo aplicado de 500 e para as amostras EMG909-100\%, EMG909-15\% e EMG909-1\%.

a dependência de $T_{B}$ extraída dessas curvas em função do campo aplicado. Para o menor campo utilizado, que foi de 50Oe, vemos que $T_{B}$ é maior para o sistema mais concentrado, conforme discutimos anteriormente. No entanto, para campos maiores, a temperatura de bloqueio das duas amostras passa a ter valores semelhantes, inclusive com o sistema mais diluído EMG9o9-1\% tendo um valor de $T_{B}$ maior do que EMG909-100\%. Isso mostra que a intensidade do campo aplicado deve ser a menor possível para não distorcer a barreira de energia das nanopartículas e obter um valor para a temperatura de bloqueio mais próximo do real.

Nas medidas que apresentamos até agora, as amostras de ferrofluido foram congeladas sem campo aplicado. Para as medidas ZFCFC e obtenção das curvas $\Delta m$ essa é uma condição necessária, já que um campo intenso poderia magnetizar a amostra e modificar a resposta magnética do sistema a essas medidas. No entanto, à temperatura ambiente quando o solvente está em seu estado líquido, a aplicação de um campo magnético faz com que as nanopartículas formem estruturas magnéticas como agulhas na direção do campo aplicado ${ }^{1}$. Portanto podemos esperar uma resposta magnética diferente quando congelamos essas amostras na presença e ausência de um campo aplicado. Escolhemos as medidas de curvas de inversão de primeira ordem para estudar essas duas condições de congelamento, já que a partir destas medidas podemos observar as distribuições de coercividade e campos de interação da amostra e também porque nestas

1 Iremos ver uma consequência direta desse efeito no próximo capítulo, na seção 4.5 sobre o efeito magnetoviscoso. 

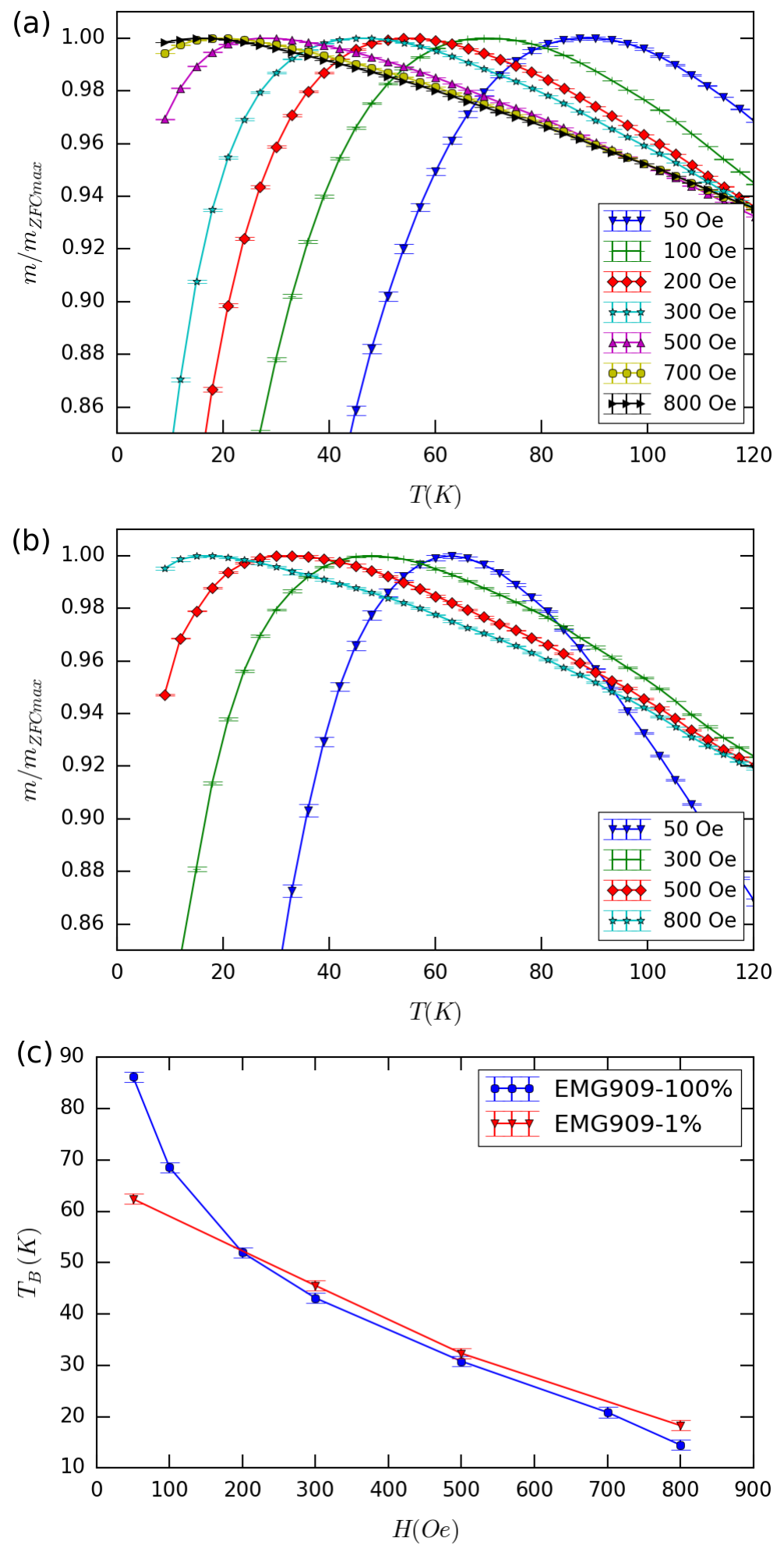

Figura 4.13: Curvas ZFC normalizadas com campo aplicado entre 50 e 8000 e para as amostras (a)EMG909-100\% e (b)EMG909- $1 \%$. Na figura (c) vemos a dependência da temperatura de bloqueio com o campo utilizado para obter as curvas ZFC-FC. 
medidas partimos da amostra já saturada, de forma que o campo aplicado durante o congelamento não prejudicaria a medida.

Na figura 4.14 (a) vemos as curvas FORCs para a amostra EMG605$100 \%$ que foi congelada a partir da temperatura ambiente até $5 \mathrm{~K}$ sem campo aplicado. Na figura (b) vemos o diagrama FORC obtido a partir das curvas mostradas em (a). Na figura (c) vemos o diagrama obtido de curvas FORC dessa mesma amostra, mas que foi congelada partir da temperatura ambiente até $5 \mathrm{~K}$ com um campo aplicado de 50000 e. Para os diagramas que mostramos em (b) e (c) vemos que a distribuição dos campos $H_{b}$ é mais significativa na região entre -700 e $+7000 e$, enquanto que $H_{c}$ se distribui entre 0 e $16500 e$. A distribuição de campos $H_{b}$ é ligeiramente deslocada para regiões negativas, o que é compatível com o caso sem interações que vimos na simulação apresentada na seção 5.4.1. Para estas duas distribuições vemos também duas regiões bem definidas, uma em $H_{c}=0$ e outra em aproximadamente $H_{c}=5300 e$. Estes dois picos na distribuição estão associados a, respectivamente, partículas menores e maiores. As partículas menores possuem também menor coercividade e um comportamento reversível a esta temperatura, já as partículas maiores apresentam um comportamento irreversível. Portanto, vemos nestes diagramas, o efeito da dispersão de tamanhos observados nas imagens de microscopia eletrônica de transmissão, figura 4.2.

Comparando agora estes dois diagramas, vemos na figura 4.14 (b) que os dois picos da distribuição, $H_{c}=0$ e $H_{c}=5300 e$, possuem praticamente a mesma intensidade. Já na figura (c) vemos que claramente o pico mais importante é em torno de $H_{c}=5300$ e. Esta mudança no diagrama está relacionada ao campo aplicado durante o congelamento da amostra. Podemos esperar que as estruturas magnéticas formadas pelas partículas quando aplicamos o campo possuem uma coercividade maior, já que elas são aglomerados de partículas. Assim, na condição (c), partículas com coercividades menores podem ter formado aglomerados com as partículas maiores e consequentemente aumentado sua coercividade.

Nos resultados apresentados até o momento estudamos nanopartículas em meios sólidos, já que os ferrofluidos estavam congelados. Quando passamos a estudar amostras em que as nanopartículas estão dispersas em um meio líquido, como por exemplo água ou óleo em amostras de ferrofluido, ou então sistemas micelares dopados com nanopartículas, passamos a ter um outro grau de liberdade em nosso sistema, já que agora as nanopartículas podem rotacionar e transladar no meio. Essa possibilidade faz com que as partículas possam rotacionar no líquido para alinhar sua magnetização com o campo aplicado, um fenômeno conhecido com relaxação de Brown. Esse novo grau de liberdade introduzido em nosso sistema dá origem a alguns fenômenos interessantes, como a possibilidade de estudar transições de fase por meio de medidas magnéticas, e também ao efeito magnetovis- 

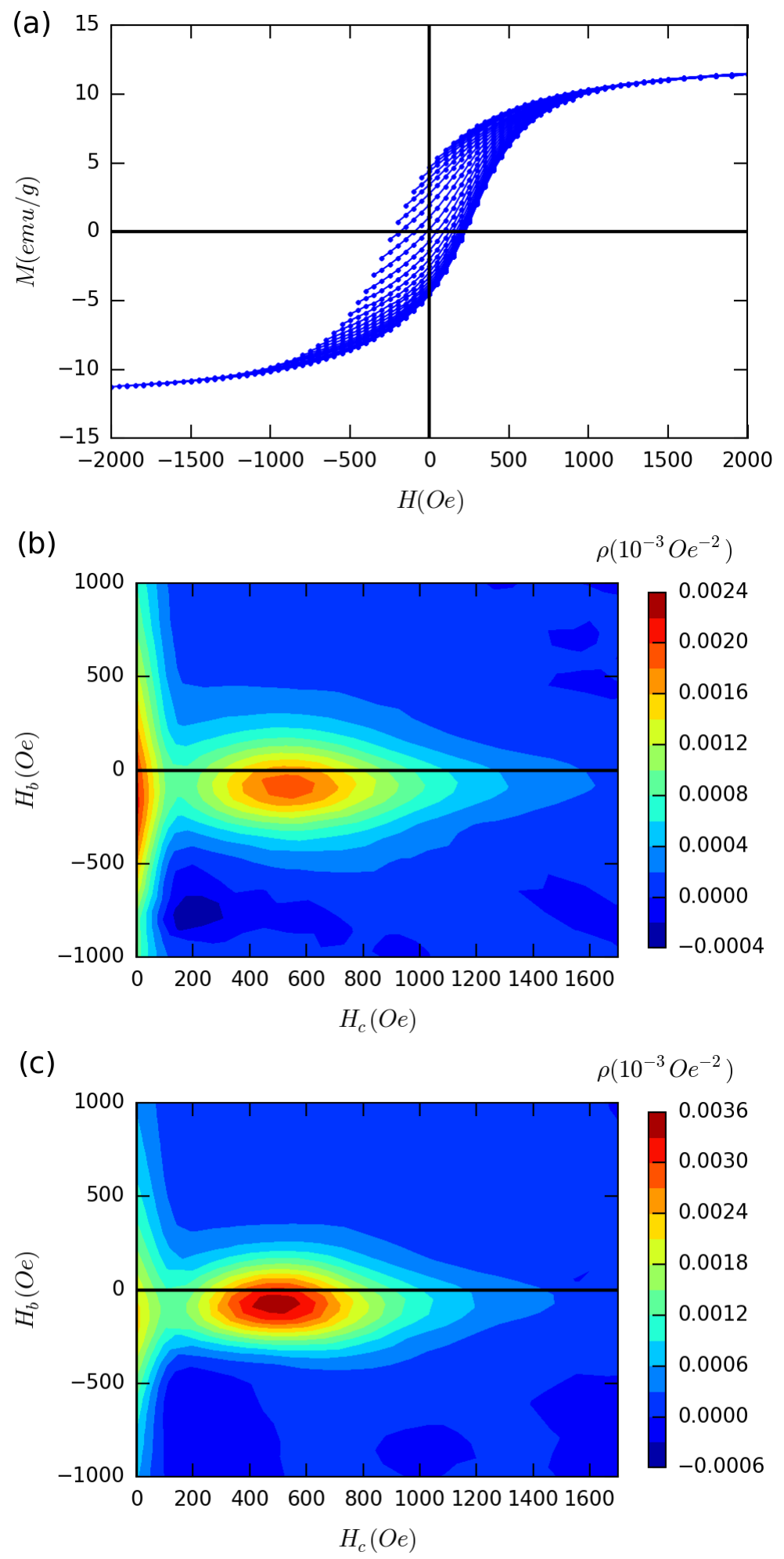

Figura 4.14: (a) Curvas de inversão de primeira ordem a $5 K$ para a amostra EMG605-100\%. (b) Diagrama FORC obtido utilizando as curvas mostradas em (a). (c) Diagrama FORC obtido após congelar a amostra com um campo aplicado de 5000Oe. 
coso, que mostra como as estruturas magnéticas na forma de agulhas que as partículas formam na presença de um campo aplicado podem se refletir em um aumento da viscosidade do sistema.

\subsection{CURVAS ZFC-FC E TRANSIÇÃO DE FASE DO ESTADO SÓLIDO PARA O LÍQUIDO EM FERROFLUIDOS}

Nesta seção mostramos como medidas de magnetização, especificamente curvas Zero Field Cooling - Field Cooling (ZFC-FC), podem fornecer informações sobre a transição entre os estados sólido e líquido de um ferrofluido.

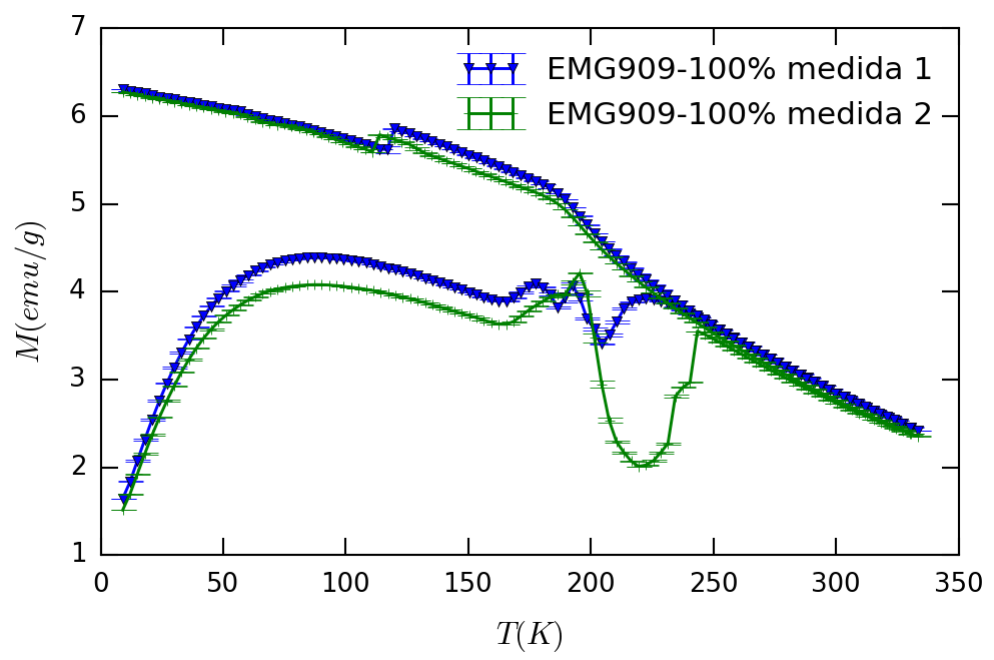

Figura 4.15: Curvas ZFC-FC com campo aplicado de 50Oe para o ferrofluido 909. As mudanças no comportamento da magnetização com a temperatura indicam as mudanças de fase de sólida para líquida (ou vice versa).

Na figura 4.15 mostramos duas medidas ZFC-FC, com campo aplicado de $500 e$, para o ferrofluido EMG909-100\% ${ }^{2}$. A primeira informação que podemos tirar dessas curvas é o valor da temperatura de bloqueio das partículas (temperatura onde ocorre o valor máximo de magnetização na curva ZFC), que para ambas as medidas é 86(1)K. A partir da temperatura de $165 \mathrm{~K}$ o comportamento das curvas ZFC começa a se mostrar mais complicado.

Sabemos que a curva de magnetização ZFC é um estado metaestável, devido ao resfriamento da amostra antes da aplicação do campo. Quando a amostra de ferrofluido está congelada, mudanças na magnetização ocorrem devido à rotação dos momentos magnéticos da partícula na direção do campo aplicado, que é conhecida como relaxação de Néel. Já quando o solvente do ferrofluido passa para o

2 Foram feitas duas medidas iguais para a mesma amostra para ver sua reprodutibilidade. 
estado líquido, além da relaxação de Néel pode ocorrer a rotação das próprias partículas dentro do líquido, que é conhecida como relaxação de Brown. Como o movimento browniano é caracterizado por uma aleatoriedade, temos na fase líquida uma situação onde é muito complicado prever o comportamento da curva $\mathrm{ZFC}$, devido à grande quantidade de variáveis que contribuem para o valor medido da magnetização.

Na figura 4.15 vemos tanto na curva ZFC quanto na FC três regiões onde a magnetização tem uma mudança no seu comportamento. Nesse tipo de amostras, a transição do estado sólido para o líquido começa a partir da interface da partícula com o solvente [118, 119], assim existe uma região de temperatura onde as partículas ainda não podem transladar, mas podem começar a apresentar a relaxação de Brown, já que na sua vizinhança o solvente já está no estado líquido. No momento em que o sistema passa totalmente para a fase líquida essas partículas passam a girar e transladar, além de também continuarem a se orientar com o campo devido à relaxação de Néel.

Na figura 4.15 vemos, ao comparar as duas medidas, que na região de temperatura entre 165 e $243 \mathrm{~K}$ a magnetização da curva ZFC possui um comportamento pouco previsível. Essa região de temperatura pode estar associado ao efeito descrito acima, quando as partículas estão começando a poder girar dentro do líquido. Para entender porque a magnetização apresenta certos vales e picos nessa região de temperatura temos que pensar que quando a amostra foi congelada a distribuição de eixos fáceis das partículas não necessariamente estava na direção do campo aplicado, mas sim em uma configuração que depende da interação entre elas (nesse tipo de amostra temos principalmente a interação dipolar e a estérica). Assim quando as partículas ganham esse grau de liberdade extra a distribuição desses eixos fáceis com o campo muda e temos uma região onde a magnetização ainda não encontrou seu estado de equilíbrio. Na região de temperatura final, quando a magnetização mostra um comportamento estritamente decrescente com o aumento da temperatura (a partir de $228 \mathrm{~K}$ para a medida 1 e $244 K$ para a medida 2), as partículas já entraram em equilíbrio com o campo aplicado.

Olhando agora para a curva FC, vemos também três regiões com diferenças no comportamento da magnetização. Primeiro de 333 a $189 \mathrm{~K}$ a magnetização aumenta com a diminuição da temperatura, como habitualmente ocorre nessas medidas. No entanto entre 189 e $120 \mathrm{~K}$ (114K para a medida 2) a derivada dessa curva muda e a 120(1)K na medida 1 e $114(1) K$ na medida 2, a magnetização das amostras mostra um decaimento abrupto, provavelmente devido à transição total do estado líquido para o sólido. Vemos que essas mudanças no comportamento da magnetização ocorrem sempre a uma temperatura mais baixa que na curva ZFC, o que evidencia o fenômeno de super-resfriamento na amostra, ou seja, a temperatura onde o ferro- 
fluido se solidifica ocorre a uma temperatura menor do que a qual ele se liquefez. Esse fenômeno já foi relatado recentemente na literatura em sistemas similares aos nossos [119, 58].
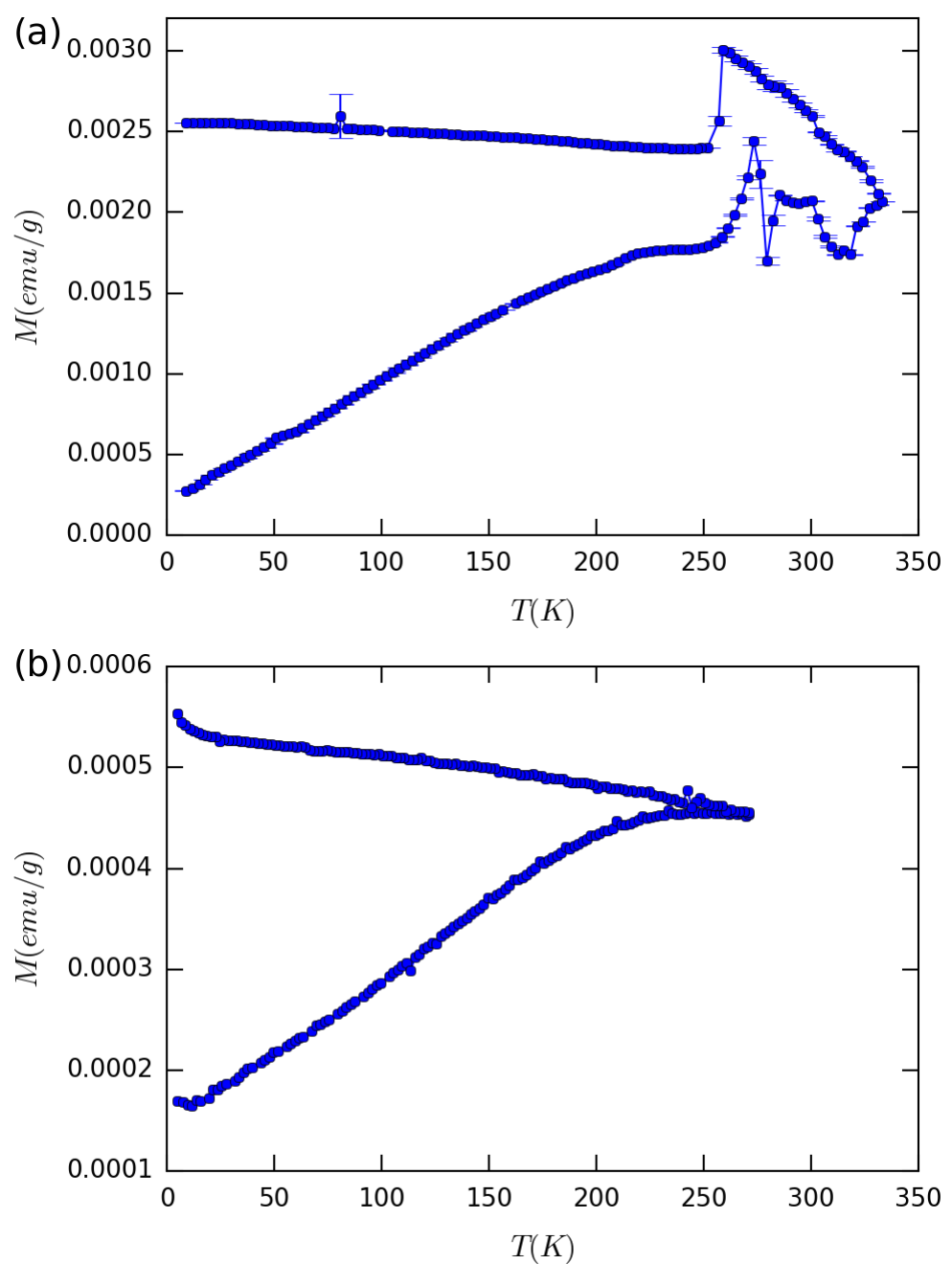

Figura 4.16: Curvas ZFC-FC com campo aplicado de 50Oe para a amostra EMG605- $1 \%$ em (a) um intervalo de temperatura indo da fase sólida pra líquida e (b) só na fase congelada.

Assim como observamos essa transição para a amostra EMG9o9$100 \%$, também foi possível observar para a amostra EMG605-1\%, como vemos na figura 4.16. Para essa amostra a temperatura de bloqueio é de 250(2)K, que é bem maior do que as obtidas para as amostras derivadas do ferrofluido EMG9og. Isso é esperado, pois como vimos nas imagens de microscopia, o ferrofluido EMG605 possui partículas magnéticas com um diâmetro médio maior do que o EMGgog. 


\subsubsection{Observação da transição de fase em cristais líquidos liotrópicos}

Preparação das amostras de cristais líquidos liotrópicos

As amostras de cristal líquido foram preparadas utilizando o sabão laurato de potássio (LK) obtido pela alcalinização do ácido láurico com $\mathrm{KOH}$ [73]. Os componentes de cada amostra foram cuidadosamente pesados numa balança analítica sendo que o primeiro reagente a ser pesado era o laurato, em seguida a água e por fim o decanol $(D e)$. O decanol costuma ser sempre o último componente devido à sua maior volatilidade.

Após a pesagem e mistura dos componentes as amostras permaneciam em repouso até que toda espuma desaparecesse. Foram preparadas amostras ternárias (água, LK e decanol) que apresentavam transição entre as fases isotrópica e nemática. Essas amostras foram dopadas com o ferrofluido EMG605, na mesma concentração da amostra EMG605-1\%.

\begin{tabular}{c|c|c|c|c}
\hline \hline Amostra & $\% \mathrm{LK}$ & $\% \mathrm{H}_{2} \mathrm{O}$ & $\% \mathrm{De}$ & $10^{14}\left(\mathrm{~cm}^{-3}\right)$ \\
\hline Am11 & 27.27 & 65.98 & 6.76 & 1 \\
Am17 & 27.19 & 66.00 & 6.81 & 1 \\
Am19 & 25.98 & 66.88 & 7.14 & 1 \\
\hline \hline
\end{tabular}

Tabela 4.7: Tabela com a composição (em \% de massa) de laurato de potássio, água e decanol de cada amostra, e número estimado de partículas magnéticas por $\mathrm{cm}^{3}$ de amostra. $\mathrm{O}$ erro na porcentagem de massa é de o,o1 \%.

A quantidade de nanopartículas magnéticas por volume do cristal líquido era de $10^{14}$ partículas por $\mathrm{cm}^{3}$. Esta diluição é suficientemente baixa para que as temperaturas onde ocorrem transições de fase no cristal líquido não sejam afetadas pela presença da magnetita [73].

\section{Curvas ZFC e transições de fase em cristais líquidos liotrópicos}

Um dos resultados apresentados na dissertação de mestrado [16] é que podemos observar transições de fases em cristais líquidos liotrópicos por meio de curvas ZFC-FC e medidas AC. No entanto, a forma como essa transição se apresenta nas medidas magnéticas pode depender de algumas variáveis como a intensidade do campo magnético aplicado, a taxa de variação da temperatura e até mesmo das dimensões do porta amostra utilizado, o que nos levou a aprofundar os estudos iniciais.

Na figura 4.17 vemos curvas ZFC-FC para a amostra Ami1 com quatro intensidades de campo aplicado: 50, 100, 400 e 2000Oe. Para a curva obtida com campo de 500 e o sino característico da magnetização (que reflete o comportamento do parâmetro de ordem da fase 

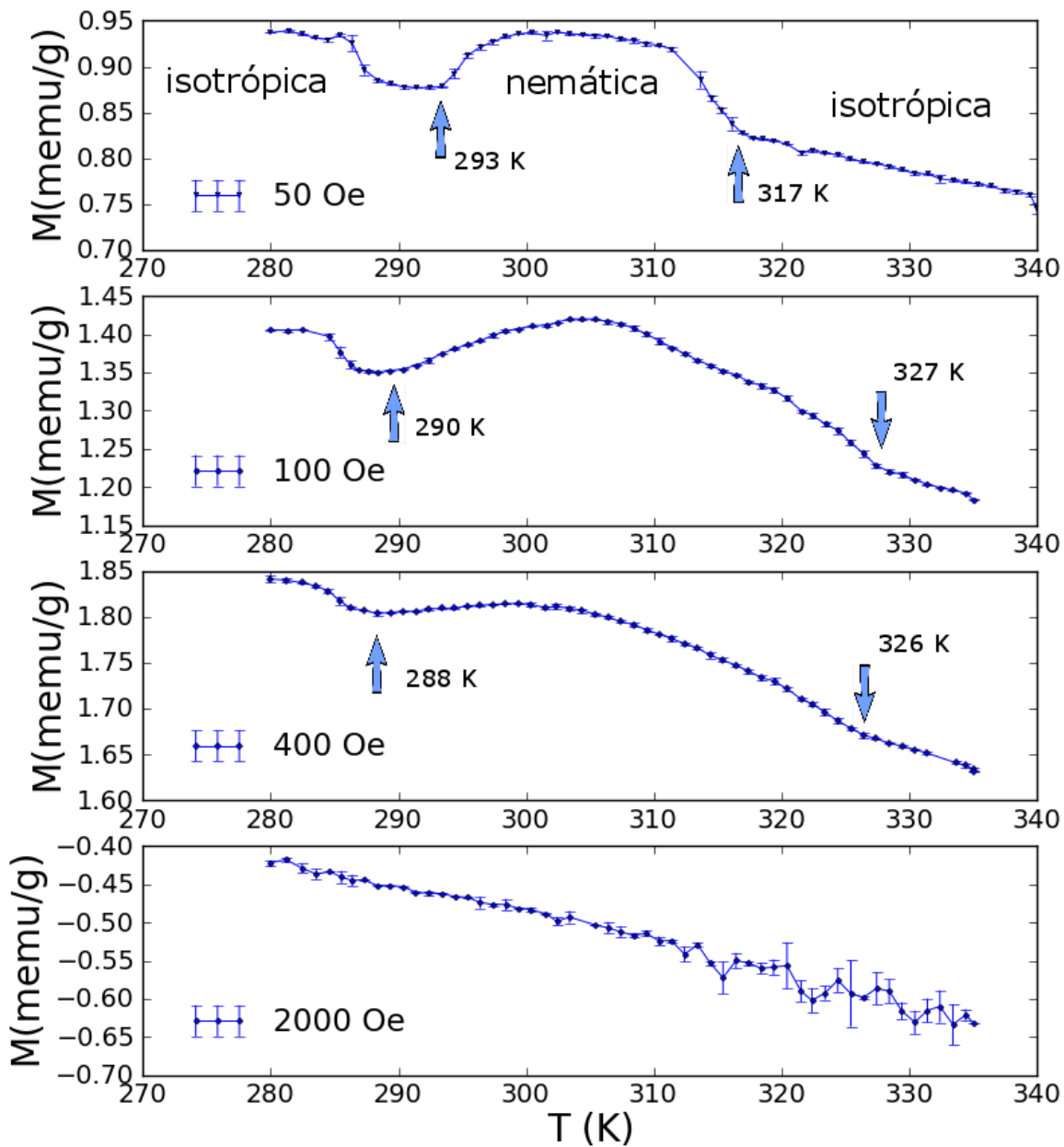

Figura 4.17: Curvas ZFC-FC com campo aplicado de 50, 100, 400 e 2000Oe para a amostra Ami1. 
nemática com a temperatura) pode ser observado claramente entre 293(1) e 317(1)K, no entanto para intensidades maiores de campo a forma desse sino se altera e perde sua intensidade, sendo que na curva medida com $20000 e$ vemos apenas a componente diamagnética do cristal líquido. Quando aumentamos a intensidade do campo magnético, temos uma situação onde é mais fácil de as partículas se alinharem com o campo e assim a influência do ordenamento espacial do cristal líquido na magnetização se torna menos evidente. Outro fato é que as temperaturas onde a magnetização muda seu comportamento, provavelmente devido à transição da fase nemática para a isotrópica, aumentaram de $317(1) \mathrm{K}$ para cerca de $326 \mathrm{~K}$ quando aumentamos a intensidade do campo aplicado. Isso pode ser o efeito do campo magnético no alinhamento das micelas, já que mesmo em uma amostra isotrópica, em uma região de temperatura próxima à transição com a fase nemática, encontramos micelas com uma anisotropia de forma. Assim, se estivéssemos em uma situação onde as micelas possuem uma anisotropia de forma, mas estão distribuídas espacialmente de tal forma que estejam na fase isotrópica, um campo poderia ordenar esse sistema.

Um fato experimental conhecido é que o ordenamento dos cristais líquidos sofre uma grande influência das bordas do recipiente que o contém. Se usarmos porta-amostras muito pequenos, como da ordem de $1 \mathrm{~mm}$ de espessura, os efeitos de borda podem ser mais importantes do que as propriedades de volume. Além dos efeitos de borda, o tempo necessário para fazer a medida de magnetização também pode influenciar a forma da curva, já que temos uma situação onde as partículas estão se alinhando com o campo e com o cristal líquido.

Como nas medidas de ressonância magnéticas ${ }^{3}$ utilizamos como porta-amostra uma pipeta de Pasteur (que possui um diâmetro de menos $1 \mathrm{~mm}$ ), fizemos um estudo para ver se nessa região de tamanho ainda era possível medir a transição entre as fases isotrópica e nemática no cristal líquido. Além disso também fizemos medidas de curvas ZFC com tempos de medidas diferentes (mais longos, com $\Delta T=1 \mathrm{~K}$ e mais curtos $\Delta T=2 K$ ). Na figura 4.18 vemos as curvas $Z F C$, em função do diâmetro do porta amostra utilizado e também em função da variação de temperatura para as amostras Am17 e Am19.

Na figura 4.18 vemos que para a medida mais lenta, $\Delta T=1 K$, a forma do parâmetro de ordem é bem diferente do que na medida mais rápida, $\Delta T=2 K$, para os porta-amostras com diâmetros maiores, sendo que o máximo da magnetização ocorre próximo da transição com a fase isotrópica. Já o diâmetro do porta-amostra, nesses tamanhos estudados, não mostrou ter uma influência na forma das curvas, nem nas temperaturas onde ocorrem as transições de fase.

3 apresentadas na seção $4 \cdot 4$ 
(a)

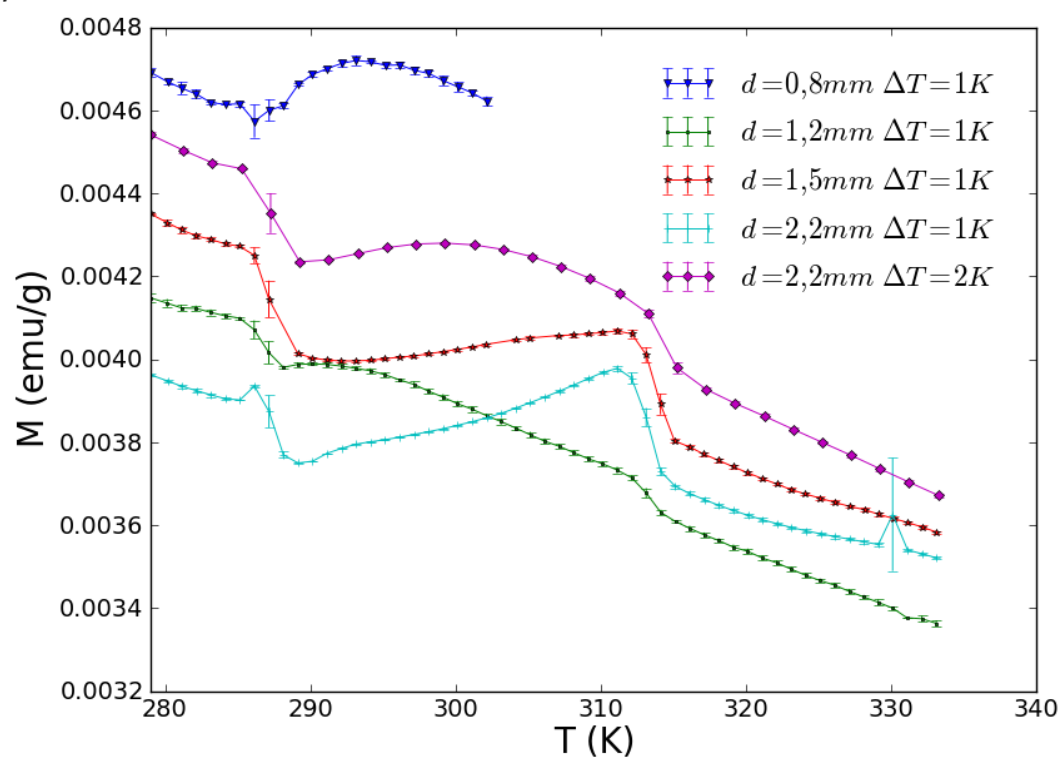

(b)

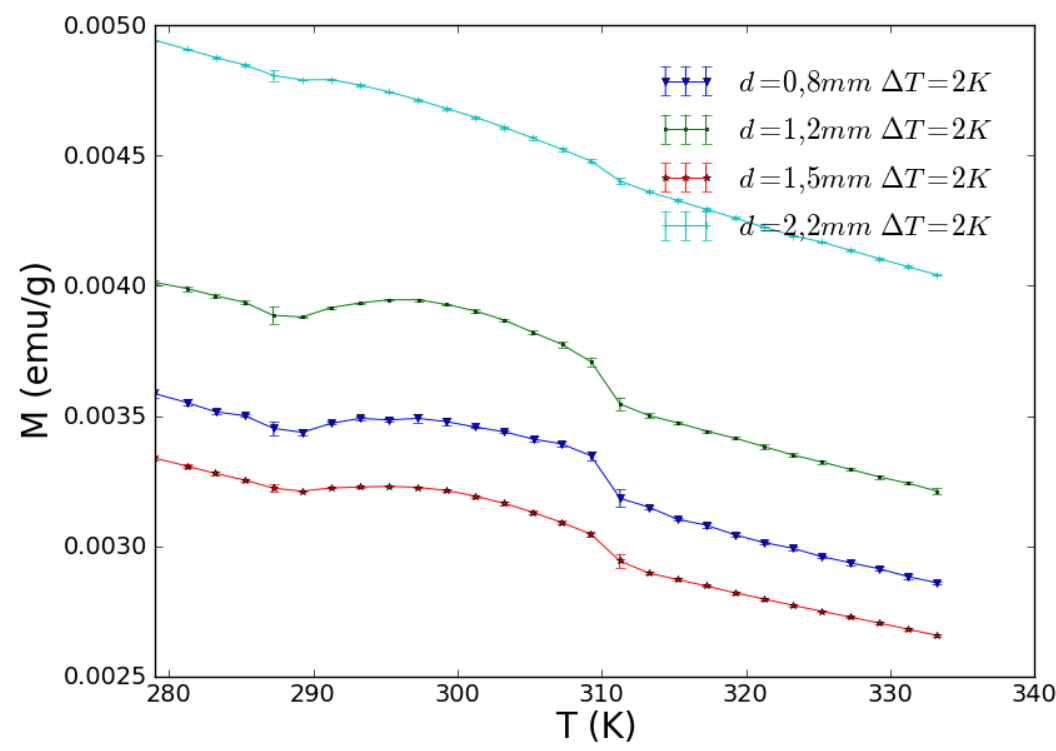

Figura 4.18: Curvas ZFC-FC, com campo aplicado de 50Oe, variando o diâmetro do porta amostra utilizado e a taxa de variação da temperatura para as amostras (a) Am17 e (b) Amig. 


\subsection{RESSONÂNCIA FERROMAGNÉTICA}

Nas seções anteriores ${ }^{4}$ vimos que existe uma diferença no comportamento magnético das nanopartículas, principalmente em baixos campos, quando mudamos o meio em que elas estão dispersas (sólido, líquido isotrópico ou cristal líquido). Medidas de ressonância ferromagnética podem dar informações sobre as anisotropias das nanopartículas, que depende tanto de fatores como seu formato e sua constituição química, quanto da orientação espacial do eixo fácil com campo magnético aplicado. Nos nossos sistemas estamos mais interessados neste último, já que o principal efeito da mudança do meio de dispersão é afetar a orientação e distribuição espacial das nanopartículas. Nessa seção vamos ver como se comporta o espectro de ressonância das nanopartículas do ferrofluido EMG605 quando elas estão diluídas somente em água ou em um cristal líquido liotrópico.

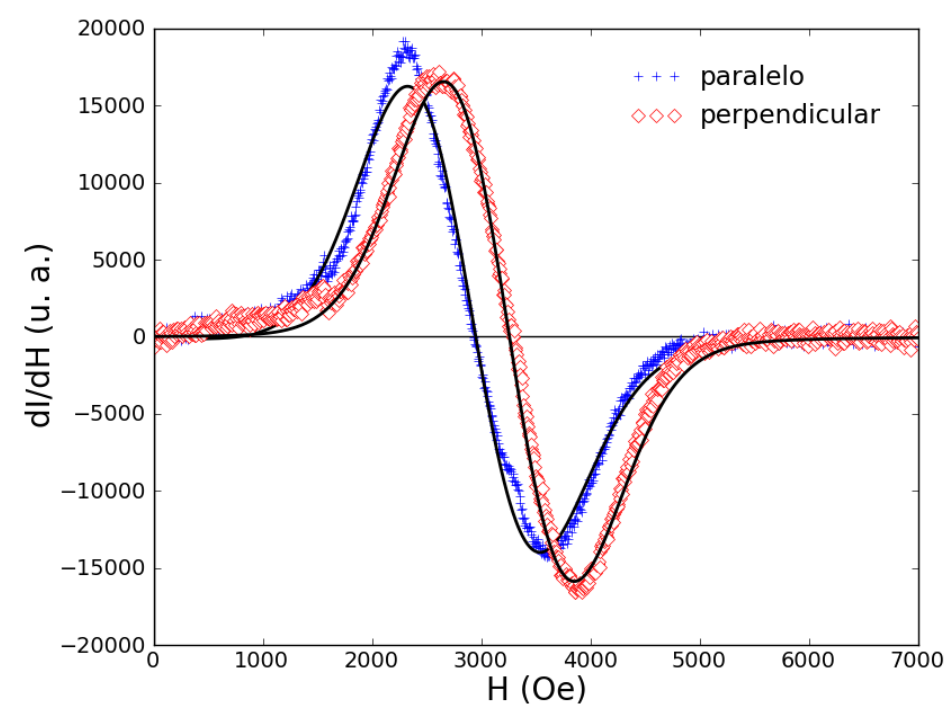

Figura 4.19: Espectros na banda X para a amostra EMG605-1\% congelada a $233 \mathrm{~K}$ com um campo aplicado de $1.5 T$. Foram tomados espectros na direção paralela e perpendicular ao campo aplicado. A linha sólida preta representa o ajuste obtido usando a equação $4 \cdot 4$.

Antes de analisar as diferenças nos espectros, é importante conhecer quanto é contribuição da anisotropia intrínseca das partículas no valor do campo de ressonância de um espectro. Uma maneira simples de estimar esse campo é congelar a amostra com um campo aplicado e tomar o espectro na direção paralela e perpendicular. Na figura 4.19 vemos os espectros obtidos a $233 \mathrm{~K}$ na banda $\mathrm{X}(f=9,40 \mathrm{GHz})$, depois de a amostra EMG605-1\% ter sido congelada sob campo aplicado de

4 Nessa seção só apresentaremos medidas de ressonância com amostras dopadas com o ferrofluido EMG605, pois essas medidas foram realizadas em abril de $2011 \mathrm{em}$ Bariloche e na época não estávamos estudando o ferrofluido EMG9o9. 
1.5T. Para encontrar o campo de anisotropia $H_{A}$, podemos usar a equação 3.32 tomando $\phi=0$ e $\phi_{n}=0$, no caso paralelo, e $\phi_{n}=\pi / 2$, no caso perpendicular. Chamando o campo de ressonância no espectro tomado na direção perpendicular de $H_{\perp}$, e $H_{\|}$na direção paralela, encontramos as seguintes expressões:

$$
\begin{aligned}
& \frac{\omega}{\gamma}=H_{\|}+H_{A} \\
& \left(\frac{\omega}{\gamma}\right)^{2}=H_{\perp}\left(H_{\perp}-H_{A}\right)
\end{aligned}
$$

Das expressões acima é possível obter o valor do campo de anisotropia $H_{A}$. Usando os valores obtidos dos espectros, $H_{\perp}=3232(10) O e$ e $H_{\|}=2854(10) O e$ encontramos um campo de anisotropia $H_{A}$ de 250(9)Oe a 233K. Com os resultados dos diâmetros médios obtidos das imagens de microscopia (seção 4.1.1), podemos estimar o campo devido à anisotropia de forma das partículas usando a relação:

$$
H_{A}=4 \pi M \Delta N
$$

sendo $M$ a magnetização da partícula e $\Delta N$ a diferença entre os fatores desmagnetizantes em duas direções ortogonais. Considerando $M=480 \mathrm{emu} / \mathrm{cm}^{3}\left[{ }_{17}\right]$ e as partículas como esferoides prolatos (semieixos $b=c<a$ ), podemos calcular o valor $\Delta N=N_{a}-N_{c}$ por meio de equações existentes na literatura [120] e estimar o campo de anisotropia como sendo $H_{A}=2740 e$, um valor que é compatível com o valor de $H_{A}$ encontrado por meio dos espectros.

Na figura 4.20 vemos o espectro na banda $X$ para alguns valores de temperatura e os melhores ajustes obtidos (linha sólida preta) para a amostra Am11. Para fazer o ajuste dos espectros de ressonância consideramos a intensidade do sinal como sendo de forma lorentziana e uma composição de absorção e dispersão [121], devido à grande quantidade de água, que faz com que a microonda seja atenuada [122] dentro da amostra. Como em princípio as nanopartículas estão livres para rotacionar dentro do líquido, usamos como peso uma distribuição gaussiana de desvio padrão $\sigma$ e centro $\left\langle H_{\text {res }}\right\rangle$. Assim, cada espectro a uma dada temperatura, foi ajustado pela expressão: 


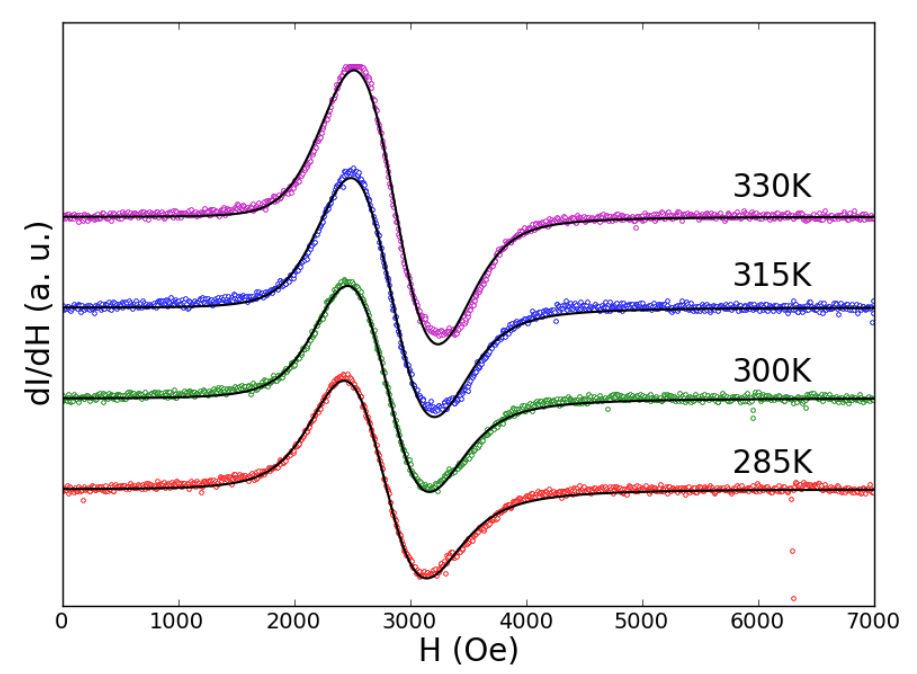

Figura 4.20: Espectro de ressonância na banda X para a amostra Amı1 para alguns valores de temperatura. A linha sólida preta representa o melhor ajuste obtido para cada temperatura.

$$
\begin{aligned}
\frac{d I}{d H}=A \frac{-\Gamma}{\sigma \pi \sqrt{2 \pi}} \int & \left\{p \frac{\left(H-H_{\text {res }}\right)}{\left[\left(H-H_{\text {res }}\right)^{2}+(\Gamma / 2)^{2}\right]^{2}}\right. \\
& \left.-(1-p) \frac{(\Gamma / 2)^{2}-\left(H-H_{r e s}\right)^{2}}{2(\Gamma / 2)\left[\left(H-H_{r e s}\right)^{2}+(\Gamma / 2)^{2}\right]^{2}}\right\} \\
& \exp \left(\frac{-\left(H_{r e s}-<H_{\text {res }}>\right)^{2}}{2 \sigma^{2}}\right) d H_{\text {res }}
\end{aligned}
$$

sendo as variáveis do ajuste o campo de ressonância médio $\left\langle H_{\text {res }}\right\rangle$, a constante multiplicativa $A$ (relacionado à intensidade do sinal), a largura da lorentziana $\Gamma$, o desvio padrão $\sigma$ da gaussiana e a porcentagem $p$ da contribuição da absorção para o sinal medido. Mantendo essas variáveis no ajuste, estamos considerando que temos uma distribuição de campos de ressonância $H_{\text {res }}$. Isso pode ser entendido lembrando que as partículas estão livres para girar dentro do fluido e dependendo do ângulo entre seu eixo fácil e o campo aplicado temos um valor diferente de $H_{\text {res }}$ para cada partícula 5 .

Na figura 4.21 vemos os parâmetros $\left\langle H_{\text {res }}\right\rangle$, $\Gamma$ e $\sigma$ ajustados para vários valores de temperatura para as amostras Am11 e EMG605-1\%. Usando os resultados do ajuste a $300 \mathrm{~K}$ para a amostra Ami1 temos um campo de ressonância médio de 2765(10)Oe. Usando a equação 3.26 podemos estimar qual seria o campo de ressonância esperado para a magnetita na banda $X$ se não tivéssemos nenhuma fonte de ani-

5 Isso sem considerar as outras variáveis possíveis, como anisotropia de forma e tamanho, que varia de partícula para partícula. 
sotropia. Usando o fator $g=2,12$ da magnetita [123, 124], e a frequência de banda $f=9,40 \mathrm{GHz}$ encontramos um campo de 3170Oe. A discordância entre este valor e o valor obtido para a amostra Amı1 é de cerca de 4000 e, um valor que é da ordem de grandeza do campo devido à anisotropia de forma das nanopartículas.

Agora vamos analisar na figura 4.21 a dependência dos parâmetros ajustados com a temperatura para as duas amostras. O primeiro gráfico mostra o aumento do campo de ressonância médio $\left\langle H_{\text {res }}\right\rangle$ com o aumento da temperatura. Isto está relacionado ao decréscimo da anisotropia efetiva das partículas devido às flutuações térmicas no regime superparamagnético [104], assim o campo devido a essa anisotropia é menor e portanto o campo de ressonância se desloca para valores maiores. Vemos também que a curva para as amostras Ami1 e EMG605-1\% são compatíveis, o que indica que a principal fonte de anisotropia que temos nessas amostras é devido às características magnéticas das partículas e não ao meio em que elas estão inseridas.

No gráfico central da figura 4.21 vemos um decréscimo na largura de linha dos espectros com a temperatura que representa o efeito do aumento do movimento das partículas, que na média tendem a suprimir a anisotropia a altas temperaturas. Nesse gráfico vemos que a curva para as duas amostras não é compatível. Alguns trabalhos mostram que interações entre partículas tem como efeito aumentar a largura de linha dos espectros de ressonância principalmente quando envolve a formação de cadeias de partículas [108, 110], enquanto que um sistema onde os eixos de anisotropia estão mais orientados com o campo magnético mostram espectros mais estreitos [109]. Levando esses fatos em conta podemos ter duas explicações para essa diferença nos valores de $\Gamma$ : na amostra de cristal líquido, as partículas tendem a ficar mais afastadas uma das outras e portanto tem uma interação menor entre elas (assim como vimos nas curvas $\Delta m$ no capítulo 5.3), o que leva a um estreitamento do espectro. Outra hipótese é que esse estreitamento do espectro pode ser um sinal do efeito do confinamento espacial que o ordenamento das micelas do cristal líquido impõe nas nanopartículas.

Por fim, o último gráfico da figura 4.21 mostra que o desvio padrão da distribuição gaussiana aumenta com o aumento da temperatura, já que as partículas ganham mais energia térmica para se movimentarem dentro do líquido. Uma informação que não pudemos ver com as medidas de ressonância é a transição de fase dos cristais líquidos, devido ao uso de campos muito intensos para observar a ressonância.

Além das ressonâncias na banda $X$, também tomamos espectros usando a banda $\mathrm{L}$ (frequência de ressonância 1.15G $\mathrm{Gz}$ ), onde vemos na figura 4.22 os espectros para as amostras Ami1 e EMG605-1\%. Para essa banda, a anisotropia das partículas era grande o suficiente para que não pudéssemos ver todo o espectro, desse modo não pudemos fazer a mesma análise que fizemos com a banda X. No entanto, apesar 

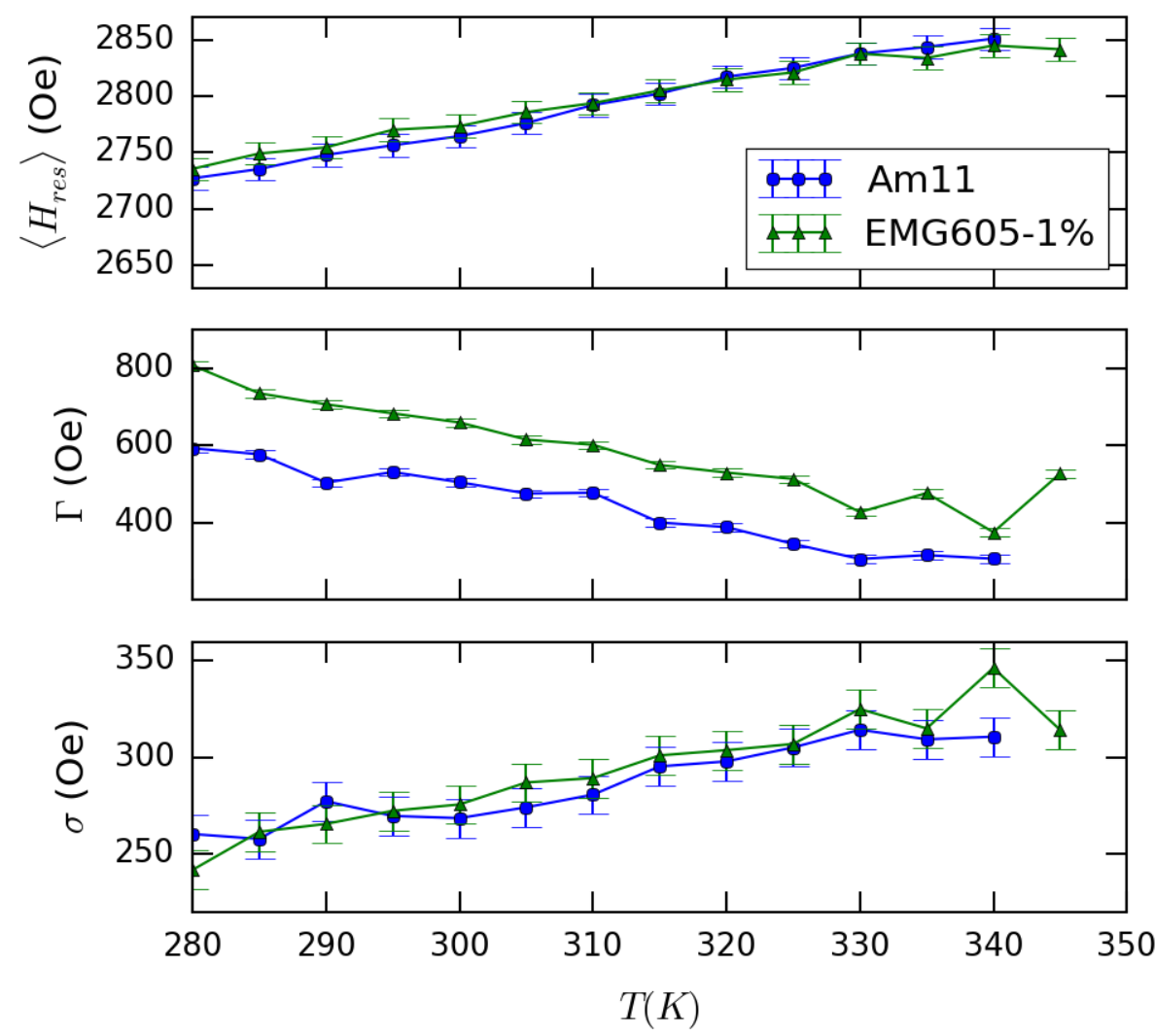

Figura 4.21: Parâmetros $\left\langle H_{\text {res }}\right\rangle$, $\Gamma$ e $\sigma$ retirados dos ajustes dos espectros de ressonância na banda $X$, a vários valores de temperatura, para as amostras Ami1 e EMG605-1\%. 
do meio espectro, podemos ver que nessa banda a largura de linha $\Gamma$ da amostra de cristal líquido é claramente menor do que a da amostra EMG605-1\%, servindo então como uma confirmação dos resultados obtidos para banda $\mathrm{X}$.

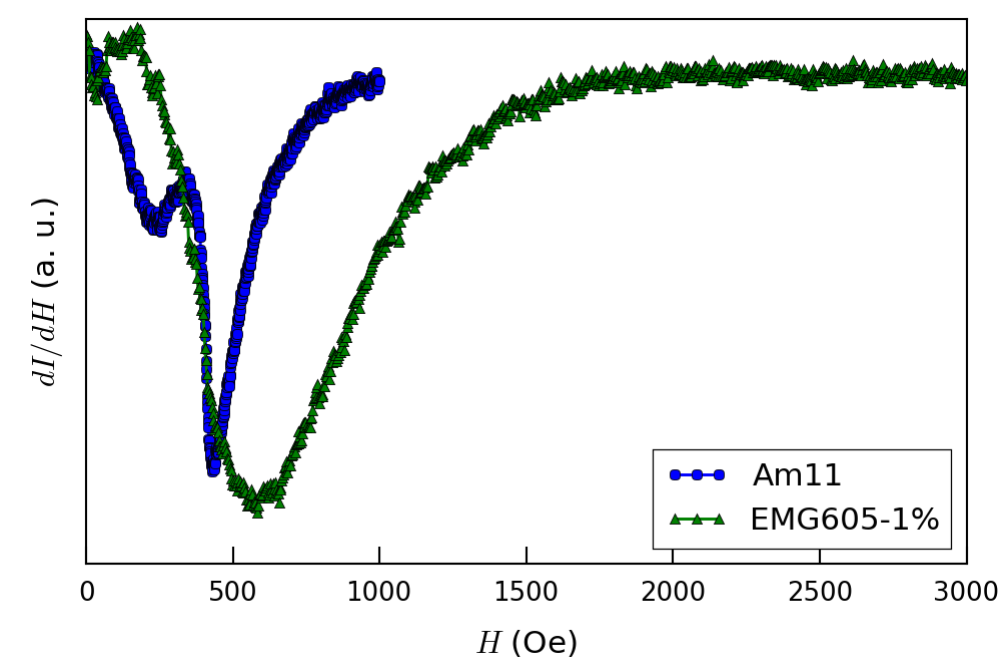

Figura 4.22: Espectro de ressonância na banda L (frequência de ressonância 1,15G Hz) para as amostras Ami1 e EMG605-1\%.

\subsection{EFeito magnetoviscoso em amostras micelares iso- TRÓPICAS}

O efeito magnetoviscoso, ou simplesmente MVE (acrônimo do termo em inglês magnetoviscous effect), se manifesta como uma mudança na viscosidade de uma suspensão de nanopartículas na presença de um campo magnético. Esse efeito ocorre devido às estruturas microscópicas que as nanopartículas formam no líquido onde estão suspensas, em geral longas cadeias em forma de agulha, na presença deste campo. Amostras de ferrofluidos foram muito estudadas nos últimos anos para explicar o MVE, mas nesse trabalho mostramos que esse efeito também pode ser observado em soluções micelares dopadas com nanopartículas magnéticas. Acreditamos que nesse sistema quando as partículas formam estruturas para se alinharem com o campo acabam induzindo uma mudança no comportamento reológico das micelas, que se manifesta como um aumento da viscosidade. A indução de ordem em sistemas micelares devido à introdução de nanopartículas magnéticas e aplicação de um campo externo é bem conhecido na literatura, no entanto a observação da manifestação desse efeito em medidas reológicas é recente e inédito no sistema que escolhemos para estudar: soluções isotrópicas micelares de laurato de potássio e água. Lembramos que esse trabalho foi desenvolvido 
na Technische Universität Dresden na Alemanha sob supervisão do professor Stefan Odenbach.

Iniciamos esta seção falando sobre a preparação das amostras e os equipamentos utilizados. Na parte de resultados, mostramos primeiramente a caracterização reológica dos sistemas micelares sem campo aplicado e posteriormente prosseguimos com a determinação da intensidade do efeito magnetoviscoso nos dois ferrofluidos usados para dopar as amostras. Finalmente apresentamos os resultados para as amostras isotrópicas dopadas com o ferrofluido e a caracterização por espalhamento dinâmico de luz.

\subsubsection{Preparação das amostras e equipamentos}

Preparamos as soluções micelares isotrópicas estudadas nesse projeto dissolvendo laurato de potássio (LK) em água destilada em diversas concentrações. A concentração das amostras, em porcentagem em massa de LK, variou de 5 a $34 \%$. Essas amostras foram dopadas com dois ferrofluidos a base de água e polidispersos, o comercial EMG605 da Ferrotec e o ferrofluido FFo59L preparados pelo Dr. Rainer Tietze da Universitätsklinikum Erlangen, Alemanha.

Para a caracterização reológica das amostra, em campo nulo, utilizamos um reômetro comercial rotacional Anton Paar Physica MCR 301, usando uma geometria de placas paralelas com diâmetro de $50 \mathrm{~mm}$ e distância entre as placas de $1.00 \mathrm{~mm}$. O efeito magneto viscoso nas amostras foi estudado em um reômetro rotacional especialmente projetado para estudar fluidos magnéticos [69], usando uma geometria de placas paralelas com diâmetro de $76 \mathrm{~mm}$ e distância entre as placas de $0.6 \mathrm{~mm}$ para as soluções micelares e $0.6 \mathrm{~mm}$ para os ferrofluidos puros e campo magnético aplicado de $25 \mathrm{kA} / \mathrm{m}$. As medidas foram realizadas a $20^{\circ} \mathrm{C}$ e uma cobertura contendo algodão embebido com água foi utilizada em ambos os reômetros para prevenir a evaporação das amostras.

Determinamos a concentração de partículas magnéticas nos ferrofluidos a partir de curvas de magnetização medidas em um magnetômetro de amostra vibrante da Lakeshore. Medidas utilizando espalhamento dinâmico de luz (DLS) foram realizadas em um equipamento HPPS (Malvern Instruments Inc.) para determinar a influência da concentração de laurato de potássio no tamanho dos aglomerados de partículas magnética após a dopagem das amostras.

\subsubsection{Caracterização reológica das amostras isotrópicas}

Antes de caracterizarmos o efeito magnetoviscoso em uma amostra é importante conhecer como é o seu comportamento reológico na ausência de campo aplicado. Para nossas amostras esperamos um comportamento newtoniano, ou seja, a tensão de cisalhamento $\tau$ deve 
ser proporcional à taxa de cisalhamento $\dot{\gamma}$, sendo que o coeficiente de proporcionalidade dá a viscosidade do fluido.

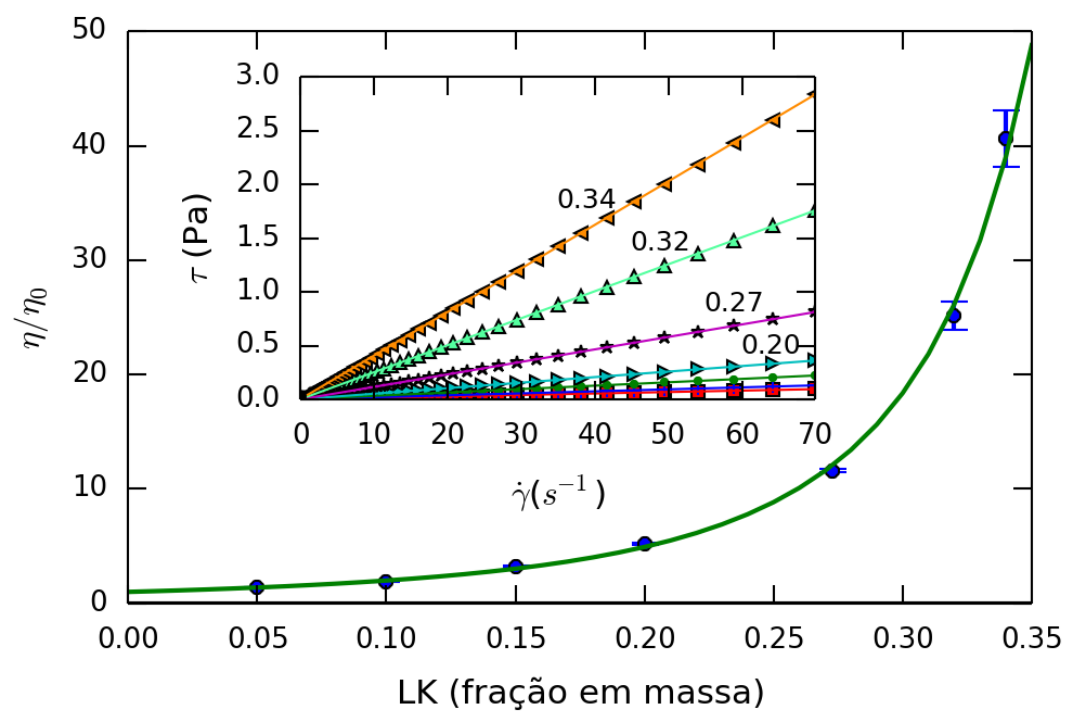

Figura 4.23: Razão da viscosidade $\eta / \eta_{0}$ das amostras isotrópicas na ausência de campo aplicado como função da fração em massa de laurato de potássio. Painel interno: Dependência da tensão de cisalhamento $\tau$ com a taxa de cisalhamento $\dot{\gamma}$ para concentrações crescentes de laurato de potássio. Cada curva corresponde a um ponto da viscosidade no gráfico principal, sendo que a viscosidade aumenta com a concertação de LK.

Na ausência de campo magnético, como esperado as amostras apresentam um comportamento newtoniano no intervalo de taxa de cisalhamento $\dot{\gamma}$ estudado, como podemos ver pela dependência linear da tensão de cisalhamento $\tau$ com $\dot{\gamma}$ no painel interno da figura 4.23. No gráfico principal dessa figura vemos que a viscosidade para essas amostras, extraídas do coeficiente angular das curvas $\tau \times \dot{\gamma}$, rapidamente aumenta com o aumento da concentração de laurato de potássio. Esse comportamento pode ser ajustado pela equação de KriegerDougherty para uma suspensão de esferas rígidas [125], dada por:

$$
\frac{\eta}{\eta_{0}}=\left(1-\frac{\Phi}{\Phi_{m}}\right)^{-[\eta] \Phi_{m}}
$$

onde $\eta$ é a viscosidade da mistura, $\eta_{0}$ a viscosidade do meio (nesse caso a água), $\Phi$ a fração volumétrica de sólidos da mistura, $\Phi_{m}$ a fração máxima de empacotamento (que no caso de esferas é de 63\%) e $[\eta]$ a viscosidade intrínseca (2.5 para esferas). Para o ajuste estimamos $\Phi$ como a concentração em massa de laurato de potássio nas amostras, pois a densidade dessas soluções pode ser aproximada pelo valor da densidade da água. Com essa consideração encontramos valores de $0.476(18)$ para $\Phi_{m}$ e $6.15(23)$ para $[\eta]$. Valores de $[\eta]$ maiores do que 
2.5 estão associados a uma assimetria das partículas [126], e indicam que o formato das micelas sob ação do cisalhamento não é esférico.

\subsubsection{Ferrofluidos}

Para estudar o efeito magnetoviscoso nas soluções micelares usamos dois ferrofluidos para dopar as amostras, o já mencionado EMG605 da Ferrotec com uma concentração de partículas de 3.0Vol.\% e um fornecido por colaboradores que chamaremos de FFo59L com concentração de $0.1 \mathrm{Vol} . \%$. Os dois ferrofluidos são a base de água e polidispersos com nanopartículas de magnetitas. Ferrofluidos a base de água são conhecidos por sua tendência à aglomeração das partículas, um efeito que pudemos observar em medidas de espalhamento dinâmico de luz (DLS do termo em inglês dynamic light scattering) para os dois ferrofluidos. Na figura 4.24 de intensidade de luz espalhada pelas amostras vemos que o tamanho dos aglomerados variam de 40 a $300 \mathrm{~nm}$ para os dois ferrofluidos.

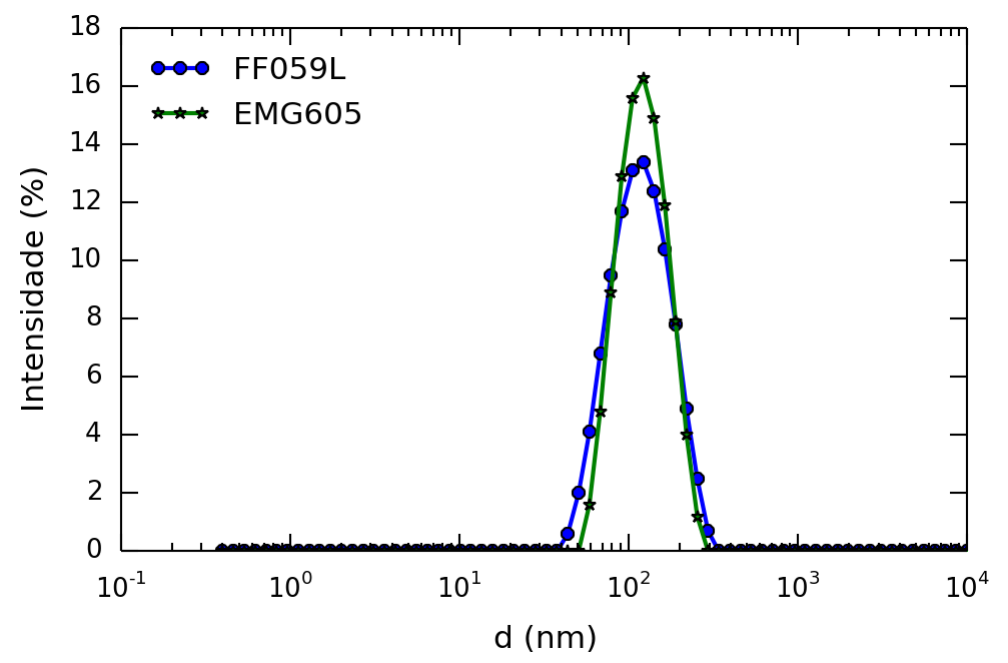

Figura 4.24: Curvas de intensidade obtidas por medidas DLS para os ferrofluidos EMG605 e FFo59L.

Para fluidos magnéticos, o efeito magnetoviscoso pode ser quantificado pela porcentagem $R$ dada por:

$$
R=\frac{\eta(H)-\eta(0)}{\eta(0)} \times 100
$$

onde $\eta(0)$ e $\eta(H)$ são as viscosidades do fluido com e sem campo aplicado, respectivamente.

Na figura 4.25 vemos a dependência de $R$ com $\dot{\gamma}$ e um campo aplicado de $25 \mathrm{kA} / \mathrm{m}$ para os ferrofluidos EMG605 e FFo59L. Como esperado, $R$ diminui com o aumento de $\dot{\gamma}$, pois o cisalhamento perturba a formação das estruturas que as nanopartículas formam na presença 


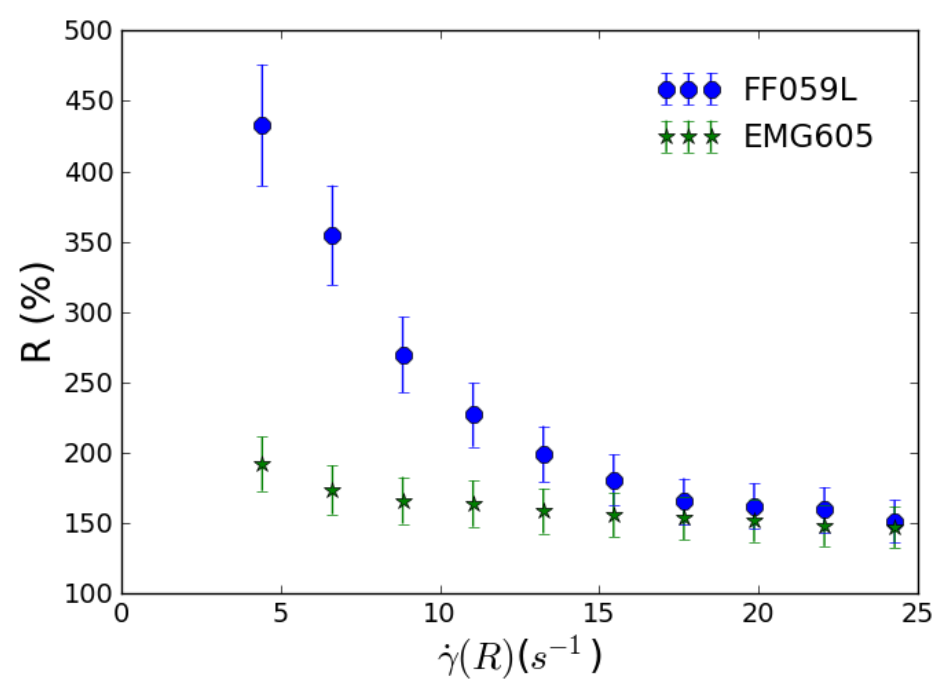

Figura 4.25: Efeito magnetoviscoso para os ferrofluidos EMG605 e FFo59L com campo aplicado de $25 \mathrm{kA} / \mathrm{m}$.

do campo e que são as responsáveis pelo aumento da viscosidade $\eta(H)$. Vemos que, para os valores menores de $\dot{\gamma}, R$ é cerca de $200 \%$ para o ferrofluido EMG605 e $400 \%$ para o FFo59L, o que podemos considerar como um efeito forte comparado a outros valores da literatura [127].

\subsubsection{Efeito magnetoviscoso em soluções isotrópicas dopadas com nanopar- tículas}

Estudamos o efeito magnetoviscoso em soluções com concentrações em massa de laurato de potássio entre 20 e $34 \%$, pois para amostras menos concentradas a viscosidade era muito baixa para a sensibilidade do sensor de torque do reômetro. Vemos a dependência de $R$ com $\dot{\gamma}$ para as amostras dopadas com os ferrofluidos EMG605 e FFo59L, com uma concentração final de nanopartículas de 5.0(5) $\times$ $10^{-3}$ e $2.0(2) \times 10^{-3}$ Vol.\%, respectivamente, na figura 4.26. Essas curvas mostram que a magnitude de $R$ é cerca de 40 a $50 \%$ para taxas de cisalhamento pequenas, mas se compararmos esses valores com o MVE para os ferrofluidos que mostramos na figura 4.25, constitui uma redução de uma ordem de grandeza na magnitude de $R$ para uma redução em três ordens de grandeza na concentração de partículas magnéticas. Isso indica que além da interação das partículas com o campo, também devemos ter uma resposta das micelas a esse ordenamento.

Outro ponto que podemos observar na figura 4.26 é que o MVE é mais alto para amostras com uma concentração menor de laurato de 

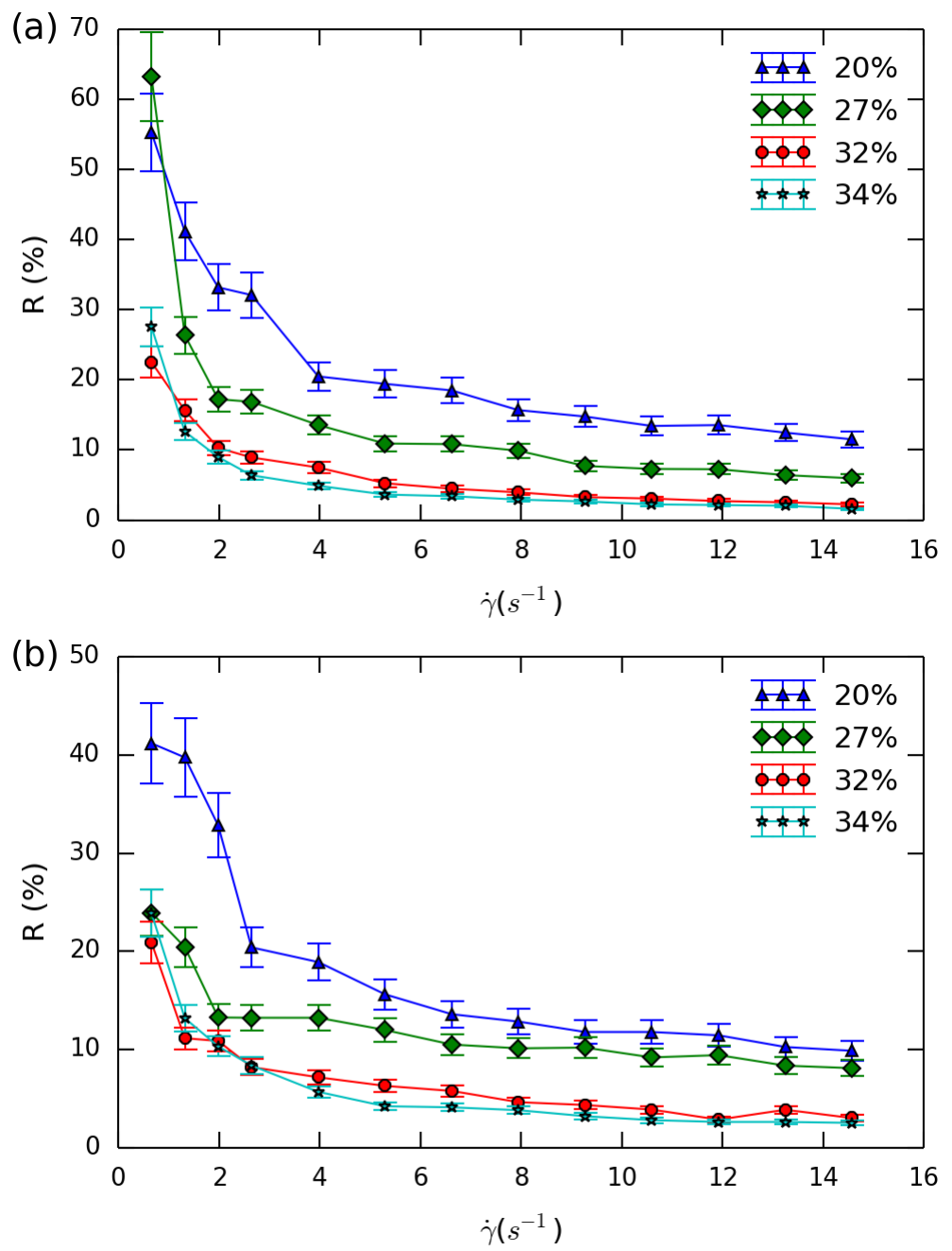

Figura 4.26: Magnitude do MVE, $R$, como função de $\dot{\gamma}$, para algumas concentrações de LK para amostras dopadas com os ferrofluidos (a) EMG605 e (b) FFo59L e campo aplicado de $25 \mathrm{kA} / \mathrm{m}$. 
potássio. Para investigar esse ponto, realizamos medidas de espalhamento dinâmico de luz para determinar a dependência dos aglomerados de partículas como uma função da concentração de LK e de partículas magnéticas.

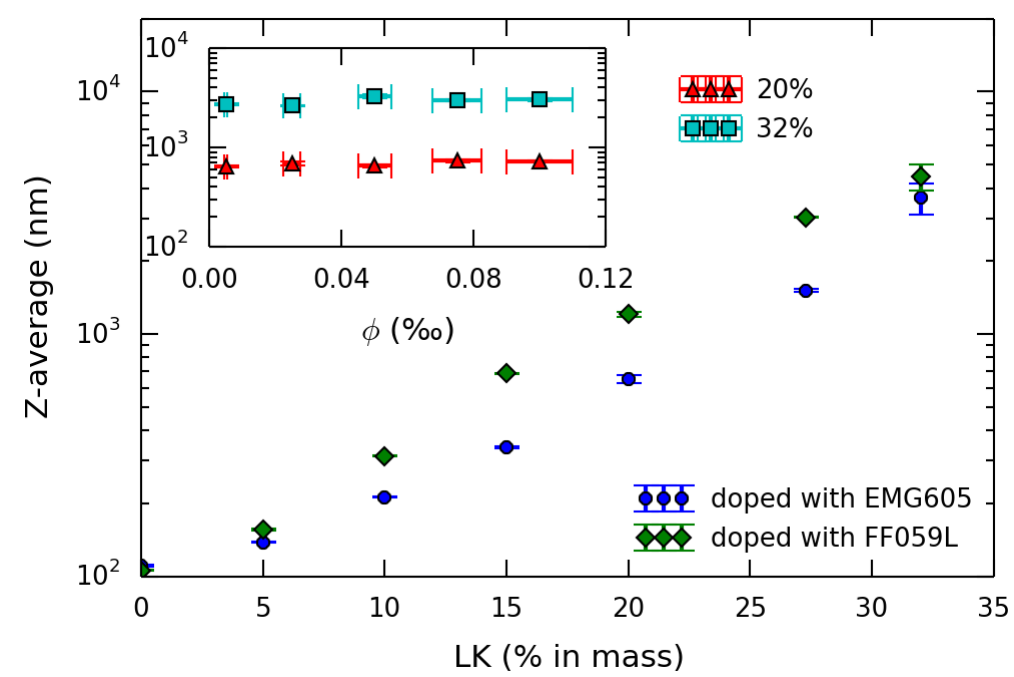

Figura 4.27: Principal: Dependência de Z-average com a concentração de LK para os ferrofluidos EMG605 e FFo59L. Painel interno: valores de Z-average como função da concentração de partículas magnéticas, $\phi$, para amostras com concentrações de laurato de potássio entre 20 e $32 \%$ e dopadas com o ferrofluido EMG605.

Na figura 4.27 vemos o parâmetro Z-average, uma quantidade calculada a partir da média da curva de intensidade resultante do espalhamento de luz e que é um resultado primário desse tipo de experimento, como uma função da concentração de LK (gráfico principal) e de partículas magnéticas $\phi$ (painel interno). Podemos ver que, para os dois ferrofluidos, concentrações mais altas de LK levam a valores mais altos de Z-average, o que está diretamente associado à existência de aglomerados maiores, ainda que esse valor não é uma medida direta do tamanho médio dos aglomerados para uma amostra polidispersa. Por exemplo, uma estimativa do tamanho médio dos aglomerados, usando a teoria de Mie [128] para as amostras com 5 e $32 \%$ de LK são de 85 e $1400 \mathrm{~nm}$, respectivamente. Quando o tamanho dos aglomerados aumenta para uma concentração fixa de partículas magnéticas, devemos ter que o número final de aglomerados é menor para amostras com uma maior concentração de LK, o que explica a diminuição de $R$ para amostras com mais laurato de potássio que podemos observar no gráfico 4.26.

Por outro lado, a concentração de partículas magnéticas $\phi$ não afeta o tamanho médio de aglomerados, como podemos ver no painel interno da figura 4.27, que mostra que Z-average para amostras dopadas com o ferrofluido EMG6o5 não muda com variação em $\phi$. Esse mesmo padrão foi confirmado para o ferrofluido FFo59L. 
Em geral o efeito magnetoviscoso é mais intenso quanto maior for a concentração de partículas magnéticas, o que vale para as amostras estudadas nesse trabalho, como pode ser visto na figura 4.28, para duas amostras com duas concentrações de LK. Vemos que as soluções isotrópicas micelares têm um grande efeito na magnitude do MVE, pois $R$ chega a atingir $140 \%$ para uma concentração de partículas magnéticas de $0.01 \%$ (figura $4.28 \mathrm{a}$ ), um valor que requer uma concentração de 3\% para o ferrofluido EMG605 em sua forma pura (figura 4.25).
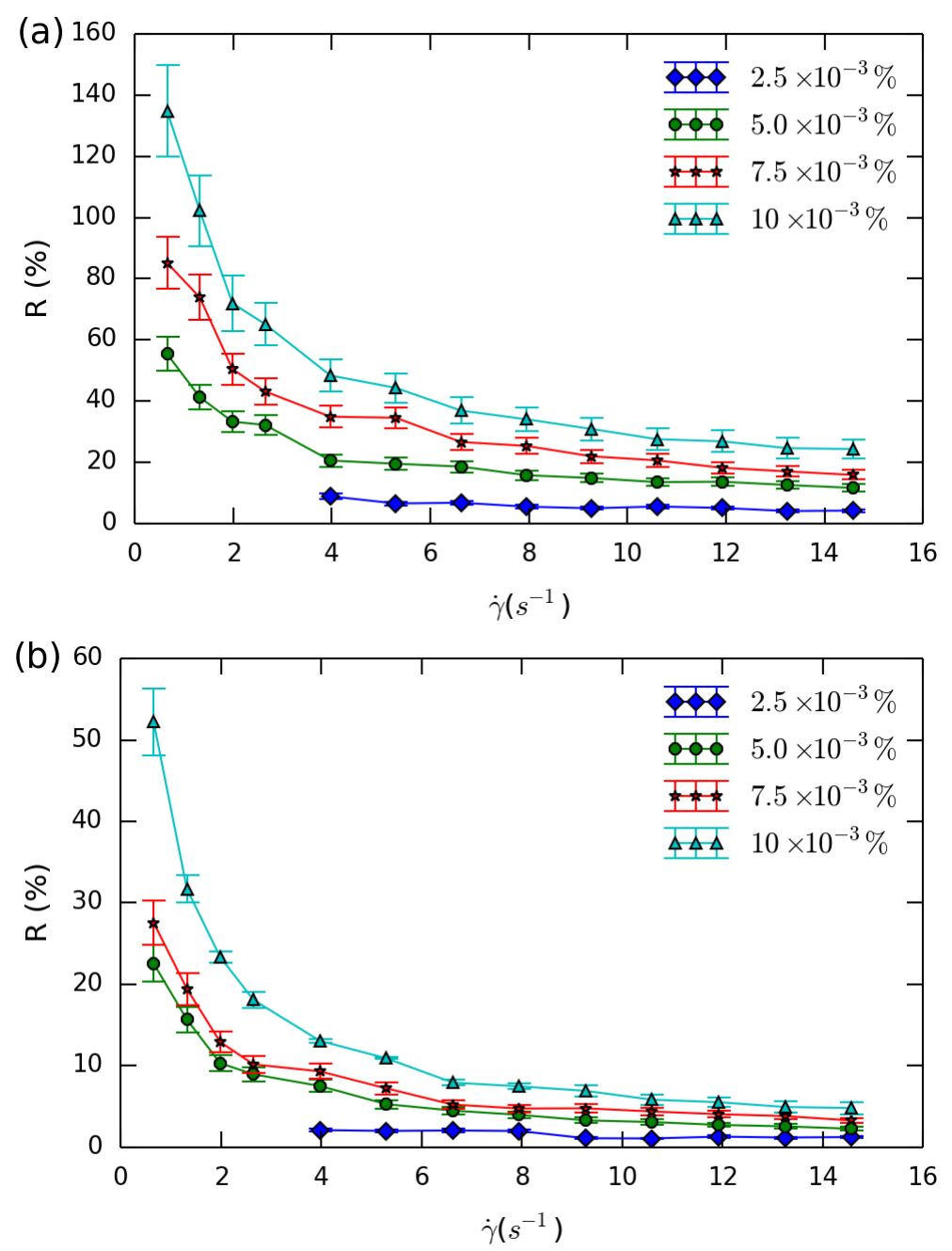

Figura 4.28: Magnitude de MVE, $R$, como função de $\dot{\gamma}$, para algumas concentrações de partículas magnéticas e concentrações de LK de (a) $20 \%$ e (b) $32 \%$.

Entendemos o efeito magnetoviscoso considerando que, na presença de um campo magnético, as partículas formam estruturas dentro do líquido que se alinham com o campo, levando a um aumento na viscosidade. Para sistemas muito diluídos, esse efeito não poderia ser observado, já que as partículas não existiriam em número sufici- 
ente para formar essas estruturas. No entanto, em nossas amostras, mesmo para concentrações bem baixas de partículas foi observado um MVE intenso. Isso indica que nessas condições as micelas, mediadas pelos aglomerados de partículas interagindo com o campo, também devem influenciar na mudança de comportamento reológico. Como a viscosidade aumenta com o campo, as micelas devem se alinhar em uma direção distinta do cisalhamento, o que significa que as partículas magnéticas devem induzir um alinhamento das micelas na direção do campo aplicado. 
Neste capítulo apresentamos um estudo das principais propriedades de um conjunto de nanopartículas fixas no espaço. Iniciamos o capítulo com um sistema de nanopartículas não interagentes [129]. Para este sistema mostramos como a passagem de um comportamento magnético ordenado para um desordenado se manifesta em algumas medidas muito usadas para caracterizar sistemas experimentais. Outro ponto que abordamos é como mudanças na camada superficial das nanopartículas podem alterar seu comportamento magnético.

O efeito das interações nas propriedades magnéticas de sistemas de nanopartículas é estudada de três maneiras distintas: inicialmente por meio de um campo médio proporcional à magnetização total do sistema, depois colocando explicitamente o termo de interação dipolar entre as partículas, e por fim considerando o caso onde as nanopartículas podem formar estruturas do tipo dímero e com interação de troca entre os momentos magnéticos superficiais.

\subsection{MÉTODOS}

Nossa simulação consiste em um sistema de nanopartículas magnéticas esféricas, não interagentes e fixas no espaço. Para levar em conta efeitos de superfície, cada partícula é constituída por momentos magnéticos em uma rede cúbica simples, sendo que o número desses momentos varia com o diâmetro da partícula. A figura 5.4 é uma ilustração tridimensional que exemplifica as partículas simuladas.

A simulação segue o algoritmo de Metropolis usando o modelo clássico de Heisenberg para representar cada momento magnético, sendo que a energia destes é dada por:

$$
E_{i}=-\mu_{0} \vec{\mu}_{i} \cdot \vec{H}-\sum_{(j)} \mathcal{J} \cos \theta_{i j}+K_{1} a^{3} \sin ^{2} \theta_{i}
$$

O primeiro termo é a energia Zeeman, onde $\mu_{i}$ é igual a $4.1 \mu_{B}$, o valor do momento magnético de uma célula unitária de magnetita. $\mathrm{O}$ segundo e o terceiro termo são, respectivamente, a energia de troca entre primeiros vizinhos $j$ e a energia magneto-cristalina uniaxial. $\mathrm{O}$ valor real da constante de troca $\mathcal{J}$ para este modelo específico não é conhecido, no entanto, como é possível estimar sua ordem de magnitude [130], adotamos valores entre $10^{-22}$ e $2.3 \times 10^{-21} \mathrm{~J}$. As constantes $K_{1}$ e $a^{3}$ são, respectivamente, a constante de anisotropia cristalina e o volume de uma célula unitária, sendo $K_{1}=2 \times 10^{4} \mathrm{~J} / \mathrm{m}^{3}$ o valor em 
módulo da constante $K_{1}$ para a magnetita a $4.2 \mathrm{~K}$ e $a=0.84 \mathrm{~nm}$, que é o parâmetro de rede da magnetita. As expressões de $\mu_{i}$ e $\vec{H}$ escritas em coordenadas esféricas são:

$$
\begin{array}{r}
\vec{H}=H\left(\sin \theta_{H} \cos \phi_{H} \hat{i}+\sin \theta_{H} \sin \phi_{H} \hat{j}+\cos \theta_{H} \hat{k}\right) \\
\vec{\mu}_{i}=\mu_{i}\left(\sin \theta_{i} \cos \phi_{i} \hat{i}+\sin \theta_{i} \sin \phi_{i} \hat{j}+\cos \theta_{i} \hat{k}\right)
\end{array}
$$

Os valores de $\theta_{H}$, o ângulo entre o eixo fácil e o campo magnético aplicado, são distribuídos uniformemente entre 0 e $\pi$, enquanto que $\phi_{H}$ são sorteados aleatoriamente entre 0 e $2 \pi$, e ambos são mantidos constantes para cada partícula durante a simulação. Com esta escolha queremos reproduzir um sistema onde os eixos fáceis são distribuídos aleatoriamente no espaço. Todas as simulações são iniciadas primeiramente com uma termalização de 5000 passos para cada momento magnético na temperatura inicial da medida. Posteriormente, usamos tipicamente 1000 passos para cada momento magnético durante o restante da simulação. Estes números nos levam a cerca de $10^{6}$ passos para cada partícula a cada nova temperatura, ou campo magnético, dependendo da medida.

Nas três seções seguintes apresentamos os três modelos que usamos para simular as partículas magnéticas.

\subsubsection{Partículas isotrópicas}

Nesta situação a expressão da energia para todos os momentos magnéticos da partícula (superfície e núcleo) é dada pela equação 5.1 e a desordem magnética é proveniente da temperatura e da ausência de vizinhos nos momentos magnéticos superficiais. Na seção 5.2 apresentaremos resultados obtidos com esse modelo.

\subsubsection{Partículas com camada morta superficial}

Para simular partículas com uma camada morta superficial, modificamos a equação 5.1 para os momentos magnéticos superficiais removendo a energia magneto-cristalina e fazendo o valor da constante de troca ser igual a $\mathcal{J}^{\prime}[18]$ :

$$
\begin{aligned}
& E_{i}^{\text {morta }}=-\mu_{0} \vec{\mu}_{i} \cdot \vec{H}-\sum_{(j)} \mathcal{J}^{\prime} \cos \theta_{i j} \\
& \mathcal{J}^{\prime}=\frac{\mathcal{J}}{2}+\Delta \mathcal{J}^{\prime}
\end{aligned}
$$


onde $\mathcal{J}$ é a constante de troca para os momentos do núcleo e $\Delta \mathcal{J}^{\prime}$ é uma variável aleatória com distribuição gaussiana e valor médio $\left\langle\Delta \mathcal{J}^{\prime}\right\rangle=\mathcal{J} / 2.6$ e desvio padrão $\sigma=0.1\left\langle\Delta \mathcal{J}^{\prime}\right\rangle$. Essas relações são tais que a diferença entre $\mathcal{J}$ e a média de $\mathcal{J}^{\prime}$ corresponde a três desvios padrões.

\subsubsection{Partículas com uma camada superficial dura}

Do ponto de vista tecnológico a ideia de magnetos cada vez menores e magneticamente duros é bastante interessante, mas esta condição pode ser limitada por efeitos térmicos. Aqui propomos um modelo onde é possível aumentar o valor da temperatura de ordenamento magnético de nanopartículas. Isto pode ser obtido adicionando uma camada externa com um forte acoplamento com os momentos magnéticos superficiais, criando assim uma camada magneticamente dura na superfície da partícula. Nesta situação a expressão de energia para os momentos superficiais é dada por:

$$
E_{\text {dura }}=-\mu_{0} \vec{\mu}_{i} \cdot \vec{H}-\sum_{(s)} \mathcal{J}^{\prime \prime} \cos \theta_{i s}-\sum_{(j)} \mathcal{J} \cos \theta_{i j}+K_{1} a^{3} \sin ^{2} \theta_{i}
$$

onde $s$ representa a soma sobre toda a camada superficial e $j$ a soma sobre os momentos internos.

\subsection{PROPRIEDADES MAGNÉTICAS DE NANOPARTÍCULAS NÃO IN- TERAGENTES}

Nesta seção mostramos as propriedades magnéticas de um sistema de nanopartículas não interagentes, mostrando como a passagem entre um regime com ordenamento magnético para outro sem se manifesta em algumas medidas magnéticas. A figura 5.I (a) mostra a dependência da magnetização com a temperatura, sem campo magnético aplicado, projetada no eixo fácil da partícula, para uma partícula isotrópica com constante de troca igual a $\mathcal{J}=10^{-22} \mathrm{~J}$. A magnetização diminui com o aumento da temperatura, mas entre 14.9 e $16.0 \mathrm{~K}$ é possível observar oscilações nos valores de magnetização, uma característica que esperamos no regime superparamagnético, que é caracterizado pela inversão da magnetização devido à ativação térmica. O ponto interessante é que a magnitude desta magnetização também diminui com o aumento da temperatura, até se anular. Este comportamento é reproduzido para diferentes sementes, e o resultado médio da amplitude obtido para 100 curvas (e consequentemente 100 sementes diferentes) é mostrado na figura 5.1 (b). Iremos definir esta temperatura onde se inicia a oscilação da magnetização como uma temperatura crítica $T_{C}$ do sistema. 

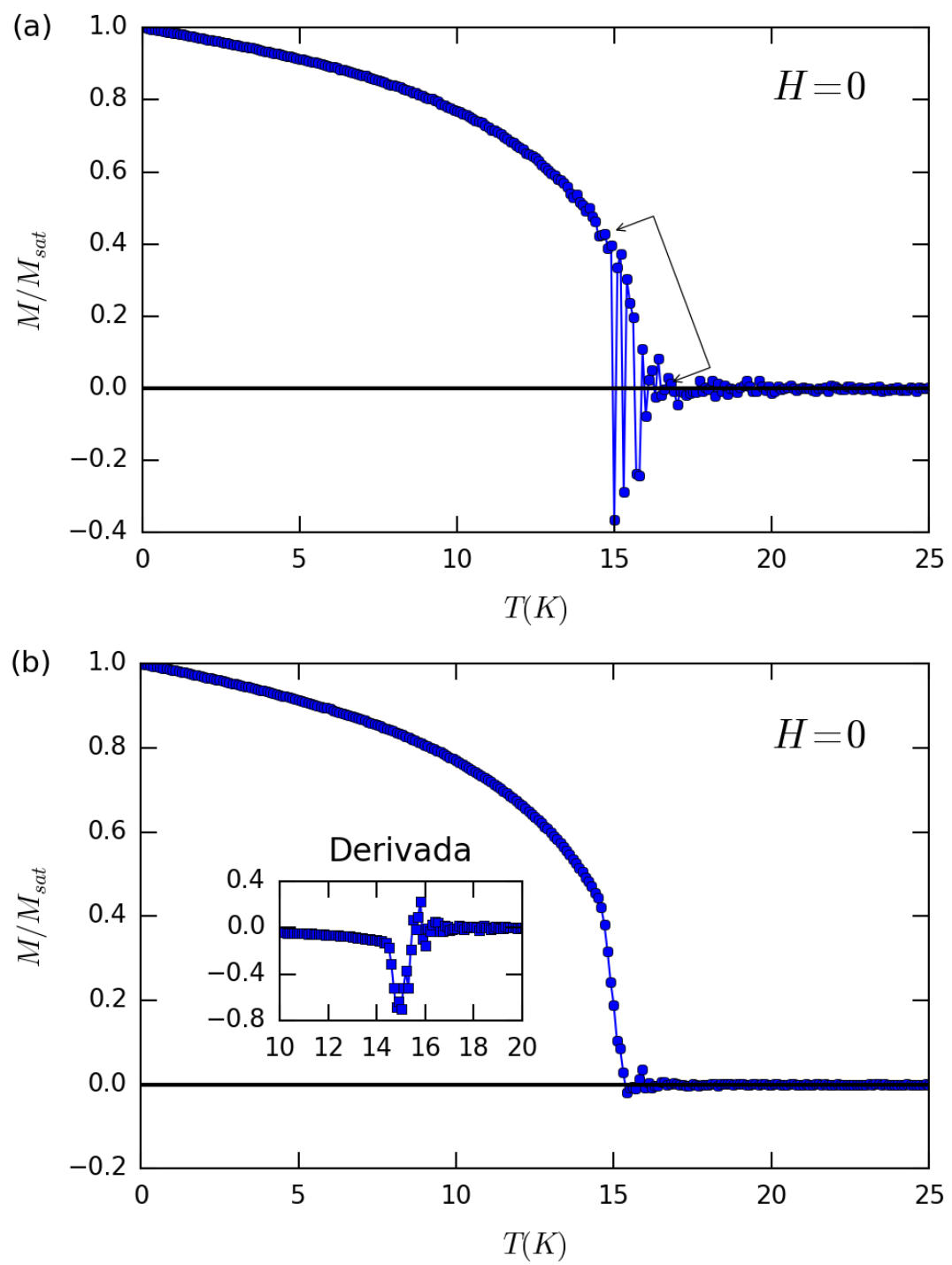

Figura 5.1: (a) Dependência da magnetização com a temperatura para uma única partícula isotrópica com $10 \mathrm{~nm}$ e constante de troca $\mathcal{J}=$ $10^{-22} \mathrm{~J}$. (b) Média das amplitudes de oscilação da magnetização usando 100 curvas diferentes. 
Em um sistema real de nanopartículas o valor da temperatura de bloqueio é tipicamente muito menor do que a temperatura de Curie do material. Nos nossos resultados, no entanto, a temperatura onde se inicia um regime com as mesmas características do regime superparamagnético é muito próxima à temperatura em que a magnetização de uma partícula é nula na ausência de um campo aplicado, que é uma característica do paramagnetismo. Como explicamos no capítulo 2, a temperatura de bloqueio de um sistema depende do tempo de medida, que na simulação de Monte Carlo é muito curto comparado ao tempo de medida de um SQUID, por exemplo. O tempo de medida associado à atualização de um momento magnético na simulação deve estar relacionado ao tempo da dinâmica de spin, que é da ordem de $10^{-9} \mathrm{~s}$, portanto para reproduzir $1 \mathrm{~s}$ seriam necessários $10^{9}$ passos de Monte Carlo, o que é computacionalmente inviável no nosso sistema. Desta forma a janela de temperatura onde observamos um comportamento superparamagnético é muito pequena, o que reflete uma limitação importante deste modelo. Devido a esta limitação, convencionamos chamar a temperatura onde nosso sistema perde o comportamento ferromagnético de temperatura crítica.

Uma característica de um conjunto de partículas superparamagnéticas ou paramagnéticas é a ausência de coercividade. A figura 5.2 (a) mostra ciclos de histerese, a diferentes temperaturas, para um conjunto de 360 partículas. A coercividade diminui com o aumento da temperatura, como mostrado no painel interno, se anulando a $16 \mathrm{~K}$.

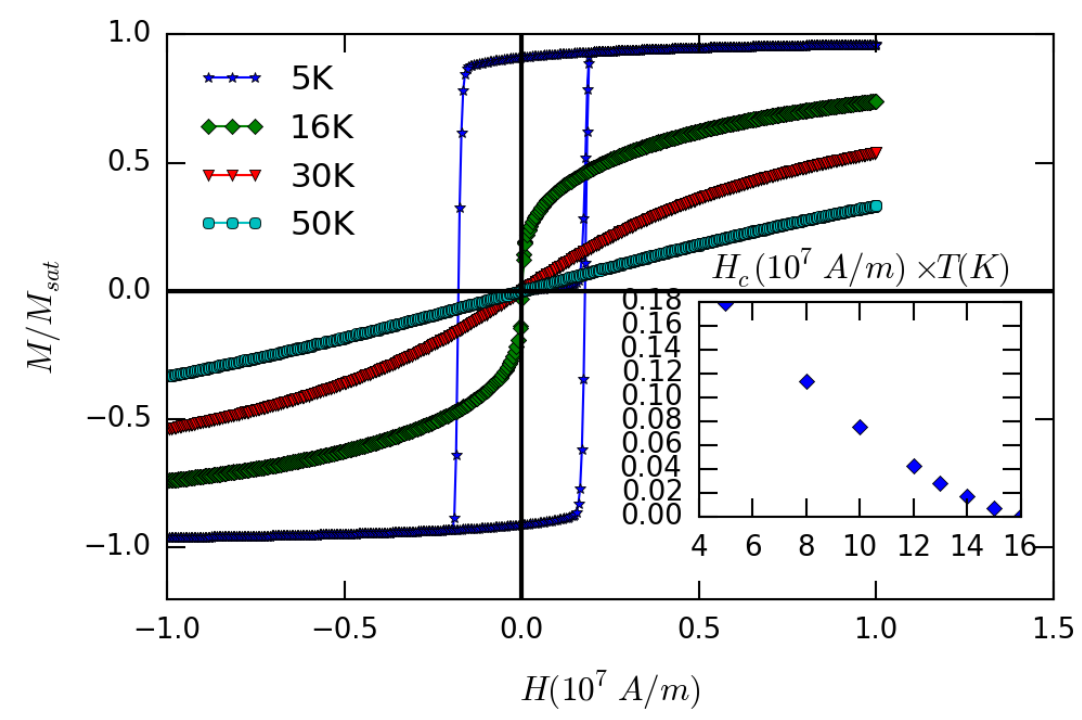

Figura 5.2: Ciclos de histerese a diferentes temperaturas para um conjunto de 360 partículas. Painel interno: dependência da coercividade com a temperatura.

Como explicado no capítulo 3, uma medida muito comum para estudar sistemas de nanopartículas são as curvas Zero Field Cooling 
- Field Cooling (ZFC-FC). Para as partículas isotrópicas, simulamos curvas ZFC-FC com um campo aplicado de $5 \times 10^{4} \mathrm{~A} / \mathrm{m}(\sim 628 \mathrm{Oe})$ em um sistema formado por 360 partículas com um ângulo $\theta_{H}$ distribuído uniformemente entre 0 e $\pi$ (figura 5.3). Nesta figura vemos que a curva ZFC parte de uma magnetização nula até o sistema ganhar energia térmica suficiente para a magnetização se alinhar com o campo magnético. Apesar de não ser usual curvas ZFC partirem de uma magnetização nula, uma ampliação na região onde ocorre a ativação térmica, painel interno, mostra o comportamento típico encontrado em sistemas experimentais. Extraímos da curva ZFC uma temperatura crítica para este sistema, dada pela temperatura onde ocorre o máximo da curva ZFC, de 16.0(5)K.

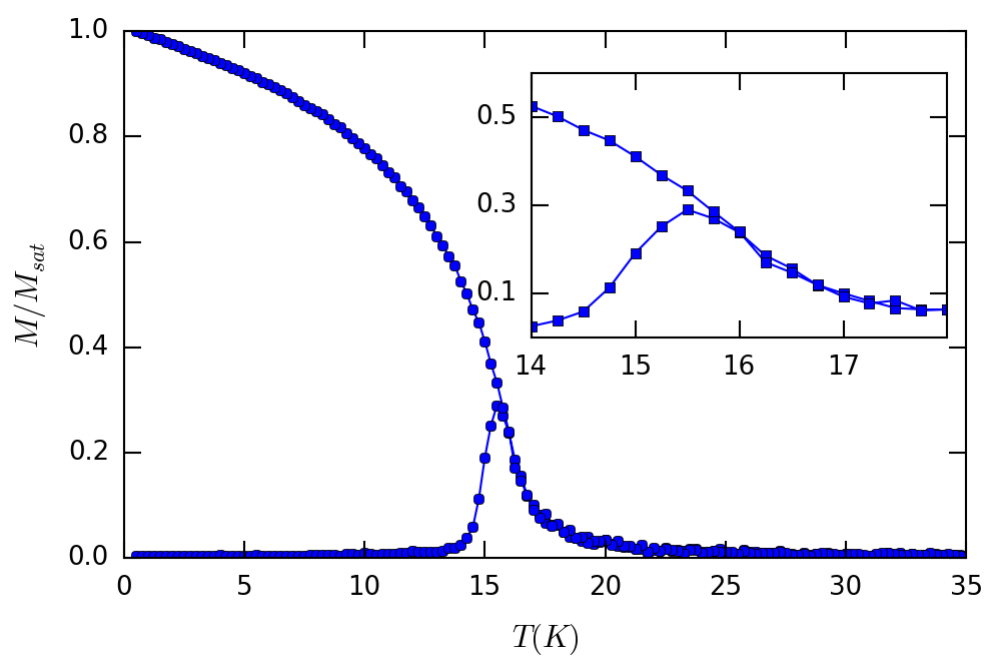

Figura 5.3: Curvas ZFC-FC para um conjunto de 360 partículas e campo aplicado de $5 \times 10^{4} \mathrm{~A} / \mathrm{m}(\sim 628 \mathrm{Oe})$.

Com um gráfico tridimensional, figura 5.4, é possível comparar a configuração de uma das partículas a $T=16 \mathrm{~K}$ na curva ZFC e a $0.5 K$ na curva FC. Dos resultados prévios sabemos que 16.0(5)K é a temperatura do máximo da curva ZFC deste conjunto de partículas e, como podemos ver na figura, os momentos magnéticos estão parcialmente alinhados na direção do campo aplicado (cone azul grande na figura). No entanto, a $0.5 \mathrm{~K}$, os momentos estão totalmente alinhados na direção do campo aplicado.

Como a energia dos momentos magnéticos é modificada quando um campo é aplicado, temos que a magnitude deste campo é importante na determinação do máximo da curva ZFC. A figura 5.5 mostra algumas curvas ZFC-FC com diferentes magnitudes de campo aplicado e, como podemos ver, a temperatura onde ocorre o máximo diminui com o aumento de $H$ até o ponto que não existe mais uma irreversibilidade magnética (para $H=5 \times 10^{6} \mathrm{~A} / \mathrm{m}$ ). Este comportamento é esperado, pois na curva FC os momentos magnéticos estão 

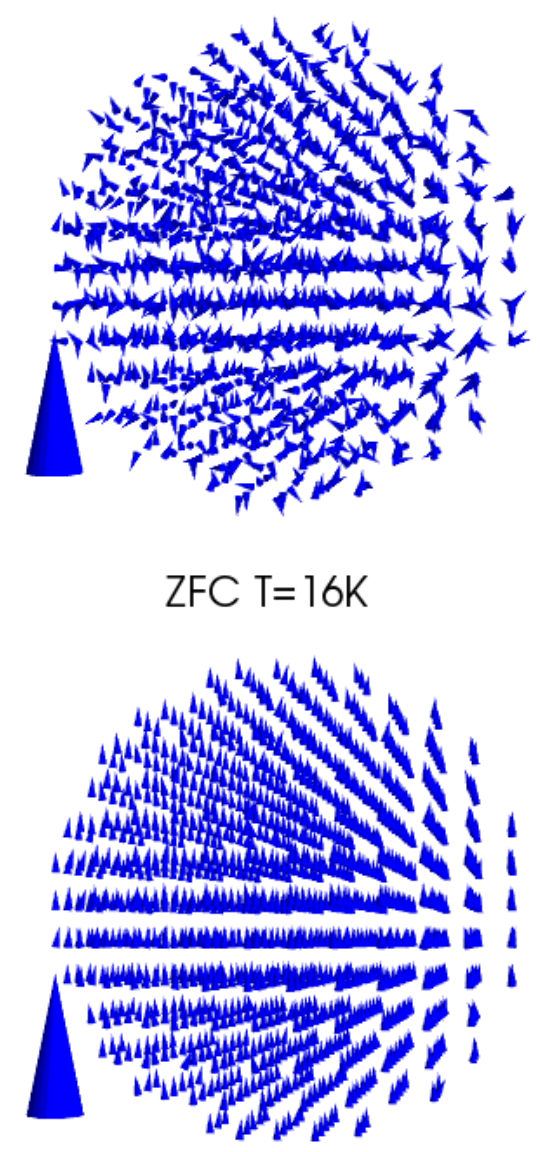

$$
\mathrm{FC} \mathrm{T}=0.5 \mathrm{~K}
$$

Figura 5.4: Gráfico tridimensional da estrutura de uma única partícula a $16 \mathrm{~K}$ na curva ZFC e a $0.5 \mathrm{~K}$ na curva FC. O cone azul grande representa a direção do campo magnético aplicado. 
mais alinhados na direção do campo, portanto se a magnitude de $H$ é aumentada temos uma situação que favorece o alinhamento dos momentos magnéticos na direção de $H$, o que se reflete na curva FC.

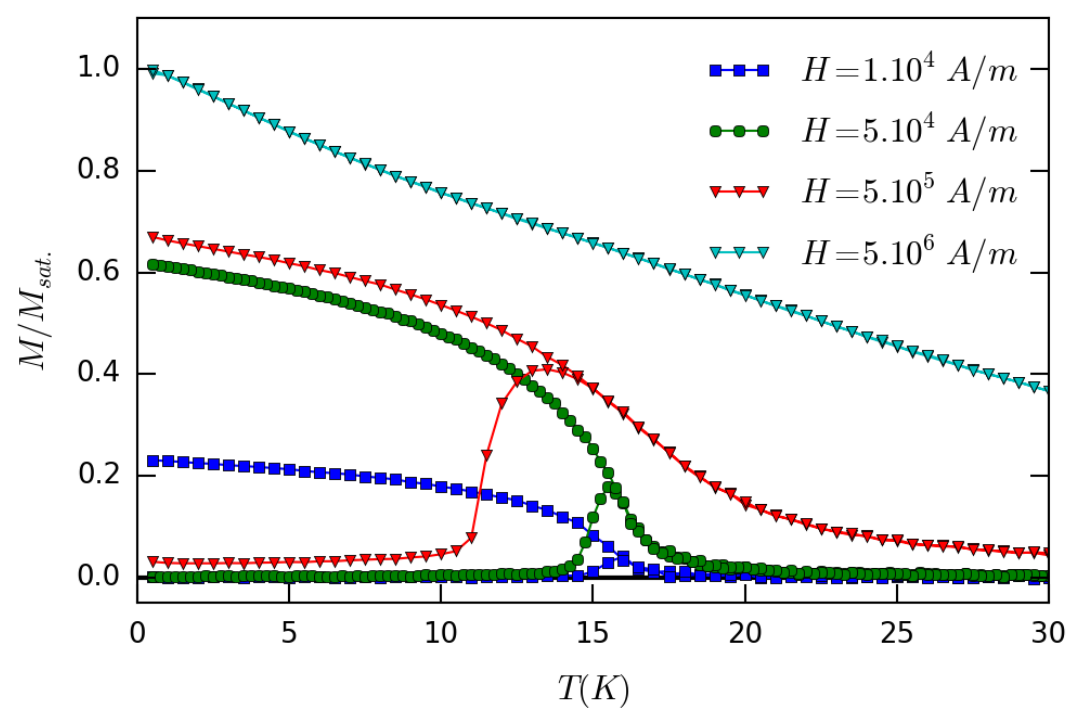

Figura 5.5: Curvas ZFC-FC de um conjunto de 360 partículas e campo aplicado de $1 \times 10^{4}, 5 \times 10^{4}, 5 \times 10^{5}$ e $5 \times 10^{6} \mathrm{~A} / \mathrm{m}$.

Nas curvas ZFC-FC que apresentamos nas figuras 5.5 e 5.3, vimos o comportamento magnético na situação em que os ângulos $\theta_{H}$ entre o eixo fácil de cada partícula e o campo eram uniformemente distribuídos entre 0 e $\pi$. Nas figuras 5.6 e 5.7 vemos as curvas ZFC-FC com campos aplicados de $1 \times 10^{4}, 5 \times 10^{4}$ e $5 \times 10^{6} \mathrm{~A} / \mathrm{m}$, para um conjunto de 360 partículas onde todas possuem o mesmo ângulo $\theta_{H}$, que assumiu valores de $\theta_{H}=0, \pi / 4, \pi / 2,3 \pi / 4, \pi$.

Na figura 5.6 vemos que para $\theta_{H}=0$ com os campos de $5 \times 10^{4}$ e $5 \times 10^{6} \mathrm{~A} / \mathrm{m}$ a curva ZFC já começa saturada, enquanto que para o campo menor vemos uma histerese térmica. Para $\theta_{H}=\pi / 4$, vemos um comportamento semelhante, no entanto somente o campo mais intenso de $5 \times 10^{6}$ é capaz de saturar a curva ZFC. Quando o ângulo entre o campo aplicado e o eixo fácil é de $\pi / 2$ temos uma situação onde precisamos de um campo mais intenso para orientar a amostra na direção do campo aplicado, fazendo com que a energia Zeeman seja mais intensa que a de anisotropia cristalina.

Nas situações em que temos $\theta_{H}=3 \pi / 4$ e $\pi$, figura 5.7, vemos que a magnetização sai de um valor negativo na curva ZFC e na FC volta orientada no sentido do campo aplicado. Nestas configurações as partículas estão inicialmente orientadas no mínimo de energia $\theta=\pi \mathrm{e}$ portanto só conseguem se orientar na direção do campo aplicado a altas temperaturas. Somente o campo mais intenso é capaz de saturar esses sistemas, de forma que a magnetização na curva ZFC se inicia na saturação, da mesma maneira que para os outros valores de $\theta_{H}$. 

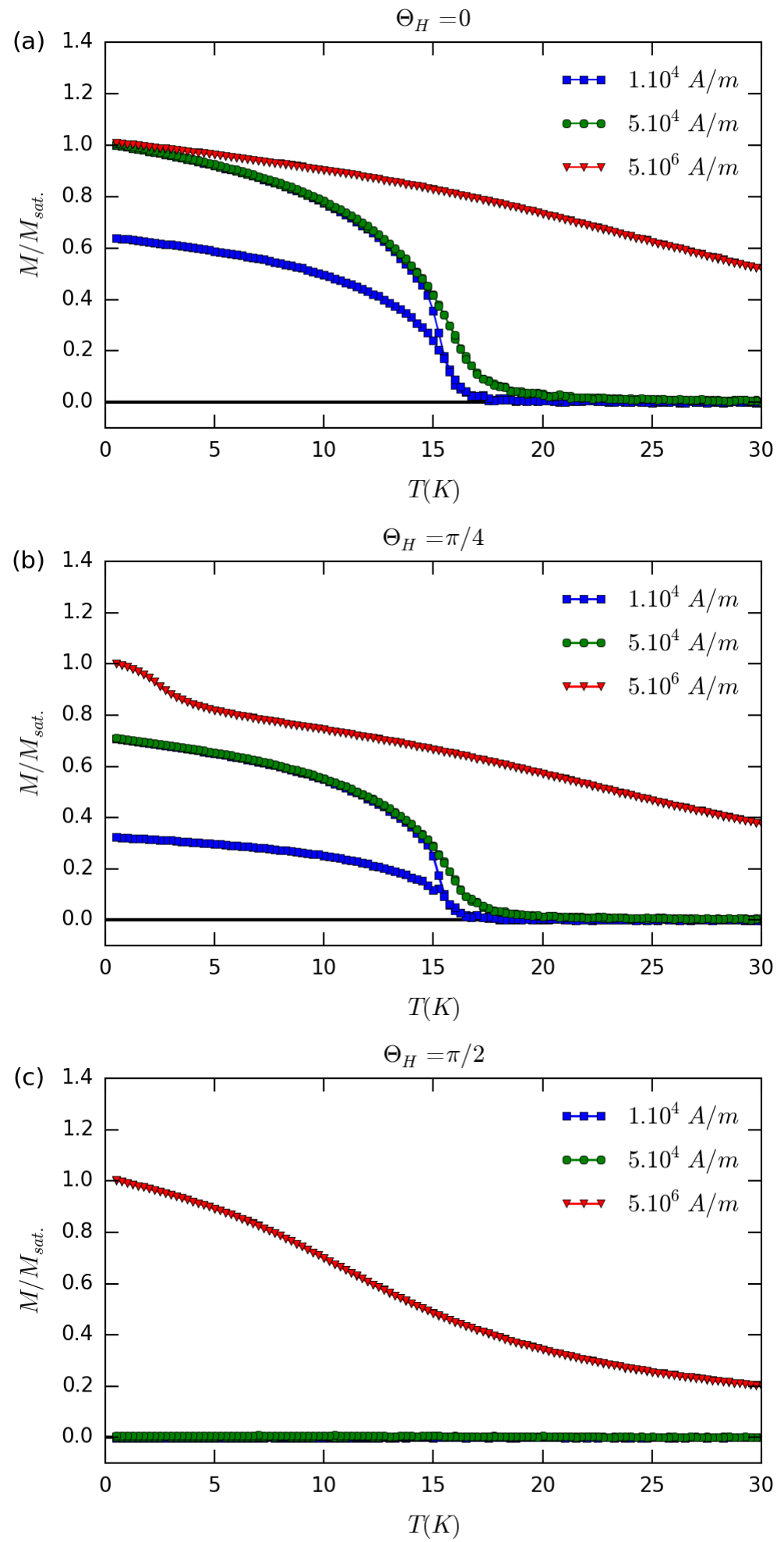

Figura 5.6: Curvas ZFC-FC com campos aplicados de $1 \times 10^{4}$ (azul), $5 \times 10^{5}$ (verde) e $5 \times 10^{6} \mathrm{~A} / \mathrm{m}$ (vermelho) para orientações entre o campo aplicado e o eixo fácil de (a) $\theta_{H}=0$, (b) $\pi / 4$ e (c) $\pi / 2$. 

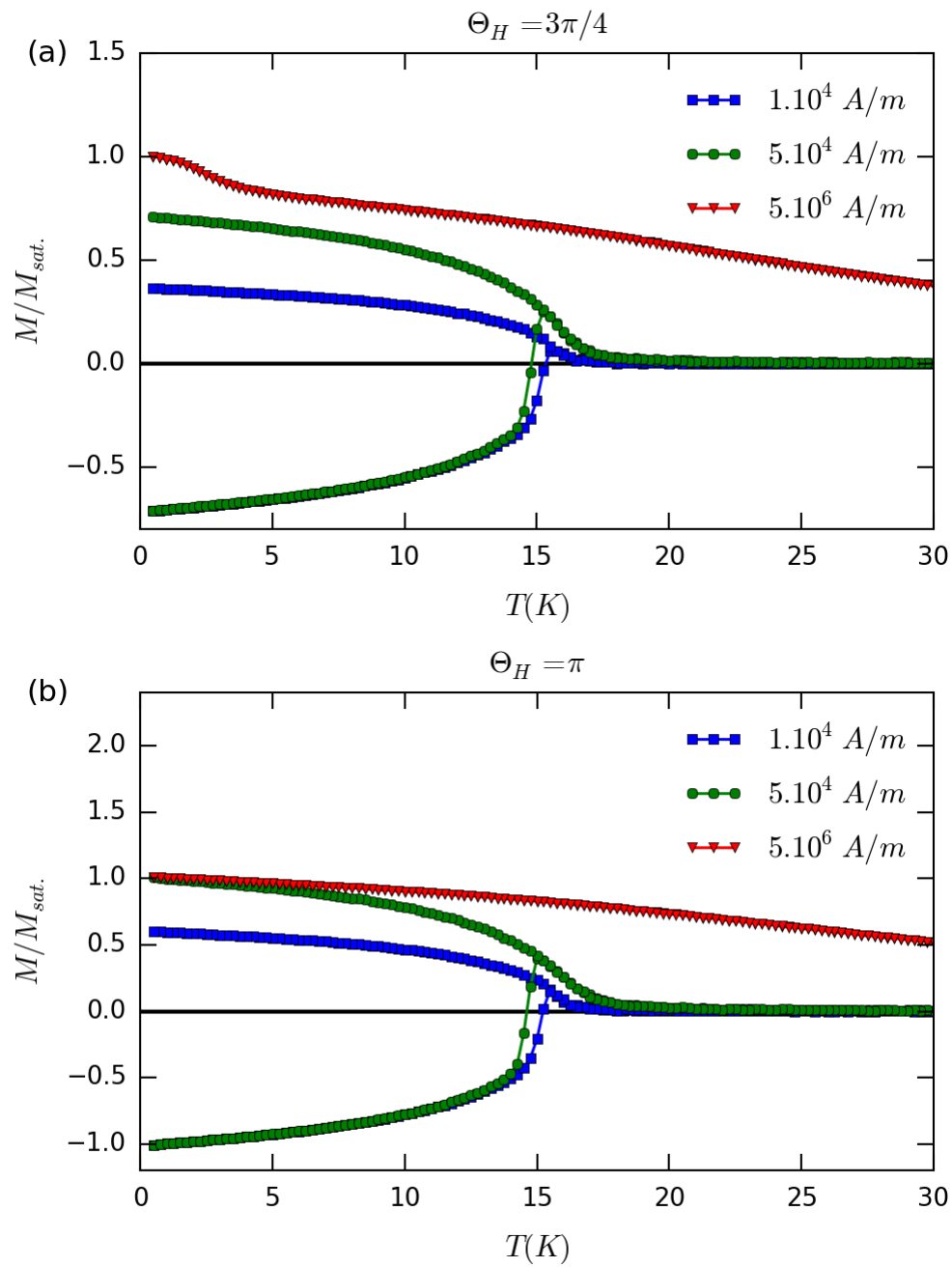

Figura 5.7: Curvas ZFC-FC com campos aplicados de $1 \times 10^{4}$ (azul), $5 \times 10^{5}$ (verde) e $5 \times 10^{6} \mathrm{~A} / \mathrm{m}$ (vermelho) para orientações entre o campo aplicado e o eixo fácil de (a) $\theta_{H}=3 \pi / 4$ e (b) $\theta_{H}=\pi$. 
Até agora consideramos o caso de um conjunto de nanopartículas com o mesmo tamanho, no entanto, como vimos na introdução, capítulo 1 , muitas das características das nanopartículas estão vinculadas ao seu tamanho. Na figura 5.8 vemos a dependência da temperatura crítica com o diâmetro $D$ das nanopartículas. Vemos que existe uma região inicial com um rápido aumento de $T_{C}$, seguido por uma região que tende a saturação. Esse comportamento pode ser bem descrito por uma lei de escala que prevê o comportamento de uma dada temperatura crítica com o comprimento de correlação de seu sistema por meio de um expoente crítico $v[131,132]$. Neste caso, podemos escrever esta lei de escala como [12]:

$$
T_{C}(D)=T_{C}^{\infty}\left[1-\left(D / D_{0}\right)^{-1 / v}\right]
$$

Na figura 5.8 a linha sólida representa o melhor ajuste da equação 5.7 com os pontos simulados. Encontramos valores para as constantes $T_{C}^{\infty}$ e $D_{0}$ de $16.9(1) K$ e $1.44(1) n m$, respectivamente, sendo que este último valor é cerca de duas vezes o parâmetro de rede da magnetita e pode representar um limite razoável entre um cluster de spins e uma partícula. O valor encontrado para o expoente crítico $v$ foi de $0.78(3)$, que é compatível com outras simulações tridimensionais de Monte Carlo utilizando o modelo de Heisenberg [133, 134] e com alguns sistemas experimentais de ferromagnetos de Heisenberg de $\mathrm{EuO}$ e EuS [135].

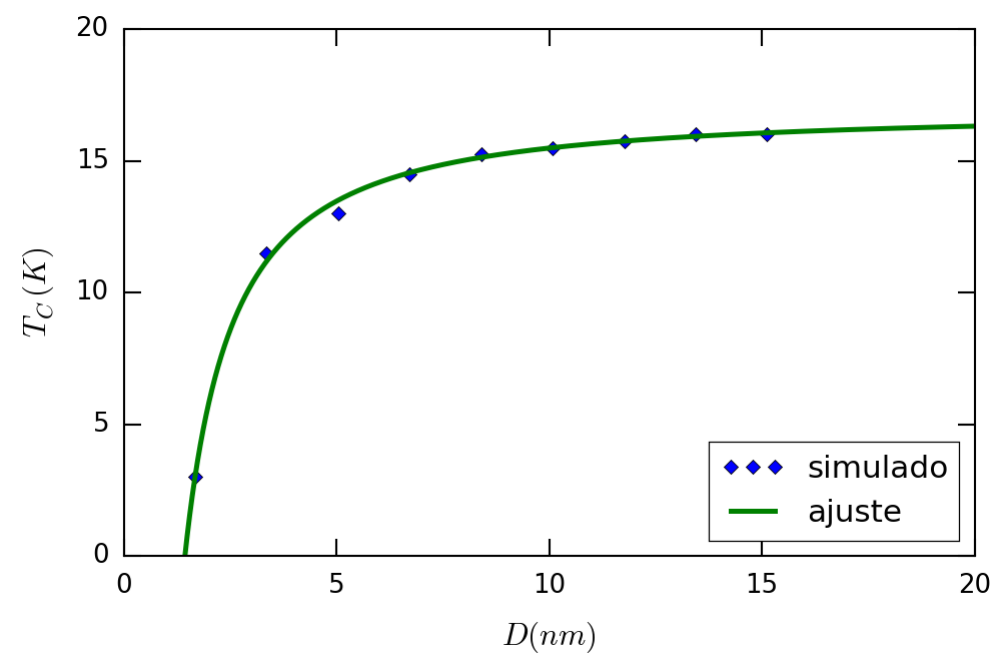

Figura 5.8: Dependência de $T_{C}$ com o diâmetro das nanopartículas. A linha sólida representa o ajuste obtido utilizando a equação 5.7. As simulações para obter $T_{B}$ foram obtidas utilizando $\mathcal{J}=10^{-22} \mathrm{~J}$ e $K_{1} a^{3}=5.3 \times 10^{-23} \mathrm{~J}$.

Outro tipo de medida que reproduzimos com esta simulação são os gráficos de Henkel $m_{d} \times m_{r}$ e curvas $\Delta m$. Na figura 5.9 (a) vemos 
o comportamento da magnetização remanente $m_{r}$ e desmagnetizante $m_{d}$ com o campo aplicado, onde ocorre a saturação a partir de um dado valor de campo. Na figura 5.9 (b) vemos o gráfico de Henkel obtido ${ }^{1}$, onde vemos que a simulação concorda bem com o comportamento linear $m_{d}=1-2 m_{r}$.
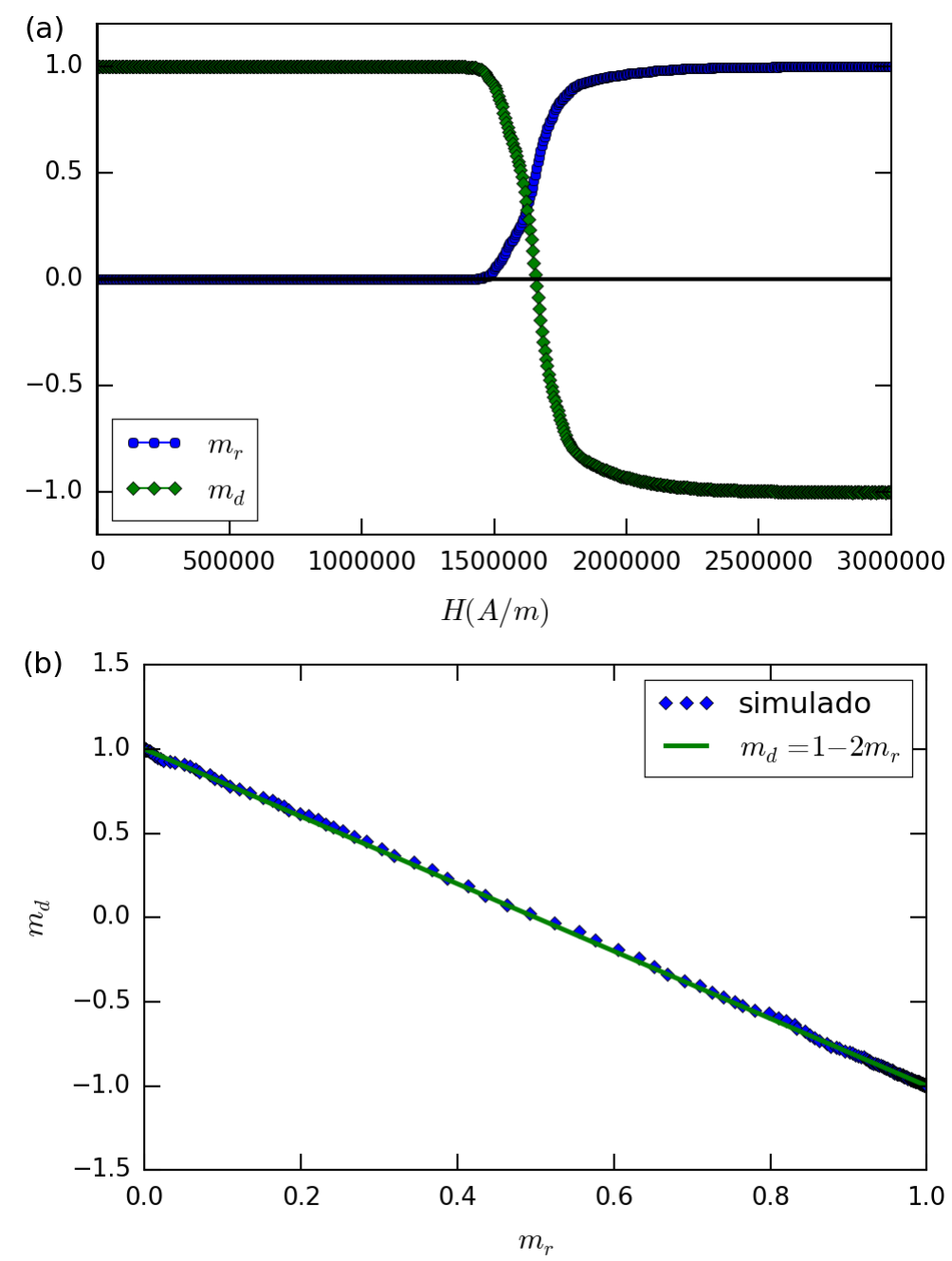

Figura 5.9: (a) Dependência da magnetização remanente $m_{r}$ e desmagnetizante $m_{d}$ com o campo aplicado para um conjunto de partículas não interagentes a $T=5 K$. (b) Gráfico de Henkel obtidos com os dados de (a). Vemos que a simulação concorda bem com o modelo.

\subsection{ALTERANDO A SUPERFÍCIE DAS PARTÍCULAS}

A superfície de nanopartículas pode ter uma grande importância em sua magnetização, dado que o número de momentos magnéticos su-

1 Aqui achamos mais ilustrativo plotar o gráfico de Henkel ao invés da curva $\Delta m$, já que para um sistema não interagente $\Delta m=0$. 
perficiais pode ser significante em relação ao número de momentos magnéticos internos. Nesta seção, usando as mudanças propostas em 5.1.2 e 5.1.3, mostraremos como dois diferentes tipos de superfície podem alterar o ordenamento magnético de nanopartículas em função da temperatura.

Para uma nanopartícula com uma camada morta superficial, podemos esperar que a temperatura crítica diminua, pois o ordenamento magnético superficial também diminui. Esta camada morta pode se originar, por exemplo, devido a uma baixa cristalinidade da superfície da partícula ou devido a uma diminuição de momentos vizinhos na superfície. Por outro lado, se os momentos superficiais tem um ordenamento magnético maior isto pode aumentar o valor de $T_{C}$. No entanto, nanopartículas diluídas em uma matriz com diferentes ordenamentos magnéticos mostraram um aumento na temperatura de bloqueio, como no caso de nanopartículas de cobalto com cerca de $4 n m$ em uma matriz antiferromagnética de $\mathrm{CoO}$ [24].

Na figura 5.10 mostramos curvas ZFC-FC para um conjunto de 360 partículas em quatro situações distintas (com $\mathcal{J}=1 \times 10^{-21} \mathrm{~J}$ ): partículas sem camada morta superficial (como explicado em 5.1.1), partículas com camada morta, e partículas com uma camada superficial magneticamente dura usando $\mathcal{J}^{\prime \prime}=2 \mathcal{J}$ e $\mathcal{J}^{\prime \prime}=4 \mathcal{J}$.

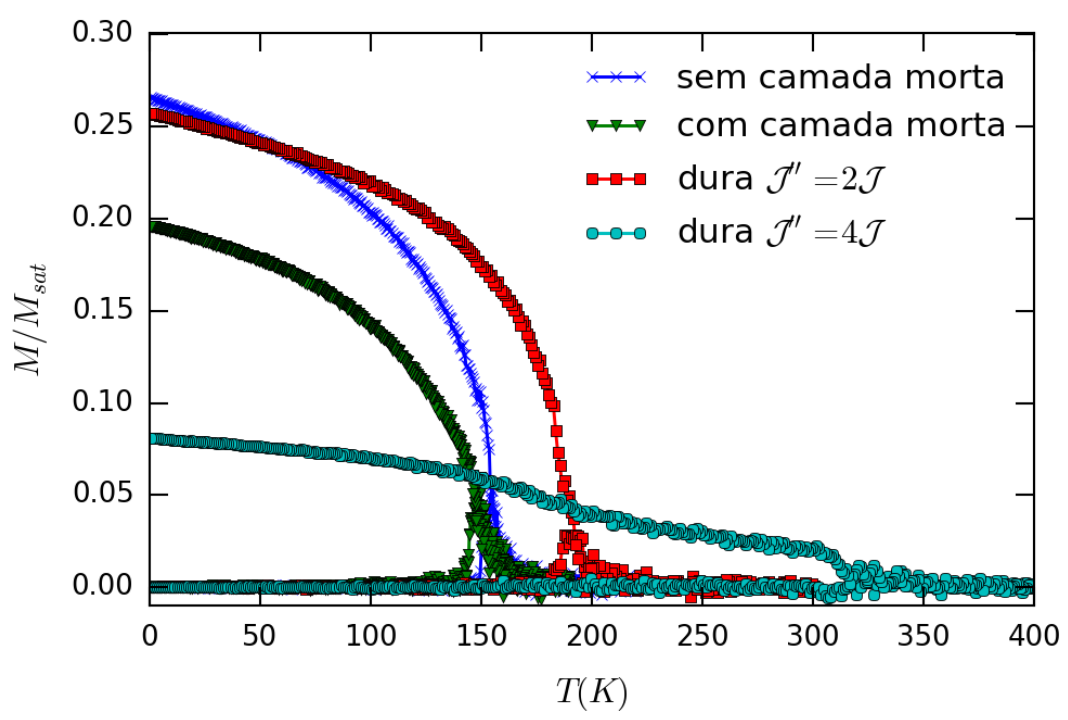

Figura 5.10: Curvas ZFC-FC para um conjunto de 360 partículas: sem camada morta, com camada morta e com uma camada superficial dura com $2 \mathcal{J}$ e $4 \mathcal{J}$.

Para uma partícula com camada morta a temperatura crítica de 147.0(5)K é um pouco menor do que quando nenhuma camada morta foi considerada, 154.8(5)K, e o valor da magnetização atingindo a $0.5 \mathrm{~K}$ na curva FC é menor do que para um conjunto de partículas sem camada morta. Para partículas com uma superfície magnetica- 
mente dura a temperatura crítica aumenta de 154 para $315 \mathrm{~K}$ usando $\mathcal{J}^{\prime \prime}=4 \mathcal{J}$. Este aumento significativo é devido aos momentos superficiais que, permanecendo mais ordenados, endurecem a partícula inteira. A simulação mostra que, se houver condições experimentais de ordenar os momentos superficiais, é possível aumentar a temperatura de bloqueio de sistemas reais, aumentando o potencial uso de nanopartículas para aplicações tecnológicas.

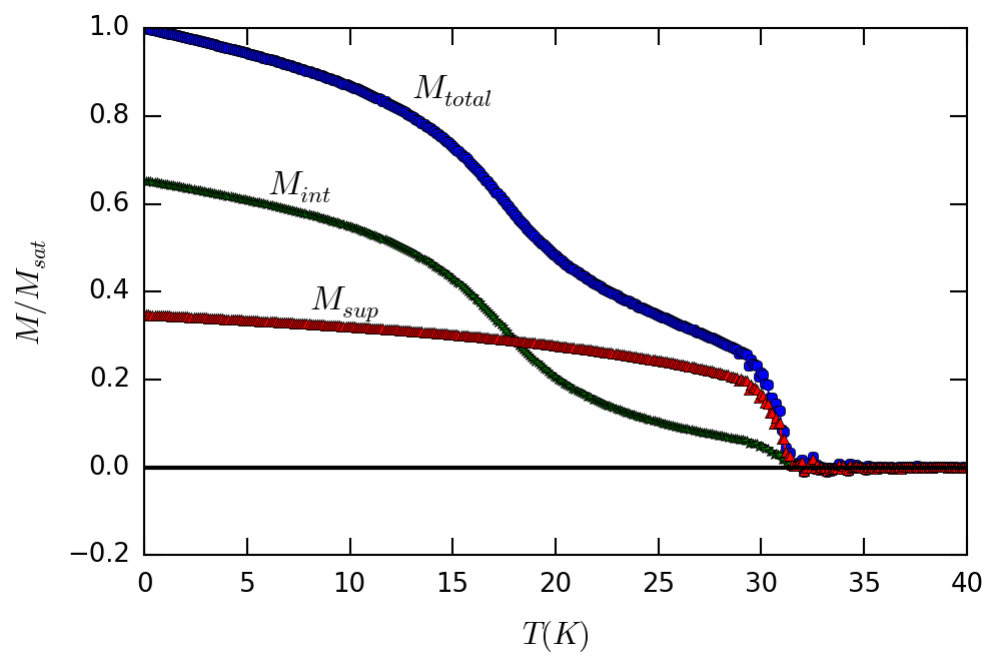

Figura 5.11: Dependência da temperatura da média total da magnetização da superfície e do núcleo usando 100 sementes distintas para uma partícula com camada superficial dura e usando $\mathcal{J}^{\prime \prime}=$ $4 \mathcal{J}=4 \times 10^{-22} \mathrm{~J}$.

Para observar a diferença do comportamento magnético entre a superfície e o núcleo de uma partícula com uma camada superficial dura (usando $\mathcal{J}^{\prime \prime}=4 \mathcal{J}$ ) a figura 5.11 mostra a magnetização total, a magnetização da superfície e a magnetização do núcleo. Vemos que a superfície apresenta o mesmo comportamento que aquele observado na figura 5.I, enquanto que o núcleo mostra dois regimes. O primeiro, até aproximadamente $16 K$, equivale ao de uma partícula homogênea, enquanto que no segundo se observa a influência da superfície, que estende o comportamento magneticamente ordenado da partícula até temperaturas bem mais elevadas.

\subsection{SIMULAÇÃO MONTE CARLO COM INTERAÇÃO ENTRE PARTÍ- CULAS}

Em um sistema concentrado de nanopartículas reais temos duas possíveis formas de interação: a dipolar e a de troca, esta última se as partículas possuem contato direto ou estão suficientemente perto. A manifestação de cada uma dessas duas interações em medidas magnéticas pode ser diferente devido à forma da sua expressão de energia. 
No caso da interação dipolar, temos um efeito global que tende a desmagnetizar o sistema, $\delta m<0$, já no caso da interação de troca esse efeito é magnetizante. Com isso em mente, antes de colocar cada uma dessas duas situações explicitamente na simulação, começamos na seção 5.4.1 com uma aproximação mais simples e menos custosa computacionalmente, onde colocamos um termo de campo médio proporcional à magnetização e que pode ser tanto magnetizante quanto desmagnetizante. Prosseguimos com a seção 5.4.3 onde mostramos resultados para o caso onde temos um conjunto de dímeros que interagem na superfície por meio da interação de troca e finalmente na seção 5.4.2 colocamos explicitamente a interação dipolar entre as partículas .

\subsubsection{Interação entre partículas usando um termo de campo médio}

A aproximação mais simples que podemos fazer para simular o efeito provocado por interações entre partículas é considerar um termo de campo médio proporcional à magnetização total do sistema: $\alpha \vec{M}$. O efeito deste termo é adicionar um campo magnético extra que pode tanto favorecer quanto desfavorecer a magnetização, dependendo do sinal do parâmetro adimensional $\alpha$. Assim adicionamos à equação 5.1 um novo termo de energia dado por $-\alpha \mu_{0} \vec{\mu}_{i} \cdot \vec{M}$, sendo que para $\alpha<0$ temos interações predominantemente desmagnetizantes e para $\alpha>0$ interações magnetizantes. Além das interações entre as partículas, $\alpha$ também pode englobar outras fontes de anisotropia magnética que não consideramos nesse modelo, como por exemplo a anisotropia de forma das partículas. No caso onde consideramos somente a anisotropia de forma, $\alpha$ pode assumir valores entre $0<\alpha<1$. No caso de partículas esféricas esse valor é de $1 / 3$.

Na maioria dos resultados apresentados nessa seção, utilizamos um conjunto de nanopartículas com uma distribuição de tamanhos dada por uma curva log-normal com mediana $\mu=1.952$ e parâmetro de escala $\sigma=0.217$. Optamos por inserir essa distribuição para aproximar mais nossos resultados dos resultados experimentais de amostras de nanopartículas, já que em muitos casos estas são polidispersas. Na figura 5.12 vemos a curva log-normal e o histograma com a frequência relativa de cada diâmetro com esses parâmetros. Devido à maneira como as partículas são simuladas, não é possível obter mais tamanhos intermediários, de forma que em nossas simulações usamos nanopartículas com cinco diâmetros diferentes.

Para confirmar se a introdução desse novo termo de energia proporciona o tipo de efeito desejado, simulamos curvas de remanência e $\Delta m$ para valores negativos e positivos de $\alpha$ a uma temperatura de $8 K$ para um conjunto de 1000 nanopartículas com distribuição de diâmetros utilizando a distribuição mostrada na figura 5.12. Na figura 5.13 (a) vemos a dependência da remanência isotérmica $m_{r}$ e a desmagne- 


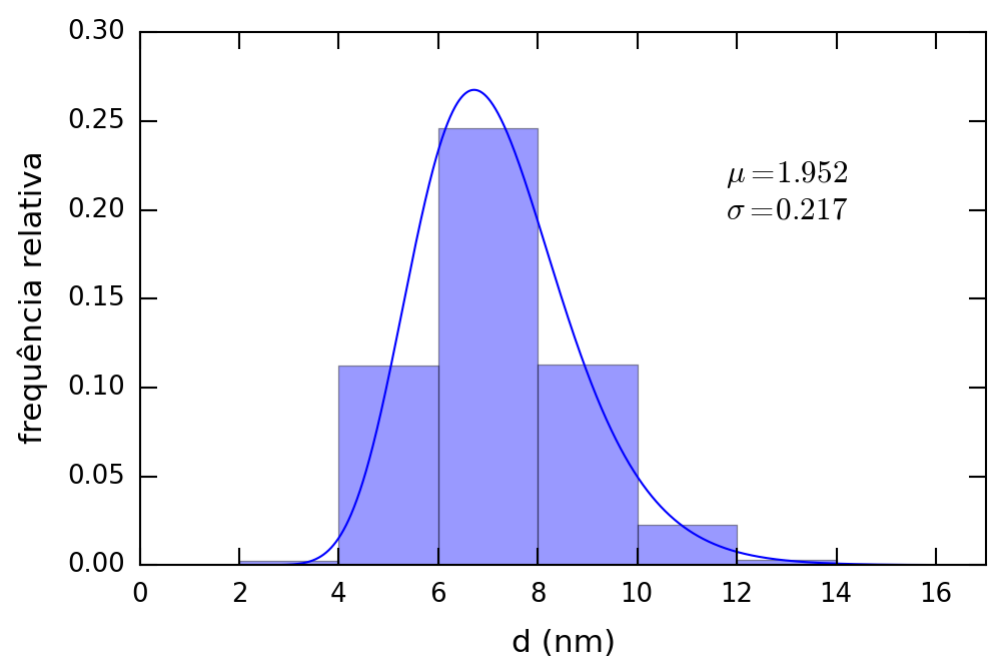

Figura 5.12: Distribuição log-normal com mediana $\mu=1.952$ e parâmetro de escala $\sigma=0.217$, e histograma com a frequência relativa de nanopartículas utilizada nas simulações.

tizante $m_{d}$ com o campo para valores de $\alpha$ de -2.0 e +2.0 . Na figura 5.13 (b) vemos que as curvas $\Delta m$ calculadas a partir de (a) mostram uma região positiva para valores positivos de $\alpha$, enquanto que, para $\alpha<0, \Delta m$ apresenta valores negativos. Um aumento no valor em módulo de $\alpha$ também aumenta o valor máximo em módulo de $\Delta m$, como esperado. Assim concluímos que esse termo de campo médio adicionado à equação 5.1 cumpre seu papel de criar interações magnetizantes e desmagnetizantes no sistema. Podemos agora estudar como cada tipo de interação altera outras propriedades magnéticas do nosso sistema de nanopartículas, como a temperatura crítica e os padrões observados em diagramas FORC.

Para entendermos o comportamento das curvas ZFC-FC em sistemas com interações magnetizantes e desmagnetizantes devemos lembrar como é feito esse tipo de medida. Para simularmos ou medirmos curvas ZFC-FC resfriamos o sistema desmagnetizado e aplicamos o campo magnético. Quando começamos a aumentar a temperatura o sistema ganha energia térmica e os momentos passam a se alinhar com o campo e consequentemente a magnetização aumenta. Se tivermos um termo de energia que favoreça a magnetização, como no caso de $\alpha>0$, é natural pensar que esse ordenamento ocorrerá a uma temperatura menor. Já no caso de $\alpha<0$ esse processo deverá ocorrer a uma temperatura maior, pois o termo extra provoca uma desmagnetização do sistema.

Nas figuras 5.14 (a) e (b) vemos as curvas ZFC-FC para valores de $\alpha$ entre -2 e +2 e campos de $H=5 \times 10^{4}$ e $5 \times 10^{5} \mathrm{~A} / \mathrm{m}$, respectivamente. Para o campo de $H=5 \times 10^{4}$, figura (a), não vemos uma diferença na temperatura crítica, sendo de $15.5 \mathrm{~K}$ para as três curvas, no entanto a magnetização é maior quanto maior for o valor 

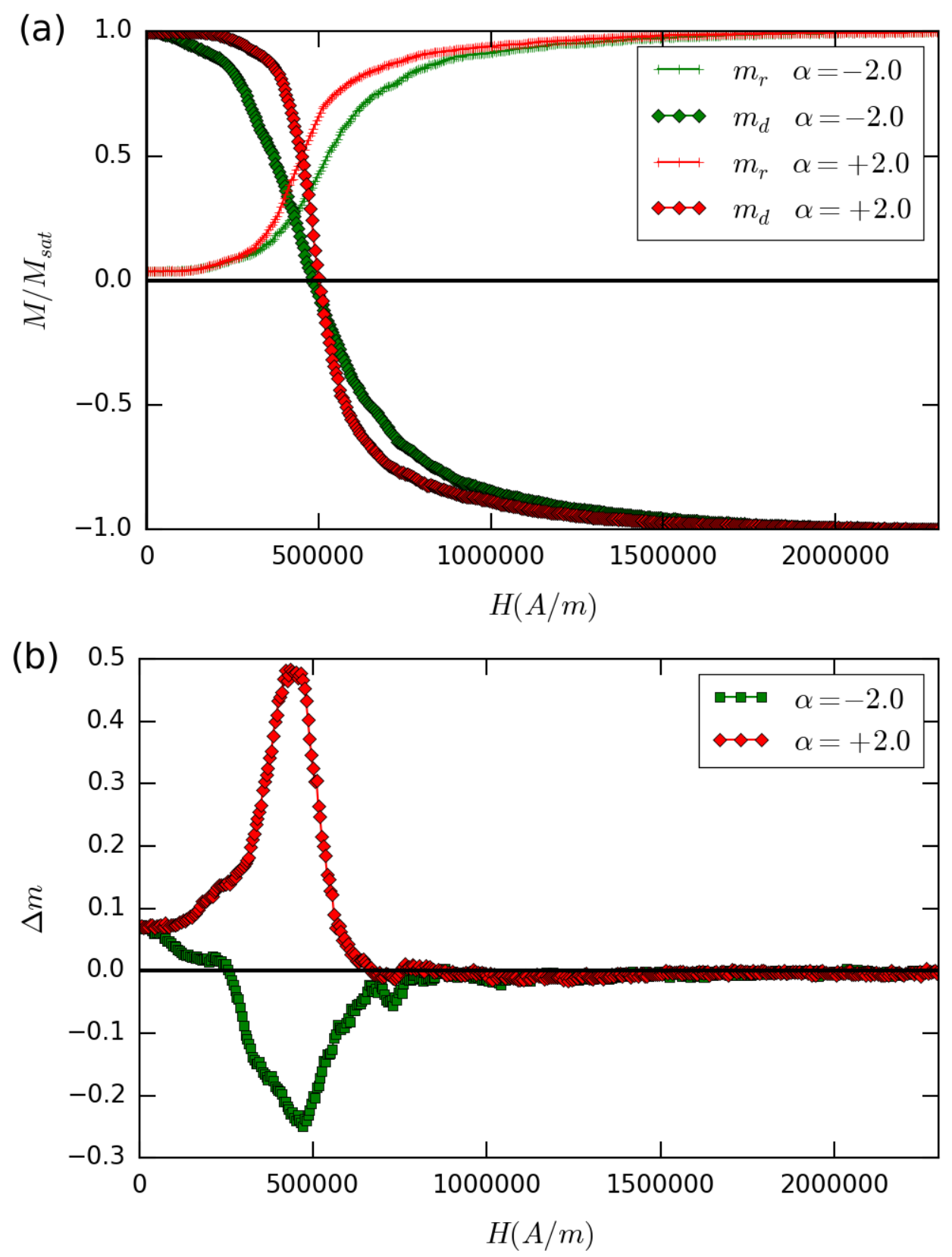

Figura 5.13: (a) Curvas de remanência para $\alpha=-2.0$ e $\alpha=+2.0$ a uma temperatura de $8 \mathrm{~K}$ para um conjunto de 1000 nanopartículas com distribuição de diâmetros seguindo uma curva log-normal com mediana $\mu=1.952$ e parâmetro de escala $\sigma=0.217$. Na figura (b) vemos as curvas $\Delta m$ obtidas a partir de (a), sendo que para $\alpha>0$ temos interações magnetizantes e para $\alpha<0$ desmagnetizantes. 
de $\alpha$. Para o campo de $5 \times 10^{5} \mathrm{~A} / \mathrm{m}$, figura (b) vemos a tendência do máximo da curva ZFC ocorrer a temperaturas $T_{\max }$ menores quando aumentamos $\alpha$, com $T_{\max }$ variando de 12.5 a $13.3(5) K$. Se adotarmos a temperatura de bloqueio como sendo $T_{\max }$, como habitualmente fazemos em medidas ZFC-FC, podemos dizer que nesta medida $T_{B}$ diminui quando temos interações magnetizantes e aumenta para interações desmagnetizantes.

Vamos agora estudar como as interações magnetizantes e desmagnetizantes se manifestam em curvas de inversão de primeira ordem, as chamadas FORCs, e em seus diagramas. Esta técnica nos permite obter um mapa das distribuições de coercividade e campos de interação do sistema, como explicamos no capítulo 3, no entanto na análise de resultados experimentais muitas vezes é difícil distinguir o efeito de cada característica magnética do sistema no diagrama FORC. Como nesta simulação podemos controlar a magnitude e o sinal do campo médio atuando nas nanopartículas, podemos correlacionar como mudanças no parâmetro $\alpha$ se refletem nestes diagramas. Além disso, para estas simulações, vamos considerar duas distribuições de tamanho de nanopartículas: a distribuição mostrada na figura 5.12 ( $\mu=1.952$ e $\sigma=0.217$ ) e outra com mais nanopartículas menores em comparação a outra distribuição $(\mu=1.455$ e $\sigma=0.262)$. Escolhemos estas duas distribuições para mostrar como a contribuição de nanopartículas com coercividades maiores ou menores se refletem nos diagramas FORC.

Analisando primeiro os resultados obtidos para um conjunto de 750 partículas com tamanhos seguindo a distribuição mostrada na figura $5.12(\mu=1.952$ e $\sigma=0.217)$, temos na figura 5.15 as curvas de inversão de primeira ordem obtidas a $11 \mathrm{~K}$ para (a) $\alpha=0.0$, (b) $\alpha=-2.0$ e (b) $\alpha=+2.0$. Estas curvas foram simuladas considerando o mesmo valor de $\Delta H_{r}=\Delta H=5 \times 10^{4} \mathrm{~A} / \mathrm{m}$, com $H_{\max }=2.5 \times 10^{6} \mathrm{~A} / \mathrm{m}$. Vemos que para os três conjuntos de FORCs temos uma região no início de cada curva (quando $H=H_{r}$ ) que é caracterizada primeiramente por uma queda no valor da magnetização, seguida por um aumento crescente de $M$ até $H=H_{\text {max }}$. Este comportamento é observado também em curvas experimentais e está relacionado à viscosidade magnética do sistema, pois quando saímos do campo $H=H_{\text {max }}$ e levamos o sistema até o campo de retorno $H=H_{r}$ é preciso esperar um certo tempo para se chegar à magnetização de equilíbrio daquele campo. Como este tempo, que na simulação seriam os passos de Monte Carlo, pode ser relativamente grande, observamos esse comportamento transitório até que a magnetização passe a aumentar com o aumento do campo. Comparando agora as figuras (a), (b) e (c), vemos que existe uma quantidade maior de curvas na região irreversível de magnetização quanto menor for o valor de $\alpha$. Este fato está relacionado à dureza magnética do sistema, já que para sistemas com interações mais magnetizantes temos ciclos mais quadrados. 

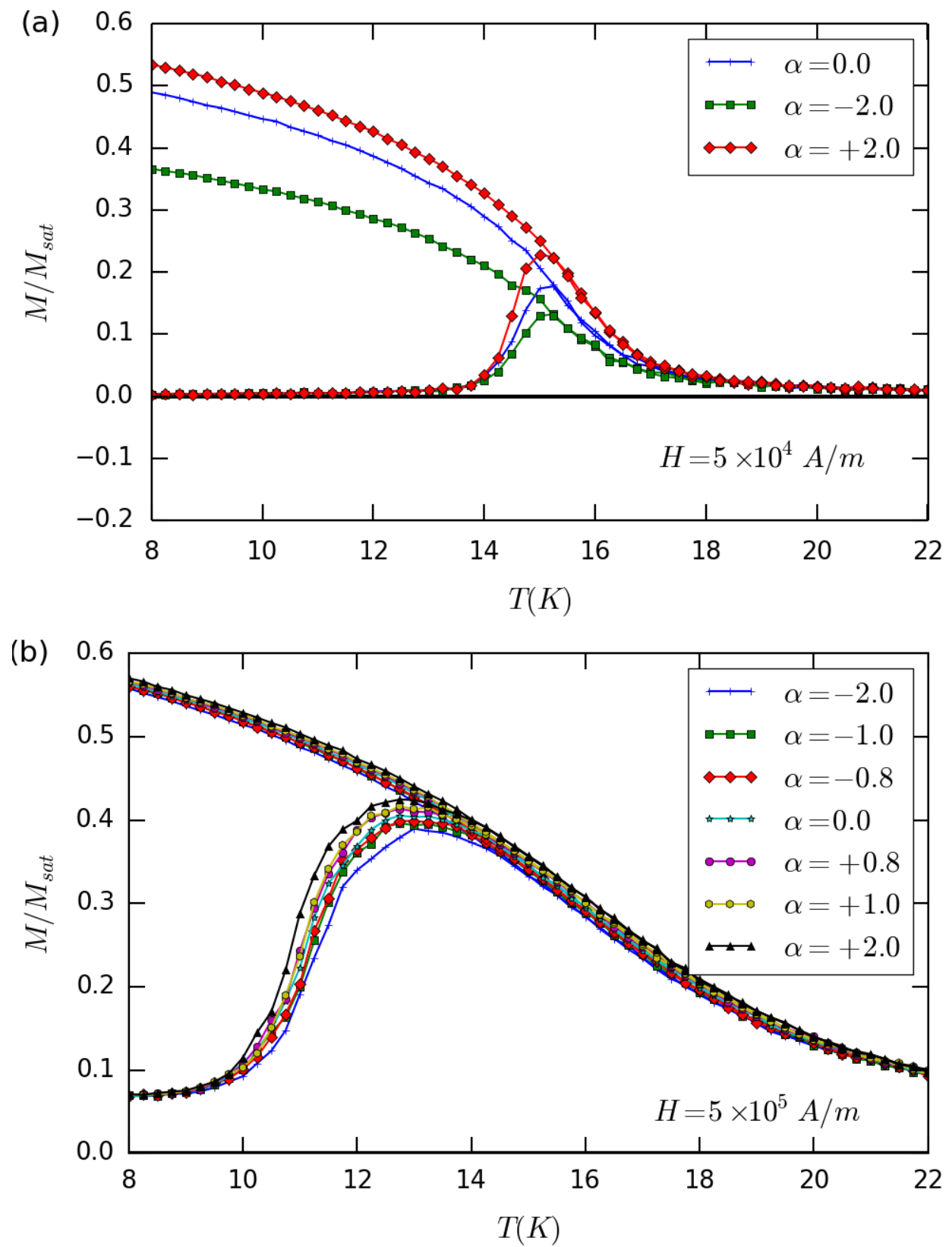

Figura 5.14: Curvas ZFC-FC com campos aplicados de $H=5 \times 10^{4}$ (a) e $5 \times 10^{5}$ (b) para valores de $\alpha$ entre -2.0 e +2.0 . 

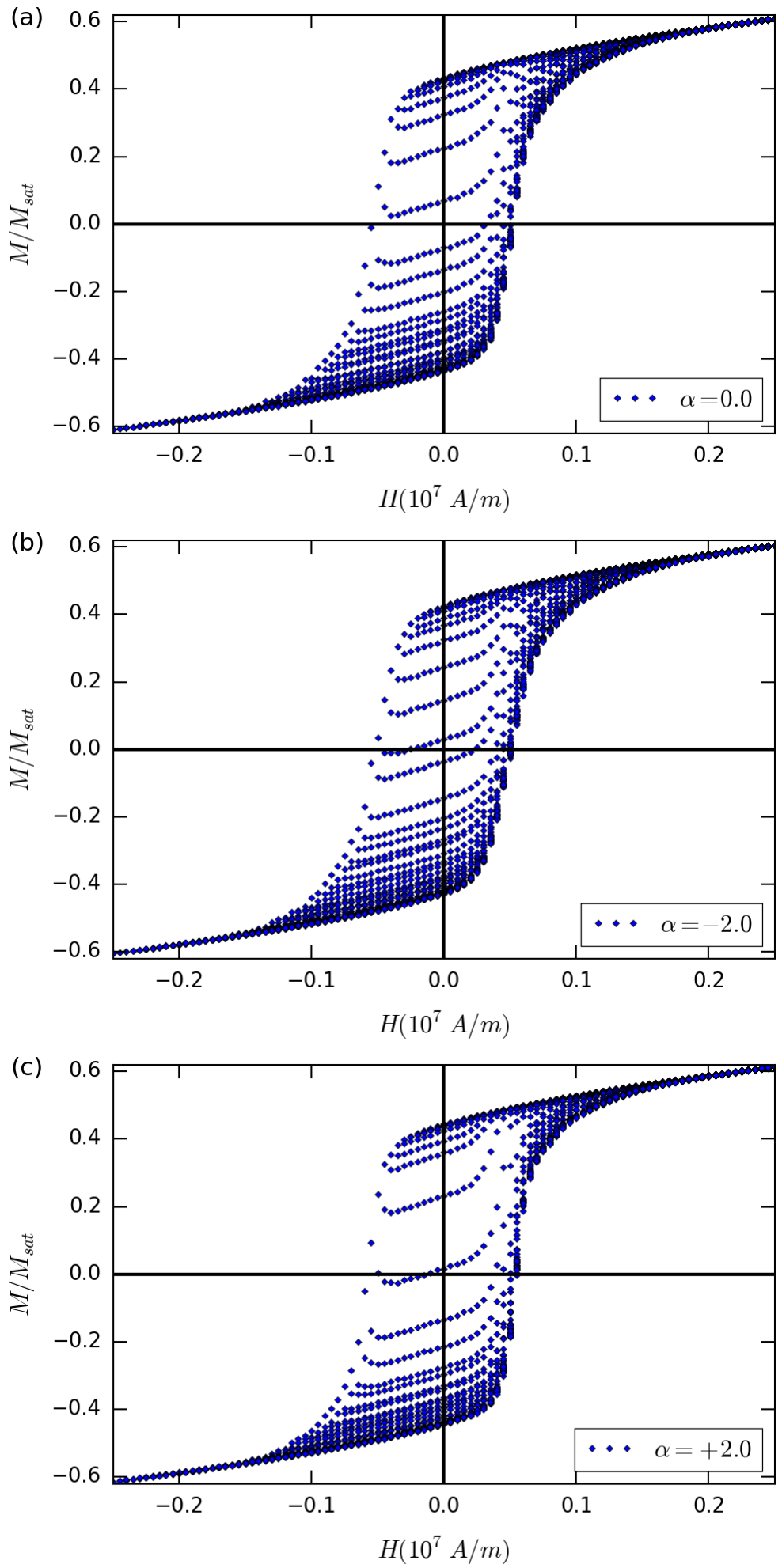

Figura 5.15: Simulação de curvas FORCs a $11 \mathrm{~K}$ utilizando uma distribuição log-normal com $\mu=1.952$ e $\sigma=0.217$ para (a) $\alpha=0.0$, (b) $\alpha=-2.0$ e $\alpha=+2.0$. 
Na figuras 5.16 (a), (b) e (c) vemos os diagramas FORC obtidos com as curvas mostradas na figura 5.15. Para a figura (a), $\alpha=0.0$, vemos que nesse caso o diagrama FORC possui um único pico centrado em um valor de $H_{b}=-0.013 \times 10^{6} \mathrm{~A} / \mathrm{m}$ e $H_{c}=0.470 \times 10^{6} \mathrm{~A} / \mathrm{m}$, este último sendo próximo ao valor da coercividade deste sistema (aproximadamente $6 \times 10^{5} \mathrm{~A} / \mathrm{m}$ a $11 \mathrm{~K}$ para partículas com diâmetro de $10 \mathrm{~nm}$, como pode ser visto na figura 5.2 da seção 5.2). Comparando com os diagramas para (b) $\alpha=-2.0$ e (c) $\alpha=+2.0$ vemos que a presença de um campo desmagnetizante desloca o pico da distribuição para $H_{b}>0$, enquanto que para $\alpha=+2.0$ na figura (c) desloca $H_{b}$ para um valor negativo. Este resultado está de acordo com a previsão de Pike et al. [96], onde temos $H_{b}>0$ para interações desmagnetizantes. Outro fato é que o sinal de $\alpha$ se reflete na largura da distribuição FORC ao longo do eixo $H_{b}$, sendo que $\alpha<0$ aumenta a largura do pico, enquanto que $\alpha>0$ diminui.

Para a segunda distribuição utilizada, $\mu=1.455$ e $\sigma=0.262$, vemos na figura 5.17 os diagramas obtidos a partir das curvas de inversão de primeira ordem de 750 partículas a uma temperatura de $11 K$ (não mostradas aqui). Em comparação aos diagramas obtidos a partir da distribuição anterior, figura 5.16, vemos agora a presença de um pico próximo a $H_{c}=0.0 \mathrm{~A} / \mathrm{m}$ e outro mais largo na região de aproximadamente $0.2 \times 10^{6} \mathrm{~A} / \mathrm{m}<H_{c}<0.5 \times 10^{6} \mathrm{~A} / \mathrm{m}$. O surgimento desse novo pico em $H_{c}=0.0 \mathrm{~A} / \mathrm{m}$ e o deslocamento do pico principal para um valor menor de $H_{c}$ está relacionado ao maior peso que as partículas menores, sendo que muitas possuem comportamento próximo da região de campos reversíveis, ao diagrama. Para as figuras (b) e (c), vemos que para esta distribuição é mais claro o efeito das interações magnetizantes e desmagnetizantes. Na figura (b) o campo médio desmagnetizante contribuiu para um pico maior próximo da região reversível, $H_{c}=0.0 \mathrm{~A} / \mathrm{m}$, enquanto que o campo médio magnetizante, figura (c), fez com que esse pico praticamente desaparecesse.

Para esta mesma distribuição, simulamos também estas três situações a uma temperatura de $13 \mathrm{~K}$, figura 5.18. Para esta temperatura, no caso sem interação, $\alpha=0.0$, temos a maioria das partículas com um comportamento magnético reversível. Quando colocamos um campo médio desmagnetizante, figura (b), o pico próximo a $H_{c}=0.0 \mathrm{~A} / \mathrm{m}$ fica ainda mais pronunciado, enquanto que na figura (c) alargamos o pico na direção de campos $H_{c}$ maiores.

\subsubsection{Interação dipolar}

Na seção anterior mostramos alguns resultados obtidos para sistemas de nanopartículas com interações magnetizantes e desmagnetizantes. Nesse caso a localização das nanopartículas não era importante, pois essa interação não dependia da posição espacial que essas estruturas ocupavam. No caso da interação dipolar a localização espacial é 

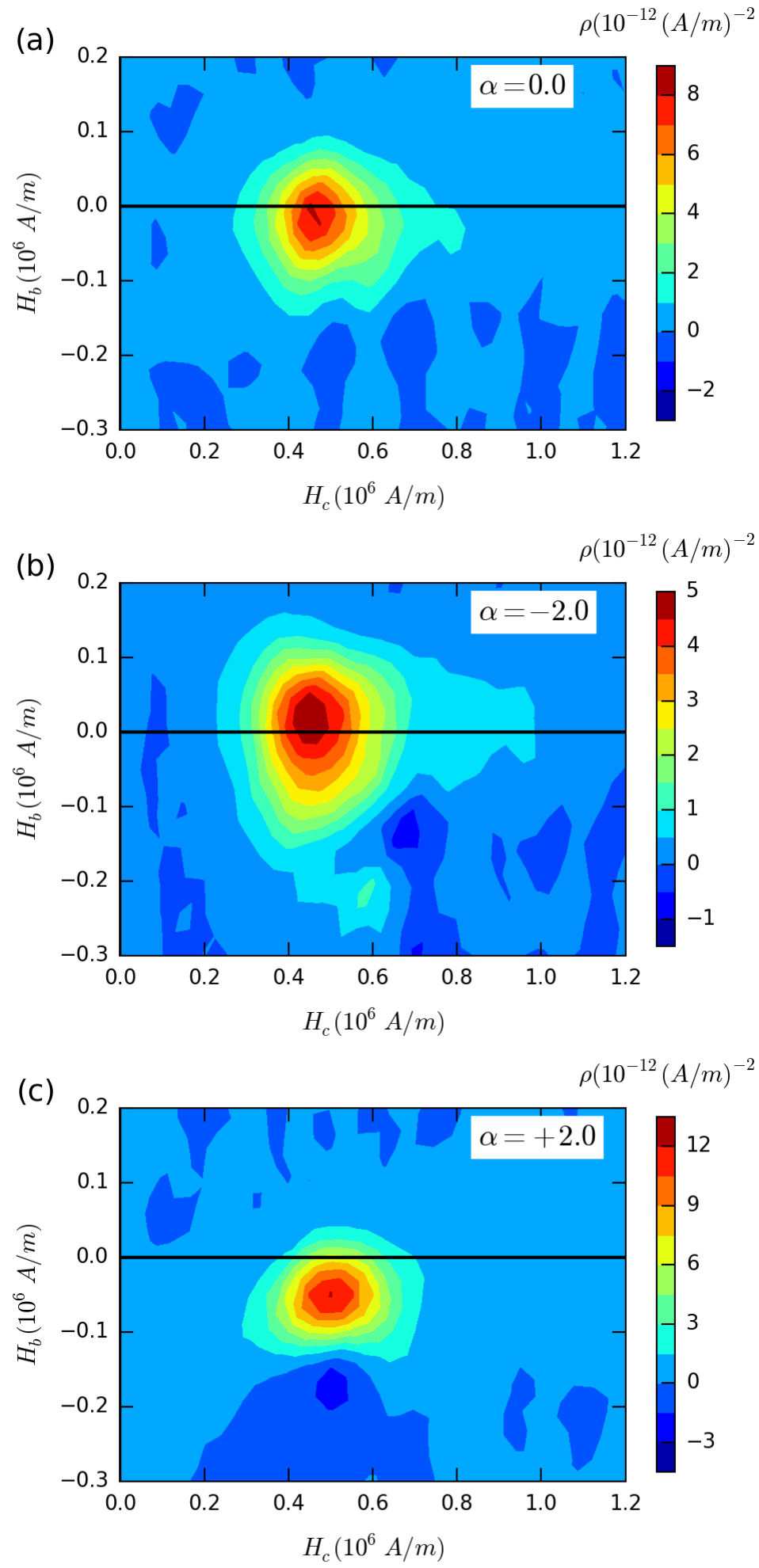

Figura 5.16: Distribuições FORCs a $11 \mathrm{~K}$ utilizando uma distribuição lognormal com $\mu=1.952$ e $\sigma=0.217$ para (a) $\alpha=0.0$, (b) $\alpha=-2.0$ e $\alpha=+2.0$. 

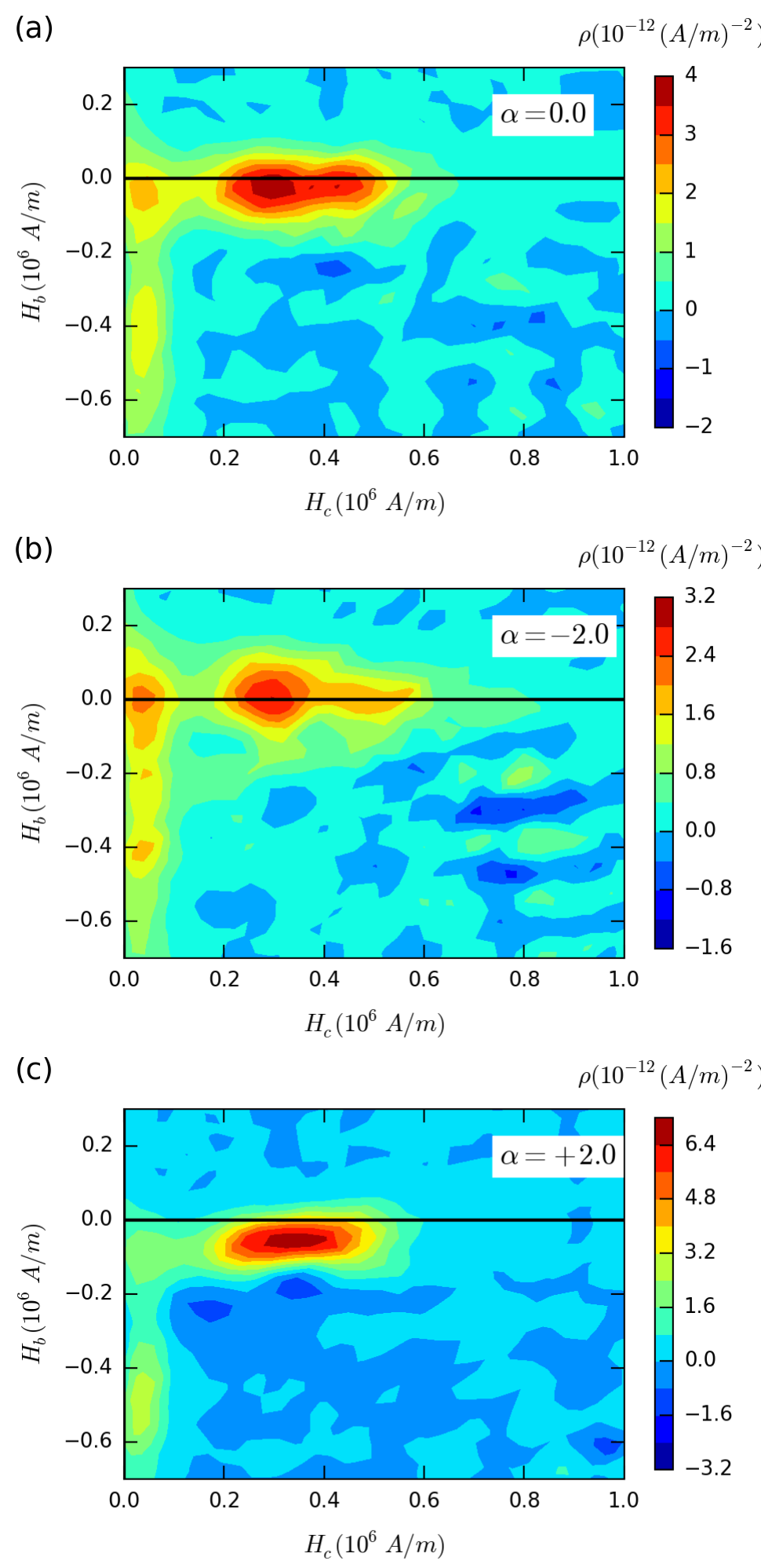

Figura 5.17: Distribuições FORCs a $11 K$ utilizando uma distribuição lognormal com $\mu=1.455$ e $\sigma=0.262$ para (a) $\alpha=0.0$, (b) $\alpha=-2.0$ e $\alpha=+2.0$. 

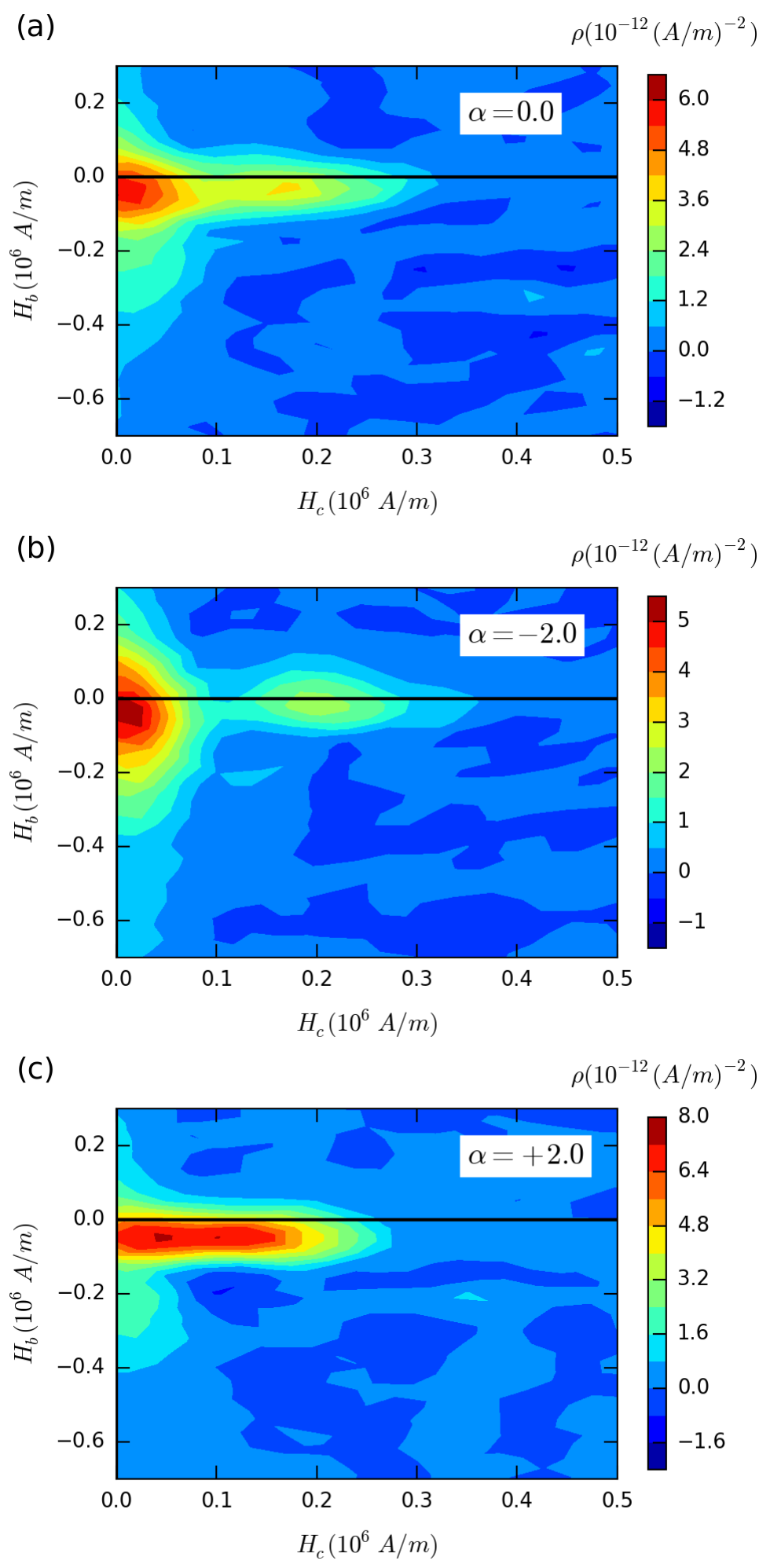

Figura 5.18: Distribuições FORCs a $13 K$ utilizando uma distribuição lognormal com $\mu=1.455$ e $\sigma=0.262$ para (a) $\alpha=0.0$, (b) $\alpha=-2.0$ e $\alpha=+2.0$. 
muito importante, pois o campo de dipolo $H_{d}$ criado por uma partícula em um determinado ponto do espaço depende da distância $\vec{r}$ entre essa partícula e esse ponto, equação 2.9. Nesse caso para colocar a interação dipolar em nossa simulação colocamos as partículas organizadas em uma rede cúbica simples tridimensional. Com esse tipo de organização é possível controlar o grau de compactação do sistema, chegando a um máximo compactamento possível e portanto uma maior interação entre as partículas. A expressão de energia da interação entre um momento $\vec{\mu}$ e um campo dipolar $\vec{H}_{d}$ é:

$$
E_{d}=-\mu_{0} \vec{\mu} \cdot \vec{H}_{d}
$$

Quando usamos as equações 5.1 e 5.2 para as simulações apresentadas até agora, estávamos fazendo os cálculos no referencial de cada partícula. No entanto nesse caso para computar o campo dipolar total sentido por uma partícula devido à presença das demais precisamos passar o campo gerado por cada partícula para o referencial do laboratório para só depois fazer a somatória de todos esses campos. Tendo a expressão para esse campo dipolar total no referencial do laboratório, passamos a expressão desse campo para o referencial da partícula e fazemos o cálculo de energia para os passos de Monte Carlo.

A mudança de referenciais pode ser feita com a técnica das matrizes de rotação, realizando, por exemplo, primeiro uma rotação no sentido anti horário de um ângulo $\phi$ em torno do eixo $z$ e depois uma rotação no sentido anti horário de um ângulo $\theta$ em torno do novo eixo $y^{\prime}$ obtido depois da primeira rotação. Após essas duas rotações, as componentes do campo gerado por uma partícula em seu referencial $H_{d}^{\text {part }}$ no referencial do laboratório $H_{d}^{\text {lab }}$ serão:

$$
\vec{H}_{d}^{l a b}=\hat{R} \vec{H}_{d}^{\text {part }}=\left[\begin{array}{ccc}
\cos \theta \cos \phi & \cos \theta \sin \phi & -\sin \theta \\
-\sin \phi & \cos \phi & 0 \\
\sin \theta \cos \phi & \sin \theta \sin \phi & \cos \theta
\end{array}\right] \vec{H}_{d}^{p a r t}
$$

Analogamente, a transformada inversa é expressa pela matriz de rotação inversa, que é dada simplesmente pela sua transposta, $\hat{R}^{T}$.

Tendo as expressões para o campo dipolar no referencial da partícula, é possível fazer a simulação como no caso não interagente apenas adicionando a expressão 5.8 a equação 5.1. Como o cálculo do campo dipolar envolve todas as demais partículas, a simulação nesse caso é um pouco mais demorada, pois devemos olhar para todos os momentos magnéticos do sistema e não apenas para os momentos da partícula que está sendo analisada. Na figura 5.19 vemos (a) as curvas de remanência e (b) as curvas $\Delta m$ para um conjunto de 512 partículas com diâmetro de $5.0 \mathrm{~nm}$. Iniciamos com um sistema de partículas 
menores, justamente por causa do tempo computacional necessário para os cálculos. Vemos nessas figuras que a interação dipolar tem um efeito desmagnetizante, sendo que o mínimo das curvas ocorrem para campos mais baixos com o aumento da temperatura.
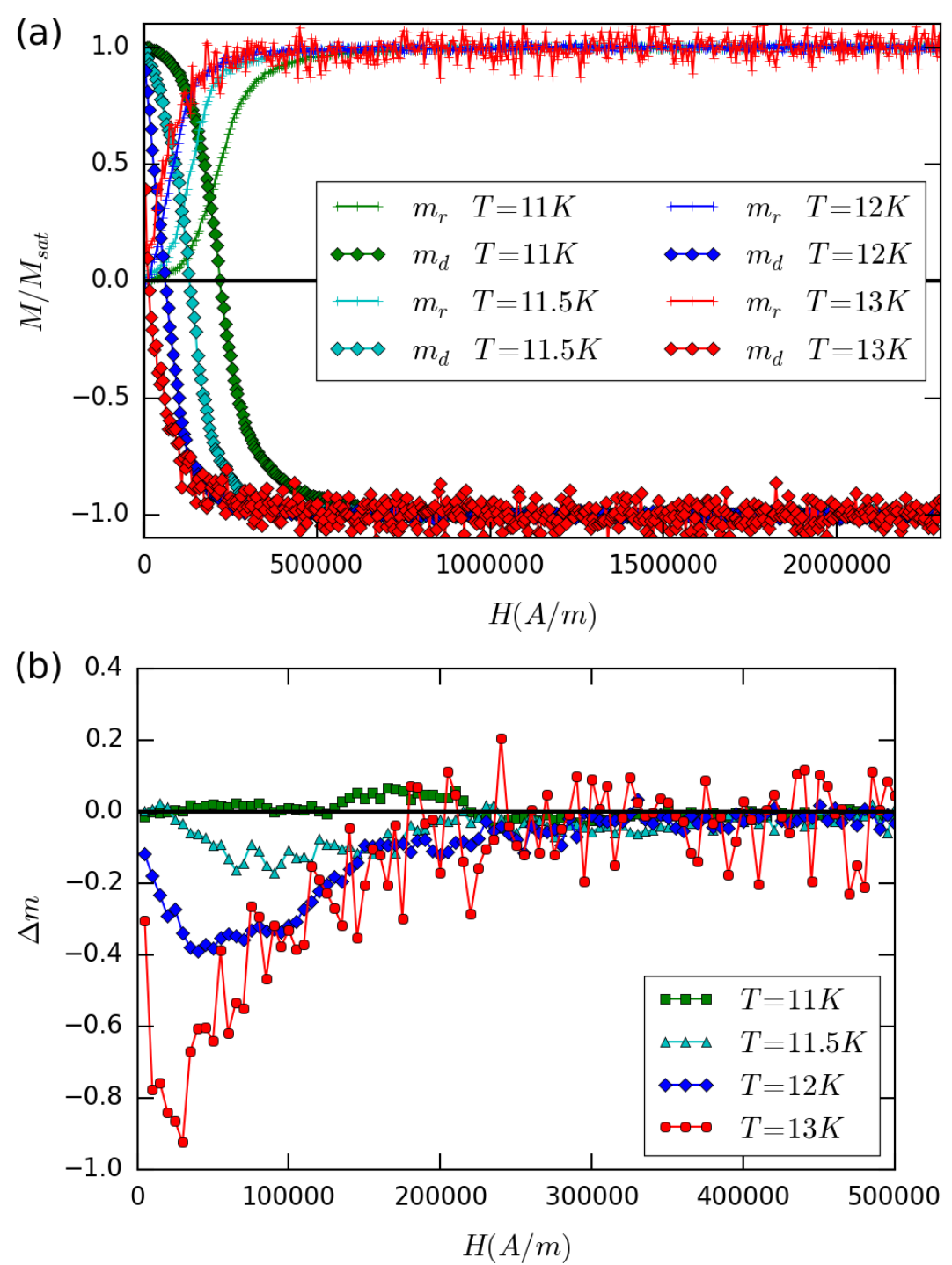

Figura 5.19: Curvas (a) de remanência e (b) $\Delta m$ para um conjunto de 512 nanopartículas com interação dipolar e diâmetro de $5.0 \mathrm{~nm}$ a $T=11,11.5,12$ e $13 K$.

Na figura 5.20 vemos as mesmas curvas, mas para um conjunto de 216 partículas com um diâmetro de $8.4 \mathrm{~nm}$. Vemos que nesse caso não é possível observar uma contribuição da interação dipolar nas curvas $\Delta m$. Esse efeito pode ser devido à pouca quantidade de partículas, que não é suficiente para criar um campo intenso em comparação a um sistema real onde há da ordem de $10^{17}$ parts. $\mathrm{cm}^{-3}$. Com estes resultados vemos que para o nosso modelo não é vantajoso utilizar a interação dipolar para estudar os efeitos de interação entre partí- 

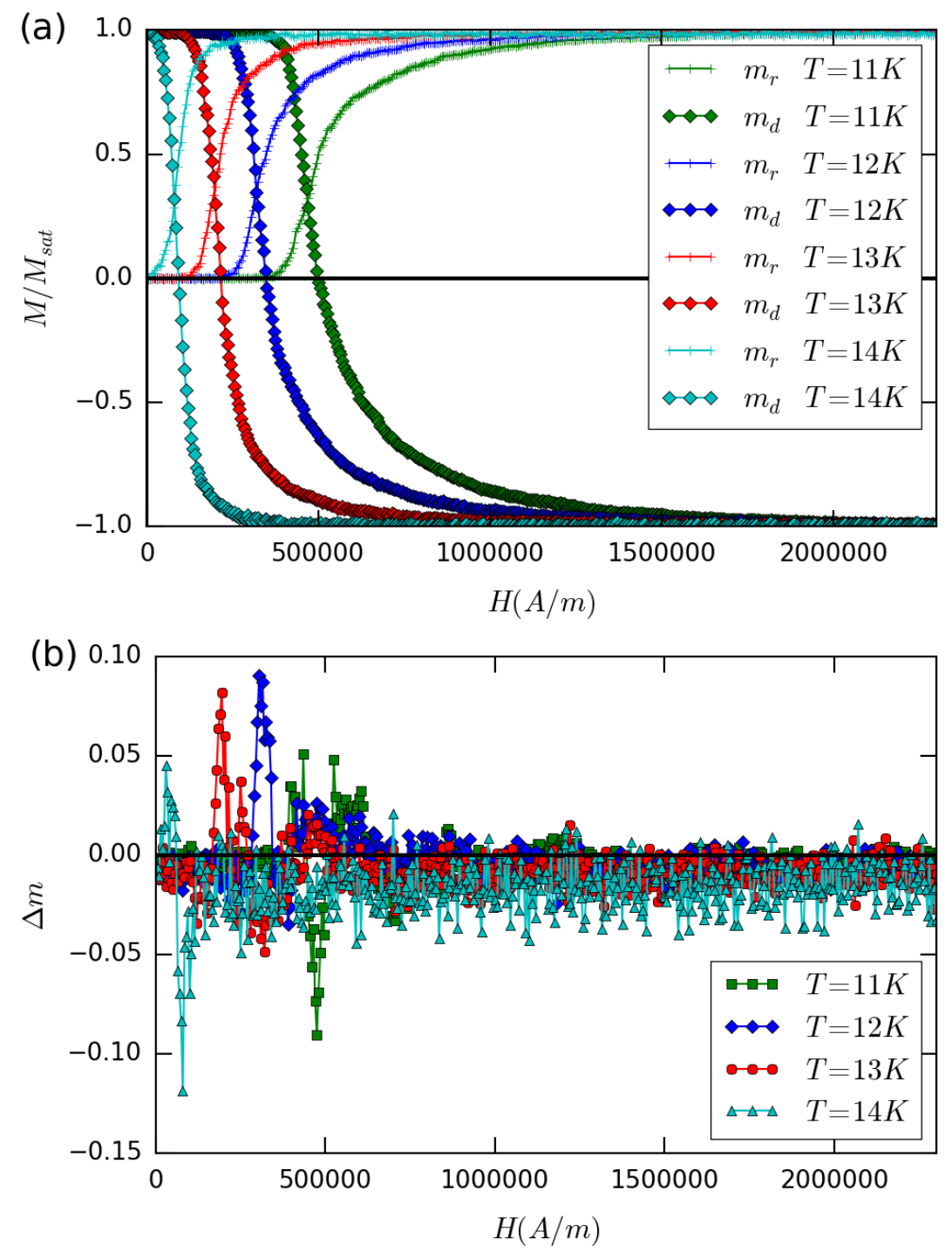

Figura 5.20: Curvas (a) de remanência e (b) $\Delta m$ para um conjunto de 216 nanopartículas com interação dipolar e diâmetro de $8.4 \mathrm{~nm}$ a $T=11,12,13$ e $14 K$. 
culas em comparação ao termo de campo médio, mostrado na seção anterior. O tempo computacional para os cálculos apresentados nesta seção era da ordem de 5 dias e mesmo assim os resultados foram ruidosos, provavelmente devido à pouca quantidade de partículas simuladas.

\subsubsection{Aglomerados de partículas}

Em amostras reais é muito comum a presença de aglomerados de duas ou mais nanopartículas, formando estruturas como dímeros e trímeros, ou mesmo longas cadeias. Nesse caso como as nanopartículas estão em contato umas com as outras, os momentos magnéticos superficiais de partículas distintas podem interagir via interação de troca. Nesta seção mostramos como o diagrama FORC de um sistema de dímeros é alterado devido à interação de troca entre duas partículas com eixos de anisotropia cristalina com orientações diferentes. A expressão de energia para os momentos magnéticos nesse caso é a mesma mostrada na equação 5.I, só que agora também há interação de troca entre os momentos de partículas vizinhas que estão lado a lado. Na figura 5.21 vemos a representação espacial de uma dessas novas estruturas. Um detalhe importante dessa simulação é que a orientação dos eixos fáceis das duas partículas que formam um dímero foi escolhido aleatoriamente, de modo que não necessariamente as duas possuem seus eixos fáceis na mesma direção.

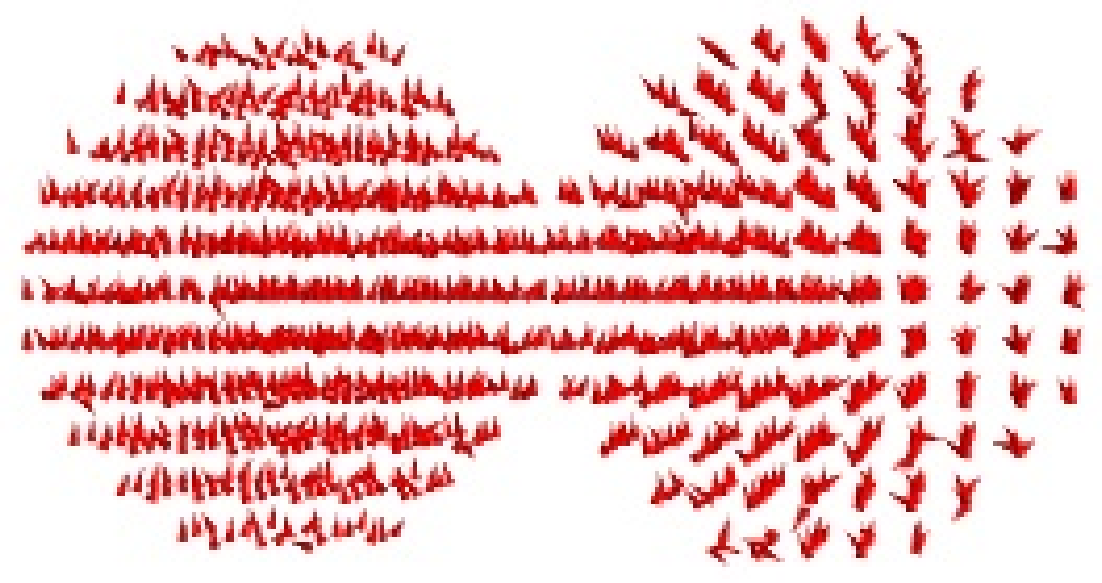

Figura 5.21: Gráfico tridimensional de um dímero formado pela aglomeração de duas nanopartículas magnéticas.

Considerando um conjunto de dímeros como os representados na figura 5.21 podemos simular as curvas FORCs e ver como o diagrama é alterado devido a existência de partículas desse tipo. Na figura 5.22 vemos um diagrama considerando um conjunto de 400 dímeros (no total de 800 nanopartículas) a $8 K$. Comparando com o gráfico apre- 
sentado na figura 5.16, por exemplo, vemos que o pico bem definido em $H_{c}=1.03 \times 10^{6} \mathrm{~A} / \mathrm{m}$ se mantém nesse caso, mas agora aparecem dois picos menos intensos para $H_{b}$ positivo e negativo. Esses dois novos picos podem representar os momentos magnéticos das partículas que estão em contato e que podem se inverter com um campo diferente dos restantes, no entanto esse diagrama ainda necessita de uma melhor compreensão. Uma dificuldade que encontramos no estudo de diagramas FORC destes sistemas é o tempo computacional necessário para obter um conjunto de dados. Os dados mostrados na figura 5.22 levaram 3 semanas de cálculos, de modo que não foi possível estendermos nossos estudos para outros valores de temperatura e de trímeros. Pretendemos continuar com essas simulações nos próximos meses, já que não há na literatura este tipo de estudo para um conjunto apreciável de aglomerados de partículas. 

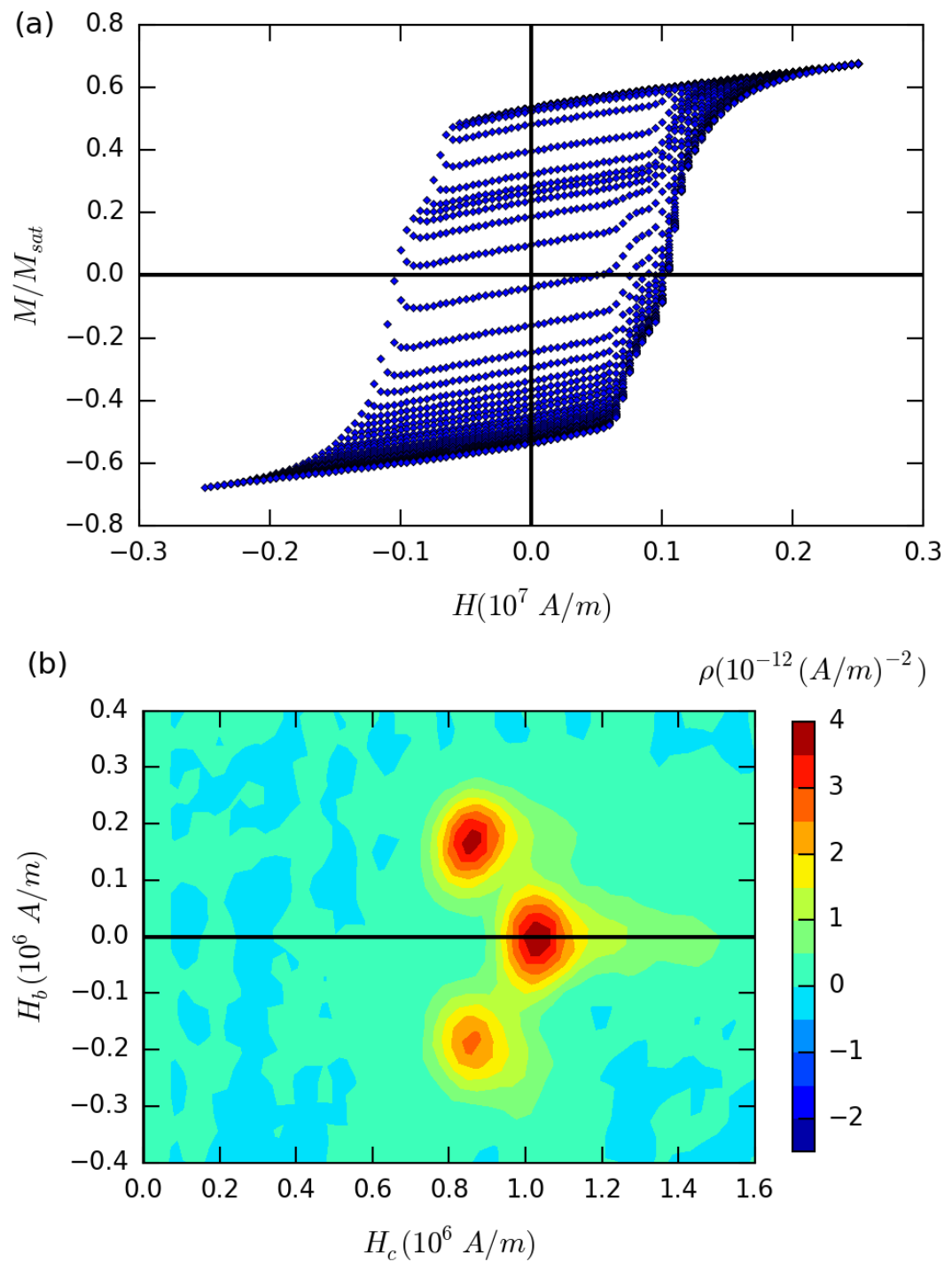

Figura 5.22: (a) Curvas de inversão de primeira ordem para um conjunto de 400 dímeros a uma temperatura de $8 K$ e (b) diagrama FORC obtido com as curvas mostradas em (a). 
Neste trabalho estudamos vários aspectos do comportamento magnético de sistemas de nanopartículas a partir de medidas experimentais e simulações Monte Carlo. Para as medidas experimentais, utilizamos ferrofluidos constituídos por nanopartículas de magnetita diluídas em água ou em óleo. Confirmamos a composição química dessas amostras a partir da difratometria de raios $X$ e espectroscopia Mössbauer, enquanto que o tamanho das nanopartículas foi obtido a partir de imagens de microscopia eletrônica de transmissão. As medidas de curvas de remanência à temperatura de $5 K$ mostraram que o comportamento magnético desses sistemas é dominado por interações desmagnetizantes, evidenciando a importância da interação dipolar entre partículas neste tipo de amostra, como já foi mostrado em outros resultados da literatura [57, 89, 7]. Variando a concentração de nanopartículas a partir do ferrofluido EMG9o9, vimos que o aumento da interação dipolar na amostra com o ferrofluido sem diluição, EMG909-100\%, se refletiu em um aumento da temperatura de bloqueio extraída de curvas ZFC-FC em comparação com as amostras mais diluídas, sendo de 96(1)K para a amostra mais concentrada e de 61(1)K para as duas amostras mais diluídas. Podemos entender esse fato lembrando da natureza desmagnetizante desta interação, que faz com que as nanopartículas precisem de mais energia térmica para se alinharem na direção do campo aplicado durante a aquisição da curva ZFC. Para as duas amostras mais diluídas, apesar da interação desmagnetizante ainda estar presente, como vimos nas curvas $\Delta m$, essa interação não se refletiu na temperatura de bloqueio, que foi a mesma para as duas amostras. Medidas de suscetibilidade AC em função da temperatura e da frequência do campo magnético aplicado mostraram que a constante de anisotropia efetiva $K_{e f}$ se mostrou dependente da concentração de nanopartículas, sendo maior para a amostra mais concentrada.

Uma característica dos ferrofluidos é a capacidade das nanopartículas se organizarem em estruturas magnéticas que minimizem a interação dipolar na presença de um campo magnético aplicado. Utilizando o ferrofluido EMG605, à base de água e que mostrava uma coercividade maior do que a do EMG9og, fizemos medidas de curvas de inversão de primeira ordem a $5 \mathrm{~K}$ em duas situações, congelando a amostra sem campo aplicado e com campo aplicado de 5000Oe. A partir da análise do diagrama FORC, vimos que a amostra congelada com campo aplicado mostrou um endurecimento magnético em relação à amostra congelada sem campo aplicado. Esse fato está 
diretamente ligado à formação das estruturas magnéticas pelas nanopartículas, que são aglomerados e portanto possuem uma maior coercividade. Também podemos esperar que estruturas na forma de agulhas também estejam associadas à uma maior coercividade com o campo aplicado na direção paralela ao eixo de simetria, como acontece para amostras de nanofios magnéticos.

Para as medidas realizadas a uma temperatura onde o solvente não estava congelado, vimos que medidas magnéticas podem dar informações sobre as transições de fase do meio. Em particular vimos a transição entre a fase sólida e líquida tanto para o ferrofluido a base de água, EMG605, quanto para o ferrofluido a base de óleo, EMG9o9 em medidas ZFC-FC. Nessas medidas o início do estado líquido na curva ZFC foi marcado por uma aleatoriedade do comportamento magnético, dado pelo rearranjo espacial dos eixos fáceis das nanopartículas na direção do campo aplicado. Outro ponto marcante destas medidas, foi a observação do fenômeno de super-resfriamento na curva FC. Para as medidas de cristais líquidos liotrópicos dopados com o ferrofluido EMG605, observamos a transição entre a fase isotrópica e a fase nemática, onde as micelas apresentam um ordenamento espacial. Vimos que a observação dessa transição nas medidas de magnetização se mostrou dependente da magnitude do campo aplicado, sendo que o campos de intensidade de 100 e $4000 e$ aumentou o intervalo de temperatura de existência da fase nemática. Para esses sistemas utilizamos medidas de ressonância ferromagnética com o intuito de observar a transição de fase líquido-cristalina, no entanto com essas medidas não foi possível observar transições de fase, possivelmente devido à intensidade do campo magnético aplicado necessário para a medida, que variou de 0 a 70000 e. Apesar de não termos observado transições de fase, essas medidas mostraram que as amostras de cristais líquidos possuem uma largura de linha maior em relação às amostras de ferrofluido diluído. Este fato pode ser relacionado tanto a presença de maiores aglomerados de partículas nos cristais líquidos quanto ao confinamento espacial imposto pelas micelas nas partículas nessas amostras. Com esses resultados não foi possível excluir nenhuma das duas hipóteses.

O último resultado experimental que apresentamos a caracterização magnetoreológica de soluções micelares de laurato de potássio dopadas com ferrofluidos a base de água. Observamos que nesses sistemas é possível observar um efeito magnetoviscoso considerável mesmo utilizando pequenas quantidade de nanopartículas para a dopagem, tipicamente concentrações de uma a duas ordens de grandezas menores do que as concentrações típicas de ferrofluidos. Nas nossas amostras observamos que a magnitude do efeito magnetoviscoso diminui com a concentração de laurato de potássio e aumenta com a concentração de nanopartículas, como usualmente observado em amostras de ferrofluidos. Nossos resultados sugerem que a observa- 
ção do efeito magnetoviscoso nesses sistemas se deve à mudanças no comportamento reológico das micelas mediado pelas interações entre o campo magnético aplicado e as partículas. A interação das partículas magnéticas com o campo levam à formação de estruturas na direção do campo aplicado que induzem um alinhamento diferente das micelas também na direção do campo, e portanto na direção oposta ao cisalhamento, que se reflete como um aumento da viscosidade.

Além das medidas experimentais mencionadas acima, também estudamos algumas propriedades magnéticas de sistemas de nanopartículas por meio de simulações Monte Carlo. No trabalho apresentado nesta tese, vimos que o comportamento das curvas ZFC-FC depende da orientação entre o eixo fácil das nanopartículas e a direção e intensidade do campo magnético aplicado. Observamos que a dependência da temperatura crítica com o diâmetro das nanopartículas pode ser descrita por uma lei de escala com expoente crítico compatível com outras simulações tridimensionais utilizando o método de Monte Carlo [133, 134]. Estudamos a contribuição da superfície no comportamento magnético de nanopartículas no caso onde a camada superficial era constituída por momentos magnéticos sem anisotropia cristalina e com uma interação de troca menor do que a do núcleo e também no caso onde a camada superficial estava em contato com uma camada magnética mais dura que o núcleo. Nossos resultados mostram que o efeito de uma camada magnética dura é muito mais dramático do que o efeito de uma camada morta, sendo possível aumentar consideravelmente a temperatura crítica de uma partícula apenas endurecendo sua superfície.

Estudamos o papel de interações entre partículas nas simulações primeiramente introduzindo um termo de campo médio proporcional à magnetização do sistema. Observamos a presença de interações magnetizantes e desmagnetizantes em curvas $\Delta m$, confirmando que esse novo termo de energia é capaz de reproduzir este tipo de comportamento observado experimentalmente. Para a temperatura de crítica extraída de curvas ZFC-FC, vimos que esta aumenta para sistemas onde a interação desmagnetizante é predominante, como observamos nas medidas experimentais de nossos ferrofluidos. Nos diagramas FORC, a presença de interações magnetizantes desloca o pico da distribuição para valores mais negativos de $H_{b}$, enquanto que interações desmagnetizantes deslocam para valores positivos de $H_{b}$. Este resultado está de acordo com um modelo proposto por Pike et. al. [96]. Para um sistema com distribuição de tamanhos, a presença de interações magnetizantes faz com que a parte reversível do diagrama diminua, enquanto que o pico para valores maiores de $H_{c}$ fique maior.

Além do termo de campo médio, colocamos um termo de energia dipolar entre partículas, mas que não se mostrou vantajoso computacionalmente. A adição deste termo à simulação demanda muito mais tempo de cálculos e necessita de um número muito maior de partí- 
culas para que os efeitos da interação dipolar sejam apreciáveis, de forma que o termo de campo médio se mostrou uma melhor alternativa para estudar a manifestação das interações nos diagramas FORC. Para o futuro, pretendemos continuar com o estudo de aglomerados de nanopartículas por meio de simulações Monte Carlo, pois o comportamento magnético deste tipo de estrutura ainda não é compreendido completamente, já que temos tanto interação de troca, quando dipolar entre as partículas, e não há simulações na literatura de grandes conjuntos desses sistemas. A dificuldade do estudo de diagramas FORC destes aglomerados está no tempo computacional necessário para a obtenção das curvas, já que o gráfico apresentado nesta tese consumiu três semanas de cálculos. Nos próximos meses pretendemos obter esses diagramas para outros valores de temperatura e posteriormente estender a simulação para um sistema de trímeros. 
Durante o período de doutorado publicamos dois artigos referentes ao conteúdo desta tese. O primeiro artigo, "Magnetic behavior of 10 nm-magnetite particles diluted in lyotropic liquid crystals", Journal of Applied Physics, vol. 109, no. 7, 2011, mostra a observação de transições de fase em cristais líquidos liotrópicos por meio de medidas magnéticas. O segundo artigo, "Monte carlo study of the magnetic properties of frozen and non-interacting nanoparticles", Journal of nanoparticle research, vol. 15, no. 9, pp. 1-10, 2013, mostra os resultados referentes à simulação de um conjunto de nanopartículas não interagentes, alterando sua superfície.

No momento temos um artigo em fase de revisão referente aos resultados sobre o efeito magnetoviscoso em soluções micelares dopadas com nanopartículas magnéticas. Pretendemos também escrever um artigo sobre o estudo de diagramas FORC com a simulação Monte Carlo de um sistema de nanopartículas interagentes, conectando com os resultados experimentais obtidos para amostras de ferrofluido. 

[1] J. Gallo, N. J. Long, and E. O. Aboagye, "Magnetic nanoparticles as contrast agents in the diagnosis and treatment of cancer," Chemical Society Reviews, vol. 42, no. 19, pp. 7816-7833, 2013. (Citado na página 1.)

[2] V. Sundar, J. Zhu, D. E. Laughlin, and J.-G. Zhu, "Novel scheme for producing nanoscale uniform grains based on templated two-phase growth," Nano letters, vol. 14, no. 3, pp. 1609-1613, 2014. (Citado na página 1.)

[3] S. C. Tang and I. Lo, "Magnetic nanoparticles: essential factors for sustainable environmental applications," Water research, vol. 47, no. 8, pp. 2613-2632, 2013. (Citado na página 1.)

[4] A. Salunkhe, V. Khot, and S. Pawar, "Magnetic hyperthermia with magnetic nanoparticles: A status review," Current topics in medicinal chemistry, vol. 14, no. 5, pp. 572-594, 2014. (Citado na página 1.)

[5] L. Wu, J. Pierre-Olivier, D. Berman, W. Imaino, A. Nelson, $\mathrm{H}$. Zhu, S. Zhang, and S. Sun, "Monolayer assembly of ferrimagnetic $\mathrm{Co}_{x} \mathrm{Fe}_{3-x} \mathrm{O}_{4}$ nanocubes for magnetic recording," Nano letters, 2014. (Citado na página 1.)

[6] X. Batlle, N. Pérez, P. Guardia, O. Iglesias, A. Labarta, F. Bartolomé, L. M. García, J. Bartolomé, A. G. Roca, M. P. Morales, and C. J. Serna, "Magnetic nanoparticles with bulklike properties," Journal of Applied Physics, vol. 109, p. o7B524, 2011. (Citado nas páginas $1,10,18$, e 74.)

[7] S. Masunaga, R. Jardim, R. Freitas, and J. Rivas, "Increase in the magnitude of the energy barrier distribution in ni nanoparticles due to dipolar interactions," Applied Physics Letters, vol. 98, no. 1, pp. 013110-013110, 2011. (Citado nas páginas 1, 14, 15, e 131.)

[8] J. Bartolomé, L. García, F. Bartolomé, F. Luis, R. López-Ruiz, F. Petroff, C. Deranlot, F. Wilhelm, A. Rogalev, P. Bencok, et al., "Magnetic polarization of noble metals by Co nanoparticles in M-capped granular multilayers $(\mathrm{M}=\mathrm{Cu}, \mathrm{Ag}$, and $\mathrm{Au})$ : $\mathrm{An} X$-ray magnetic circular dichroism study," Physical Review B, vol. 77, no. 18 , p. 184420,2008 . (Citado na página 1.)

[9] E. C. Stoner and E. Wohlfarth, "A mechanism of magnetic hysteresis in heterogeneous alloys," Philosophical Transactions of the 
Royal Society of London. Series A. Mathematical and Physical Sciences, pp. 599-642, 1948. (Citado nas páginas I e 8.)

[10] L. D. Landau and E. Lifshitz, Statistical Physics Part II. Pergamon Press, 1980. (Citado na página 1.)

[11] G. T. Landi, Simulações estocásticas de nanopartículas magnéticas. Tese de Doutorado, Universidade de São Paulo, 2012. (Citado na página 1.$)$

[12] O. Iglesias and A. Labarta, "Finite-size and surface effects in maghemite nanoparticles: Monte Carlo simulations," Physical Review B, vol. 63, no. 18, p. 184416, 2001. (Citado nas páginas 1, 17, e 111.)

[13] Y. Labaye, O. Crisan, L. Berger, J. Greneche, and J. Coey, "Surface anisotropy in ferromagnetic nanoparticles," Journal of applied physics, vol. 91, no. 10, pp. 8715-8717, 2002. (Citado na página 1.)

[14] F. Brochard and P. G. de Gennes, "Theory of magnetic suspensions in liquid crystals," Journal de Physique, vol. 31, pp. 691-708, julho 1970. (Citado nas páginas 2, 21, e 25.)

[15] J.-G. Zhu and H. N. Bertram, "Magnetization reversal in $\mathrm{CoCr}$ perpendicular thin films," Journal of applied physics, vol. 66, no. 3, pp. 1291-1307, 1989. (Citado na página 2.)

[16] F. R. Arantes, "Estudo do comportamento magnético de nanopartículas de magnetita e nanofios de níquel diluídos em cristais líquidos liotrópicos," Dissertação de Mestrado, Universidade de São Paulo, 2010. (Citado nas páginas 2, 21, 23, e 83.)

[17] R. C. O'Handley, Modern Magnetic Materials: Principles and Applications. Massachusetts Institute of Technology: WileyInterscience Publication, 2000. (Citado nas páginas 5, 74, e 88.)

[18] J. M. D. Coey, Magnetism and Magnetic Materials. Cambridge: Cambridge University Press, 2010. (Citado nas páginas 6, 8, 9, 47, e 102.)

[19] H.-y. Duan, J. Wang, L. Li, V. Aguilar, and G.-m. Zhao, “Magnetic properties of barium ferrite nanoparticles: Quantitative test of the Stoner-Wohlfarth theory for uniaxial single-domain magnetic particles," Physics Letters A, vol. 377, no. 38, pp. 2659-2662, 2013. (Citado nas páginas 10 e 11.)

[20] R. H. Kodama, A. E. Berkowitz, E. McNiff Jr, and S. Foner, "Surface spin disorder in $\mathrm{NiFe}_{2} \mathrm{O}^{4}$ nanoparticles," Physical Review Letters, vol. 77, no. 2, p. 394, 1996. (Citado nas páginas 10 e 12.) 
[21] C. Vázquez-Vázquez, M. López-Quintela, M. Bujan-Nunez, and J. Rivas, "Finite size and surface effects on the magnetic properties of cobalt ferrite nanoparticles," Journal of Nanoparticle Research, vol. 13, no. 4, pp. 1663-1676, 2011. (Citado na página 10.)

[22] J. M. D. Coey, "Noncollinear spin arrangement in ultrafine ferrimagnetic crystallites," Physical Review Letters, vol. 27, no. 17, p. 1140, 1971. (Citado na página 10.)

[23] F. Bødker, S. Mørup, and S. Linderoth, "Surface effects in metallic iron nanoparticles," Physical Review Letters, vol. 72, no. 2, p. 282, 1994. (Citado na página 13.)

[24] V. Skumryev, S. Stoyanov, Y. Zhang, G. Hadjipanayis, D. Givord, and J. Nogués, "Beating the superparamagnetic limit with exchange bias," Nature, vol. 423, no. 6942, pp. 850-853, 2003. (Citado nas páginas 13 e 113.)

[25] T.-J. Yoon, H. Lee, H. Shao, and R. Weissleder, "Highly magnetic core-shell nanoparticles with a unique magnetization mechanism," Angewandte Chemie International Edition, vol. 50, no. 20, pp. 4663-4666, 2011. (Citado na página 13.)

[26] J. Salafranca, J. Gazquez, N. Pérez, A. Labarta, S. T. Pantelides, S. J. Pennycook, X. Batlle, and M. Varela, "Surfactant organic molecules restore magnetism in metal-oxide nanoparticle surfaces," Nano letters, vol. 12, no. 5, pp. 2499-2503, 2012. (Citado na página 13.)

[27] S. Singamaneni, V. N. Bliznyuk, C. Binek, and E. Y. Tsymbal, "Magnetic nanoparticles: recent advances in synthesis, self-assembly and applications," Journal of Materials Chemistry, vol. 21, no. 42, pp. 16819-16845, 2011. (Citado na página 14.)

[28] O. Akdogan, W. Li, B. Balasubramanian, D. Sellmyer, and G. Hadjipanayis, "Effect of exchange interactions on the coercivity of $\mathrm{SmCO}_{5}$ nanoparticles made by cluster beam deposition," Advanced Functional Materials, vol. 23, no. 26, pp. 32623267, 2013. (Citado nas páginas 14, 15, 39, e 75.)

[29] Y. Lee, H. Lee, P. B. Messersmith, and T. G. Park, "A bioinspired polymeric template for $\mathrm{ID}$ assembly of metallic nanoparticles, semiconductor quantum dots, and magnetic nanoparticles," Macromolecular rapid communications, vol. 31, no. 24, pp. 2109-2114, 2010. (Citado nas páginas 14 e 16.)

[30] K. Binder and D. Landau, A Guide to Monte Carlo Simulations in Statistical Physics, vol. 10. Cambridge University Press Cambridge, 2000. (Citado nas páginas 16 e 56.) 
[31] M. Leblanc, M. Plumer, J. Whitehead, and J. Mercer, "Transition temperature and magnetic properties of the granular Ising model in two dimensions studied by Monte Carlo simulations: Impact of intragrain spin structure," Physical Review B, vol. 82, no. 17, p. 174435, 2010. (Citado na página 16.)

[32] S. Russ and A. Bunde, "Relaxation in ordered systems of ultrafine magnetic particles: effect of the exchange interaction," Journal of Physics: Condensed Matter, vol. 23, no. 12, p. 126001, 2011. (Citado na página 16.)

[33] L. Berger, Y. Labaye, M. Tamine, and J. Coey, "Ferromagnetic nanoparticles with strong surface anisotropy: Spin structures and magnetization processes," Physical Review B, vol. 77, no. 10, p. 104431, 2008. (Citado nas páginas 16 e 17.)

[34] A. Zaim, M. Kerouad, and M. Boughrara, "Monte Carlo study of the magnetic behavior of a mixed spin $(1,3 / 2)$ ferrimagnetic nanoparticle," Solid State Communications, vol. 158, pp. 76-81, 2013. (Citado na página 16.)

[35] N. Metropolis, A. W. Rosenbluth, M. N. Rosenbluth, A. H. Teller, and E. Teller, "Equation of state calculations by fast computing machines," The journal of chemical physics, vol. 21, no. 6, pp. 1087-1092, 1953. (Citado nas páginas 17 e 56.)

[36] Oे. Iglesias and A. Labarta, "Role of surface disorder on the magnetic properties and hysteresis of nanoparticles," Physica B: Condensed Matter, vol. 343, no. 1, pp. 286-292, 2004. (Citado na página 17.)

[37] O. Iglesias and A. Labarta, "Influence of surface anisotropy on the hysteresis of magnetic nanoparticles," Journal of magnetism and magnetic materials, vol. 290, pp. 738-741, 2005. (Citado na página 17.)

[38] L. B. Ho, T. N. Lan, and T. H. Hai, "Monte Carlo simulations of core/shell nanoparticles containing interfacial defects: Role of disordered ferromagnetic spins," Physica B: Condensed Matter, vol. 430, pp. 10-13, 2013. (Citado na página 17.)

[39] Ò. Iglesias, X. Batlle, and A. Labarta, "Microscopic origin of exchange bias in core/shell nanoparticles," Physical Review B, vol. 72, no. 21, p. 212401, 2005. (Citado na página 17.)

[40] E. Eftaxias and K. Trohidou, "Numerical study of the exchange bias effects in magnetic nanoparticles with core/shell morphology," Physical Review B, vol. 71, no. 13, p. 134406, 2005. (Citado na página 17.$)$ 
[41] D. Serantes, D. Baldomir, M. Pereiro, J. Arias, C. Mateo-Mateo, M. Buján-Núñez, C. Vázquez-Vázquez, and J. Rivas, "Interplay between the magnetic field and the dipolar interaction on a magnetic nanoparticle system: A Monte Carlo study," Journal of Non-Crystalline Solids, vol. 354, no. 47, pp. 5224-5226, 2008. (Citado na página 17.)

[42] G. Margaris, K. Trohidou, V. Iannotti, G. Ausanio, L. Lanotte, and D. Fiorani, "Magnetic behavior of dense nanoparticle assemblies: Interplay of interparticle interactions and particle system morphology," Physical Review B, vol. 86, no. 21, p. 214425, 2012. (Citado na página 17.)

[43] M. Porto, "Effect of positional disorder in systems of ultrafine ferromagnetic particles," The European Physical Journal BCondensed Matter and Complex Systems, vol. 26, no. 2, pp. 229234, 2002. (Citado na página 17.)

[44] A. Jordan, R. Scholz, P. Wust, H. Fähling, and R. Felix, "Magnetic fluid hyperthermia (MFH): Cancer treatment with AC magnetic field induced excitation of biocompatible superparamagnetic nanoparticles," Journal of Magnetism and Magnetic Materials, vol. 201, no. 1-3, pp. 413-419, 1999. (Citado na página 17.)

[45] S. Odenbach, Ferrofluids, Magnetically Controllable Fluids and Their Applications. Germany: Springer, 2009. (Citado nas páginas 17 e 20.)

[46] A. Gupta and M. Gupta, "Synthesis and surface engineering of iron oxide nanoparticles for biomedical applications," Biomaterials, vol. 26, no. 18, pp. 3995-4021, 2005. (Citado na página 18.)

[47] S. Odenbach, Magnetoviscous Effects in Ferrofluids. Germany: Springer, 2002. (Citado nas páginas 18 , 20, e 24.)

[48] J. Bacri, D. Salin, et al., "Instability of ferrofluid magnetic drops under magnetic field," Journal de Physique Lettres, vol. 43, no. 17, pp. 649-654, 1982. (Citado na página 18.)

[49] R. Richter and I. Barashenkov, "Two-dimensional solitons on the surface of magnetic fluids," Physical review letters, vol. 94, no. 18 , p. 184503 , 2005. (Citado na página 18.)

[50] G. F. Maxwell, "Wikipedia: Ferrofluid large spikes." Website acessado em 24.06.2012. http://pt.wikipedia.org/ wiki/Ficheiro:Ferrofluid_large_spikes.jpg. (Citado na página 18.)

[51] R. Hergt, R. Hiergeist, I. Hilger, W. Kaiser, Y. Lapatnikov, S. Margel, and U. Richter, "Maghemite nanoparticles with very high 
AC-losses for application in RF-magnetic hyperthermia," Journal of Magnetism and Magnetic Materials, vol. 270, no. 3, pp. 345357, 2004. (Citado na página 19.)

[52] W. Brown Jr, "Thermal fluctuations of a single-domain particle," Physical Review, vol. 130, no. 5, p. 1677, 1963. (Citado na página 20.)

[53] S. Odenbach, Colloidal Magnetic Fluids: Basics, Development and Application of Ferrofluids, vol. 763. Springer, 2009. (Citado nas páginas 20 e 21 .)

[54] M. Martsenyuk, Y. Raikher, and M. Shliomis, "On the kinetics of magnetization of suspensions of ferromagnetic particles," Sov. Phys._JETP, vol. 38, pp. 413-6, 1974. (Citado na página 20.)

[55] S. Odenbach, "Recent progress in magnetic fluid research," Journal of Physics: Condensed Matter, vol. 16, p. R1135, 2004. (Citado na página 20.)

[56] C. Holm and J. Weis, "The structure of ferrofluids: A status report," Current opinion in colloid E interface science, vol. 10, no. 3 , pp. 133-140, 2005. (Citado na página 20.)

[57] K. Butter, P. Bomans, P. Frederik, G. Vroege, A. Philipse, et al., "Direct observation of dipolar chains in iron ferrofluids by cryogenic electron microscopy," Nature materials, vol. 2, no. 2, pp. 8891, 2003. (Citado nas páginas 20 e 131.)

[58] G. Cheng, C. Dennis, R. Shull, and A. Walker, "Influence of the colloidal environment on the magnetic behavior of cobalt nanoparticles," Langmuir, vol. 23, no. 23, pp. 11740-11746, 2007. (Citado nas páginas 20, 22, e 82.)

[59] T. Wen, W. Liang, and K. Krishnan, "Coupling of blocking and melting in cobalt ferrofluids," Journal of Applied Physics, vol. 107, no. 9, pp. o9B501-09B501, 2010. (Citado na página 20.)

[6o] F. Arantes, A. Figueiredo Neto, and D. Cornejo, "Magnetic behavior of $10 \mathrm{~nm}$-magnetite particles diluted in lyotropic liquid crystals," Journal of Applied Physics, vol. 109, no. 7, 2011. (Citado nas páginas 21, 23, e 25.)

[61] A. M. F. Neto and S. R. A. Salinas, The Physics of Lyotropic Liquid Crystal. New York: Oxford, 2005. (Citado na página 23.)

[62] A. M. F. N. Y. Galerne and L. Liébert, “Orientational order parameter and shape anisotropy of the micelles in a lyotropic nematic phase," Phys. Rev. A, vol. 31, pp. 4047-4048, Jun 1985. (Citado nas páginas 23 e 24.) 
[63] R. E. Rosensweig, R. Kaiser, and G. Miskolczy, "Viscosity of magnetic fluid in a magnetic field," Journal of Colloid and Interface Science, vol. 29, no. 4, pp. 680-686, 1969. (Citado na página 24.)

[64] J. P. McTague, "Magnetoviscosity of magnetic colloids," The Journal of Chemical Physics, vol. 51, p. 133, 1969. (Citado na página 24.)

[65] M. I. Shliomis, "Effective viscosity of magnetic suspensions," Soviet Journal of Experimental and Theoretical Physics, vol. 34, p. 1291, 1972. (Citado na página 24.)

[66] L. M. Pop and S. Odenbach, "Investigation of the microscopic reason for the magnetoviscous effect in ferrofluids studied by small angle neutron scattering," Journal of Physics: Condensed Matter, vol. 18, no. 38, p. S2785, 2006. (Citado na página 24.)

[67] P. Ilg, E. Coquelle, and S. Hess, "Structure and rheology of ferrofluids: simulation results and kinetic models," Journal of Physics: Condensed Matter, vol. 18, no. 38, p. S2757, 2006. (Citado na página 24.)

[68] S. Odenbach and K. Raj, "The influence of large particles and agglomerates on the magnetoviscous effect in ferrofluids," Magnetohydrodynamics, vol. 36, no. 4, pp. 312-319, 2000. (Citado na página 24.)

[69] S. Odenbach, T. Rylewicz, and M. Heyen, "A rheometer dedicated for the investigation of viscoelastic effects in commercial magnetic fluids," Journal of magnetism and magnetic materials, vol. 201, no. 1, pp. 155-158, 1999. (Citado nas páginas 24, 25, e 93.)

[70] D. I. Santiago-Quiñonez and C. R, “Enhanced rheological properties of dilute suspensions of magnetic nanoparticles in a concentrated amphiphilic surfactant solution," Soft Matter, vol. 8, no. 19, pp. 5327-5333, 2012. (Citado na página 25.)

[71] J. C. Bacri and A. M. F. Neto, "Dynamics of lyotropic ferronematic liquid crystals submitted to magnetic fields," Physical Review E, vol. 50, no. 5, p. 3860, 1994. (Citado na página 25.)

[72] V. Berejnov, J. C. Bacri, V. Cabuil, R. Perzynski, and Y. Raikher, "Lyotropic ferronematics: Magnetic orientational transition in the discotic phase," EPL (Europhysics Letters), vol. 41, no. 5, p. 507, 1998. (Citado na página 25.)

[73] V. B. et al, "Lyotropic system potassium laurate/1decanol/water as a carrier medium for a ferronematic 
liquid crystal: Phase diagram study," J. Phys. Chem. B, vol. 102, pp. 7132-7138, 1998. (Citado nas páginas 25 e 83.)

[74] C. Quilliet, V. Ponsinet, and V. Cabuil, "Magnetically doped hexagonal lyotropic phases," The Journal of Physical Chemistry, vol. 98, no. 14, pp. 3566-3569, 1994. (Citado na página 25.)

[75] D. Bonn, J. Meunier, O. Greffier, A. Al-Kahwaji, and H. Kellay, "Bistability in non-Newtonian flow: rheology of lyotropic liquid crystals," Physical Review E, vol. 58, no. 2, p. 2115, 1998. (Citado na página 25.$)$

[76] M. E. Cates and S. M. Fielding, "Rheology of giant micelles," Advances in Physics, vol. 55, no. 7-8, pp. 799-879, 2006. (Citado na página 25.)

[77] E. Cappelaere, J. F. Berret, J. P. Decruppe, R. Cressely, and P. Lindner, "Rheology, birefringence, and small-angle neutron scattering in a charged micellar system: Evidence of a shearinduced phase transition," Physical Review E, vol. 56, no. 2, p. 1869, 1997. (Citado na página 25.)

[78] B. E. Warren, X-ray Diffraction. Courier Dover Publications, 1969. (Citado na página 27.)

[79] Y. Hou, J. Yu, and S. Gao, "Solvothermal reduction synthesis and characterization of superparamagnetic magnetite nanoparticles," Journal of Materials Chemistry, vol. 13, no. 8, pp. 19831987, 2003. (Citado nas páginas 28 e 29.)

[8o] D. B. Williams and C. B. Carter, The Transmission Electron Microscope. Springer, 1996. (Citado na página 30.)

[81] E. Lima Jr, T. Torres, L. Rossi, H. Rechenberg, T. Berquo, A. Ibarra, C. Marquina, M. Ibarra, and G. Goya, "Size dependence of the magnetic relaxation and specific power absorption in iron oxide nanoparticles," Journal of nanoparticle research, vol. 15, no. 5, pp. 1-11, 2013. (Citado na página 31.)

[82] U. Gonser, Mössbauer spectroscopy. Berlin-Heidelberg-New York: Springer-Verlag, 1975. (Citado na página 31.)

[83] H. R. Rechenberg, "Introdução à espectroscopia Mössbauer." Notas de aula, 1995. (Citado na página 31.)

[84] V. V. Ovchinnikov, Mössbauer analysis of the Atomic and Magnetic Structure of Alloys. Cambridge Int Science Publishing, 2006. (Citado na página 34.) 
[85] M. McElfresh, "Fundamentals of magnetism and magnetic measurements featuring Quantum Design's magnetic property measurement system," Quantum Design, vol. 11578, 1994. (Citado na página 33.)

[86] W. Nunes, E. De Biasi, C. Meneses, M. Knobel, H. Winnischofer, T. Rocha, and D. Zanchet, "Magnetic behavior of Ni nanoparticles with high disordered atomic structure," Applied Physics Letters, vol. 92, no. 18, p. 183113, 2008. (Citado nas páginas 35 e 36.)

[87] E. Wohlfarth, "Relations between different modes of acquisition of the remanent magnetization of ferromagnetic particles," Journal of Applied Physics, vol. 29, no. 3, pp. 595-596, 1958. (Citado na página 37.)

[88] J. Geshev and M. Mikhov, "Remanence curves for a disordered system of three-and four-axial fine particles. Henkel-type plots," Journal of Magnetism and Magnetic Materials, vol. 104, pp. 15691570, 1992. (Citado na página 38.)

[89] W. Nunes, F. Cebollada, M. Knobel, and D. Zanchet, "Effects of dipolar interactions on the magnetic properties of $\gamma$-FeO nanoparticles in the blocked state," Journal of applied physics, vol. 99, p. 08N705, 2006. (Citado nas páginas 38, 75, e 131.)

[9o] J. Garcia-Otero, M. Porto, and J. Rivas, "Henkel plots of single-domain ferromagnetic particles," Journal of Applied Physics, vol. 87, p. 7376, 2000. (Citado na página 38.)

[91] F. Preisach, "Über die magnetische Nachwirkung," Zeitschrift für physik, vol. 94, no. 5-6, pp. 277-302, 1935. (Citado na página 41.)

[92] I. D. Mayergoyz, The Classical Preisach Model of Hysteresis. Springer, 1991. (Citado na página 41.)

[93] G. Bertotti, Hysteresis in magnetism: for physicists, materials scientists, and engineers. Academic press, 1998. (Citado na página 41.)

[94] G. Bertotti, V. Basso, M. LoBue, and A. Magni, "Thermodynamics, hysteresis, and micromagnetics," The Science of Hysteresis, vol. 2, pp. 1-106, 2006. (Citado na página 41.)

[95] D. R. Cornejo, “Contribuições ao estudo do magnetismo em sistemas de baixa dimensionalidade," Tese de Livre Docência, Universidade de São Paulo, 2014. (Citado nas páginas 41 e 42.)

[96] C. R. Pike, A. P. Roberts, and K. L. Verosub, “Characterizing interactions in fine magnetic particle systems using first order reversal curves," Journal of Applied Physics, vol. 85, no. 9, pp. 666o6667, 1999. (Citado nas páginas 43, 121, e 133.) 
[97] D. Heslop and A. R. Muxworthy, "Aspects of calculating firstorder reversal curve distributions," Journal of magnetism and magnetic materials, vol. 288, pp. 155-167, 2005. (Citado na página 43.)

[98] J. Gittleman, B. Abeles, and S. Bozowski, "Superparamagnetism and relaxation effects in granular $\mathrm{Ni}-\mathrm{SiO}_{2}$ and $\mathrm{Ni}-\mathrm{Al}_{2} \mathrm{O}_{3}$ films," Physical review B, vol. 9, no. 9, p. 3891, 1974. (Citado na página 45.)

[99] J. Mamani, A. Costa-Filho, D. Cornejo, E. Vieira, and L. Gamarra, "Synthesis and characterization of magnetite nanoparticles coated with lauric acid," Materials Characterization, vol. 81, pp. 28-36, 2013. (Citado nas páginas 45 e 46.)

[10o] G. E. Pake, Paramagnetic resonance. New York: W.A. Benjamin, 1962. (Citado na página 47.)

[101] S. V. Vonsovskii, Ferromagnetic Resonance. Great Britain: Pergamon Press, 1966. (Citado nas páginas 47 e 49.)

[102] S. M. Rezende, Ressonância Ferromagnética e Ondas de Spin. Brasil: Notas de aula da segunda Escola Brasileira de Magnetismo, 1999. (Citado na página 47.)

[103] C. Vittoria, Microwave properties of magnetic films. Singapore: World Scientific, 1993. (Citado na página 49.)

[104] E. de Biasi, C. Ramos, and R. Zysler, "Size and anisotropy determination by ferromagnetic resonance in dispersed magnetic nanoparticle systems," Journal of Magnetism and Magnetic Materials, vol. 262, pp. 235-241, 2003. (Citado nas páginas 49 e 90.)

[105] F. Gazeau, V. Shilov, J. C. Bacri, E. Dubois, F. Gendron, R. Perzynski, Y. L. Raikher, and V. I. Stepanov, "Magnetic resonance of nanoparticles in a ferrofluid: evidence of thermofluctuational effects," Journal of Magnetism and Magnetic Materials, vol. 202, pp. 535-546, 1998. (Citado nas páginas 50, 51, e 52.)

[106] C. Marin, "Thermal and particle size distribution effects on the ferromagnetic resonance in magnetic fluids," Journal of magnetism and magnetic materials, vol. 300, no. 2, pp. 397-406, 2006. (Citado nas páginas 50 e 51 .)

[107] Y. Raikher and V. Stepanov, "Magnetic resonances in ferrofluids: temperature effects," Journal of magnetism and magnetic materials, vol. 149, no. 1, pp. 34-37, 1995. (Citado na página 50.)

[108] C. Marin, "The particle concentration effect on magnetic resonance linewidth for magnetic liquids with chain aggregates," Journal of magnetism and magnetic materials, vol. 250, pp. 197-202, 2002. (Citado nas páginas 50, 51, 52, e 90.) 
[109] U. Netzelmann, "Ferromagnetic resonance of particulate magnetic recording tapes," Journal of Applied Physics, vol. 68, no. 4, pp. 1800-1807, 1990. (Citado nas páginas 50 e 90.)

[110] I. Hrianca, I. Mălăescu, F. Claici, and C. Marin, "The influence of particle concentration in ferrofluids on broadening of the magnetic resonance line," Journal of magnetism and magnetic materials, vol. 201, no. 1, pp. 126-128, 1999. (Citado nas páginas 51 e 90.)

[111] P. Morais, G. Gonçalves, A. Bakuzis, K. Skeff Neto, and F. Pelegrini, "Experimental evidence of dimer disruption in ionic ferrofluid:: a ferromagnetic resonance investigation," Journal of magnetism and magnetic materials, vol. 225, no. 1, pp. 84-88, 2001. (Citado na página 51.)

[112] F. Pelegrini, A. Pereira, and P. Morais, "Ferromagnetic resonance line of ferrite ferrofluids at high microwave power," Journal of magnetism and magnetic materials, vol. 289, pp. 84-86, 2005. (Citado na página 51.)

[113] C. Macosko, "Rheology: Principles, measurements, and applications," VCH, New York, 1994. (Citado na página 53.)

[114] M. Okube, T. Yasue, and S. Sasaki, "Residual-density mapping and site-selective determination of anomalous scattering factors to examine the origin of the FeK pre-edge peak of magnetite," Journal of synchrotron radiation, vol. 19, no. 5, pp. 759-767, 2012. (Citado na página 64.)

[115] R. T. Downs and M. Hall-Wallace, "The American Mineralogist crystal structure database," American Mineralogist, vol. 88, no. 1, pp. 247-250, 2003. (Citado na página 64.)

[116] J. Vargas, W. Nunes, L. Socolovsky, M. Knobel, and D. Zanchet, "Effect of dipolar interaction observed in iron-based nanoparticles," Physical Review B, vol. 72, no. 18, p. 184428, 2005. (Citado na página 71.$)$

[117] G. Goya, T. Berquo, F. Fonseca, and M. Morales, "Static and dynamic magnetic properties of spherical magnetite nanoparticles," Journal of Applied Physics, vol. 94, p. 3520, 2003. (Citado na página 74 .)

[118] R. Cahn, "Melting and the surface," Nature, vol. 323, no. 6090, pp. 668-669, 1986. (Citado na página 81.)

[119] T. Wen, W. Liang, and K. Krishnan, "Coupling of blocking and melting in cobalt ferrofluids," Journal of Applied Physics, vol. 107, no. 9, pp. o9B501-09B501, 2010. (Citado nas páginas 81 e 82.) 
[120] J. Osborn, "Demagnetizing factors of the general ellipsoid," Physical Review, vol. 67, no. 11-12, pp. 351-357, 1945. (Citado na página 88. )

[121] A. Marshall and D. Roe, "Dispersion versus absorption: spectral line shape analysis for radiofrequency and microwave spectrometry," Analytical Chemistry, vol. 50, no. 6, pp. 756-763, 1978. (Citado na página 88.)

[122] U. Kaatze, "Complex permittivity of water as a function of frequency and temperature," Journal of Chemical and Engineering Data, vol. 34, no. 4, pp. 371-374, 1989. (Citado na página 88.)

[123] L. R. Bickford, "Ferromagnetic resonance absorption in magnetite single crystals," Phys. Rev., vol. 78, pp. 449-457, May 1950. (Citado na página 90.)

[124] P. Van der Heijden, M. Van Opstal, C. Swüste, P. Bloemen, J. Gaines, and $\mathrm{W}$. De Jonge, "A ferromagnetic resonance study on ultra-thin $\mathrm{Fe}_{3} \mathrm{O}_{4}$ layers grown on (o o 1 ) MgO," Journal of magnetism and magnetic materials, vol. 182, no. 1, pp. 71-80, 1998. (Citado na página 90.)

[125] I. M. Krieger and T. J. Dougherty, "A mechanism for nonNewtonian flow in suspensions of rigid spheres," Journal of Rheology, vol. 3, p. 137, 1959. (Citado na página 94.)

[126] P. C. Hiemenz and R. Rajagopalan, Principles of Colloid and Surface Chemistry, revised and expanded, vol. 14. CRC Press, 1997. (Citado na página 95.)

[127] J. Nowak and S. Odenbach, "Magnetoviscous effect in a biocompatible ferrofluid," Magnetics, IEEE Transactions on, vol. 49, no. 1, pp. 208-212, 2013. (Citado na página 96.)

[128] G. Mie, "Beiträge zur optik trüber medien, speziell kolloidaler metallösungen," Annalen der physik, vol. 330, no. 3, pp. 377-445, 1908. (Citado na página 98.)

[129] F. R. Arantes and D. R. Cornejo, "Monte Carlo study of the magnetic properties of frozen and non-interacting nanoparticles," Journal of nanoparticle research, vol. 15, no. 9, pp. 1-10, 2013. (Citado na página 101.)

[130] C. Srivastava, G. Srinivasan, and N. Nanadikar, "Exchange constants in spinel ferrites," Physical Review B, vol. 19, no. 1, p. 499, 1979. (Citado na página 101.)

[131] D. Landau, "Finite-size behavior of the simple-cubic Ising lattice," Physical Review B, vol. 14, no. 1, p. 255, 1976. (Citado na página 111.) 
[132] H. E. Stanley, "Scaling, universality, and renormalization: Three pillars of modern critical phenomena," Reviews of modern physics, vol. 71, no. 2, p. S358, 1999. (Citado na página 111.)

[133] P. Peczak, A. M. Ferrenberg, and D. Landau, "High-accuracy Monte Carlo study of the three-dimensional classical heisenberg ferromagnet," Physical Review B, vol. 43, no. 7, p. 6087, 1991. (Citado nas páginas 111 e 133.)

[134] K. Chen, A. M. Ferrenberg, and D. Landau, "Static critical behavior of three-dimensional classical heisenberg models: A highresolution Monte Carlo study," Physical Review B, vol. 48, no. 5, p. 3249, 1993. (Citado nas páginas 111 e 133.)

[135] J. Als-Nielsen, O. Dietrich, W. Kunnmann, and L. Passell, "Critical behavior of the Heisenberg ferromagnets EuO and EuS," Physical Review Letters, vol. 27, no. 11, p. 741, 1971. (Citado na página 111.$)$

[136] A.-H. Lu, E. e. Salabas, and F. Schüth, "Magnetic nanoparticles: synthesis, protection, functionalization, and application," Angewandte Chemie International Edition, vol. 46, no. 8, pp. 1222$1244,2007$. 